\title{
MIXED-MEMBER
}

ELECTORAL

SYSTEMS IN

CONSTITUTIONAL

CONTEXT

TAIWAN, JAPAN, and BEYOND

E D I T E D B Y

NATHAN F. BATTO, CHI HUANG, ALEXANDER C. TAN, \& GARY W. COX 


\section{Mixed-Member Electoral Systems in Constitutional Context}

Reformers have promoted mixed-member electoral systems as the "best of both worlds." In this volume, internationally recognized political scientists evaluate the ways in which the introduction of a mixed-member electoral system affects the configuration of political parties. The contributors examine several political phenomena, including cabinet post allocation, nominations, preelectoral coalitions, split-ticket voting, and the size of party systems and faction systems. Significantly, they also consider various ways in which the constitutional system-especially whether the head of government is elected directly or indirectly-can modify the incentives created by the electoral system.

Part I of the book provides an in-depth comparison of Taiwan and Japan, both of which moved from single nontransferable vote systems to mixed-member majoritarian systems. These cases demonstrate that the higher the payoffs of attaining the executive office and the greater degree of cross-district coordination required to win it, the stronger the incentives for elites to form and stay in the major parties. In such a context, a country will move rapidly toward a two-party system. In Part II, the contributors apply this theoretical logic to other countries with mixed-member systems and find that executive competition has the same effect on legislative electoral rules in countries as disparate as Thailand, the Philippines, New Zealand, Bolivia, and Russia.

The findings presented here demonstrate that the success of electoral reform depends not only on the specification of new electoral rules per se but also on the political context-and especially the constitutional framework-within which such rules are embedded. 


\section{NEW COMPARATIVE POLITICS}

Series Editor $\quad$ Michael Laver, New York University

Editorial Board Ken Benoit, Trinity College, Dublin

Gary Cox, Stanford University

Simon Hix, London School of Economics

John Huber, Columbia University

Herbert Kitschelt, Duke University

G. Bingham Powell, University of Rochester

Kaare Strøm, University of California, San Diego

George Tsebelis, University of Michigan

Leonard Wantchekon, Princeton University

The New Comparative Politics series brings together cutting-edge work on social conflict, political economy, and institutional development. Whatever its substantive focus, each book in the series builds on solid theoretical foundations; uses rigorous empirical analysis; and deals with timely, politically relevant questions.

Curbing Bailouts: Bank Crises and Democratic Accountability in

Comparative Perspective

Guillermo Rosas

The Madisonian Turn: Political Parties and Parliamentary

Democracy in Nordic Europe

Edited by Torbjörn Bergman and Kaare Strøm

Political Survival of Small Parties in Europe

Jae-Jae Spoon

Veto Power: Institutional Design in the European Union

Jonathan B. Slapin

Democracy, Dictatorship, and Term Limits

Alexander Baturo

Democracy, Electoral Systems, and Judicial Empowerment in Developing Countries Vineeta Yadav and Bumba Mukherjee

The Latin American Voter: Pursuing Representation and

Accountability in Challenging Contexts

Edited by Ryan E. Carlin, Matthew M. Singer, and Elizabeth J. Zechmeister

The European Union and the Rise of Regionalist Parties

Seth K. Jolly

Gender Quotas and Democratic Participation: Recruiting Candidates for

Elective Offices in Germany

Louise K. Davidson-Schmich

Mixed-Member Electoral Systems in Constitutional Context: Taiwan, Japan, and Beyond Edited by Nathan F. Batto, Chi Huang, Alexander C. Tan, and Gary W. Cox 


\section{MIXED-MEMBER \\ ELECTORAL SYSTEMS IN \\ CONSTITUTIONAL CONTEXT}

Taiwan, Japan, and Beyond

Edited by Nathan F. Batto, Chi Huang, Alexander C. Tan, and Gary W. Cox 
Copyright () by the University of Michigan 2016

All rights reserved

This book may not be reproduced, in whole or in part, including illustrations, in any form (beyond that copying permitted by Sections 107 and 108 of the U.S. Copyright Law and except by reviewers for the public press), without written permission from the publisher.

Published in the United States of America by the

University of Michigan Press

Manufactured in the United States of America

@ Printed on acid-free paper

$\begin{array}{llllllll}2019 & 2018 & 2017 & 2016 & 4 & 3 & 2 & 1\end{array}$

A CIP catalog record for this book is available from the British Library.

Library of Congress Cataloging-in-Publication Data

Names: Batto, Nathan F., editor. I Huang, Chi, 1953-editor. I Tan, Alexander C., editor. I Cox, Gary W., editor.

Title: Mixed-member electoral systems in constitutional context : Taiwan, Japan, and beyond / edited by Nathan F. Batto, Chi Huang, Alexander C. Tan, and Gary W. Cox

Description: Ann Arbor : University of Michigan Press, 2016. I Series: New comparative politics I Includes bibliographical references and index.

Identifiers: LCCN 2015038638| ISBN 9780472119738 (hardback) | ISBN 9780472121588 (ebook)

Subjects: LCSH: Proportional representation-Taiwan. I Proportional representationJapan. I Representative government and representation-Taiwan. I Representative government and representation-Japan. I Political parties-Taiwan. I Political parties-Japan. I Elections-Taiwan. I Elections-Japan. I Electoral systems | BISAC: POLITICAL SCIENCE / Political Process / Elections.

Classification: LCC JQ1536.M59 2016 I DDC 324.6-dc23

LC record available at http://lccn.loc.gov/2015038638 


\section{Acknowledgments}

The genesis of this volume lies in an attempt to answer a basic research question that surfaced in a roundtable of the second annual Asian Election Studies Conference held at the Election Study Center (ESC) of the National Chengchi University (NCCU), Taiwan, in May 2010. Why was it that Taiwan and Japan, two similar East Asian countries that had both switched from similar single nontransferable vote to similar mixed-member majoritarian legislative electoral systems, had displayed such divergent speeds and degrees in moving toward the theoretically expected consolidation of their party systems? A brainstorm with Gary Cox during his visit to the ESC in November 2011 sparked the idea of taking into account the constitutional context in which the electoral systems operate.

As with any book-length project, we have a number of people and institutions to thank. We thank the ESC and its director, Lu-huei Chen, for continuous administrative support throughout the life of the project. A book with twenty-one coauthors based in fifteen institutions spanning four countries needs some sort of institutional base, and the ESC provided that home. We also wish to acknowledge our four home institutions, the Institute of Political Science at Academia Sinica, National Chengchi University, the University of Canterbury, and Stanford University. In addition to paying our salaries, the four institutions have allowed us the time and resources necessary to complete this book.

All the chapters are original contributions prepared specifically for this book. Earlier versions of most of the chapters in this volume were presented at the workshop on "Elections in Taiwan and Japan under the 
Mixed-Member Majoritarian System" held on April 20, 2012, at ESC of NCCU in Taiwan. The workshop was funded by the Election and Citizens' Participation (ECP) Project, a Top University grant from the Ministry of Education in Taiwan with Chi Huang as the principal investigator. We would like to extend thanks to all the scholars from Taiwan, Japan, the United States, and New Zealand who participated in the workshop and patiently worked with us on completing this edited book project.

We express our deepest appreciation and admiration to Lu-huei Chen, Yin-lung Chou, Shih-chan Dai, Tzu-ping Liu, Hung-chung Wang, Chungli $\mathrm{Wu}$, and Misa Nishikawa for their intellectual contributions and tolerance in the face of our unreasonable requests.

Finally, we have more personal debts of gratitude. Nathan Batto thanks his wife, Lavai Fu-yi Yang, for her patience, encouragement, and inspiration. Chi Huang thanks Election and Citizens' Participation Project assistant ZeQui He for his help in compiling the manuscript for this edited volume during the review process. 


\section{Contents}

List of Abbreviations ix

Introduction: Legislature-Centric and Executive-Centric

Theories of Party Systems and Faction Systems 1

Nathan F. Batto and Gary W. Cox

PART I. THE CONSEQUENCES OF MMM ON POLITICAL

COORDINATION IN TAIWAN AND JAPAN

One The Consequences of MMM on Party Systems 25

Chi Huang, Ming-Feng Kuo, and Hans Stockton

Two The Consequences of Constitutional Systems on

Party Systems 52

Jib-wen Lin

THREE LDP Factions under SNTV and MMM 73

Yoshiaki Kobayashi and Hiroki Tsukiyama

FOUR Executive Competition, Electoral Rules, and Faction Systems

in Taiwan 102

Nathan F. Batto and Hsin-ta Huang

FIVE Innovations in Candidate Selection Methods 135

Eric Chen-bua Yu, Kaori Shoji, and Nathan F. Batto

sıx Post Allocation, List Nominations, and Preelectoral Coalitions under MMM 165

Kuniaki Nemoto and Chia-bung Tsai 
SEVEN Split-Ticket Voting under MMM 194

T. Y. Wang, Chang-chib Lin, and Yi-ching Hsiao

PART II. COORDINATION IN MIXED-MEMBER SYSTEMS IN

COMPARATIVE PERSPECTIVE

EIGHT Thailand and the Philippines under MMM 229

Allen Hicken

NINE Political Consequences of New Zealand's MMP System in Comparative Perspective 247

Matthew S. Shugart and Alexander C. Tan

TEN Presidents and Blank Votes in the Bolivian and Russian

Mixed-Member Systems 278

Nathan F. Batto, Henry A. Kim, and Natalia Matukbno

Conclusions: Mixed-Member Systems Embedded within

Constitutional Systems 300

Chi Huang

Contributors 311

Index 317 


\section{List of Abbreviations}

General Terms

CSM candidate selection method

HC House of Councillors

HR House of Representatives

MM mixed-member

MMM mixed-member majoritarian

MMP mixed-member proportional

$\mathrm{N}_{\text {local }} \quad$ average effective number of electoral parties in each district

$\mathrm{N}_{\mathrm{PR}} \quad$ effective number of electoral parties in PR tier

$\mathrm{N}_{\text {Pres }} \quad$ effective number of presidential candidates

$\mathrm{N}_{\mathrm{S}} \quad$ effective number of parliamentary parties

$\mathrm{N}_{\text {SMD }} \quad$ effective number of electoral parties in SMD tier

$\mathrm{N}_{\text {SNTV }}$ effective number of electoral parties in SNTV tier

$\mathrm{N}_{\mathrm{V}} \quad$ effective number of electoral parties

PR proportional representation

SMD single-member district

SMP single-member plurality

SNTV single nontransferable vote

Political Parties in Taiwan

DPP Democratic Progressive Party

KMT Nationalist Party (Kuomintang) 
NP New Party

NPSU Non-Partisan Solidarity Union

PFP People First Party

TSU Taiwan Solidarity Union

Political Parties in Japan

CGP Clean Government Party (Komeito)

DPJ Democratic Party of Japan

JCP Japanese Communist Party

JRP Japan Restoration Party

JSP Japan Socialist Party

LDP Liberal Democratic Party

PNP People's New Party (Nihon Shinto)

SDP Social Democratic Party 
INTRODUCTION

\title{
Legislature-Centric and Executive- Centric Theories of Party Systems and Faction Systems
}

\author{
Nathan F. Batto and Gary W. Cox
}

Two central tenets of the New Institutional paradigm are that institutions shape incentives and that how they do so depends on the specific context in which they are embedded. Building on these tenets, this book argues that electoral systems are embedded within constitutional systems and that whether the head of government is directly or indirectly elected affects how the legislative electoral system shapes politicians' incentives. Parties everywhere care about winning both legislative seats and executive offices. This book keeps both kinds of payoff in view and analyzes how constitutional strictures have mediated politicians' reactions to new mixed-member electoral rules in several countries.

\section{Mixed-Member Electoral Systems}

Mixed-member electoral systems have been touted as having the potential to be "the electoral reform of the twenty-first century" (Shugart and Wattenberg 2001, 1). The basic idea behind such systems is simple. Some legislators are elected in single-member districts (SMDs) under plurality rule, while others are elected in multimember districts under some version of proportional representation (PR). Ideally, this offers citizens 
the "best of both worlds," combining the direct ties between representatives and voters that characterize SMD systems with the proportionality that defines PR systems, and thereby promoting moderate and stable politics (Shugart and Wattenberg 2001, chap. 25). Politicians all over the world have found these promises enticing, and, in recent years, countries opting for new electoral systems have more often than not chosen from the mixed-member family. Currently 32 countries use some version of a mixed-member system, including such diverse cases as Mexico, Ukraine, Andorra, South Korea, Venezuela, Romania, Jordan, Hungary, Mongolia, Lithuania, and Germany. ${ }^{1}$

In this book, we focus most heavily on two prominent East Asian examples of mixed-member reform: Taiwan and Japan. However, many of the arguments we make are general; and empirically the book considers several other relevant cases-including Thailand, the Philippines, New Zealand, Bolivia, and Russia. The angle from which we examine mixedmember reforms hinges on the distinction between legislature-centric and executive-centric theories of electoral systems, to which we turn next.

\section{Legislature-Centric and Executive-Centric Theories}

Standard theories of electoral systems often start by assuming that actors mainly want to win seats in the national legislature. Such theories then analyze how different electoral systems push seat-maximizing parties toward different strategies in vote coordination, internal party organization, nominations, collaboration with other parties, and so on. We call such theories legislature-centric because they focus on how the electoral rules governing pursuit of legislative seats affect strategies. In these theories, the key factor driving politicians is their recognition that groups smaller than a certain threshold, determined by the legislative electoral rules, will be unable to efficiently translate their popular support into seats. In other words, failure to coordinate invites punishment in the form of lost legislative seats.

But of course politicians have other incentives to coordinate. In particular, larger parties may sometimes be essential vehicles for the pursuit of executive office-both ministerial portfolios and the chief executive position (whether prime minister or president). Thus, another way to think about coordination, which one might call executive-centric, focuses on how efficiently groups of different sizes can convert their ambitions for executive office into reality. In this line of theories, attention centers on the executive electoral rules. While early contributions to executive-centric theory (e.g., Shugart 1995; Cox 1997, chaps. 10-11) focused on presidential elec- 
tions, Hicken (2009) articulated a broader theory relevant to both nonpresidential and presidential regimes. In the executive-centric line of theories, failure to coordinate invites punishment in the form of lost executive posts.

In reality, politicians care about both legislative seats and executive offices. Their decisions to form larger parties or split into smaller ones should thus reflect their calculations about how such maneuvers will affect their payoff in both seats and offices, weighted by their concern for each. Because executive posts are generally viewed as more powerful and desirable than legislative seats, one might even argue that theories of political coordination should be primarily executive-centric. This is consistent with work on party linkage or aggregation, such as Cox (1997, chaps. 1011), Chhibber and Kollman (2004) and Hicken (2009), which stresses the extent to which cross-district linkage of legislative candidates is influenced by the extent of executive power.

\section{How to Analyze the Electoral Reforms in Taiwan and Japan}

To illustrate how constitutional systems adjust the incentives set up by electoral systems, this book starts with a narrow substantive focus. In particular, it looks at one of the classic topics in the electoral systems literature-the number of competitors-in the context of Taiwan and Japan. It then gradually expands outward, both in the range of political phenomena covered and in geographical scope. This introduction focuses on the evolution of party systems and faction systems after electoral reform in Taiwan and Japan.

\section{Précis}

Taiwan and Japan used similar single nontransferable vote (SNTV) electoral systems prior to reform and moved to similar mixed-member majoritarian (MMM) systems after it. If one considers the electoral system in isolation, the different outcomes in the two countries may seem puzzling. In each case, standard theories would predict that moving from SNTV to MMM should have induced greater coordination among competitors, reducing both the effective number of parties and the internal factionalization of the major parties. Yet, these very similar reforms have had noticeably different effects. In Japan, the hoped-for reduction in the effective number of parties has been rather slow in coming, and the number of factions has, if anything, actually increased. In Taiwan, in contrast, the party 
system almost immediately fell into a two-party mold after the reform of 2005, while the reform has seemed to have very little impact on the number of factions.

Bringing the constitutional systems into the analysis provides a much richer and more satisfying explanation. The different ways in which executive posts were allotted in the two countries-parliamentary Japan and semipresidential Taiwan-provided a much stronger impetus for party consolidation in the latter. Factions have also been affected in both countries, though the most important changes have been in areas other than the number of factions.

In the next several sections, we flesh out the argument just sketched. We begin by providing a slightly more detailed account of what the electoral reforms in Japan and Taiwan entailed.

\section{The Substance of the Electoral Reforms in Japan and Taiwan}

This section provides a quick sketch of the electoral rules before and after reform. The rules are reviewed in full detail in chapter 1 .

Japan and Taiwan both used SNTV systems to conduct their elections prior to reform, and they now both use MMM systems. Japan held its first MMM election in 1996 and Taiwan followed suit in 2008.

There were some modest differences in the countries' prereform systems. All seats in Japan were elected by SNTV, and most districts had three to five seats with an average of 3.96. Taiwan's districts were slightly larger on average with an average of 5.68 seats per district. More significantly, Taiwan also had a party list tier, which elected $22 \%$ of the total seats. However, voters did not vote directly for the list tier; instead, party lists were elected on the basis of votes from the SNTV tier.

In Japan's first MMM election, 300 seats were elected in SMDs while 200 were elected in the list tier. In subsequent elections, the list tier was reduced to 180 seats. Taiwan's MMM system featured 73 SMDs, 34 party list seats, and six seats reserved for indigenous peoples in two SNTV districts. Note that in both countries, SMD seats outnumber list seats by a considerable margin. Among the more important differences, Taiwan has a single national list where Japan has eleven regional lists, and Taiwan does not allow dual candidacies while Japan does.

In sum, while there are some notable differences in the electoral rules, readers should not lose sight of the overriding similarities. In both coun- 
tries, politicians and voters who had become accustomed to competing under SNTV rules had to adjust to a new set of incentives presented by new MMM rules.

\section{A Legislature-Centric View of Electoral Reform}

As noted above, a legislature-centric perspective draws attention to the incentives created by the electoral system used to elect the national legislature. Since both Taiwan and Japan changed their electoral systems from SNTV to MMM, new incentives should have reshaped party and faction systems in predictable ways.

\section{Parties}

The literature on electoral systems suggests that the change from SNTV to MMM in Japan and Taiwan should have reduced the number of political parties. Since SNTV has multiseat districts and voters can only support one candidate, a plurality is not necessary for victory. The more seats there are, the lower the threshold for victory is. Moreover, because parties do not need to win a plurality, there is no need to compete over the median voter. Small parties can build their support bases around nonmedian platforms (Cox 1990). SNTV should thus be able to sustain a multiparty system.

In contrast, MMM combines the logic of single-member-plurality (SMP) and list PR. Duvergerian incentives toward bipolar competition under SMP rules are well known (see Duverger 1954; Rae 1967; Cox 1997). Since a plurality is necessary for victory, smaller competitors tend to be weeded out, either because voters choose not to waste their votes on small parties or because, after suffering a string of defeats, small parties simply die off. If the two competitors are the same in all districts across the country, SMP should lead to a two-party system.

In MMM systems, this Duvergerian logic is mitigated by the existence of the list tier. Small parties may not be able to win nominal seats, but they can win list seats. However, small parties do not get full proportional value for their votes. Because the two tiers are not linked, small parties win a proportional number of list tier seats, but this still leaves them underrepresented in the SMDs and thus in the full chamber. Moreover, because the nominal tier is so much bigger than the list tier in East Asian systems, the proportionality of the list tier is overwhelmed by the majoritarian out- 
comes of the nominal tier. The MMM systems in Japan and Taiwan thus put severe pressure on small parties, creating incentives for a shift toward a two-party system.

As Chi Huang, Ming-Feng Kuo, and Hans Stockton document (chapter 1), these expectations have been met much more closely in Taiwan than in Japan. In Taiwan, the first MMM election saw the effective number of parties $^{2}$ in the legislature plunge from 3.26 in 2004 to a mere 1.75 in 2008; this is exactly what conventional theories would predict. In Japan, however, the trend has not been so clear. In fact, compared to the 1986 and 1990 SNTV elections, the first two MMM elections had a higher effective number of parliamentary parties. There has been a slow reduction of parties over the past decade, but this decrease in the number of parties has taken five elections under the new system. Japan's change has been slow and gradual; Taiwan's has been quick and dramatic.

\section{Factions}

A legislature-centric view suggests that electoral reform also should have affected the internal factions of the major parties in Japan and Taiwan. It is no simple task to define precisely what a faction is. One set of scholars has tried to conceptualize factions by looking at various critical dimensions, such as a group's organization, stability over time, ideological orientation, or its propensity toward rent-seeking. ${ }^{3}$ The problem is that factions often evolve and shift across these various lines. A second set of scholars worries less about the specific manifestation of the groups and more about the fact that a subgroup exists and contests power. Boucek, building on Zariski (1960) and Belloni and Beller (1978), defines factionalism as "the partitioning of a political party ... into sub-units which are more or less institutionalized and who engage in collective action to achieve their members' particular objectives" $(2009,14)$. One particular advantage of this definition for our project is that the locus of the competition determines the nature of the faction. For example, competition over control of local governments implies locally oriented factions (Belloni and Beller 1978). However, while Boucek's conceptualization is intentionally broad and inclusive, in this book we are only interested in the subset of factions that try to win power by nominating legislative candidates and securing executive posts. ${ }^{4}$

Factionalization of parties has been prominent in both Japan and Taiwan, and several authors have argued that the SNTV electoral system promoted factionalism. Most accounts are based on the experience of the Japanese Liberal Democratic Party (LDP) and can be summarized as fol- 
lows. A party wishing to win a majority of seats must nominate multiple candidates in most districts, and the competition within the party for nominations is intense. Factions arise as nominating coalitions, and they help their members run credible campaigns by centrally collecting financial resources. Factions generally avoid supporting more than one person in each district, and the ideal situation for a faction would be to nominate exactly one candidate in each district (Thayer 1969, chap. 2; Fukui 1970, chap. 5; Curtis 1971, chap. 1; Baerwald 1986, 22; Curtis 1988, 82-86; Cox and Rosenbluth 1993). ${ }^{5}$

Perhaps the clearest exposition of a legislature-centric theory of factions comes from Kohno (1992), who argues that there were five major factions during the SNTV era because the largest electoral districts had five seats. Supporting his view, Kohno shows that, while the four bigger factions nominated candidates in most districts, the smaller Komoto faction nominated most of its candidates in five-seat districts. ${ }^{6}$

In Taiwan, Rigger (1999) tells a similar story about the Democratic Progressive Party's (DPP) factions in the 1990s. One of the factions' major roles is to help members win nominations. For much of the democratic era, DPP nominations were decided, at least in part, by allowing party members to vote. Factions recruit both candidates and party members, and they mobilize their members to vote on behalf of their candidates. District magnitude varies much more widely in Taiwan than in Japan, so factions do not always try to nominate their own candidate in each district. Instead, they often trade support across district lines. Money does not play as important a role in DPP as in LDP factional politics, but the DPP factions do provide electoral resources in the form of association with a national figure. Both in the nomination contest and in the general election, a DPP candidate can brand himself as "the Chen Shui-bian candidate," for example (Rigger 2001, chap. 5).

If the SNTV electoral system was, in fact, the critical factor in sustaining multiple intraparty factions, we might see changes after electoral reform. In MMM, each district has only one seat, so a party should only nominate one candidate. The literature suggests that competition for nominations is much like competition for seats, in that the decision rule is critical in determining how much consolidation to expect. If nominations are determined by a plurality rule, standard Duvergerian logic suggests that two big factions should form to contest each nomination. However, a different rule, such as requiring an absolute majority, may allow smaller factions some bargaining space in which to maneuver (Key 1984 [1949]; Duverger 1954; Canon 1978; Shugart and Carey 1992). 
What is the decision rule for nominations in Taiwan and Japan? In Taiwan, contested nominations are now decided by telephone polls. The procedures are less transparent in Japan, where back-room negotiations determine most contentious questions (see chapter 5 for more on nominations in Japan and Taiwan). Telephone polls use a plurality rule, and the single-shot contest does not allow runners-up any opportunity to use their demonstrated strength as bargaining chips. Japanese back-room negotiations allow smaller factions much more opportunity to trade their support in return for other concessions. Thus Taiwan's nominations can be considered as using the plurality rule, while Japanese nominations can be seen as employing a majority rule. This implies that the pressures toward two factions should be stronger in Taiwan than in Japan.

However, the pressure to consolidate the faction system in Japan should not be underestimated. The literature suggests that majoritarian systems will not support an unlimited number of actors. For example, a runoff system will theoretically only support three candidates (Cox 1997). Empirically, majoritarian systems have, in fact, discriminated against small parties (Farrell 2011). In sum, there should be reductive pressure in both countries, though it should be stronger in Taiwan than in Japan. ${ }^{7}$

To recap, both the LDP and DPP had four big factions and several smaller ones in the SNTV era. If the factions were, in fact, products of the electoral systems, the new MMM systems should have brought about some consolidation. In Taiwan, the new system should have pushed toward two big factions and perhaps a few smaller ones. In Japan, the pressures would have been weaker but still clearly reductive.

This, however, is not a good description of the actual empirical record. To show this, we shall consider the LDP, DPP and Kuomintang (KMT) factions in turn.

The five major LDP factions have continued to exist in the postreform era. They have become less influential in the area of nominations (Cox, Rosenbluth, and Thies 1999, 42-47), but the continued presence of so many factions suggests that contesting nominations was not the only, or perhaps even the major, reason for their existence. In fact, the LDP faction system has actually expanded. In addition to the five old factions, four newer factions have emerged. Rather than consolidating into fewer factions, the LDP system has trended in the opposite direction.

The DPP faction system has also undergone significant changes, but the current system is arguably just as complex as the prereform system. In the 1990s, the DPP had four big factions and several smaller ones. These factions were formally organized and physically headquartered in legisla- 
tive offices. Today, factions are all informally organized, and only one of the old factions survives. Two other major factions are led by former premiers and presidential aspirants. A fourth faction centered on former President Chen Shui-bian is waning in strength, while a fifth faction led by the 2012 presidential candidate is growing and may soon rival the big three factions. Several smaller factions also continue to operate. This reshuffling of the faction system is not compatible with legislature-centric expectations. There were major changes in the early 2000s, long before electoral reform, when the factions aligned in the direction of two big coalitions. In 2006, after the electoral reform had been passed and one might expect a two-faction system to emerge, the system was reorganized into multiple informal factions.

KMT internal factions have never fit the SNTV electoral model very well. At the national level, the KMT has had three periods of clear factional divisions during the democratic era. In the early 1990s, the party was often divided into the mainstream and nonmainstream camps, led by President Lee Teng-hui and Premier Hau Pei-tsun, respectively (Tien 1996; Lin and Teddards 2003). In the late 1990s, the KMT was again split into two factions, with one led by Lee and his protégé, Vice President Lien Chan, and the other led by Governor James Soong (Diamond 2001). Finally, in the period before the 2008 election, the party was split into supporters of Speaker Wang Jin-pyng and former Taipei City mayor Ma Ying-jeou. All three of these splits can be understood as struggles between the KMT's nativist and orthodox Chinese wings. Two of the splits occurred during the SNTV era, while the third happened as the new electoral system was being drawn up, yet all three featured two big factions. District magnitude in the legislative electoral system seems to have made no difference.

This impression is strengthened by looking at the KMT's local factions. ${ }^{8}$ The KMT's local factions are based in a specific county. Since legislative districts in the SNTV era were counties, an electoral-systems theory of factionalism would predict that the number of local factions should depend on the number of seats available in each county. In fact, there were almost always two local factions. This was true in both small counties and big counties. For instance, in Taichung County, which had between six and 11 seats, the two KMT factions generally each nominated two or three legislative candidates. Moreover, local factions commonly nominated multiple candidates in each district for the County Assembly elections, which were also conducted under SNTV rules. The KMT's local factions have not seen any dramatic changes since electoral reform. 


\section{Adding an Executive-Centric Perspective}

We have reviewed legislature-centric arguments that the electoral reforms in Japan and Taiwan should have reduced the number of parties and factions; and pointed out that the empirical record does not fit well with the theoretical predictions. In this section, we begin the process of explaining this discrepancy between theory and evidence by adding an executivecentric perspective. In this perspective, the pursuit of executive posts drives politicians, so the ways in which these posts are allotted is crucial.

\section{Parties}

From an executive-centric standpoint, the opening of executive positions to competition from opposition parties was an important milestone in the development of both countries' party systems. Both Japan and Taiwan experienced a long period of one-party dominance. In Taiwan, one-party dominance was legally mandated until 1986. Thereafter, it continued for some time because of the KMT's enormous resource advantages. In Japan, one-party dominance was not legally mandated. However, U.S. disapproval of the Japan Socialist Party (JSP) strongly militated against their participation in government, as did the LDP's resource advantages as the party of government.

During the period of one-party dominance in Taiwan, the opposition's incentive to coalesce was lessened by the common belief that they could not win, even were they better coordinated. Prior to 1986, the opposition had no chance of peacefully assuming power. From 1986 until 1991, the KMT's grip on the Legislative Yuan was assured by the presence of mainland representatives; and the opposition might have doubted the KMT's willingness to hold fair presidential elections or to relinquish power should they lose. Similarly, during the period of one-party dominance in Japan, the opposition faced a significant disincentive to coordination. U.S. opposition to JSP participation in government both reduced the chance that an opposition alliance could win and reduced the value of winning. The structural barriers to opposition governance in both countries meant that poor coordination was not the only, or main, reason the opposition believed executive power was unobtainable. Thus, the opposition could fragment without paying a penalty in lost executive offices, as those offices were already beyond its grasp for other reasons.

The period of one-party dominance ended in the early 1990s in Japan and in the early 2000s in Taiwan. Once the prime ministership in Japan 
and the presidency in Taiwan became realistic goals, opposition parties had greater incentives to settle their differences and present a unified front in the competition for the top spot and to make compromises necessary to bring new segments of voters into their coalition. From an executivecentric perspective, the key reforms in both Japan and Taiwan were those removing structural barriers impeding opposition competition for executive office. In Taiwan, this meant lifting martial law and legalizing new political parties (1987), mandating the retirement of the mainland representatives (1991), and directly electing the entire legislature (1992) and the president (1996). In Japan, structural barriers lessened as U.S. opposition to JSP involvement in government relaxed, especially after the Cold War's end. In both cases, the period of one-party dominance-with its associated and widespread belief that the opposition could never win powerwas dramatically shattered by a somewhat unexpected rotation of power. Both of these rotations came about because of splits in the old dominant party, not because the opposition first cobbled together a majority in the electorate. However, the triumph of the seven-party coalition in Japan in 1993 and the DPP's victory with a $39 \%$ plurality in the 2000 presidential election both made it clear that the executive was now in play.

The Japanese and Taiwanese responded to the onset of competitive politics for control of the executive quite differently. In Taiwan, the top prize, the presidency, could be won only by winning a plurality in the presidential election. Competition for the presidency thus drove the system toward two main candidates who, in turn, had strong incentives to organize legislators behind their candidacies.

Theoretically, politicians may take some time to adapt to the coordinating incentives of plurality elections. Indeed, the recognition that the first two parties to establish themselves as viable routes to the presidency will likely be permanent features of the electoral landscape can raise the initial stakes and prevent coordination in the short run, as suggested by Fillipov, Ordeshook, and Shvetsova (1999). The best example of this on the Taiwanese scene is the formation of the People First Party after the 2000 election. After running a rebel campaign in 2000, thereby throwing the presidency to the DPP, James Soong found it easier to form a new party and contest the leadership of the Blue camp ${ }^{9}$ from outside, than to try to return to the KMT fold and secure its nomination. In the event, Soong was not able to establish himself as the consensus candidate and ended up accepting the second spot on a joint ticket in 2004. A merger of the two parties has been a continual possibility, especially after it became clear the People First Party would not displace the KMT as leader of the Blue camp 
(Fell 2008). A somewhat different hiccup on the way toward bipartism was the Taiwan Solidarity Union, formed by former president Lee Teng-hui for the explicit purpose of leading his followers from the Blue camp into the Green camp (Wu 2002).

All told, then, the emergence of plurality competition for the presidency was the main engine driving a bipolarization of politics into a Blue camp/Green camp format with echoes of the French quadrille bipolaire. The SNTV system for legislative elections provided space for multiple parties to survive within each camp. After the change to MMM, this space for small parties shrank dramatically, and the party system quickly reduced to the two presidential contestants.

In Japan, things were different. Because the prime minister was elected indirectly, by the Diet, there were two viable routes to winning the prime ministership and other ministerial positions. One was to organize a large enough party (or coalition) to win a parliamentary majority at the legislative elections and then divide the ministerial portfolios among the victors. Call this the electoral strategy. A second option was to win as many seats as possible and then, if no other party won a majority, bargain one's way into office after the election. Call this the postelectoral strategy.

At this point, one can see why the emergence of close competition for the top executive position in Japan might not lead to bipartism in the Diet. Indirect election of a cabinet can be like electing a plural executive ( $M$ seats) using a two-stage electoral process. To the extent this analogy holds, one expects up to $M+1$ viable competitors. To put the point another way, if enough competitors for the prime ministership (and other executive offices) pursue a postelectoral strategy, then multiple parties can compete in the legislative elections, leaving the final selection to legislative bargaining. It is only if enough competitors for executive office opt for an electoral strategy that one expects a reduction in the number of parties (or the emergence of preelection alliances, on which see Carroll and Cox 2007).

By this account, the emergence of real competition for the top executive post(s), rather than electoral reforms, drove the evolution of the party system in both Japan and Taiwan. The responses differed because direct election of a powerful president demanded an electoral strategy, whereas indirect election of a relatively less powerful prime minister allowed a mixture of electoral and postelectoral strategies.

\section{Factions}

What accounts for the various changes or lack of changes in the parties' faction systems? An executive-centric explanation stresses the number of 
important posts at stake. With a directly elected, nondivisible prize such as the presidency, competitors tended to divide into two factions. Where the prize was divisible, as with cabinet posts, it was not so important to aggregate into just two big factions. Multiple factions could survive by bargaining for a share of cabinet positions.

An executive-centric perspective makes the persistence of multiple LDP factions more understandable. Most accounts of Japanese factions cite the electoral system as one reason for the factions' existence, but also stress the importance of bargaining over cabinet positions. Indeed, since the 1950s, the LDP's seniority system has ensured that cabinet positions are distributed more or less proportionally among the different factions. The factions have also fought for their fair share of other senior posts. While the electoral system changed, the parliamentary system and the number of important cabinet posts available did not. Since the number of cabinet posts is quite high, Japan's system could theoretically support even more factions. In fact, Yoshiaki Kobayashi and Hiroki Tsukiyama (chapter 3) suggest that the emergence of the four newer LDP factions is due, at least in part, to the prime minister's preference to give important posts to smaller rival factions.

KMT factionalism also makes much more sense from an executivecentric perspective. All three periods of heightened factionalism at the national level were struggles over the presidency. In the latter two, the question was which faction would represent the KMT in the presidential elections of 2000 and 2008. In the first case, the question was whether the president or the premier would dominate politics in the new democratic system. Likewise, local factionalism was based on competition over executive power. County executives have been directly elected since the 1950s, and many local factions can trace their history back to those first elections. Almost all accounts of KMT local factions stress winning the county government and controlling its resources as the most important goal. Winning legislative or county assembly seats in SNTV elections is decidedly less important.

The shifts in the number of DPP factions require a more complex explanation. Before 2000, DPP politicians focused on winning seats in the legislature, and a legislature-centric explanation is quite useful. In the late 1980 s and early 1990s, with only a small number of seats open to elections and not much support in the electorate, the DPP often could only nominate one candidates and it had two main factions, a more radical New Tide faction and a more moderate Formosa faction. As the number of seats up for election increased and the party's popularity grew in the 1990s, the DPP nominated more candidates per district. At the same time, 
two new factions, the Welfare Alliance and the Justice Alliance, arose. In 2000, Chen Shui-bian won the presidency and the faction system changed dramatically. The Formosa faction disintegrated, Chen's Justice Alliance grew dramatically, and the Justice Alliance and New Tide faction forged a coalition, creating a clear distinction between those in power and those out of power. As Chen's two terms in office neared an end, the faction system changed once again, moving away from the nascent bifactional system. The DPP formally dissolved its factions in 2006, allowing the main presidential contenders an opportunity to build new coalitions around themselves. However, the DPP has not seen the emergence of a pure bifactional system; in addition to the factions built to support President Chen and three presidential aspirants, one old faction survived and several smaller ones formed. The other factions seem to be operating on the legislature-centric model rather than focusing on winning the presidential nomination. They organize primarily to win posts in SNTV elections, such as those for the legislative party list, city councils, or the DPP's Central Executive Committee, and they trade support across district lines to win nominations in single-seat elections, such as those for local mayors or seats in the legislative nominal tier. Thus, DPP factions are currently organized around a mixture of executive-centric and legislature-centric logics.

Combining the legislature-centric and executive-centric perspectives also provides insight toward another interesting question, why factions vary so much in their institutionalization. When factions are mainly vehicles to place their paramount leader in high executive office, they can be rather kaleidoscopic, rising and falling rapidly with their leaders' fortunes. In contrast, when factions become organizations to provide nomination and election assistance to all their legislative members, as well as helping them move up a lengthy hierarchy of internal posts, then they will be much more stable and institutionalized.

Japanese and Taiwanese factions fit this argument quite well. LDP factions help a legislator advance through every step of his or her career, and LDP factions are famously highly institutionalized. The main purpose of KMT factions has been to fill the top executive office, and KMT factions have been more loosely organized. The national factions faded away as soon as the contest over the presidency was resolved. Some local factions, such as the Taichung factions examined in chapter 4, have had long life spans, yet even they are informally organized. Other local factions are much more ephemeral and seemingly reorganize whenever a new person is elected into the top local office. Indeed, the in-power faction in many townships is referred to simply as the "town hall faction," and it is often opposed by 
"the farmers' association faction." The DPP has experienced both sides of the spectrum. In the 1990s, when factions were primarily focused on winning seats in the legislature and controlling party posts, DPP factions were formally organized and quite stable. When the presidency came into play, the factions were formally abolished, factional affiliations became far more ambiguous, and factional activities become far less rigidly organized.

\section{Dual Candidacy}

An executive-centric perspective may also help us understand why Japan allowed dual candidacy while Taiwan did not.

The LDP's factions had famously resisted electoral reform for decades. When they could no longer block reform, they still perceived multiple executive prizes for which they might compete. The current occupants of these plum posts faced a choice between adopting intraparty rules allowing dual nomination or not.

Allowing dual candidacy (and operating them in the way the LDP did) improved the liquidity of the market in which the factional chiefs bargained for LDP nominations for their followers. Without dual candidacy, the nominations that the factions could trade came in four basic denominations, ordered from most to least valuable: safe slots on the party list; safe districts; marginal slots on the party list; and marginal districts. Allowing dual candidacy created a fifth denomination, less valuable than any of the others: a marginal zombie slot. ${ }^{10}$ This allowed finer trades among the factions, helping them avoid bargaining failures (which would take the form of multiple conservative candidates in the SMDs). It is not surprising that the LDP chose to implement party rules that allowed zombies, given that the Japanese factions had long experience in bargaining over the LDP nomination under the SNTV system; that the array of executive offices for which they competed had not changed; and that the cost of bargaining failure was higher under the new electoral system.

In contrast to Japan, Taiwan had a much simpler bargaining context and did not adopt dual candidacy. When there was one preeminent prize, the presidency, that was reasonably attainable, Taiwanese parties tended to have two main factions or coalitions vying for that position. These factions had less need to create a small-denomination coin (zombie slots) in order to ensure that their bargaining over legislative nominations did not break down, simply because the bargain between two was simpler than the bargain between many. Moreover, the consequence of bargaining failure was less severe. Because the presidency was directly elected, losing a seat in the 
legislature due to a nomination squabble would not immediately translate into a lower probability of winning the chief executive position, as it would in parliamentary Japan.

\section{Structure of the Volume}

The remainder of this volume will explore and develop the themes laid out in this introduction, starting from a narrow focus and moving outward. Part I compares the experiences of Japan and Taiwan. The first four chapters expand directly on the sketches of the party and faction systems laid out in the introduction. The next three chapters move to other aspects of the political systems in the two countries to show that many other aspects of politics can also be fruitfully explored by considering both a legislaturecentric and executive-centric perspective. Part II moves beyond Japan and Taiwan to other countries that have mixed-member electoral systems. In countries as diverse as Thailand, the Philippines, New Zealand, Bolivia, and Russia, the way the executive is elected has reverberations throughout the political system, causing the mixed-member systems to operate quite differently in different countries.

Chapter 1 lays out a concrete foundation for all the subsequent chapters. After describing the electoral rules in Taiwan and Japan in detail, Chi Huang, Ming-Feng Kuo, and Hans Stockton present the initial puzzlethat following electoral reform, the number of parties decreased gradually in Japan but very quickly in Taiwan. The authors then explore the degree to which this difference can be explained by the small variations in the electoral rules in the two countries, arguing that electoral rules can only account for part of the difference. Methodologically, Huang, Kuo, and Stockton present their argument in the framework of a most similar systems design and an interrupted time series with electoral reform as the interrupting event. This approach is adopted throughout part I of this volume, though it is implicit rather than explicit in the other chapters.

Chapter 2 takes up the unresolved puzzle from chapter 1. Since electoral rules cannot fully explain the numbers of parties, Jih-wen Lin examines the impact of the constitutional rules. Lin argues that Japan's parliamentary system provides opportunities for smaller parties to exercise influence over cabinet portfolios. In contrast, since cabinet positions in Taiwan's semipresidential system are determined by the president, there is little incentive for politicians to split from the two big parties. Taken together, the first 
two chapters provide a fuller explanation for the different party systems in Taiwan and Japan after electoral reform.

Chapters 3 and 4 investigate changes in the faction systems in Japan and Taiwan. Following electoral reform in Japan, many analysts expected the LDP's factions to wither away and viewed their persistence as a bit of a puzzle. The most common explanation is that factions have retained an important role in allotting cabinet and party posts. Koshiaki Kobayashi and Hiroki Tsukiyama build on this notion by examining how the LDP party president has leveraged his institutional power to expand the influence of his own faction. Especially when the LDP president is personally popular, he has given his own faction a disproportionate share of nominations and posts. However, other factions remain viable because the prime minister still needs their support in parliamentary confidence votes. In Chapter 4, Nathan F. Batto and Hsin-ta Huang discuss the limited impact electoral reform has had on the KMT's and DPP's internal factions. For both parties, competition over executive posts and the continuing use of SNTV in other elections has been more important to the faction systems than the adoption of $M M M$ in legislative elections.

Chapters 5, 6, and 7 move beyond a narrow focus on the numbers of competitors to look more broadly at how parties, candidates, and voters have adapted to the new electoral systems. In chapter 5, Eric Chen-hua Yu, Kaori Shoji, and Nathan F. Batto examine candidate selection. In both Taiwan and Japan, parties have responded to the new electoral system by adapting new methods for identifying and nominating candidates. In Taiwan, polling primaries have become the default system for both major parties, while Japanese parties have increasingly turned to the kobo (public recruitment) system. Both of these institutions can be seen as attempts to select a candidate capable of appealing to pluralities or even majorities of voters in the district. Chapter 6 investigates trends in campaign strategies under the new electoral regimes. Kuniaki Nemoto and Chia-hung Tsai argue that the new electoral system has led to increasingly party-centered campaign strategies. Parties have increasingly used list nominations and cabinet positions strategically to try to enhance party popularity and further broad party goals. They have also reacted to the new system by forming preelectoral coalitions. However, the different institutional rules have affected the extent to which parties in Japan and Taiwan have adopted these new strategies. Chapter 7 looks at split-ticket voting. T. Y. Wang, Chang-chih Lin, and Yi-ching Hsiao argue that split-ticket voting takes place mostly within, rather than across, the two big camps. Supporters of 
larger and smaller parties face quite different strategic contexts. In particular, smaller parties have a strong incentive to educate their supporters on the different ways in which votes are counted in the two tiers, and this is reflected in patterns of split-ticket voting.

Part II turns outward. While the theoretical logic presented in this introduction is grounded in the concrete realities of Japan and Taiwan, much of it can easily be transplanted to other contexts. In chapter 8 , Hicken examines how the number of parties evolved in two Southeast Asian countries that have adopted MMM, Thailand and the Philippines. At first glance, these might appear to be counter-examples, since the presidential Philippines retains a fragmented party system while parliamentary Thailand has moved to a two-party system. However, Allen Hicken argues that these developments are, in fact, quite compatible with the logic of executive competition. In Thailand, reforms have produced highly nationalized politics and a dominant prime minister who has little need to compromise with other parties or minority factions within his party. In effect, what we have termed the postelectoral strategy was simply not viable in Thailand, and the result was, predictably, a two-party system. In the Philippines, Hicken argues that there are systemic disincentives for presidential hopefuls to engage in party-building. This results in a fragmented field in presidential elections, which, in turn, inflates the number of parties in the legislature. In chapter 9, Matthew S. Shugart and Alexander C. Tan move farther afield, looking at the mushrooming number of parties in New Zealand. Once considered the quintessential example of Westminster-style parliamentary democracy, New Zealand now has a quite fragmented party system, with as many as eight parties winning seats in parliament. Shugart and Tan argue that this fragmentation is due to both the permissive MMP electoral rules and the profitability of postelection strategies. The fragmentation has precluded majority party governments, and small parties have consistently been able to gain access to the cabinet. The result is a party system with two big parties and many small parties. In chapter 10, Nathan A. Batto, Henry F. Kim, and Natalia Matukhno look at how presidential candidates affect voting in legislative elections in Bolivia and Russia, two countries very dissimilar to each other as well as to Taiwan and Japan. Voters in Bolivia and Russia have the option to vote "blank" or "against all," an option that is exercised far more often in the nominal tier than in the list tier. Many parties in these two countries are personal vehicles for presidential candidates and have difficulty fielding a full roster of credible district candidates. While voters might vote for the party list to support the presidential candidate, they are less likely to see connections between the larger party and the nominal 
tier candidate, especially in inchoate parties. That is, they may not vote for the nominal tier candidate from their favorite presidential candidate's party, even if they are not attracted to any other district candidate. In fact, blank voting in the nominal tier is more common where inchoate parties are more popular.

Finally, Chi Huang's conclusion brings the focus squarely back to the interactions between the constitutional system and the electoral system. In light of the theoretical and empirical lessons of this volume, Huang reminds us that similar institutions embedded within different concrete contexts can produce very different outcomes.

\section{NOTES}

1. Data are from the International IDEA website. http://www.idea.int/esd/ (accessed January 29, 2014).

2. As is the standard practice, we use Laakso and Taagepera's (1979) index to operationalize our conceptual variable, coordination. We acknowledge that this index does not always accurately measure the degree of coordination in the system. For example, a value of roughly two can be obtained with two parties of .51 and .49 but also with three parties of size $.66, .17$, and .17 . Several authors, such as Dunleavy and Boucek (2003) and Gaines and Taagepera (2013), have proposed new measures to address this deficiency. Nonetheless, the Laakso and Taagepera index has the advantages of simplicity and familiarity to most readers, so we continue to employ it while waiting for a consensus to emerge on a new standard.

3. For example, Duverger considers factions to simply be the product of how much internal diversity a party allowed its members (1954). Rose suggests that factions must be organized and stable over time (1964). Sartori proposes that factions be classified on four dimensions, including organization, motivation, ideology, and their position on the Left-Right spectrum (1976). The International Comparative Political Parties project, led by Kenneth Janda, operationalized factions by measuring legislative cohesion, ideology, issues, leadership, strategy and tactics, and party purges (Janda 1993). For a review of different conceptualizations of factions, see Boucek (2009).

4. In privileging this subset, we follow in the tradition of V. O. Key, who considers a faction to be any combination of actors who support a particular candidate (1984 [1949]).

5. Factions can also play a role in dividing the vote equally among a party's several candidates in multimember districts (see McCubbins and Rosenbluth 1995).

6. The Japanese literature pays less attention to the JSP factions but tends to view them also as products of the electoral incentives inherent in SNTV.

7. These pressures might be tempered somewhat by the list tier. Smaller factions might survive by contesting list seats, though the relatively small list tiers in Japan and Taiwan limit the attractiveness of this survival strategy.

8. On the KMT's local factions, see Jacobs 2008; Rigger 1999, chap. 4; Chen 1996; Bosco 1992; and chapter 4, this volume. 
9. The Blue camp is a loose coalition of pro-unification parties, including the KMT, the PFP, and the New Party. The Green camp is a coalition of proindependence parties, including the DPP and the TSU.

10. The Japanese media labeled dual candidates who lose in the district race but win a list seat as "zombies," since they have been killed in one tier but brought back to life in the other.

\section{REFERENCES}

Baerwald, Hans H. 1986. Party Politics in Japan. Winchester, MA: Allen \& Unwin. Belloni, Frank P., and Dennis C. Beller, eds. 1978. Faction Politics: Political Parties and Factionalism in Comparative Perspectives. Santa Barbara, CA: ABC-Clio.

Bosco, Joseph. 1992. "Taiwan Factions: Guanxi, Patronage, and the State in Local Politics." Ethnology 31:157-83.

Boucek, Françoise. 2009. "Rethinking Factionalism: Typologies, Intra-Party Dynamics and Three Faces of Factionalism." Party Politics 15 (4): 1-31.

Canon, Bradley C. 1978. "Factionalism in the South: A Test of Theory and a Revisitation of V. O. Key." American Fournal of Political Science 22 (4): 833-48.

Carroll, Royce, and Gary W. Cox. 2007. "The Logic of Gamson's Law: Preelection Coalitions and Portfolio Allocation." American fournal of Political Science 51:300-313.

Chen, Ming-tong. 1996. "Local Factions and Elections in Taiwan's Democratization." In Taiwan's Electoral Politics and Democratic Transition: Riding the Third Wave, ed. Hung-mao Tien. Armonk, NY: M. E. Sharpe.

Chhibber, Pradeep, and Kenneth Kollman. 2004. The Formation of National Party Systems: Federalism and Party Competition in Canada, Great Britain, India, and the United States. Princeton: Princeton University Press.

Cox, Gary W. 1990. "Centripetal and Centrifugal Incentives in Electoral Systems.” American fournal of Political Science 34:903-35.

Cox, Gary W. 1997. Making Votes Count. New York: Cambridge University Press.

Cox, Gary W., and Frances M. Rosenbluth. 1993. "The Electoral Fortunes of Legislative Factions in Japan." American Political Science Review 87 (3): 577-89.

Cox, Gary W., Frances M. Rosenbluth, and Michael P. Thies. 1999. "Electoral Rules, Career Ambition, and Party Structure: Comparing Factions in Japan's Upper and Lower Houses." American fournal of Political Science 44 (1): 115-22.

Curtis, Gerald L. 1971. Election Campaigning Zapanese Style. New York: Columbia University Press.

Curtis, Gerald L. 1988. The Fapanese Way of Politics. New York: Columbia University Press.

Diamond, Larry. 2001. "Anatomy of an Electoral Earthquake: How the KMT Lost and the DPP won the 2000 Presidential Election." In Taiwan's Presidential Politics: Democratization and Cross-Strait Relations in the Twenty-First Century, ed. Muthiah Alagappa. Armonk, NY: M. E. Sharpe.

Dunleavy, Patrick, and Françoise Boucek. 2003. "Constructing the Number of Parties." Party Politics 9 (3): 291-315.

Duverger, Maurice. 1954. Political Parties. New York: Wiley. 
Farrell, David M. 2011. Electoral Systems: A Comparative Introduction. 2nd ed. New York: Palgrave Macmillan.

Fell, Dafydd. 2008. "Inter-Party Competition in Taiwan: Toward a New Party System?" In Presidential Politics in Taiwan: The Administration of Chen Shui-bian, ed. Steven M. Goldstein and Julian Chang. Norwalk, CT: Eastbridge.

Fillipov, Mikhail G., Peter C. Ordeshook, and Olga V. Shvetsova. 1999. "Party Fragmentation and Presidential Elections in Post-Communist Democracies." Constitutional Political Economy 10:3-26.

Fukui, Haruhiro. 1970. Party in Power: The Fapanese Liberal-Democrats and PolicyMaking. Berkeley: University of California Press.

Gaines, Brian J., and Rein Taagepera. 2013. "How to Operationalize Two-Partyness." Fournal of Elections, Public Opinion, and Parties 23 (4): 387-404.

Hicken, Allen. 2009. Building Party Systems in Developing Democracies. New York: Cambridge University Press.

Jacobs, J. Bruce. 2008. Local Politics in Rural Taiwan under Dictatorship and Democracy. Norwalk, CT: Eastbridge.

Janda, Kenneth. 1993. "Comparative Political Parties: Research and Theory." In Political Science: The State of the Discipline II, ed. Ada W. Finifter. Washington, DC: American Political Science Association.

Key, V. O., Jr. 1984 [1949]. Southern Politics in State and Nation. Knoxville: University of Tennessee Press.

Kohno, Masaru. 1992. "Rational Foundations for the Organization of the Liberal Democratic Party in Japan.” World Politics 44:369-97.

Laakso, Markku, and Rein Taagepera. 1979. "Effective Number of Parties: A Measure with Application to West Europe." Comparative Political Studies 12 (1): 3-27.

Lin, Chia-lung, and Bo Teddards. 2003. "Lee Teng-hui: Transformational Leadership in Taiwan's Transition." In Sayonara to the Lee Teng-bui Era: Politics in Taiwan, 1988-2000, ed. Wei-chin Lee and T. Y. Wang. Lanham, MD: University Press of America.

McCubbins, Mathew D., and Frances Rosenbluth. 1995. "Party Provision for Personal Politics: Dividing the Vote in Japan." In Structure and Policy in Fapan and the United States, ed. Peter F. Cowhey and Mathew D. McCubbins. Cambridge: Cambridge University Press.

Rae, Douglas. 1967. The Political Consequences of Electoral Laws. New Haven: Yale University Press.

Rigger, Shelley. 1999. Politics in Taiwan: Voting for Democracy. New York: Routledge. Rigger, Shelley. 2001. From Opposition to Power: Taiwan's Democratic Progressive Party. Boulder: Lynne Rienner.

Rose, Richard. 1964. "Parties, Factions, and Tendencies in Britain." Political Studies $12: 33-46$.

Sartori, Giovanni. 1976. Parties and Party Systems: A Framework for Analysis. New York: Cambridge University Press.

Shugart, Matthew Søberg. 1995. "The Electoral Cycle and Institutional Sources of Divided Presidential Government." American Political Science Review 89 (2): 327-43.

Shugart, Matthew Søberg, and John M. Carey. 1992. Presidents and Assemblies: Constitutional Design and Electoral Dynamics. New York: Cambridge University Press. 
Shugart, Matthew Søberg, and Martin P. Wattenberg, eds. 2001. Mixed-Member Electoral Systems: The Best of Both Worlds? New York: Oxford University Press.

Thayer, Nathaniel B. 1969. How the Conservatives Rule Japan. Princeton: Princeton University Press.

Tien, Hung-mao. 1996. "Elections and Taiwan's Democratic Development." In Taiwan's Electoral Politics and Democratic Transition: Riding the Third Wave, ed. Hung-mao Tien. Armonk, NY: M. E. Sharpe.

Wu, Yu-shan. 2002. "Taiwan in 2001: Stalemated on All Fronts." Asian Survey 42 (1): 29-38.

Zariski, Raphael. 1960. "Party Factions and Comparative Politics: Some Preliminary Observations." Midwest Fournal of Political Science 4 (1): 27-51. 
PART ONE

The Consequences of MMM on Political Coordination in Taiwan and Japan 


\title{
The Consequences of MMM on Party Systems
}

\author{
Chi Huang, Ming-Feng Kuo, and Hans Stockton
}

Electoral systems determine how votes cast in an election are translated into seats in the legislature, and thus to a large extent determine who wins and who loses in the political arena. The past two decades has seen a striking increase in the prevalence of mixed-member electoral systems. By combining the advantages of plurality rule and proportional representation, these mixed systems attempt to strike a balance between the two. The intended and unintended consequences of such hybrid efforts have attracted considerable attention from scholars (e.g., Jou 2009; Ferrara 2004; Golder 2005; Huang 2011; Huang and Wang 2014; Huang, Wang, and Kuo 2008; Kostadinova 2002; Kohno 1997; Kuo, Huang, and Wang 2012; Lin 2008; Massicotte and Blais 1999; Moser and Scheiner 2004, 2012; Nishikawa and Herron 2004; Norris 2004; Reed 1999). Since the 1990s, democratic countries all over the world, as diverse as Italy, Scotland, Mexico, Bolivia, Venezuela, Russia, Albania, Hungary, Georgia, Lithuania, and New Zealand, have adopted mixed-member electoral systems. This is also true for many Asian countries, including Japan, Taiwan, Korea, Thailand, and the Philippines.

Despite their considerable differences in forms of government and political culture, congruent patterns in the new electoral systems are evident across the Asian democracies. Japan, Taiwan, Korea, Thailand and the 
Philippines all opted for mixed-member majoritarian (MMM) variants and all of them chose to weight the system heavily in favor of the majoritarian element and against the PR list (Reilly 2006, 2007).

This chapter examines legislative elections in two Asian democracies, Taiwan and Japan, in order to answer a basic research question: why these two countries, having switched from single nontransferable vote (SNTV) to similar new MMM systems, displayed such divergent speeds and degrees of reaching theoretically expected political consequences. Specifically, we examine the change in party systems from multiparty to two-party systems. After electoral reform, Japan saw a gradual evolution from a multiparty to a two-party system over several election cycles, while the party system in Taiwan changed immediately and dramatically in the first postreform election (Huang 2011).

Japan and Taiwan may constitute a no less comparable pair of subjects than Giannetti and Grofman's (2011) choice of Italy and Japan. A comparative study of these two East Asian countries, while "controlling" for similarities, can shed some light on (1) the differential effects resulting from differing constitutional structure, and (2) how seemingly "minor" differences in electoral rules can disproportionately influence political consequences (see table 1.1 for a summary of electoral rules in Japan and Taiwan). We therefore adopt a quasi-experimental design by treating Japan and Taiwan as two nonequivalent but similar countries sharing the same sequence of electoral system change yet at different time periods a decade apart. When Japan experiences the change in 1996 Taiwan serves as a control, and when Taiwan later experiences the change in 2008 Japan serves as the control. This design allows us not only to evaluate the speed and degree of the effects of electoral reform but to isolate potential causes of such effects as well.

The remainder of this chapter is divided into five sections. The first section briefly describes the historical context of the formation of major parties in Japan and Taiwan, explains why the SNTV system helped to sustain the one-party dominant system, and summarizes other negative political consequences under SNTV. The second section traces the goals of electoral reform from SNTV to MMM systems in Japan and Taiwan. We then compare the rules of MMM systems in Japan and Taiwan by focusing on some subtle differences whose political consequences deserve closer examination. The third section presents detailed comparative analyses of these two countries with aggregate-level data, and furthermore we employ a piecewise regression of "interrupted time-series with switching replications" quasi-experimental design to analyze their differences. The fourth 
section pinpoints some differences in similar electoral rules that partially solve the puzzle. The final section concludes that a complete solution requires a more general theory of electoral systems imbedded within constitutional structures, that is, the executive-centric theory that takes into account the political payoffs of the executive offices and the degree of elite coordination required to capture the executive offices.

\section{Party Politics under SNTV in Japan and Taiwan}

The evolutions of party systems in Japan and Taiwan have mirrored each other to a remarkable extent. Over time, these nascent democracies, each operating under dominant party arrangements, had transitioned into quite vibrant, multiparty systems. This was reversed as a consequence of electoral revisions that then led to the emergence of a two-party system under current circumstances. In Taiwan, the Nationalist Party (Kuomintang, KMT) has retained uninterrupted control of the country's legislature since the transition, although vacillating from single-party majority to majority in coalition and back to single-party majority. Japan's Liberal Democratic Party (LDP) experienced similar vacillation, albeit with a short interruption after 1993 and again between 2009 and 2012.

The LDP emerged in Japan in 1955 after the merger of two conservative parties (the Liberals and the Democrats) that shared support among business interests and rural areas. The LDP dominated government for

TABLE 1.1. Electoral Rules in Japan and Taiwan before and after Electoral Reform

\begin{tabular}{lccccc}
\hline & \multicolumn{2}{c}{ Japan } & & \multicolumn{2}{c}{ Taiwan } \\
\cline { 2 - 3 } \cline { 5 - 6 } & before & after & & before & after \\
\hline Total seats & 511 & $500^{\mathrm{a}}$ & & 225 & 113 \\
SNTV seats & 511 & & & 176 & $6^{\mathrm{b}}$ \\
$\quad$ Number of districts & 129 & & & 31 & 2 \\
$\quad$ Average seats per district & 4.0 & & & 5.7 & 3.0 \\
SMD seats & & 300 & & & 73 \\
Party list seats & & $200^{\mathrm{a}}$ & & 49 & 34 \\
$\quad$ Number of lists & & 11 & & 2 & 1 \\
$\quad$ Average seats per list & & $18.2^{\mathrm{a}}$ & & 24.5 & 34.0 \\
Legal threshold for list & & none & & $5 \%$ & $5 \%$ \\
Dual candidacy allowed? & & yes & & no & no \\
Best loser provision? & & yes & & no & no \\
\hline
\end{tabular}

${ }^{\text {aIn }} 2000$ and subsequent elections, the number of list tier seats and total seats were reduced to 180 and 480 , respectively. The average number of seats per list declined to 16.4 .

${ }^{\mathrm{b}}$ Reserved for aboriginals. 
38 years until a stunning loss to a coalition of "clean government" parties in 1993 (Reed and Shimizu 2009, 5). The LDP quickly returned to power in 1996, but not until after the electoral reforms discussed in this chapter were pushed through. Despite the existence of robust opposition parties, such as the Japan Socialist Party, opposition parties were never quite strong enough to challenge the LDP's dominance. This party arrangement is commonly known as the 1955 System. Given the LDP's command of approximately two-thirds of the Diet seats from one election to the next, this 1955 System is also referred to as a One-and-a-Half Party System (Flanagan et al. 1991, 5; Scheiner 2006, 37). ${ }^{1}$

Founded on the mainland in 1919, the KMT has matured during two distinct periods of time. The KMT was the ruling party of the Republic of China on the mainland for most of the period from 1919 to 1949. Since 1949, the KMT's jurisdiction has been limited to Taiwan and its surrounding islands. Competitive party politics emerged after 1986, the transition to full democracy was completed in the early 1990s, and the longtime opposition Democratic Progressive Party (DPP) even won the presidency in 2000 and 2004. However, the KMT has retained continuous control of Taiwan's legislative branch. In the early part of the democratic era, the KMT retained a degree of dominance similar to that of the LDP. After 2001, splinter parties forced the KMT into coalition arrangements, but the party returned to a dominant status in the first postreform election of 2008 (see, for example, Stockton 2010).

Both countries employed a SNTV electoral system for their national legislatures. In SNTV, each district has one or more seats and each voter can cast only one ballot for one specific candidate. There is no provision for preference rankings, so if a voter supports a candidate who does not win, the vote cannot be transferred to a second-favorite candidate. Similarly, if a candidate wins more votes than she needs, her excess votes cannot be transferred to other candidates.

Japan's SNTV system was fairly straightforward. In 1993, the last election before reform, Japan elected 511 seats from 129 districts, an average of 3.96 seats per district. Each district had between two and six seats, and the great majority had three, four, or five seats.

Taiwan's prereform system was more complex by comparison. In the 2004 election, there were a total of 225 seats. Of these, 176 seats were elected in 31 SNTV districts, for an average district magnitude of 5.68 seats per district. ${ }^{2}$ Several districts had only 1 seat, while the largest district had 13 seats. The median SNTV legislator was elected from a district with 8 seats. 
In addition to the 176 SNTV seats, there were also 49 seats elected by closed list PR on two separate lists. The list designated for national party representatives had 41 seats, while the list designated for overseas representatives had 8 seats. There was no separate party list ballot for the PR seats. Instead, all the votes for the party nominees running in the SNTV districts were summed to obtain each party's national total. For all parties with at least $5 \%$ of the national vote, these totals were used to apportion seats on the two lists using a largest remainders formula. Since there was no second ballot for the party list seats, only $22 \%$ of the seats were elected through the party lists, and each vote mattered so much more in the local race than in the national party totals, ${ }^{3}$ campaigns focused almost entirely on the SNTV portion of the election.

As for processes of democratic transition, both Japan and Taiwan have experienced similar democratic development paths from a single dominant party system to a period of multiparty politics and then finally to a twoparty system. Scholars have attributed one-party dominance as the reason for the implementation of SNTV electoral rules. Under SNTV, political parties must coordinate their supporters' votes within constituencies in order to more evenly distribute votes across candidates. Without successful coordination, weaker candidates will get too few votes while stronger copartisans will absorb too many votes. If effective, intraparty coordination can result in political parties gaining an overrepresentation bonus. Attempting to benefit from the bonus of seats, a rational political party will nominate a bare number of candidates in each constituency in the SNTV electoral system if they can overcome the problems of coordination of nomination and division of votes. Governing parties have a tremendous advantage because they can use the resources of the state to overcome these coordination problems (Cox 1996, 1997; Cox and Niou 1994; Cox and Rosenbluth 1993, 1996; Patterson and Stockton 2010; Rochon 1981). Many studies have found that a key reason for prolonged periods of LDP dominance was the LDP's ability to accomplish strategic nomination and vote coordination (Browne and Patterson 1999; Cox 1997; Horiuchi and Kohno 2004)..$^{4}$ If governing parties are expected to do well under SNTV, so are small parties. Small parties face much milder coordination problems since they often only nominate one candidate in any given district. With only one candidate, vote division is not a challenge (Taagepera and Shugart 1989, 28). Under SNTV, there is electoral space for small parties, and this should lead to a multiparty system.

Several negative political consequences have been ascribed to SNTV. The vote share necessary to win a seat decreases as the number of seats 
increases. For example, a candidate won a seat in a 16-seat district in Taiwan in 1992 with only $2.6 \%$ of the total vote. Since candidates can win with support from a small minority of voters, they can appeal to nonmedian constituencies. Thus, candidates often took more extreme and sensational positions and appealed to highly personalized and niche voters (Flanagan et al. 1991). Correspondingly, Reed (1994) and Ramseyer and Rosenbluth (1997) also found that Diet members in Japan under the SNTV system were preoccupied with district service and fund-raising at the expense of their work in the legislature. Furthermore, given that party members are competing for both nominations and seats, SNTV accentuates intraparty competition, giving rise to factionalism and hampering interparty competition at the decisive election stage. In electoral campaigns, party platforms are of limited use since there are usually competing candidates running under the same party label. This means that campaigns are usually less focused on debates about national public policies. Instead, candidates have to emphasize personal qualities, such as local interests and social connections, and they typically build extensive and costly personal organizations to mobilize voters. This localized, mobilization-based campaign style is much more expensive than one based on national debates over public policy, and the demand for funds inevitably leads to parties cozying up to corporations and systemic corruption (Cox 1997; Cox and Rosenbluth 1993; Yu Wang 2011).

In summation, both Taiwan and Japan experienced numerous institutional challenges such as fractional politics, extremism, intraparty competition, money politics, the inefficiency of parliament, and absence of power alternation during the development of democracy. Numerous studies traced these disadvantages to SNTV (Cox and Rosenbluth 1993; Cox and Thies 1998; Richardson 1988; Yeh-li Wang 2011). Because of continuous scandals and the inefficiency of parliament, subsequent electoral reform enjoyed widespread public support (Shiratori 1995; Yu Wang 2011).

\section{Electoral Reform and Differences in the MMM Systems}

Both Japan and Taiwan abandoned SNTV in favor of a new MMM system. In both countries, proponents argued that electoral reform would produce a shift from the existing candidate-oriented campaign mode to policy-driven party politics and would ultimately improve government efficiency by encouraging alternations in government, such as in the adversarial two-party systems prevalent in the United States and the United 
Kingdom (Sakamoto 1999; Yeh-li Wang 2011). In the following section, we briefly describe the electoral reform, introduce the new electoral systems in Japan and Taiwan, and summarize their similarities and differences. In both countries the electoral reforms were initiated by a coalition/minority government trying to push for changes for its own sake, but the governing parties were eventually forced to compromise with the former dominant party maneuvering to stage a comeback.

Although various electoral reform plans had been proposed for decades in Japan, it took defeat of the dominant LDP in the 1993 House of Representatives (HR) election to realize the reform. The outbreak of a series of corruption scandals in campaign finances, especially the Recruit scandal involving the Noburo Takeshita administration and Sagawa Kyubin scandal involving former LDP vice president Shin Kanemaru, paved the way for internal conflicts inside the LDP. Dissatisfied factions splintered off from the LDP and formed new parties such as the New Party Sakigake and the Japan Renewal Party. After the 1993 HR election, Morihiro Hosakawa took office by forming an eight-party anti-LDP coalition. The coalition government's bill of electoral reform passed the HR and yet was rejected by the House of Councillors in late 1993. Hosakawa chose to negotiate with the LDP and abandoned the coalition plan's single national PR constituency by establishing eleven regional constituencies, a compromise with the LDP's prefectural PR constituencies. Finally, in January 1994 the Japanese Diet passed the electoral law reform bills, abolishing the old SNTV system and adopting a new MMM system. This episode is recounted in detail by Curtis (1999) and Reed and Thies (2001).

The 1994 electoral reform in Japan and its first implementation in 1996 sent a shockwave through neighboring Taiwan where the SNTV system had also been blamed for intraparty competition, factionalism, and money politics (see, for example, Cox 1996; Cox and Niou 1994). In the late 1996 National Development Meeting summoned by President Lee Teng-hui of the KMT, a consensus was reached to replace SNTV with a mixed-member system. However, a proposed constitutional amendment about electoral reform attempt failed in 1997 because the then-ruling KMT insisted on a Japanese-style MMM system while the then-opposition DPP and New Party supported a German-style MMP system. Three years later, the DPP won the 2000 presidential election while the Pan-Blue parties maintained control of majority seats in the Legislative Yuan and dragged their feet over the DPP administration. After winning reelection in 2004, President Chen Shui-bian vigorously pushed for electoral reform by championing a proposal to "cut the assembly size in half" in order to "end the chaos in 
the Legislative Yuan." KMT chair Lien Chan, worrying about public support in the upcoming 2004 legislative election, threw his support behind the reform. The reform was unpopular with the rank-and-file legislators in both major parties, since they were not happy about half the seats in the legislature being eliminated. However, both caucuses went along with their party leaders and reluctantly voted in late 2004 to send the constitutional amendment proposal to the National Assembly for ratification. The National Assembly ratified the amendment in June 2005 with support from the two big parties. The smaller parties all opposed the reform, fearing a bleak future under the new MMM system.

Mixed-member systems have two tiers of seats. In the nominal tier, voters cast their votes for specific candidates. Most commonly, the nominal tier is conducted using single-member districts (SMDs) and the plurality rule, though there are other variants. ${ }^{5}$ In the list tier, seats are apportioned proportionally by party lists. Most mixed-member systems, including both the Japanese and Taiwanese variants, have a separate ballot for the list tier. In other words, voters cast two votes, one in the nominal tier to elect a representative from their local SMD, and one in the list tier to determine the apportionment of seats to the various party lists (Shugart and Wattenberg 2001, 10-13). ${ }^{6}$

The Japanese system adopted in 1994 had 500 seats. In the nominal tier, 300 seats are elected by the plurality rule in SMDs. In the 1996 election, there were 200 seats in the list tier apportioned by the D'Hondt rule. In 2000 and in subsequent elections, the number of list tier seats was reduced to 180 . The new Taiwanese system has a total of 113 seats. The nominal tier includes 73 seats elected by plurality in SMDs and six seats in two national SNTV districts for Mountain and Plains Aborigines. The remaining 34 seats comprise the list tier and are apportioned by a largest remainder rule. Note that in both Japan and Taiwan, the nominal tier seats far outnumber the list tier seats. As such, the incentives created by the nominal tier may also be more powerful than those created by the list tier. In particular, giving such weight to the nominal tier is damaging to smaller parties, since smaller parties often find winning a plurality in an SMD election to be a daunting challenge and rely heavily on seats from the list tier for survival. With fewer list tier seats available, smaller parties find it harder to survive. Furthermore, the drastic reduction in average district magnitude undoubtedly increases the level of disproportionality and, usually, the effective number of parties.

Despite the apparent similarities of the Japanese and Taiwanese MMM systems, there are some subtle differences whose political consequences 
deserve closer examination. Here we concentrate on dual candidacy, the best loser provision, the proportion of seats allocated to the list tier, the number of PR constituencies, and the electoral threshold.

The MMM system in Japan allows dual candidacy, in which a candidate is allowed to register simultaneously in both the nominal and list tiers. If the candidate wins the SMD, his name is removed from the party list, and all the other candidates on the list move up one rank. A double-listed candidate who loses the SMD can still win a list seat. In popular Japanese parlance, candidates who are killed in the SMD races but come back to life in the list tier are known as zombies. While double candidacy is common in mixed-member proportional systems around the world, in Japan this has proven to be one of the more controversial aspects of the MMM system. Table 1.2 shows that most parties in Japan other than the Clean Government Party (Komeito, CGP) and the Japan Communist Party take full advantage of this dual candidacy rule. In Taiwan, dual candidacy is not allowed, and seats are awarded by a strict closed-list rule.

Japan further allows lists to be ordered on the basis of which dually nominated candidates prove to be the "best losers" in the nominal tier SMDs. Parties present lists in which multiple nominees are ranked at the same position. These ties are broken by results in the SMDs. Specifically, they are ranked by dividing their own SMD vote by the winning candidate's vote. Losers who get a higher percentage of the winning total are ranked higher on the list. As with dual candidacy, parties make heavy use of the best loser provision, and this practice is increasing (see Nemoto and Tsai, chapter 6, this volume). Dual candidacy and the best loser provision reduce conflict within the party by avoiding fights over rankings and provide an incentive for SMD candidates to win as many votes as possible even if they are unlikely to win the SMD seat (Reed and Thies 2001, 383).

TABLE 1.2. Dual Candidacy Rates of Political Parties in Japan

\begin{tabular}{|c|c|c|c|c|c|c|c|}
\hline & LDP & DPJ & JCP & SDP & CGP & $\begin{array}{c}\text { Japan } \\
\text { Restoration } \\
\text { Party (JRP) }\end{array}$ & $\begin{array}{c}\text { Tomorrow } \\
\text { Party of Japan } \\
\text { (TPJ) }\end{array}$ \\
\hline 1996 & 90.3 & - & 10.4 & 100.0 & - & - & - \\
\hline 2000 & 95.9 & 98.8 & 11.3 & 100.0 & 38.9 & - & - \\
\hline 2003 & 92.1 & 98.9 & 10.3 & 100.0 & 0.0 & - & - \\
\hline 2005 & 96.6 & 98.6 & 8.0 & 94.7 & 0.0 & - & - \\
\hline 2009 & 93.1 & 98.9 & 39.5 & 100.0 & 0.0 & - & - \\
\hline 2012 & 96.2 & 100.0 & 4.0 & 100.0 & 0.0 & 100.0 & 98.2 \\
\hline
\end{tabular}

Source: Japanese National Diet Library WARP Database, http://warp.ndl.go.jp/search/; http://www. soumu.go.jp/senkyo/senkyo_s/data/index.html. Asahi Shimbun Company, "Japan's Lower House Election Results, 2012" (CD-ROM) (Tokyo: Asahi Shimbun Company, 2013). 
Japan allocates slightly more seats to the list tier than Taiwan. In Japan, $37.5 \%$ of seats are in the list tier, while only $30.1 \%$ of seats are elected by party lists in Taiwan.

Taiwan has a single national list with 34 seats. To win any of these seats, parties must win at least $5 \%$ of the national list tier vote. This $5 \%$ legal threshold discriminates against smaller parties, since without a legal threshold parties winning at least $2.9 \%$ of the vote ${ }^{7}$ would be able to win a seat. In 2008, only the two big parties passed the threshold, and two small parties, the New Party (4.0\%) and Taiwan Solidarity Union (TSU) (3.5\%), were denied seats because of the threshold. In 2012, the TSU (9.0\%) and the People First Party (5.5\%) joined the two major parties in passing the threshold, and no other party got as much as $2.9 \%$.

In Japan, the 180 list tier seats are further distributed into 11 regional blocks, ranging from 6 to 29 seats in each PR constituency

TABLE 1.3. Japan's PR Constituencies and Seats in HR Elections: 1996-2012

\begin{tabular}{|c|c|c|c|c|c|}
\hline \multirow[b]{2}{*}{ PR Blocs } & \multirow[b]{2}{*}{ Areas } & \multirow[b]{2}{*}{1996} & \multirow[b]{2}{*}{2000} & \multirow{2}{*}{\multicolumn{2}{|c|}{$\begin{array}{c}\text { Effective Threshold } \\
2003-12 \quad 2003-12\end{array}$}} \\
\hline & & & & & \\
\hline Hokkaido & Hokkaido & 9 & 8 & 8 & 8.33 \\
\hline Tohoku & $\begin{array}{l}\text { Amori, Iwate, Miyagi, Akita, } \\
\text { Yamagata, Fukushima }\end{array}$ & 16 & 14 & 14 & 5.00 \\
\hline Kita-Kanto & $\begin{array}{l}\text { Ibaraki, Tochigi, Gunma, } \\
\text { Saitama }\end{array}$ & 21 & 20 & 20 & 3.57 \\
\hline $\begin{array}{l}\text { Minami- } \\
\text { Kanto }\end{array}$ & Chiba, Kanagawa, Yamanashi & 23 & 21 & 22 & 3.26 \\
\hline Tokyo & Tokyo & 19 & 17 & 17 & 4.17 \\
\hline $\begin{array}{l}\text { Hokuriku- } \\
\text { Shinetsu }\end{array}$ & $\begin{array}{l}\text { Niigata, Nagano, Toyama, } \\
\text { Ishikawa, Fukui }\end{array}$ & 13 & 11 & 11 & 6.25 \\
\hline Tokai & Gifu, Aichi, Shizuoka, Mie & 23 & 21 & 21 & 3.41 \\
\hline Kinki & $\begin{array}{l}\text { Wakayama, Nara, Kyoto, } \\
\text { Osaka, Shiga, Hyogo }\end{array}$ & 33 & 30 & 29 & 2.50 \\
\hline Chugoku & $\begin{array}{l}\text { Tottori, Shimane, Okayama, } \\
\text { Hiroshima, Yamaguchi }\end{array}$ & 13 & 11 & 11 & 6.25 \\
\hline Shikoku & $\begin{array}{l}\text { Kagawa, Tokushima, Ehime, } \\
\text { Kochi }\end{array}$ & 7 & 6 & 6 & 10.71 \\
\hline \multirow[t]{2}{*}{ Kyushu } & $\begin{array}{l}\text { Kagoshima, Fukuoka, } \\
\text { Miyazaki, Saga, Ōita, } \\
\text { Kumamoto, Nagasaki, } \\
\text { Okinawa }\end{array}$ & 23 & 21 & 21 & 3.41 \\
\hline & Total & 200 & 180 & 180 & $4.31^{\mathrm{b}}$ \\
\hline
\end{tabular}

Source: "Proportional Representation Districts and Seats of Japanese Lower House," Japanese Ministry of Internal Affairs and Communications website: http://www.soumu.go.jp/senkyo/senkyo_s/news/senkyo/ shu_teisu/index.html. Senkyoho Kenkyukai (Election Law Study Community), ed. Senkyoho to Seiji shikinho tesatsu [The guide of Japanese electoral law and political funds control law]. Nagoya: Shinnippon-Hoki Publishing, 1995.

aAccording to Lijphart $(1997,74)$, given the district magnitude $m$, the effective threshold is $.75 /(m+1)$.

${ }^{\mathrm{b}}$ Computed based on the average number of seats: 16.4 . 
(see table 1.3). Japan has no legal threshold, so the share of the list tier vote needed to win a seat is determined by the number of seats in each constituency.

\section{After Electoral Reform: Differences in the Political Consequences between Japan and Taiwan}

The differences in constitutional structures and electoral rules discussed above appear to have divergent political consequences in Japan and Taiwan, and they deserve careful and detailed comparative analyses. In this section, we detect and compare the consequences using electoral data based on macro-level patterns of party competition. After exploring the patterns of each country's party system formation, we advance a quasi-experimental research design referred to as a "switching replication" to test for any substantial impact of electoral reform.

\section{Patterns of Party Competition}

Researchers often return to Duverger's classic arguments on electoral systems and their political consequences. According to Duverger $(1959,217)$, "the simple-majority single ballot system favors the two-party system." $\mathrm{He}$ provides two factors to explain why a third party cannot survive in this electoral system. Duverger $(1959,224)$ argues that "the mechanical factor consists in the 'under-representation' of the third, i.e. the weakest party, its percentage of seats being inferior to its percentage of the poll." The second factor is a more ambiguous one. Because supporters of a third party do not want to waste their votes, Duverger $(1959,226)$ argues that it is "their natural tendency to transfer their vote to the less evil of its two adversaries in order to prevent the success of the greater evil." Duverger $(1959,205)$ thus asserted that single-member district plurality would tend to generate two-party competition, and he also proposed that PR systems would encourage multiparty competition.

Mixed-member electoral systems are characterized as hybrids of SMD and PR tiers. Since the primary feature of the MMM system adopted by Japan and Taiwan is the independent relationship between SMD and PR tiers, "the typical majoritarian boost received by a large party in the nominal tier is not likely to be wiped away by proportional allocation from the list tier" (Shugart and Wattenberg 2001, 13). Furthermore, the PR portion in Japan accounts for only $37.5 \%$ of the 480 total seats since 2000 and in Taiwan accounts for only $30.1 \%$ of the 113 total seats. It seems logical to 
argue that the gravity force of Duverger's law will exert pressure on small parties and thus push down the number of parties. Indeed macro-level data in tables 1.4 and 1.5 seem to conform to Duverger's law and indicate that the impact of electoral reforms on party systems in the two countries is a movement toward two-party competition, albeit at different speeds. ${ }^{8}$

Tables 1.4 and 1.5 present the Laakso-Taagepera effective number of electoral parties $\left(\mathrm{N}_{\mathrm{v}}\right)$ and effective number of parliamentary parties $\left(\mathrm{N}_{\mathrm{S}}\right)$ from an SNTV to a MMM system for these two countries (Laakso and Taagepera 1979; Taagepera and Shugart 1989). According to Duverger's law, the number of parties in SMDs would shift toward two due to mechanical effects and strategic voting due to psychological effects. But Duverger's hypothesis predicts that multiple parties remain in the PR tier of the system because voters have stronger incentives to vote sincerely. This is indeed what we see in table 1.4 for Japan's HR elections over time. The effective number of electoral parties in the SMD tier $\left(\mathrm{N}_{\mathrm{SMD}}\right)$ fluctuated between the first two elections after the 1994 reform as Japan

TABLE 1.4. Effective Number of Parties in Japan: 1958-2012

\begin{tabular}{lcccc}
\hline Year & $\mathrm{N}_{\mathrm{SNTV}}$ & $\mathrm{N}_{\mathrm{SMD}}$ & $\mathrm{N}_{\mathrm{PR}}$ & $\mathrm{N}_{\mathrm{S}}$ \\
\hline 1958 & 2.24 & & & 1.98 \\
1960 & 2.40 & & & 2.00 \\
1963 & 2.55 & & & 2.15 \\
1967 & 3.03 & & & 2.41 \\
1969 & 3.35 & & & 2.50 \\
1972 & 3.41 & & & 2.67 \\
1976 & 4.02 & & & 3.18 \\
1979 & 3.76 & & & 3.29 \\
1980 & 3.44 & & & 2.74 \\
1983 & 3.64 & & & 3.23 \\
1986 & 3.35 & & & 2.57 \\
1990 & 3.42 & & & 2.70 \\
1993 & 5.15 & & & 4.14 \\
1996 & & 3.86 & 4.28 & 2.93 \\
2000 & & 3.77 & 5.15 & 3.16 \\
2003 & & 2.97 & 3.42 & 2.59 \\
2005 & & 2.71 & 3.72 & 2.26 \\
2009 & & 2.64 & 3.66 & 2.10 \\
2012 & & 3.81 & 5.79 & 2.45 \\
\hline
\end{tabular}

Source: Japanese National Diet Library WARP Database: http:// warp.ndl.go.jp/search/; Tokifumi Mizusaki and Mori Hiroki, Sousenkyu no tokubyou bunseki: 1958-2005 [Japanese general elections: 19582005] (Tokyo: Bokutakusha, 2007), 26-27; Asahi Shimbun Company, "Japan's Lower House Election Results, 2012" [CD-ROM] (Tokyo: Asahi Shimbun Company, 2013). 
went through a period of party realignment but then dropped sharply below 3.0 parties for the three elections in 2003, 2005, and 2009. ${ }^{9}$ The effective number of electoral parties in PR tier $\left(\mathrm{N}_{\mathrm{PR}}\right)$ has also declined over time, though it has consistently been higher than its SMD counterpart and remained above 3.5 after the 2003 election. With more than $62 \%$ of the HR seats allocated to the SMD tier, it is not surprising that the $\mathrm{N}_{\mathrm{S}}$ dropped below the $\mathrm{N}_{\mathrm{SMD}}$. In short, throughout the period from 1996 to 2009 in Japan, partisan politics were largely focused on the contest between the Liberal Democratic Party (LDP) and the second largest party (e.g. the New Frontier Party in 1996 and the Democratic Party of Japan since 2000).

As Jou $(2009,2010)$ points out, during this decade, party competition in Japan's SMD tier witnessed two distinct patterns: urban areas converging toward a two-party system while rural constituencies remaining dominated by the LDP (see also Yu Wang 2011). The landslide victory of the Democratic Party of Japan (DPJ) with 64\% of the seats in the 2009 HR election and the formation of the DPJ-centered coalition government appear to have ushered in a new era of government with the alternation of two major parties (Arase 2010; Krauss and Pekkanen 2011; Maeda 2010). The pendulum swinging back to the LDP with $61.3 \%$ of the total seats in the $2012 \mathrm{HR}$ election is further evidence of this trend. But it also seems that MMM can produce extreme one-party dominance and decimate opposition parties.

The data for Taiwan's legislative elections are presented in table 1.5. These clearly indicate that there was an immediate and dramatic drop in all three indicators of the effective number of parties. Whereas the $\mathrm{N}_{\mathrm{SNTV}}$

TABLE 1.5. Effective Number of Parties in Taiwan: 1992-2012

\begin{tabular}{lcccc}
\hline Year & $\mathrm{N}_{\mathrm{SNTV}}$ & $\mathrm{N}_{\mathrm{SMD}}$ & $\mathrm{N}_{\mathrm{PR}}$ & $\mathrm{N}_{\mathrm{S}}$ \\
\hline 1992 & 2.52 & & & 2.46 \\
1995 & 2.90 & & & 2.63 \\
1998 & 3.14 & & & 2.53 \\
2001 & 4.14 & & & 3.24 \\
2004 & 3.76 & & & 3.08 \\
2008 & & 2.29 & 2.49 & 1.47 \\
2012 & & 2.32 & 3.03 & 1.97 \\
\hline
\end{tabular}

Source: Data for 1992-2008 elections results from Election Study Center, National Chengchi University, website: http://vote.nccu. edu.tw/cec/vote4.asp? pass1=B; data for the 2012 election result from Taiwan's Political Geography Information System (TPGIS) website: http://tpgis.nccu.edu.tw/MainPage/. 
in the 2004 SNTV elections had been 3.76, in $2008 \mathrm{~N}_{\text {SMD }}$ plunged to 2.29, just as Duverger's Law suggests. Furthermore, the $\mathrm{N}_{\mathrm{PR}}$ measure was a mere 2.49. It took Japan a decade and a half and five HR elections to evolve into a true two-party system, but this transformation was realized almost immediately in Taiwan. As in Japan, the dominance of the nominal tier led to a lower number of parliamentary parties than electoral parties. In 2008, the $\mathrm{N}_{\mathrm{S}}$ was a mere 1.47 , which is much closer to one-party dominance than one would expect in a democracy. Even with a much stronger performance by the DPP and after the People First Party split from the Pan-Blue coalition and ran its own candidates in the 2012 legislative election, the $\mathrm{N}_{\mathrm{S}}$ rose only slightly to 1.97 and $\mathrm{N}_{\mathrm{SMD}}$ grew only to 2.32 and $\mathrm{N}_{\mathrm{PR}} 3.03$, respectively.

\section{Evaluating the Impact of Electoral Reform: A Quasi-Experimental Design}

This study applies the logic of "most similar systems" design (MSSD) in the comparative politics tradition (Przeworski and Teune 1970) to the "interrupted time series" (ITS) quasi-experiment frequently used in the fields of policy evaluation (Campbell and Stanley 1963). Most similar systems design involves matching two cases that experience different outcomes while appearing to be very similar in as many respects as possible except on key theoretical points. The goal of this design is to identify the difference that is responsible for contrasting outcomes. Those similarities between two cases can be considered relatively "controlled for" and thus ruled out as possible causes. The remaining differences between the two cases emerge as the candidates causing their divergent outcomes. MSSD thus facilitates causal inference.

Japan and Taiwan are selected following the logic of the most similar systems design. In other words, they are chosen for this study because they are relatively similar in many respects. Both are densely populated island countries along the Asian continent without rich natural resources and yet have built relatively healthy open economies with broadly distributed wealth. Both have Confucian and Buddhist cultural heritages as well. Although Japan is under a parliamentary system and Taiwan is under a semipresidential system, both countries otherwise have similar governing institutions led by a longtime dominant clientelistic political party and disciplined bureaucrats. Indeed, Taiwan was a Japanese colony for 50 years, and many of its institutional structures and behavioral habits can be traced directly to Japanese sources.

The ITS design, on the other hand, involves one experimental group 
and repeated observations before and after an intervention (Shadish, Cook, and Campbell 2002, 175). The weakness of this single time series design is the threat of history to the internal validity of causality. That is, there is always the possibility that factors other than the event under investigation come to influence the dependent variable at about the same time the intervention occurs.

If we can find two nonequivalent but relatively similar countries, each of which has the same sequence of electoral system change yet at different times, then a certain degree of control can still be achieved. That is, when one country experiences intervention the other serves as a control, and when the control nation later experiences the event the original treatment case serves as the control (Shadish, Cook, and Campbell 2002, 192). Applying this "ITS with switching replications" design to this study, it can be diagrammed as:

\section{$\mathrm{OOOOOXOOOOO}$}

\section{$\mathrm{OOOOOOOOXOO}$}

where each $\mathrm{O}$ represents an observation of the dependent variable (i.e., $\mathrm{N}_{\mathrm{S}}$ ), and $\mathrm{X}$ stands for the occurrence to the event (i.e., shift from SNTV to MMM system).

Figure 1.1 displays the evolution of the effective number of parliamentary parties in Japan and Taiwan, respectively. In general, both countries experience a rising trend during the SNTV period and then witness a decline after adopting the MMM system. However, the decline is more abrupt and immediate in Taiwan than in Japan. In terms of a cross-country comparison, when Japan first implemented the MMM system in 1996 and started to show a slow decline trend in $\mathrm{N}_{\mathrm{S}}$, Taiwan showed no such change. Similarly, when Taiwan first implemented the MMM system and experienced a sharp decline in $\mathrm{N}_{\mathrm{S}}$ in 2008 , Japan's $\mathrm{N}_{\mathrm{S}}$ had already reached a steady state of nearly two. This switching pattern strengthens our confidence in making a causal inference from the impact of electoral system change.

\section{Impact Analysis}

Box and Tiao's (1975) ITS analysis is often used to assess the impact of a discrete intervention on a social process (see, for example, Box, Jenkins, and Reinsel 2008; McCleary and Hay 1980). However, this method requires one to identify and estimate a noise model based on the preintervention 


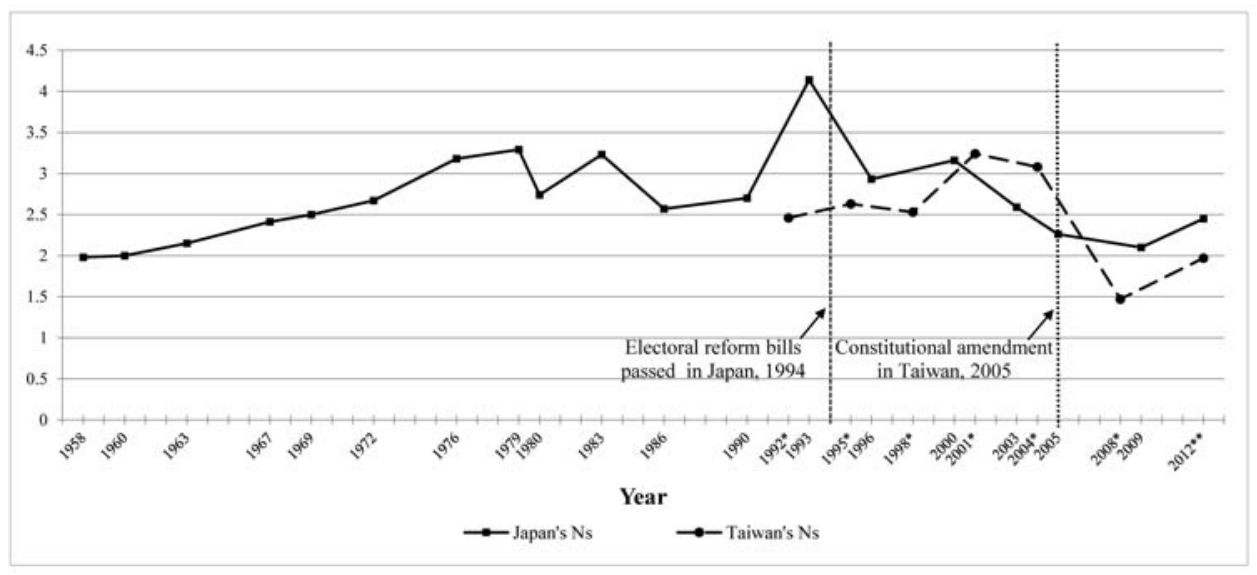

Fig. 1.1. Effective number of parliamentary parties $\left(N_{\mathrm{s}}\right)$ : Japan and Taiwan (Note: Years with "*" denote Legislative Yuan elections in Taiwan, while years without "*" refer to lower house elections in Japan; "**" denotes general elections held in both Taiwan and Japan. Data from Japanese National Diet Library WARP Database: http://warp.ndl.go.jp/search/; Tokifumi Mizusaki and Mori Hiroki, Sousenkyu no tokuhyou bunseki: 1958-2005 [Japanese general elections: 1958-2005], 26-27 (Tokyo: Bokutakusha, 2007); Yomiuri Online: http:// www.yomiuri.co.jp/election/shugiin/2012/kaihyou/, accessed on March 28, 2013.)

series as a benchmark for comparison with the entire series. Given the limitation of the frequency of legislative elections held in the past half century and thus the number of observations available for this study, the five (for Taiwan) to thirteen (for Japan) observations before electoral system changes occurred are obviously too few to apply Box and Tiao's techniques. We therefore turn to the piecewise linear regression approach of ITS (Greene 2012; Lewis-Beck 1986; Marsh and Cormier 2002), which takes advantage of the entire series and is still able to assess the impact of events. The method is to regress the dependent variable upon independent variables representing a trend and events. Each event, in turn, is represented by a dummy variable (which captures the drop or jump in intercept change) and a postintervention time counter (which captures the slope change).

Based on the piecewise linear regression approach, the equation we use to evaluate the impact of shifting from the SNTV to MMM system in Japan is specified as follows:

$$
Y_{t}=\beta_{0}+\beta_{1} T_{t}+\beta_{2} D_{1 t}+\beta_{3} C_{1 t}+\beta_{4} D_{2 t}+\beta_{5} C_{2 t}+\varepsilon_{t}
$$

where 
$Y_{t}=$ dependent variables, $\mathrm{N}_{\mathrm{S}}$

$T_{t}=$ a counter for time from 1 to the last observation

$D_{1 t}=$ a dummy variable indicating the implementation of the MMM

system in Japan, that is, $D_{1 t}=1$ since year 1996

$C_{1 t}=$ a postintervention time counter scored 0 before 1996 and 1, 2,

3 ... for observations on and after 1996

$D_{2 t}=$ a dummy variable indicating the implementation of the MMM

system in Taiwan, that is, $D_{2 t}=1$ since year 2008

$C_{2 t}=$ a postintervention time counter scored 0 before 2008 and 1,2,

3 ... for observations on and after 2008.

The equation for assessing electoral system change in Taiwan is similar to the equation (1.1) for Japan except that its observations start from 1992 when the island held its first free and open Legislative Yuan elections and thus consists of only seven observations up to the 2012 election. Given this extremely short time series and thus small degree of freedom, statistical estimates serve only as a supplement to the visual inspection of figures. If our hypothesis is correct, that is, if electoral system change causes a gradual shift in the party system in Japan while leading to an immediate alignment in Taiwan, then we expect divergent patterns of impact in the two countries. That is, we expect no abrupt change in intercept $D_{1 t}$ but only a slow change in slope $C_{1 t}$ in Japan. On the other hand, we expect at least an abrupt change in intercept $D_{2 t}$ and perhaps also in slope $C_{2 t}$ in the case of Taiwan.

Statistical results for the $\mathrm{N}_{\mathrm{S}}$ of Japan and Taiwan are presented in table 1.6. They generally confirm the visual inspection of figure 1.1. For both countries, the evolution of the $\mathrm{N}_{\mathrm{S}}$ changes only when each country shifts from the SNTV to the new MMM system. Furthermore, the general pattern of change fits our expectation. There is no significant change in slope since 1996 but only a slight decline in slope $\left(C_{1 t}=-0.120\right)$ in the case of Japan. In contrast, there is an abrupt drop in level $\left(D_{2 t}=-2.155\right)$ in the case of Taiwan in $2008,{ }^{10}$ albeit no change in slope is detected perhaps due to the fact that only two elections have been held after the electoral reform. The ITS design uses Taiwan's reform as a control for Japan and Japan's reform as a control for Taiwan. In the Japan model, the variables for Taiwanese reform are not significantly different from zero, and a parallel result holds in the Taiwan model. This provides an added level of confidence that the changes in the party systems were, in fact, due to the treatment variable, electoral reform. Overall, what both figure 1.1 and table 
1.6 show is a gradual shift from a multiparty system to a two-party system taking place over several elections after reform in Japan, but a sudden and abrupt shift in the first postreform election in Taiwan.

\section{Why Different Speeds toward a Two-Party System?}

The differences between Japan and Taiwan discussed above pose an interesting question. Why did it take Japan almost one and a half decades to gradually consolidate toward a two-party system and strategic voting pattern (see Scheiner and Tronconi 2011, 102) while in Taiwan the impact of the new electoral system was immediate and extreme? To what extent are these different rates of change the result of different electoral rules, such as dual candidacy, the best loser provision, the number of party list constituencies, the threshold for list constituencies, and the proportion of seats allocated to the nominal and list tiers? We speculate that all these elements contribute to the divergent results.

One reason why the number of electoral parties may not have declined as precipitously as expected has to do with contamination effects. A number of studies have noted that in mixed-member systems, in order to lift the $\mathrm{PR}$ votes, party elites may field candidates in single-member districts to give the party label a human face, regardless of the chance of winning the

TABLE 1.6. Impact of MMM on $N_{s}$ : Japan and Taiwan

\begin{tabular}{|c|c|c|c|c|}
\hline \multirow{2}{*}{$\begin{array}{l}\text { Effective number of parliamentary } \\
\text { parties }\left(\mathrm{N}_{\mathrm{S}}\right)\end{array}$} & \multicolumn{2}{|c|}{ Japan } & \multicolumn{2}{|c|}{ Taiwan } \\
\hline & Coefficient & (S.E.) & Coefficient & (S.E.) \\
\hline Time Counter $T_{t}$ & $0.042^{* \star *}$ & $(0.010)$ & 0.057 & $(0.167)$ \\
\hline $\begin{array}{l}\text { Adopting MMM System in Japan } \\
\left(D_{1 t}=1 \text { since } 1996\right)\end{array}$ & -0.367 & $(0.440)$ & -0.230 & $(0.648)$ \\
\hline $\begin{array}{l}\text { Trend under MMM in Japan } \\
\quad\left(C_{1 t} \text { time counter since } 1996\right)\end{array}$ & $-0.120^{\dagger}$ & $(0.056)$ & 0.035 & $(0.187)$ \\
\hline $\begin{array}{l}\text { Adopting MMM System in Taiwan } \\
\qquad\left(D_{2 t}=1 \text { since 2008) }\right.\end{array}$ & -0.400 & $(0.777)$ & $-2.155^{\#}$ & $(0.707)$ \\
\hline $\begin{array}{l}\text { Trend under MMM in Taiwan } \\
\quad\left(C_{2 t} \text { time counter since } 2008\right)\end{array}$ & 0.195 & $(0.186)$ & 0.033 & $(0.151)$ \\
\hline Constant & $1.978^{*+*}$ & $(0.202)$ & 2.403 & $(0.488)$ \\
\hline$R^{2}$ & \multicolumn{2}{|c|}{$0.651^{* *}$} & \multicolumn{2}{|c|}{0.944} \\
\hline Adjusted $R^{2}$ & \multicolumn{2}{|c|}{0.516} & \multicolumn{2}{|c|}{0.663} \\
\hline Number of observations & \multicolumn{2}{|c|}{19} & \multicolumn{2}{|c|}{7} \\
\hline
\end{tabular}

${ }^{+} p<0.1 ; p<0.05 ; " p<0.01 ; " * p<0.001$.

${ }^{\#}|t|=3.05$ but is insignificant $(p>0.1)$ due to too few observations and degrees of freedom in Taiwan. 
district seat. Electoral incentives in one tier thus "contaminate" those in the other tier, complicating the insights from Duvergerian laws (Cox and Schoppa 2002; Herron and Nishikawa 2001; Moser and Scheiner 2004). This might account for higher than expected $\mathrm{N}_{\mathrm{V}}$. However, these extra candidates are assumed to be sure losers, and they should not affect $\mathrm{N}_{\mathrm{S}}$. Moreover, contamination effects yield no insight into the differences in the evolution of the party system in Japan and Taiwan.

Taiwan's list tier has a legal 5\% threshold. In Japan, the average regional constituency has an implied threshold of $5.8 \%$. This is marginally higher than in Taiwan, so one might conclude that the Japanese system is more unfriendly to small parties. However, because the number of seats on each regional list varies, so does the threshold. If we look at Lijphart's (1994, 27; 1997, 74) estimate for effective threshold, ${ }^{11}$ small parties in Japan have even more opportunities. In Shikoku, with only six seats, the effective threshold is $10.71 \%$ and is a very high barrier for small parties. In contrast, Kinki has 29 seats, and small parties might not be intimidated at all by the relatively low $2.5 \%$ threshold since a party with $2.5 \%$ has a reasonable chance to win a seat. In fact, six out of the 11 regional constituencies have thresholds under 5\% (see the last column of table 1.3). In short, there are opportunities for small parties to win list seats in the larger regions, and small parties in Japan can strategically concentrate their efforts on regions in which they have a reasonable chance of exceeding the threshold.

The differences in the thresholds imply that small parties should find more opportunities to win list seats in Japan than in Taiwan. Unlike in Taiwan, they do not have to cross a relatively high $5 \%$ national threshold to survive. Instead, they can win one or two seats with a somewhat lower vote and build on this foundation in future elections. They can also concentrate their resources in the most favorable regions and ignore less promising areas. These opportunities are further enhanced by the fact that Japan allocates a slightly higher percentage of seats to the list tier.

We suspect that dual candidacy and the best loser provision also help small parties survive in Japan. Candidates who "die gloriously" in their SMDs can be "revived" in the PR tier as "zombies" and thus have strong incentives to cultivate local connections and campaign hard in their SMDs. This hard work, in turn, can result in higher party votes in the list tier (though see Maeda 2008 for an opposing view). Kuo, Huang, and Wang (2012) analyzed Japanese House elections from 1996 to 2009 and found evidence that smaller parties such as the Social Democratic Party and losing major parties such as the LDP in 2009 relied more on dual candidacy's lifting effects on PR votes. The Social Democratic Party did use 
the dual candidacy strategy to improve their PR votes and furthermore to sustain their seats in parliament. In Taiwan, on the other hand, there is no mechanism for such interactions between SMD and PR ballots since no dual candidacy is allowed. Huang (2010) evaluated the effects of the TSU's nomination of 13 district candidates on their PR vote shares in the 2008 elections in Taiwan and indeed found no evidence of interaction between the SMD and PR tiers.

Neither Taiwan's nor Japan's electoral system is friendly to small parties, but small parties have a better chance of survival in Japan's system. Yet we suspect that these contrasting electoral rules cannot fully explain why small parties have fared so much better in Japan than in Taiwan. A more complete explanation requires consideration of differences in the constitutional designs of each country, a topic Lin takes up in chapter 2 and others develop in the rest of this volume.

\section{Concluding Remarks}

Institutions do matter, and even seemingly "minor" differences may produce significantly different outcomes. This chapter explores the effect on party systems of several such differences between Japan and Taiwan, including dual candidacy, the best loser provision, the proportion of seats allocated to the list tier, the number of PR constituencies, and the electoral threshold. Whether and to what extent these differences produce the divergent consequences discussed above call for further careful comparative studies and rigorous causal analyses.

Japan and Taiwan undertook similar electoral reforms from SNTV to MMM, and they both experienced a similar development from a multiparty system to a two-party system. However, the speeds at which the party systems transformed after electoral reform varied significantly. We argue that the combination of some seemingly "minor" differences in electoral systems contributed to these divergent results by providing more opportunities for smaller parties to survive in Japan than in Taiwan. However, we do not argue that differences in the electoral rules can fully account for the larger numbers of parties in Japan. Electoral systems cannot be delinked from the wider constitutional arrangements in which they occur. As Lin argues in the next chapter, analyses of party system change are best served when we focus not only on changing rules but also on the constitutional context in which they are embedded. Specifically, researchers should 
keep both legislative seats and executive offices in view while analyzing the effects of legislative electoral systems.

\section{NOTES}

1. In the 1955 System, the main debates on national policies between the ruling LDP and opposition parties were mainly based on the conservative-progressive political ideology spectrum. Their debate was as follows: (1) whether Japan should move toward becoming a capitalist or a socialist state; (2) whether or not the ninth statement of Japan's constitution should be amended; (3) whether or not the U.S.-Japan Treaty (Ampou) alliance should be maintained; (4) in terms of defense, whether military forces in Japan should be enhanced or remain neutral (Yang 2002, $65)$.

2. In all, 168 representatives were elected from 29 geographically defined districts. Another eight members were elected from two nationwide districts reserved for Plains Aborigines and Mountain Aborigines.

3. Usually, 40,000 votes were sufficient to elect a district candidate, whereas each seat on the national party representatives list needed about 200,000 votes.

4. Some studies further indicates that in " 1955 system," because the LDP usually took two-thirds of the seats in the Diet, and the opposition parties could not cooperate with each other to challenge the LDP-dominant regime, the power alternation was only between the main factions inside the LDP, not alternation between parties (Reed 2003, 21).

5. The prereform Taiwanese system was technically a MMM system since it had a nominal tier, with voters choosing specific candidates in the SNTV tier, as well as a list tier. However, for the purpose of clarity, this volume will refer to the prereform system as an SNTV system. MMM will refer narrowly to the postreform systems in Japan and Taiwan with nominal tiers composed of SMDs.

6. Mixed-member systems are commonly divided into two categories, mixedmember majoritarian (MMM) and mixed-member proportional (MMP). The critical factor is whether the two tiers are linked. In MMM, the tiers are not linked, so seats are determined independently in each tier. That is, if a party wins $50 \%$ of the party list votes, it wins $50 \%$ of the list tier seats, regardless of whether it won all, some, or none of the nominal tier seats. The plurality formula used in the nominal tier can lead to significant disproportionality, and the list tier in MMM systems merely mitigates rather than erases this disproportionality. In MMP systems, the two tiers are linked in order to produce a proportional outcome. Each party's total seat share is determined by the list tier vote, and, depending on the number of seats it wins in the nominal tier, it is awarded the appropriate number of party list seats necessary to obtain a proportional share of seats in the overall chamber (Shugart and Wattenberg 2001, 13-17).

7. The theoretical threshold is $1 /(m+1)$.

8. By "speeds" we mean the number of elections it takes to reach similar results.

9. The $\mathrm{N}_{\mathrm{SMD}}$ remained high (3.77) in Japan's 2000 House election. This was partly because the coalition partnership of the LDP and CGP did not effectively 
coordinate their nominations. Specifically, the LDP and CGP have formed a coalition to nominate candidates to compete against non-LDP candidates in all elections since 2000. In most districts, CGP supporters were supposed to vote for an LDP candidate, and the LDP gave organizational votes to support CGP's PR list candidates. But in the 2000 election, the coalition did not work very well, as the LDP and CGP simultaneously fielded SMD candidates in four districts. Since the 2003 election, this problem has been overcome. See also Nemoto and Tsai, chapter 6 , this volume.

10. With five variables and only seven cases in the Taiwan model, even large $t$-values do not reach conventional levels of significance. In the following pages we adopt a rule of thumb of a $t$-ratio above 2 as a rough guideline for interpreting the case of Taiwan.

11. The effective threshold is estimated as $.75 /(m+1)$.

\section{REFERENCES}

Arase, David. 2010. “Japan in 2009: A Historic Election Year.” Asian Survey 50 (1): $40-55$.

Asahi Shimbun Company. 2013. "Japan's Lower House Election Results, 2012” [in Japanese] (CD-ROM). Tokyo: Asahi Shimbun.

Box, George E. P., Gyilym M. Jenkins, and Gregory C. Reinsel. 2008. Time Series Analysis: Forecasting and Control. Hoboken, NJ: John Wiley and Sons.

Box, G. E. P., and G. C. Tiao. 1975. "Intervention Analysis with Applications to Economic and Environmental Problem." Fournal of the American Statistical Association 70 (349): 70-79.

Browne, Eric C., and Dennis Patterson. 1999. "An Empirical Theory of National Nominating Behavior." British fournal of Political Science 29 (2): 259-89.

Campbell, Donald T., and Julian C. Stanley. 1963. Experimental and QuasiExperimental Designs for Research. Boston: Houghton Mifflin.

Cox, Gary W. 1996. "Is the Single Non-Transferable Vote Superproportional? Evidence from Japan and Taiwan.” American Fournal of Political Science 40 (3): 740-55.

Cox, Gary W. 1997. Making Votes Count: Strategic Coordination in the World's Electoral Systems. Cambridge: Cambridge University Press.

Cox, Gary W., and Emerson Niou. 1994. "Seat Bonuses under the Single NonTransferable Vote System: Evidence from Japan and Taiwan.” Comparative Politics 26 (2): 221-36.

Cox, Gary W., and Frances Rosenbluth. 1993. "The Electoral Fortunes of Legislative Factions in Japan." American Political Science Review 87 (3): 577-89.

Cox, Gary W., and Frances Rosenbluth. 1996. "Factional Competition for the Party Endorsement." British Fournal of Political Science 26 (2): 259-69.

Cox, Gary W., and Michael F. Thies. 1998. "The Cost of Intraparty Competition: The Single, Non-Transferable Vote and Money Politics in Japan." Comparative Political Studies 31 (3): 267-91.

Cox, Karen E., and Leonard J. Schoppa. 2002. "Interaction Effects in MixedMember Electoral Systems: Theory and Evidence from Germany, Japan, and Italy." Comparative Political Studies 35 (9): 1027-53. 
Curtis, Gerald L. 1999. The Logic of Japanese Politics. New York: Columbia University Press.

Duverger, Maurice. 1959. Political Parties: Their Organization and Activity in the Modern State. 2nd English ed. New York: John Wiley and Sons.

Farrell, David M. 2011. Electoral Systems: A Comparative Introduction. 2nd ed. New York: Palgrave Macmillan.

Ferrara, Federico. 2004. "Electoral Coordination and the Strategic Desertion of Strong Parties in Compensatory Mixed Systems with Negative Vote Transfers." Electoral Studies 23 (3): 391-413.

Ferrara, Federico, Erik S. Herron, and Misa Nishikawa. 2005. Mixed Electoral Systems: Contamination and Its Consequences. New York: Palgrave Macmillan.

Flanagan, Scott C., Shinsaku Kohei, Ichiro Miyake, Bradley M. Richardson, and Joji Watanuki. 1991. The Fapanese Voter. New Haven: Yale University Press.

Fujimura, Naofumi. 2007. "The Power Relationship between the Prime Minister and Ruling Party Legislators: The Postal Service Privatization Act of 2005 in Japan." Fapanese Fournal of Political Science 8 (2): 233-61.

Gaunder, Alisa. 2007. Political Reform in Japan: Leadership Looming Large. London: Routledge.

Giannetti, Daniela, and Bernard Grofman. 2011. "Introduction: Long-Run Consequences of Electoral Rules Change: Comparing Italy and Japan." In $A \mathrm{Natu-}$ ral Experiment on Electoral Law Reform: Evaluating the Long Run Consequences of 1990s Electoral Reform in Italy and Japan, ed. Daniela Giannetti and Bernard Grofman, 1-12 . New York: Springer.

Golder, Matt. 2005. "Democratic Electoral Systems around the World, 19462000." Electoral Studies 24 (1): 103-21.

Greene, William H. 2012. Econometric Analysis. 7th ed. Essex, England: Pearson Education.

Hayao, Kenji. 1993. The Fapanese Prime Minister and Public Policy. Pittsburgh: University of Pittsburgh Press.

Herron, Erik S., and Misa Nishikawa. 2001. "Contamination Effects and the Number of Parties in Mixed-Superposition Electoral Systems." Electoral Studies 20 (1): $63-86$.

Hicken, Allen, and Yuko Kasuya. 2003. "A Guide to the Constitutional Structures and Electoral Systems of East, South and Southeast Asia." Electoral Studies 22 (1): 121-51.

Horiuchi, Yusaku, and Masaru Kohno. 2004. "SNTV and Its Political Consequences: Mechanical Effect, Strategic Candidate Nomination, and the Origins of Japan's One-Party Dominance." Paper delivered at the 2004 Annual Meeting of American Political Science Association, Chicago, September 2-5.

Huang, Chi. 2008. "Contexts and Consequences of Electoral Systems" [in Chinese]. In Rube Pinggu Xuanzhi Bianqian: Fangfalun de Tantao [The consequences of electoral system change: Methodological perspectives], ed. Chi Huang and Chin-hsing Yu, 1-18. Taipei: Wunan Press.

Huang, Chi. 2010. "Causal Inference and Treatment Effect Evaluation: Partial Identification Approach and Its Application to Electoral System Effect" [in Chinese]. Xuanju Yanjiu [Journal of Electoral Studies] 17 (2): 103-34.

Huang, Chi. 2011. "Political Consequences of the MMM Electoral Systems in Tai- 
wan and Japan." Paper presented at the 2011 Annual Meeting of the American Political Science Association, Seattle, September 1-4.

Huang, Chi. 2013. "Taiwan's Political Geography Information System (TPGIS)" http://tpgis.nccu.edu.tw/nccu/ (accessed on March 1, 2013).

Huang, Chi, Lu-huei Chen, and Ying-lung Chou. 2008. "Taiwan's New Mixed Electoral System and Its Effects on 2008 Legislative Election" Presented at the 2008 Annual Meeting of the Japanese Association of Electoral Studies, Tokyo, May 17-18.

Huang, Chi, Ding-ming Wang, and Ming-feng Kuo. 2008. "Straight- and SplitTicket Voting in a Mixed-Member Majoritarian System: An Analysis of the 1996 House Election in Japan" [in Chinese]. Xuanju Yanjiu [Journal of Electoral Studies] 15 (2): 1-36.

Huang, Chi, and T. Y. Wang. 2014. "Presidential Coattails in Taiwan: An Analysis of Voter- and Candidate-Specific Data." Electoral Studies 33 (March): 175-85.

Japanese National Diet Library WARP Database [in Japanese]. http://warp.ndl. go.jp/search/.

Jou, Willy. 2009. "Electoral Reform and Party System Development in Japan and Taiwan." Asian Survey 49 (5): 759-85.

Jou, Willy. 2010. "Toward a Two-Party System or Two Party Systems? Patterns of Competition in Japan's Single-Member Districts, 1996-2005.” Party Politics 16 (3): 370-93.

Kabashima, Ikuo, and Gill Steel. 2007. "How Junichiro Koizumi Seized the Leadership of Japan's Liberal Democratic Party.” Japanese Fournal of Political Science 8 (1): 95-114.

Kohno, Masaru. 1997. "Voter Turnout and Strategic Ticket-Splitting under Japan's New Electoral Rules.” Asia Survey 37 (5): 429-40.

Kostadinova, T. 2002. "Do Mixed Electoral Systems Matter? A Cross-National Analysis of Their Effects in Eastern Europe." Electoral Studies 21 (1): 23-34.

Krauss, Ellis S., and Benjamin Nyblade. 2005. "Presidentialization' in Japan? The Prime Minister, Media, and Elections in Japan.” British Journal of Political Science 35 (2): 357-68.

Krauss, Ellis S., and Robert J. Pekkanen. 2011. The Rise and Fall of Japan's LDP: Political Party Organizations as Historical Institutions. Ithaca: Cornell University Press.

Kuo, Ming-feng, Chi Huang, and Ding-ming Wang. 2012. "The Contamination Effect in a Mixed-Member Majoritarian System: The Influence of LDP's Dual Candidacy in Japanese House Elections (1996-2005)" [in Chinese]. Zhengzhi Kexue Luncong [Taiwanese Journal of Political Science] 51:161-216.

Kuroda, Yasumasa. 2005. The Core of Japanese Democracy: Latent Interparty Politics. New York: Palgrave Macmillan.

Laakso, Markku, and Rein Taagepera. 1979. "Effective Number of Parties: A Measure with Application to West Europe." Comparative Political Studies 12 (1): 3-27.

Lewis-Beck, Michael S. 1986. "Interrupted Time Series." In New Tools for Social Scientists: Advances and Applications in Research Methods, ed. William D. Berry and Michael S. Lewis-Beck, 209-40. Beverly Hills: Sage.

Lijphart, Arend. 1994. Electoral Systems and Party Systems: A Study of Twenty-Seven Democracies, 1945-1990. Oxford: Oxford University Press. 
Lijphart, Arend. 1997. "The Difficult Science of Electoral Systems: A Commentary on the Critique by Alberto Penadés." Electoral Studies 16 (1): 73-77.

Lin, Jih-wen. 2008. "To Lose Is to Win: The Candidate-Placement Strategy of Minor Parties under Japan's Mixed-Member Majoritarian System" [in Chinese]. Hsuanchu Yanjiu [Journal of Electoral Studies] 15 (2): 37-66.

Marsh, Lawrence C., and David R. Cormier. 2002. Spline Regression Models. Thousand Oaks, CA: Sage.

Maeda, Ko. 2008. "Re-Examining the Contamination Effect of Japan's Mixed Electoral System Using the Treatment-Effects Model.” Electoral Studies 27 (4): 723-31.

Maeda, Ko. 2010. "Factors behind the Historic Defeat of Japan's Liberal Democratic Party in 2009." Asian Survey 50 (5): 888-907.

Massicotte, L., and A. Blais. 1999. "Mixed Electoral Systems: A Conceptual and Empirical Survey." Electoral Studies 18 (3): 341-66.

McCleary, Richard, and Richard A. Hay Jr. 1980. Applied Time Series Analysis for the Social Sciences. Beverly Hills: Sage.

Moser, Robert G., and Ethan Scheiner. 2004. "Mixed Electoral Systems and Electoral System Effects: Controlled Comparison and Cross-National Analysis." Electoral Studies 23 (4): 575-99.

Moser, Robert G., and Ethan Scheiner. 2012. Electoral Systems and Political Context: How the Effects of Rules Vary across New and Established Democracies. Cambridge: Cambridge University Press.

Nishikawa, Misa, and Eric S. Herron. 2004. "Mixed Electoral Rules' Impact on Party Systems.” Electoral Studies 23 (4): 753-68.

Nohlen, Dieter, Forian Grotz, and Christof Hartmann, eds. 2001. Elections in Asia and Pacific: A Data Handbook, Volumes 1 and 2. Oxford: Oxford University Press.

Norris, Pippa. 2004. Electoral Engineering: Voting Rules and Political Behavior. Cambridge: Cambridge University Press.

Patterson, Dennis, and Hans Stockton. 2010. "Strategies, Institutions, and Outcomes under SNTV in Taiwan, 1992-2004.” Fournal of East Asian Studies 10 (1): 31-60.

Przeworski, Adam, and Henry Teune. 1970. The Logic of Comparative Social Inquiry. New York: John Wiley and Sons.

Ramseyer, J. Mark, and Frances M. Rosenbluth. 1997. Fapan's Political Marketplace: With a New Preface. Cambridge: Harvard University Press.

Reed, Steven R. 1994. "Democracy and the Personal Vote: A Cautionary Tale from Japan.” Electoral Studies 13 (1): 17-28.

Reed, Steven R. 1999. "Strategic Voting in the 1996 Japanese General Election." Comparative Political Studies 33 (2): 257-70.

Reed, Steven R., ed. 2003. Fapanese Electoral Politics: Creating a New Party System. London: RoutledgeCurzon.

Reed, Steven R. 2005. "Japan: Haltingly toward a Two-Party System.” In The Politics of Electoral Systems, ed. Michael Gallagher and Paul Mitchell, 277-93. Oxford: Oxford University.

Reed, Steven R., and Kay Shimizu. 2009. "An Overview of Postwar Politics." In Political Change in Fapan: Electoral Behavior, Party Realignment, and the Koizumi Reforms, ed. Steven R. Reed, Kenneth Mori McElwain, and Kay Shimizu, 5-25. Baltimore: Brookings Institution. 
Reed, Steven R., and Michael F. Thies. 2001. "The Causes of Electoral Reform in Japan." In Mixed-Member Electoral Systems: The Best of Both Worlds?, ed. Matthew Søberg Shugart and Martin P. Wattenberg, 152-72. Oxford: Oxford University Press.

Reilly, Benjamin. 2006. Democracy and Diversity: Political Engineering in the AsiaPacific. Oxford: Oxford University Press.

Reilly, Benjamin. 2007. "Democratization and Electoral Reform in the Asia-Pacific Region.” Comparative Political Studies 40 (11): 1350-71.

Richardson, Bradley M. 1988. "Constituency Candidates versus Parties in Japanese Voting Behavior." American Political Science Review 82 (3): 695-718.

Rochon, Thomas. 1981. "Electoral Systems and the Basis for the Vote: The Case of Japan." In Parties, Candidates and Voters in Fapan: Six Quantitative Studies, ed. J. C. Campbell. Michigan Papers in Japanese Studies, No. 2, 1-28. Ann Arbor: University of Michigan Center for Japanese Study.

Sakamoto, Takayuki. 1999. "Explaining Electoral Reform: Japan versus Italy and New Zealand.” Party Politics 5 (4): 419-38.

Scheiner, Ethan. 2006. Democracy without Competition in Japan: Opposition Failure in One-Party Dominant State. Cambridge: Cambridge University Press.

Scheiner, Ethan, and Filippo Tronconi. 2011. "Electoral Reform in Italy and Japan: Unanticipated Outcomes?" In A Natural Experiment on Electoral Law Reform: Evaluating the Long Run Consequences of 1990s Electoral Reform in Italy and Fapan, ed. Daniela Giannetti and Bernard Grofman, 97-114. New York: Springer.

Senkyoho Kenkyukai (Election Law Study Community), ed. 1995. Senkyobo to Seiji shikinho tesatsu [The guide of Japanese electoral law and political funds control law]. Nagoya: Shinnippon-Hoki Publishing.

Shadish, William R., Thomas S. Cook, and Donald T. Campbell. 2002. Experimental and Quasi-Experimental Designs for Generalized Causal Inference. Boston: Houghton Mifflin.

Shiratori, Rei. 1995. "The Politics of Electoral Reform in Japan.” International Political Science Review 16 (1): 79-94.

Shen, Yu-chung. 2005. "Relationship between the Executive and the Legislative under the Condition of Institutions: A Case Study of Taiwan's Constitutional Framework after 1997" [in Chinese]. Zhengzhi Kexue Luncong [Taiwanese Journal of Political Science] 23:27-60.

Shen, Yu-chung. 2011. "The Content of Dual-Executive Systems under SemiPresidentialism" [in Chinese]. Zhengzhi Kexue Luncong [Taiwanese Journal of Political Science] 27:33-64.

Shugart, Matthew Søberg, and John M. Carey. 1992. Presidents and Assemblies: Constitutional Design and Electoral Dynamics. New York: Cambridge University Press.

Shugart, Matthew Søberg, and Martin P. Wattenberg. 2001. "Mixed-Member Electoral Systems: A Definition and Typology.” In Mixed-Member Electoral Systems: The Best of Both Worlds?, ed. Matthew Søberg Shugart and Martin P. Wattenberg, 7-24. Oxford: Oxford University Press.

Stockton, Hans. 2010. "How Rules Matter: Electoral Reform in Taiwan." Social Science Quarterly 91 (1): 21-41. 
Taagepera, Rein, and Matthew Søberg Shugart. 1989. Seats and Votes: The Effects and Determinants of Electoral Systems. New Haven: Yale University Press.

Tokifumi, Mizusaki, and Mori Hiroki. 2007. Sousenkyu no tokubyou bunseki: 19582005 [Japanese general elections: 1958-2005]. Tokyo: Bokutakusha.

Wang, Ding-ming, and Ming-feng Kuo. 2009. "Voting Behavior under Mixed Electoral System: A Comparison between Taiwan and Japan during the Electoral Transition" [in Chinese]. Xuanju Yanjiu [Journal of Electoral Studies] 16 (2): 101-30.

Wang, Ding-ming, Ming-feng Kuo, and Chi Huang. 2008. "Exploration of the Duverger's Psychological Effect on Electoral Transition: The Experience of the Electoral Reform in Japan" [in Chinese]. Wenti Yu Yanjiu [Issues and Studies] 47 (3): 1-28.

Wang, Yeh-li. 2011. Bijiao Xuanju Zbidu [Comparative Electoral Systems]. Taipei: Wunan.

Wang, Yu. 2011. "Evaluating the Candidate Incumbency Effect in Japan's SingleMember District Elections, 1996-2005.” Representation 47 (2): 171-85.

Yang, Chun-chih. 2002. "Japanese Coalition Government and Political Reform in the Post-Cold War Era" [in Chinese]. Zhengzhi Kexue Luncong [Taiwanese Journal of Political Science] 16:63-88. 


\title{
The Consequences of Constitutional Systems on Party Systems
}

\author{
fib-wen Lin
}

Is the Mixed-Member Majoritarian System

Creating a Two-Party System?

For the competitors of a legislative election, winning a seat is only the first step toward sharing political power. How powers are distributed depends on the constitutional arrangement of executive-legislative relations, but studies on electoral systems are largely legislative-centric. An executivecentric theory of electoral systems plays an important role in filling this gap. Japan and Taiwan are perfect cases-they traveled a similar path of electoral reform but are distinguishable by constitutional systems. The following analysis explains why these two cases are worth comparing.

The first reason is the similarity of Japan and Taiwan compared with the global pattern. From a comparative perspective, the Asian model deserves special attention. As pointed out by Reilly (2007a, 2007b), the Asian experience is characterized by a decrease in proportionality, while the trend in the rest of the world is just the opposite. ${ }^{1}$ If an increase in proportionality results from the fragmentation of the party system, the best justification of the Asian model of electoral reform is the expectation of a more efficient and stable government. Indeed, the introduction of a majoritarian-leaning electoral system is likely to improve government stability as it will reduce the number of parties (Duverger 1964; Rae 1971; Lijphart and Grofman 
1984). Another effect of a majoritarian-leaning electoral system is that it facilitates power turnover when an election is competitive: when only one winner is to be elected, a party gains no seats at all if it falls one vote short of the winning party. By creating a larger seat swing, a majoritarian-leaning system makes it easier for the voters to hold the ruling party accountable. Within the Asian model, Japan and Taiwan are good cases to compare. ${ }^{2}$ Both countries are in East Asia and are embedded in a political culture that emphasizes personal connections; both traveled down a similar path of electoral reform and saw a decrease in the number of parties.

The second reason is their difference in executive-legislative relations. As the dependent variable, small parties play a more important role in Japan than in Taiwan, and the effective number of parties in Taiwan is decreasing faster than it is in Japan (Jou 2009). We thus have two cases of the "most similar system design" to compare. The question is how to link the party system to the constitutional system, the independent variable of this chapter.

As Huang, Kuo, and Stockton detail in chapter 1, small parties-those that ranked third or lower in legislative elections-have fared far better in Japan than in Taiwan. There are some differences in the Japanese and Taiwanese mixed-member majoritarian (MMM) systems, but Huang, Kuo, and Stockton conclude that these variations cannot fully account for the differences in the fates of small parties in the two systems.

This chapter argues that the differing constitutional systems, not the differing electoral systems, are the most important source of the contrasting fates of small parties. If the electoral system determines the winning threshold of each electoral district, the rule of portfolio allocation specified by the constitution affects the incentive for legislators elected in different constituencies to join a national political party. The major hypothesis of this chapter is that MMM does make it harder for weaker candidates to win in each district, but whether the winners across all districts are from two parties still depends on how the executive offices are distributed. Given Japan's parliamentary system, prime ministers are elected by the Diet. Legislators can thus bargain with the prime minister by threatening to defect from the ruling party-splinter parties are sometimes formed in these circumstances. In contrast, Taiwan's executive offices are allocated by the president without legislative participation, giving legislators elected in different districts a strong motivation to stay in the national parties. Another complication is the legislative process: while Taiwan has a unicameral legislature, the Diet of Japan includes the House of Representatives (HR) and the House of Councillors (HC), with the latter mandated to approve the 
policy bills proposed by the prime minister. It has been pointed out that bicameralism-especially using different formulas to elect the delegates of the two chambers-strengthens the leverage of small parties because intercameral agreement is needed to adopt a bill (Hammond and Miller 1987; Riker 1992; Brennan and Hamlin 1992; Tsebelis and Money 1997; Heller 2001; Druckman and Thies 2002). The influence of Taiwan's small parties on policy making is limited because its unicameral legislature does not give them the chance to reject government bills.

How the head of state, the head of government, and the legislature interact with each other in Taiwan and Japan is presented in table 2.1. It is clear that the major difference between the two constitutional systems is the rule of portfolio allocation: Taiwan's premier and ministers are appointed by the president, the de facto supreme leader, without legislative participation; the Japanese prime minister is designated from among the members of the Diet by a resolution of the Diet before he appoints his cabinet ministers. Taiwan's small parties have little role to play in the unicameral legislature, whereas Japan's bicameralism gives large parties an incentive to include nonpivotal small parties as coalition partners so that the latter can help adopt the government bills in the upper house. How these constitutional systems are related to the number of parties will be discussed later.

In the next section, we will show how the role of political parties in portfolio allocation is defined by the constitutional system and how Riker's size principle can be used to derive hypotheses. Sections three and four will examine how party politics interact with the constitutional systems of Taiwan and Japan, and how small parties have different capacities in the allocation of executive positions. Section five concludes by addressing the

TABLE 2.1. The Constitutional System in Taiwan and Japan

\begin{tabular}{|c|c|c|}
\hline & Taiwan & Japan \\
\hline Head of state & President: de facto leader & Emperor: symbolic head \\
\hline $\begin{array}{l}\text { Appointment of head } \\
\text { of government }\end{array}$ & $\begin{array}{l}\text { Premier is appointed by } \\
\text { president without legislative } \\
\text { consent; ministers are } \\
\text { appointed by president at } \\
\text { premier's recommendation. }\end{array}$ & $\begin{array}{l}\text { Before appointing the cabinet } \\
\text { ministers, prime minister is } \\
\text { designated by the Diet with the } \\
\text { HR playing the decisive role. }\end{array}$ \\
\hline Legislature & $\begin{array}{l}\text { Unicameralism. Legislative Yuan } \\
\text { can pass vote of no confidence } \\
\text { in premier and veto policy } \\
\text { proposals. }\end{array}$ & $\begin{array}{l}\text { Bicameralism. The HR can pass } \\
\text { vote of no confidence in prime } \\
\text { minister, HC can veto most } \\
\text { policy proposals. }\end{array}$ \\
\hline
\end{tabular}

Source: author's analysis of the constitutions of the two countries. 
general implications of this study and how the number of parties may be affected by constitutional designs.

\section{The Role of Political Parties in Portfolio Allocation in Different Constitutions}

Political parties coordinate both in elections and in the distribution of executive offices (Shugart 1995; Cox 1997; Hicken 2009). In elections, the electoral system is the key determinant of what a party can do. If an electoral system requires the candidates nominated by the same party to compete for the same set of voters, the party should nominate an optimal number of candidates; if a party nominates only one candidate, coordination should take place before the election starts. Thus, the shift from SNTV to MMM marks a great transformation in the electoral roles of parties. Even so, maximizing its presence in the legislature is just the first kind of coordination work a party has to undertake. Once elected, legislators have to think about how to make the best use of their influence over portfolio allocation, which is the real goal of many politicians. In democracies, portfolio allocation is an important way to make policy changes (Budge and Laver 1986). Since the number of ministerial positions to be distributed is fixed, the "minimal winning coalition" principle holds: every member in the winning coalition should make itself pivotal, so that each can maximize its share of the portfolios, hence its influence over the policies to be implemented by the ministry (Riker 1962). This principle implies that the size of the coalition and the parties in it should both be minimal because unnecessary members will reduce the share each can get.

The constitutional system defines what a minimal winning coalition is. The Japanese constitution makes every party a potential pivot. The highest executive power is held by the prime minister, who is designated by both chambers of the Diet-with the HR playing the decisive role-and then formally appointed by the emperor. ${ }^{3}$ The power of Japan's small parties is enhanced by its bicameralism in two ways. First, it is easier for a small party to win a seat in the HC elections because the electoral system mixes 48 national PR seats with 73 SNTV seats. Second, Japan's bicameralism is almost symmetric because the $\mathrm{HC}$ can veto most bills proposed by the prime minister, which will in turn put the prime minister's leadership at stake. Small parties can thus exchange their legislative veto power for political resources. Nevertheless, Japanese prime ministers do not always want to invite small parties to join their cabinets because of a trade-off 
between policy making and portfolio allocation. The prime minister can compromise with the small parties without allocating any position to their members. Whether a small party wishes to join the cabinet also depends on how much the prime minister needs its support to pass legislation.

Taiwan's constitutional system arranges the allocation of ministerial positions differently. Taiwan's premier is appointed unilaterally by the popularly elected president, leaving no role for the political parties to play. According to the constitution, cabinet ministers are selected by the premier, but, in practice, they are handpicked by the president. Although the legislators can launch a censure motion against the premier by rallying majority support, such a move is quite unlikely because it will put the jobs of the legislators at risk. What the president has to keep in mind is whether the legislature is controlled by an opposition majority. If this is the case, the legislators may use their veto power to prevent government bills from being adopted.

Another concern is the electoral system. Under SNTV, major parties nominate multiple candidates in most districts, the legislators tend to deliver resources to a particular group of voters, and the parties are usually factionalized. Particularist distribution of government resources is prevalent in both MMM and SNTV, but the targets of the pork may differ. It is quite common for single-member district systems to encourage pork-barrel bills targeting the undecided voters in the competitive districts rather than just a particular set of constituents. Moreover, legislators elected under MMM are supposed to represent the whole constituency, giving them the incentive to choose policy stances different from those of the central government. A shift from SNTV to MMM thus decreases the incentives for internal factionalization. Nevertheless, there is a major difference between Taiwan and Japan. In Taiwan, the directly elected president creates more pressure for Taiwanese legislators to align their campaign appeals with a major national party, but Japanese legislators are freer to tailor their messages to the local district, perhaps even to the point of representing a third party.

We can now hypothesize how the partisan composition of the Taiwanese and Japanese cabinets is affected by their respective constitutional systems. First, Taiwan does not have a tradition of coalition government, and political parties have a limited influence on cabinet formation. This affects both big parties and small parties. Small parties should be shut out of the cabinet almost entirely. However, this does not mean that members of the president's party will monopolize all seats in the cabinet. The president can appoint ministers as he sees fit, and he may choose to appoint a significant 
number of nonpartisan figures to the cabinet. Tavits $(2008,43)$ has argued that directly elected presidents have a preference to name nonpartisan ministers to demonstrate their status as the head of state. ${ }^{4}$ The incentive to appoint nonpartisan ministers is particularly strong when the president is leading a minority party. Rather than opting for a single-party minority cabinet, which might cause gridlock, or a multiparty majority cabinet, which might weaken the president's leadership, the president may prefer to appoint nonpartisan ministers to depoliticize the cabinet and convey the image of the president as leader of the entire country. Critically, while nonpartisan ministers may help the president dampen opposition from other parties in the legislature or appeal to a wider segment of the electorate, they are not representatives of or responsible to opposition parties. Alternatively, if the primary threat to the president's power comes from factions within his own majority party, he may be more likely to emphasize his role as head of the party and prefer to appoint fewer nonpartisan ministers. The percentage of nonpartisan ministers can thus give clues to the influence of the president on cabinet formation.

In sum, there is no need to test the number of parties in Taiwan's cabinets, because ministers are predominantly from the president's party or nonpartisans. ${ }^{5}$ Rather, nonpartisan ministers play a much more important role in highlighting the president's role in ministerial appointment. Thus, we expect that, in Taiwan, the percentage of nonpartisan ministers is higher (1) in divided government than in unified government and (2) when MMM is the electoral system than when SNTV was used.

Second, political parties in Japan should exercise a greater influence on cabinet formation than their Taiwanese counterparts, for the Constitution of Japan requires the prime ministers to be elected by members of the Diet. Since most cabinet ministers are concurrently legislators, we can examine how the number of parties in the cabinet can be explained by the key variables. ${ }^{6}$ The number of parties in the cabinet should increase when the cabinet is not in control of the upper house. Further, if MMM accelerates the turnover of parties in power, prime ministers should have less confidence that they will be able to maintain a majority in the HC. Thus, we expect the number of parties in the cabinet to rise after electoral reform. The logic behind these hypotheses is that the bargaining power of small parties is increased if the probability of the prime minister encountering bicameral deadlock becomes higher. The second test operationalizes the prime minister's influence in cabinet formation in a slightly different way. We expect the percentage of ministers from the prime minister's party to decrease when the party of most cabinet members does not hold the upper house majority or when MMM is used, 
because these factors will weaken the leadership of the prime minister for the reasons already discussed.

The difference in constitutional systems permeates other political arenas. If legislators play different roles in the allocation of executive offices, the voters' expectations of them should also diverge. Taiwan's legislative elections have become highly presidentialized and focus on the debate over national identity issues between the two largest parties. MMM reduces Taiwan's effective number of parties to less than two because the number of presidential candidates is usually two. Japan lacks a centralized national leader, and legislative candidates can compete on constituency issues, some of which may be related to the national division among the political parties while others are local in focus. Since the constituency cleavage plays an important role in Japan, we expect the effective number of parties to be higher than in Taiwan.

What we see above are theoretical models with rich empirical implications. In the next two sections, we will demonstrate how the constitutional system affects the portfolio allocation in the two cases, and therefore the number and power of small parties. We will discuss Taiwan first because the evolution of its party system shows clearly the power of the constitutional system despite the intervening variables that a young democracy usually faces.

\section{How Taiwan's Unicameral Semipresidential System Intermediates the Impact of Electoral Reform}

To validate the claim that MMM has reduced the number of parties but variations in the constitutional system give political parties different roles to play, this section will describe how Taiwan's unicameral semipresidential constitution has strongly depressed the influence of political parties on cabinet formation and given the president a great deal of freedom to fill executive offices.

Taiwan's constitution is parliamentary by design but highly presidential in practice. ${ }^{7}$ The seven constitutional reforms enacted since 1991 endeavored to make the president's de facto powers constitutional by stipulating a popularly elected president; they further enhanced the president's power by removing the Legislative Yuan's power to confirm the presidential appointment of the premier. The Legislative Yuan can pass a vote of no confidence in the premier but the premier cannot initiate a snap election $(\operatorname{Lin} 2011){ }^{8}$ Before 2000, executive congruency gave the president the power to dismiss 
the premier, making Taiwan a president-parliamentary regime (Shugart and Carey 1992; Shugart 2005). The president dominated the appointment of the premier even when the government was divided (2000-2008). Based on this practice, no popularly elected president has consulted the legislature when appointing a premier or his cabinet ministers.

By this design, the president appoints and dismisses the cabinet ministers with the latter's accountability to the legislature in mind. The ways in which the legislators hold the cabinet accountable include a vote of no confidence-which is rarely considered-and the blocking of executive proposals - which is often applied. When explaining the president's decision in portfolio allocation, MMM is also an important factor because the majorities represented by the president in the whole nation and the legislators in the MMM districts may be incongruent. To ease the pressure from MMM and opposition parties, we expect the percentage of nonpartisan ministers in the cabinet to follow this order: MMM plus divided government $>S N T V$ plus divided government $>M M M$ plus unified government $>$ SNTV plus unified government. We do not make the number of parties in the cabinet as a variable because the cabinets are predominantly composed of the president's party and nonpartisans rather than the nonpresidential parties.

Given the limited influence of Taiwan's small parties on cabinet formation, we will directly examine how the aforementioned variables affect the president's role in portfolio allocation. Table 2.2 shows how much the president dominates cabinet formation by the percentage of ministers from his party. ${ }^{9}$ Counting the change in electoral systems and the president's majority status, the data include several possible divisions, with the "MMM plus divided government" type thus far absent. Since the percentage is a continuous variable and the independent variables are categorical, we run a one-way ANOVA by the following groupings: (1) whether a president leads a unified or a divided government, (2) electoral systems, and (3) the three presidential periods. For (3), a reasonable hypothesis is that President Lee Teng-hui had the highest percentage of ministers from his own party because he led a unified government with legislators elected under SNTV; the lowest percentage should be found under the Chen Shui-bian presidency, as Chen never assembled a majority cabinet, especially when the Kuomintang (KMT) dominated the Legislative Yuan. Standing in between, Ma Ying-jeou's strategy represents the presidentialized unified government that MMM produces.

The results in table 2.3 validate the hypotheses. Overall, the average percentage of ministers from the president's party is 58.55 . If the percentages of ministers from the president's party are compared according to 
whether the president controls the legislative majority or not, the "yes" and the "no" groups have an average of $72.3 \%$ and $44.1 \%$, respectively. It is evident that divided government forced President Chen to appoint more nonpartisan ministers to water down the cabinet's DPP makeup so as to decrease the likelihood of his policies being rejected by the Legislative Yuan. If the data are compared according to the electoral system, the "SNTV" group has $61.6 \%$ and the "MMM" group has $49.4 \%$ on average. Finally, if the average percentages for the three presidents are compared, the "Lee period" is 96.6, the "Chen period" is 44.1, and the "Ma period" is 49.4. All one-way ANOVA tests show the expected sign, and the differences between the three presidents are not only statistically significant but also larger than the other two comparisons. ${ }^{10}$

The cabinets headed by premiers appointed by President Ma are a salient illustration of the dominance of the president—as the head of state rather than the chairperson of the ruling party—in cabinet formation. Ma's KMT has held a clear majority of legislative seats throughout his two terms in office. However, table 2.3 shows that the percentage of ministers from the president's party, already low in 2008 compared to those of President Lee, has further decreased in the intervening years. ${ }^{11}$ Ma's preference for

TABLE 2.2. Partisan Profile of Taiwan's Cabinet Ministers

\begin{tabular}{|c|c|c|c|c|c|c|}
\hline President & Party & Premier & $\begin{array}{l}\text { Premier } \\
\text { party }\end{array}$ & $\begin{array}{l}\text { Term } \\
\text { begins }\end{array}$ & $\begin{array}{l}\text { Ministers } \\
\text { from } \\
\text { president's } \\
\text { party }\end{array}$ & $\begin{array}{l}\text { Whether } \\
\text { largest } \\
\text { party } \\
\text { controls } \\
\text { majority } \\
(=1)\end{array}$ \\
\hline Lee Teng-hui & KMT & Hau Pei-tsun & KMT & $6 / 1 / 1990$ & $95.24 \%$ & $\mathrm{KMT}=1$ \\
\hline Lee Teng-hui & KMT & Lien Chan & KMT & $2 / 27 / 1993$ & $98.31 \%$ & $\mathrm{KMT}=1$ \\
\hline Lee Teng-hui & KMT & Siew Wan-chang & KMT & 9/7/1997 & $96.30 \%$ & $\mathrm{KMT}=1$ \\
\hline Chen Shui-bian & DPP & Tang Fei & KMT & $5 / 20 / 2000$ & $24.32 \%$ & $\mathrm{KMT}=1$ \\
\hline Chen Shui-bian & DPP & Chang Chun-hsiung & DPP & $10 / 6 / 2000$ & $26.47 \%$ & $\mathrm{KMT}=1$ \\
\hline Chen Shui-bian & DPP & Yu Shyi-kun & DPP & $2 / 1 / 2002$ & $44.74 \%$ & $\mathrm{DPP}=0$ \\
\hline Chen Shui-bian & DPP & Hsieh Chang-ting & DPP & $2 / 1 / 2005$ & $62.16 \%$ & $\mathrm{DPP}=0$ \\
\hline Chen Shui-bian & DPP & Su Tseng-chang & DPP & $1 / 25 / 2006$ & $55.56 \%$ & $\mathrm{DPP}=0$ \\
\hline Chen Shui-bian & DPP & Chang Chun-hsiung & $\mathrm{DPP}$ & $5 / 21 / 2007$ & $51.43 \%$ & $\mathrm{DPP}=0$ \\
\hline Ma Ying-jeou & KMT & Liu Chao-shiuan & KMT & $5 / 20 / 2008$ & $66.67 \%$ & $\mathrm{KMT}=1$ \\
\hline Ma Ying-jeou & KMT & Wu Den-yih & KMT & $9 / 10 / 2009$ & $47.22 \%$ & $\mathrm{KMT}=1$ \\
\hline Ma Ying-jeou & KMT & Chen Chun & KMT & $2 / 6 / 2012$ & $34.21 \%$ & $\mathrm{KMT}=1$ \\
\hline
\end{tabular}

Source: Yu and Zhu (2001a, 2001b), Guoshiguan Zhengjiaochu (1994, 1998, 2001), Liu (2006), Liu (1994), and the United Daily News online database (http://udndata.com/library/), accessed March 19, 2012.

Note: The number of ministers is person-time. Whether a minister comes from a particular party depends on whether he/she is (was) a member of the central committee or receives (received) paid jobs from the party, or represented the party in the elections. 
appointing nonpartisan scholars and civil servants as ministers reflects his ambivalence regarding the partisan composition of the cabinet. Given the KMT's dominance in the legislature, Ma must have minimized the role of political parties when forming his cabinets.

The strong influence of the president on portfolio allocation extends to elections. Two effects can be observed. The first is that Taiwan's presidential elections may have a contamination effect on legislative elections. ${ }^{12}$ If the two elections are held concurrently or within a short period of time, voters may use information from the highly prominent presidential race to make their decisions in the less salient legislative race. Since the presidential race encourages supporters of small parties to vote strategically, they may apply the same logic to legislative elections regardless of the strength of the small party's local candidate. Presidential elections thus intensify the Duvergerian obstacles ${ }^{13}$ facing small parties in district elections. The second effect concerns cleavage structure. Campaigning dominated by the presidential race will restrain the capacity of small parties to articulate their favorite issues. In Taiwan, small parties are forced to stand with a particular camp first of all and then distance themselves from that camp's leading presidential candidate. In the legislative election of 2012, James Soong, the leader of the People First Party, was the only presidential candidate who claimed that Taiwan should eventually be reunified with the mainland. The Taiwan Solidarity Union, at the opposite extreme, was quite insistent that Taiwan's independent sovereignty should not be infringed upon. So the two small parties could be clearly identified by their positions on national identity. That helped these small parties to consolidate their PR seats, but the overall effect was limited. What MMM does is to sharply decrease the influence of the small parties when the campaign issues are set by the large parties.

TABLE 2.3. One-Way ANOVA for Partisan Compositions of Taiwan's Cabinets

\begin{tabular}{llccc}
\hline & & Mean & Variance & Sig. \\
\hline $\begin{array}{llccc}\text { Compared by presidential } \\
\text { majority }\end{array}$ & No & 0.441 & 0.024 & \multirow{2}{*}{0.052} \\
Compared by SNTV or & SNTV & 0.723 & 0.078 & \\
MMM & MMM & 0.616 & 0.084 & 0.516 \\
Compared by presidents & Lee & 0.494 & 0.027 & \\
& Chen & 0.966 & 0.000 & \\
& Ma & 0.441 & 0.024 & 0.002 \\
\hline
\end{tabular}

Source: Author's calculation. 


\section{How Japan's Bicameral Parliamentary System Intermediates the Impact of Electoral Reform}

Taiwan can be seen as a baseline when we turn our attention to Japan, a country with a longer experience of democracy under a stable constitutional system. When compared with Taiwan, Japan's cabinet formation is dominated by legislative parties, giving electoral systems a more important role to play. We expect to see that the number of parties in the cabinet increases and the percentage of ministers coming from the prime minister's party decreases after MMM is introduced, especially if the cabinet does not bold the majority of seats in the $H C$.

A review of Japan's Constitution will be helpful here. Japan's prime minister shall be designated by the Diet before he appoints the cabinet ministers. According to Article 67 of the Constitution, disagreement between the two chambers about the designation of the prime minister is eventually determined by the HR. According to Article 69, the HR can pass a resolution of nonconfidence in the prime minister or reject a confidence motion proposed by the latter-after which the prime minister must resign — but the prime minister can also actively dissolve the HR and call for an early election. No such relationship exists between the prime minister and the $\mathrm{HC}$, but the latter can veto bills passed by the HR-except prime minister designation, treaty, and budgetary bills-unless the government can pass them a second time by a two-thirds majority in the HR.

In sum, Japan's bicameral parliamentary system strengthens the bargaining power of the small parties when the prime minister's party is unable to control the HC. Small parties can win seats in the HC and boycott government bills even if they are weak in the HR. Since MMM tends to create larger seat swings in the elections of the HR, the prime minister becomes less confident that he will control the majorities of both chambers. Nevertheless, it is optional whether the prime minister will expand the coalition to control the majority of the HC, for reasons already explained in the theoretical section.

We use Japan's portfolio allocation to test the hypotheses concerning the role of the small parties. Table 2.4 displays the partisan composition of Japan's cabinets, including the percentage of ministers from the prime minister's party and the number of parties (nonpartisan included) in the cabinets. When determining the size of the cabinet, the denominator is the number of ministers rather than their positions because a minister may concurrently hold more than one position. Note that we do not count control of the HC before 1955 because that period saw a tumultuous realign- 
ment of Japan's party system, making it difficult to measure the partisan composition of the cabinets. We should also focus on cabinets formed by prime ministers heading the largest party, otherwise the coalition governments will by nature be oversized.

We will use the screened data to display the role of the small parties. Since the dependent variable is continuous, we run two parts of a one-way ANOVA to test if the means are different as a result of the categories we choose. The first hypothesis is to see whether the number of parties in the Japanese cabinet varies by whether (1) the cabinet parties hold the majority of seats of the HC and (2) the electoral system for the HR is MMM. For the second part of the hypotheses, we will use the same categories to test how much the average percentage of ministers coming from the prime minister's party makes a difference. This is the opposite dimension of a similar variable.

The empirical data are shown in tables $2.5 \mathrm{a}$ and $2.5 \mathrm{~b}$. The results largely confirm our expectation. What we see from the first half of table $2.5 \mathrm{a}$ is that the number of small parties in the cabinet goes up when the cabinet fails to have continuous control of the upper house. The implied message is interesting: the more the cabinet is unable to control the upper house, the greater the bargaining power of the small parties because they can threaten the prime minister and boycott his policy bills. By the same logic, the small parties lose their pivotal positions if the ruling party can unilaterally control the two chambers. The second half of table 2.5 a delivers a similar message in an even clearer way. Under SNTV, the prime ministers would leave a countable number of positions for the nonpartisans rather than for the small parties because the latter are dispensable. ${ }^{14}$ The adoption of MMM changed the strategy of portfolio allocation because the fear of losing power in an MMM race made the collaboration with some small parties inevitable, even if the number of the nonpartisan ministers remains the same. The underlying cause is that a majoritarian-leaning electoral system like MMM renders the undecided voters decisive and compels the prime minister to be mindful of the parties representing their interests.

For the second part of the hypothesis, we use the percentage of ministers from the prime minister's party to test the effects of the same set of variables. Note that Japan's parliamentary rule requires the prime ministers to be elected by the Diet, with the HR playing the decisive role. The denominator is therefore "the ministers from the parties of the prime minister and the small parties in the cabinet." The average percentage of ministers from the prime minister's party when the cabinet has continuous control of the upper house is $92.9 \%$, which is higher than the $89.1 \%$ when 
TABLE 2.4. Partisan Profile of Japan's Cabinet Ministers

\begin{tabular}{|c|c|c|c|c|c|c|}
\hline Prime minister & $\begin{array}{l}\text { PM's } \\
\text { party }\end{array}$ & $\begin{array}{l}\text { Term } \\
\text { begins }\end{array}$ & $\begin{array}{c}\text { Number of } \\
\text { non-PM } \\
\text { parties }\end{array}$ & $\begin{array}{l}\text { Ministers } \\
\text { from PM's } \\
\text { party }\end{array}$ & $\begin{array}{c}\text { Cabinet } \\
\text { always } \\
\text { controls } \\
\text { HC }\end{array}$ & MMM \\
\hline *Shigeru Yoshida (I) & JLP & $5 / 22 / 1946$ & 5 & $32.26 \%$ & 0 & 0 \\
\hline *Tetsu Katayama & JSP & $5 / 24 / 1947$ & 4 & $39.29 \%$ & 0 & 0 \\
\hline${ }^{*}$ Hitoshi Ashita & $\mathrm{DP}$ & $3 / 10 / 1948$ & 3 & $46.67 \%$ & 0 & 0 \\
\hline *Shigeru Yoshida (IIa) & DLP & $10 / 15 / 1948$ & 2 & $77.78 \%$ & 0 & 0 \\
\hline *Shigeru Yoshida (IIb) & LP & $6 / 28 / 1950$ & 4 & $44.26 \%$ & 0 & 0 \\
\hline *Shigeru Yoshida (IIb) & LP & $10 / 30 / 1953$ & 3 & $79.17 \%$ & 0 & 0 \\
\hline *Shigeru Yoshida (IIb) & LP & $5 / 21 / 1954$ & 1 & $93.33 \%$ & 0 & 0 \\
\hline Ichiro Hatoyama (a) & JDP & $12 / 10 / 1954$ & 1 & $85.00 \%$ & 0 & 0 \\
\hline Ichiro Hatoyama (a) & LDP & $11 / 22 / 1955$ & 1 & $90.91 \%$ & 0 & 0 \\
\hline Ichiro Hatoyama (a) & LDP & $11 / 22 / 1956$ & 1 & $94.74 \%$ & 0 & 0 \\
\hline Tanzan Ishibashi & LDP & $12 / 23 / 1956$ & 1 & $95.00 \%$ & 0 & 0 \\
\hline Nobusuke Kishi & LDP & $2 / 25 / 1957$ & 1 & $94.59 \%$ & 0 & 0 \\
\hline Nobusuke Kishi & LDP & $6 / 12 / 1958$ & 1 & $97.73 \%$ & 0 & 0 \\
\hline Hayato Ikeda & LDP & $7 / 19 / 1960$ & 1 & $95.24 \%$ & 1 & 0 \\
\hline Hayato Ikeda & LDP & $12 / 8 / 1960$ & 1 & $98.33 \%$ & 1 & 0 \\
\hline Hayato Ikeda & LDP & $12 / 9 / 1963$ & 1 & $97.30 \%$ & 1 & 0 \\
\hline Eisaku Sato & LDP & $11 / 9 / 1964$ & 1 & $98.55 \%$ & 1 & 0 \\
\hline Eisaku Sato & LDP & $2 / 17 / 1967$ & 1 & $98.04 \%$ & 1 & 0 \\
\hline Eisaku Sato & LDP & $1 / 14 / 1970$ & 1 & $97.78 \%$ & 1 & 0 \\
\hline Kakuei Tanaka & LDP & $7 / 7 / 1972$ & 1 & $95.45 \%$ & 1 & 0 \\
\hline Kakuei Tanaka & LDP & $12 / 22 / 1973$ & 1 & $98.11 \%$ & 1 & 0 \\
\hline Takeo Miki & LDP & $12 / 9 / 1974$ & 1 & $92.11 \%$ & 1 & 0 \\
\hline Takeo Fukuda & LDP & $12 / 24 / 1976$ & 1 & $95.35 \%$ & 1 & 0 \\
\hline Masayoshi Ohira & LDP & $12 / 7 / 1978$ & 1 & $95.45 \%$ & 0 & 0 \\
\hline Masayoshi Ohira & LDP & $11 / 9 / 1979$ & 1 & $91.30 \%$ & 0 & 0 \\
\hline Zenko Suzuki & LDP & $7 / 17 / 1980$ & 1 & $97.56 \%$ & 1 & 0 \\
\hline Yasuhiro Nakasone & LDP & $11 / 27 / 1982$ & 1 & $91.67 \%$ & 1 & 0 \\
\hline Yasuhiro Nakasone & LDP & $12 / 271983$ & 1 & $98.28 \%$ & 1 & 0 \\
\hline Yasuhiro Nakasone & LDP & $7 / 221986$ & 1 & $95.83 \%$ & 1 & 0 \\
\hline Noboru Takeshita & LDP & $11 / 6 / 1987$ & 1 & $95.35 \%$ & 1 & 0 \\
\hline Sosuke Uno & LDP & $6 / 3 / 1989$ & 1 & $95.45 \%$ & 1 & 0 \\
\hline Toshiki Kaifu & LDP & $8 / 10 / 1989$ & 1 & $95.65 \%$ & 0 & 0 \\
\hline Toshiki Kaifu & LDP & $2 / 28 / 1990$ & 1 & $97.56 \%$ & 0 & 0 \\
\hline Kiichi Miyazawa & LDP & $11 / 5 / 1991$ & 1 & $95.65 \%$ & 0 & 0 \\
\hline${ }^{*}$ Morihiro Hosokawa & $\mathrm{JNP}$ & $8 / 9 / 1993$ & 7 & $18.18 \%$ & 0 & 0 \\
\hline *Tsutomu Hata & JRP & $4 / 28 / 1994$ & 6 & $39.13 \%$ & 0 & 0 \\
\hline *Tomiichi Murayama & SDP & 6/30/1994 & 3 & $24.44 \%$ & 0 & 0 \\
\hline Ryutaro Hashimoto & LDP & $1 / 11 / 1996$ & 3 & $54.55 \%$ & 1 & 1 \\
\hline Ryutaro Hashimoto & LDP & $11 / 7 / 1996$ & 1 & $97.56 \%$ & 0 & 1 \\
\hline Keizo Obuchi & LDP & $7 / 30 / 1998$ & 3 & $84.09 \%$ & 0 & 1 \\
\hline Yoshiro Mori & LDP & $4 / 5 / 2000$ & 3 & $80.00 \%$ & 0 & 1 \\
\hline Yoshiro Mori & LDP & $11 / 7 / 2000$ & 3 & $82.35 \%$ & 0 & 1 \\
\hline Junichiro Koizumi & LDP & $4 / 26 / 2001$ & 4 & $79.49 \%$ & 0 & 1 \\
\hline Junichiro Koizumi & LDP & $11 / 19 / 2003$ & 2 & $82.86 \%$ & 1 & 1 \\
\hline Junichiro Koizumi & LDP & $9 / 21 / 2005$ & 2 & $90.91 \%$ & 1 & 1 \\
\hline Shinzo Abe & LDP & $9 / 26 / 2006$ & 2 & $88.89 \%$ & 1 & 1 \\
\hline
\end{tabular}




\begin{tabular}{|c|c|c|c|c|c|c|}
\hline Prime minister & $\begin{array}{l}\text { PM's } \\
\text { party }\end{array}$ & $\begin{array}{l}\text { Term } \\
\text { begins }\end{array}$ & $\begin{array}{c}\text { Number of } \\
\text { non-PM } \\
\text { parties }\end{array}$ & $\begin{array}{l}\text { Ministers } \\
\text { from PM's } \\
\text { party }\end{array}$ & $\begin{array}{c}\text { Cabinet } \\
\text { always } \\
\text { controls } \\
\text { HC }\end{array}$ & MMM \\
\hline Yasuo Fukuda & LDP & $9 / 26 / 2007$ & 2 & $84.38 \%$ & 0 & 1 \\
\hline Taro Aso & LDP & $9 / 24 / 2008$ & 3 & $75.00 \%$ & 0 & 1 \\
\hline Yukio Hatoyama & DPJ & $9 / 16 / 2009$ & 3 & $83.33 \%$ & 0 & 1 \\
\hline Naoto Kan & DPJ & 6/8/2010 & 2 & $88.10 \%$ & 0 & 1 \\
\hline Yoshihiko Noda & DPJ & $9 / 2 / 2011$ & 2 & $82.22 \%$ & 0 & 1 \\
\hline
\end{tabular}

Source: Toshio (1990), Rei (1986, 1987), Kyofu (1996), and Naikaku seido hyakujunen kinen shi henshu iinkai (1996). In addition, the partisan composition of cabinets formed after MMM was introduced can be found at the website of the major newspapers.

Notes: (1) Members of cabinet includes ministers, the chief secretary, and commission chairpersons. Nonpartisans are seen as one party when counting the non-PM parties. (2) Ministers holding concurrent positions are counted only once. (3) Whether a cabinet always controls the $\mathrm{HC}$ is determined by the whole term of a prime minister. For this reason, "0" may include prime ministers with interrupted majority supports from the HC. (4) Prime ministers indicated by an asterisk $\left(^{*}\right)$ are not from the LDP or the DPJ and are excluded from analysis, except the first cabinet of Ichiro Hatoyama, who became the first LDP prime minister in November 1955. Cabinets resulting from party switching are also not counted. (5) A coalition government is defined by whether the cabinet includes at least two parties (nonpartisans excluded).

TABLE 2.5A. One-Way ANOVA for the Number of Coalition Parties in Japan's Cabinets

\begin{tabular}{llccc}
\hline & & Mean & Variance & Sig. \\
\hline $\begin{array}{l}\text { Compared by whether the } \\
\text { coalition parties always }\end{array}$ & No & 1.762 & 0.991 & 0.050 \\
$\begin{array}{l}\text { control the upper house } \\
\text { Compared by SNTV or }\end{array}$ & SNTV & 1.250 & 0.303 & \\
MMM & MMM & 2.000 & 0.000 & \\
\hline
\end{tabular}

Source: Author's calculation.

TABLE 2.5B. One-Way ANOVA for the Ratio of Ministers from PM's Party in Japan's Cabinets

\begin{tabular}{llccc}
\hline & & Mean & Variance & Sig. \\
\hline $\begin{array}{l}\text { Compared by whether the } \\
\text { coalition parties always }\end{array}$ & No & 0.891 & 0.005 & 0.160 \\
$\begin{array}{l}\text { control the upper house } \\
\text { Compared by SNTV or }\end{array}$ & SNTV & 0.929 & 0.010 & \\
MMM & MMM & 0.953 & 0.001 & \\
\hline
\end{tabular}

Source: Author's calculation. 
it lacks continuous control. This result suggests an interesting dynamic: the prime minster's influence on cabinet formation declines when the cabinet fails to control the upper house. A likely cause is that bicameral deadlock weakens the prime minister's position in his cabinet. If so, electoral reform should have a significant impact because MMM is supposed to promote policy debates among political parties. Indeed, $95.3 \%$ of the ministers are from the prime minister's party when SNTV is used; this is reduced to $82.4 \%$ after MMM is introduced. In this sense, electoral reform enhances the bargaining power of the small parties on policy making even though their representatives are reduced in number.

To highlight the growing influence of Japan's small parties, consider the example of the cabinet organized by Prime Minister Yukio Hatoyama (2009-10). Hatoyama's Democratic Party of Japan (DPJ) gained 308 of the 480 seats $(64.17 \%)$ in the HR election of 2009 but still invited the heads of two small parties to join his cabinet: Shizuka Kamei from the People's New Party (PNP) as the minister of state for financial services and minister of state for postal reform, and Mizuho Fukushima from the Social Democratic Party (SDP) as the minister of state for consumer affairs and food safety, social affairs, and gender equality. Especially noteworthy is Fukushima, who was a member of the HC at that time. The DPJ chose to offer cabinet positions to the two smaller parties and they chose to accept them because there was a degree of policy congruence among the three parties, making it easier for them to garner support from the upper house to form a temporary majority. However, the alliance was fragile, and Fukushima resigned her position in 2010 over the issue of the Marine Corps Air Station Futenma. ${ }^{15}$ When the degree of policy congruence was high, the SDP was able to use its position in the upper house to win a cabinet seat; when the degree of policy congruence decreased, the SDP decided to withdraw from the cabinet and dampen the credibility of the Hatoyama cabinet. Thus this example neatly illustrates the opportunities small parties are afforded in Japan's constitutional system as well as the trade-offs among cabinet portfolios, policy positions, and support in the parliament that large parties much consider.

Japan's party system is further fragmented by its parliamentary elections. Because Japan lacks a central leader, MMM reduces the differences between political parties and gives some politicians a reason to establish their own parties. For many voters, the party platforms are intangible-at least more intangible than real politicians-and contenders in each constituency tend to embody their ideas through their personal image or social connections. One trend has been the formation of small parties by 
politicians who are not very different from their fellows in the parties from which they originated. Such a trend is further endogenized by the fact that the new electoral system is conducive to regime turnover (at the national and local levels). This helps explain why some local potentates have an incentive to defect from their parties as long as they have a chance of winning the seat. Thus, the lack of a centralized leader makes some small parties powerful enough to grab the SMP seats.

Nevertheless, MMM is not exactly an SMP system: the latter gives electoral contenders much less motivation to build their own parties, whereas the former creates contamination effects that small parties can utilize to gain some seats. Taiwan also adopted MMM, but the role of its small parties is much less salient than that of small parties in Japan. As we have seen, this difference cannot be fully accounted for by the design of the electoral system. It is the constitutional system that explains the varying amounts of bargaining power of the small parties.

\section{Conclusion}

Few topics can be studied as rigorously and fruitfully as those concerning electoral systems. Concepts like the threshold of winning and effective number of parties apply to all electoral systems and are well recognized in the literature. MMM, by giving priority to single-member district competitions, is expected to decrease the number of parties. This expectation finds support in Japan and Taiwan, both of which shifted their electoral systems from SNTV to the majoritarian-leaning MMM systems. Although the effective number of parties is smaller when measured in relative terms, the absolute number of parties in Japan is always higher than that of Taiwan, leaving a puzzle to be explained.

This chapter takes an executive-centered approach to answer this puzzle. A theory of portfolio allocation suggests that a constitutional system instituted with more players who can veto the appointment of the head of government, and hence portfolio allocation, makes small parties more influential. Exogenously imposed, the rule of portfolio allocation gives small parties an endogenous interest in breaking away from the large parties in and after the legislative election. This theory explains why Japan's bicameral parliamentary system creates bargaining power for Japan's small parties, and why Taiwan's unicameral semipresidential system makes the small parties much less effective than the president when executive offices are to be arranged. Furthermore, Japan's parliamentary system gives some 
electoral competitors the justification to run a campaign at the district level because the party platform is less visible than a real candidate. The chances of Japan's small parties receiving seats are thus higher than those of their counterparts in Taiwan.

The partisan composition of cabinets in Taiwan and Japan corroborates this argument. For Taiwan, we expect the percentage of nonpartisan ministers to be increased by MMM and the president's inability to control the Legislative Yuan, for both will increase the likelihood of the executive proposals being rejected, and nonpartisan ministers can buffer such pressure. The one-way ANOVA dividing the data by three Taiwanese presidents offers a significant count of the percentages of nonpartisan ministers. That is, Taiwan's constitutional system makes the president the paramount leader subject to the different degrees of legislative distrust of the executive officers, for which electoral reform plays an important role. Small parties are almost entirely cut out of cabinet positions, as the semipresidential system denies them any opportunity to negotiate for ministerial posts. In Japan's parliamentary system, the HR approves the appointment of the prime minister and the $\mathrm{HC}$ can veto most policy bills. Since the prime minister should receive majority support from the HR, whether the cabinet also controls the $\mathrm{HC}$ becomes a major determinant of the cabinet's partisan composition. We expect the number of parties in the cabinet to increase and the percentage of ministers from the prime minister's party to decline when the cabinet fails to control the upper house majority. If MMM reduces factionalism and speeds up power transitions, we expect the electoral reform to increase the number of parties in the cabinet and decrease the percentages of ministers from the prime minister's party. These hypotheses are confirmed, and the effects of MMM are especially impressive.

Comparing the partisan compositions of the cabinets of the two countries, we find Japan to have far more ministers from the prime minister's party than Taiwan has ministers from the president's party. The weights of the other parties are high in Japan while Taiwan's president tends to fill the executive positions by selecting ministers without partisanship or those from his party instead of parties with similar ideologies. This result supports the theory of portfolio allocation.

Taiwan and Japan are specific cases with general implications. We can make a further generalization by considering the two extreme possibilities: (1) a unicameral presidential system where the president heads the government and is the only agent responsible for portfolio allocation, and (2) a multichamber parliamentary system where the appointment of ministers 
has to be agreed to by the political parties in all chambers. In the first case, the number of nonpartisan ministers should be high; in the latter, political parties play decisive roles in cabinet formation and the number of ministers from the prime minister's party depends on to what extent the prime minister controls the chambers. What electoral reform does is to alter the number of parties the political leader can choose from rather than the rules regulating portfolio allocation. That is why we need to consider the electoral system and the constitutional system together to explain a country's party system.

\section{NOTES}

1. One should not equate the decrease in proportionality with the shift from proportional representation to a majoritarian system (see Reilly 2007a, 1359). In Reilly's cases, Cambodia switched from closed-list PR to the closed-list PR with the highest average method, Indonesia changed from closed-list PR to open-list PR, the Philippines substituted plurality-block with MMM, and Thailand replaced block vote with MMM. Only in South Korea, Japan, and Taiwan was there a change from the single nontransferable vote (SNTV) to MMM.

2. The Republic of Korea (South Korea) also abandoned SNTV (two-member district) in 1988 and replaced it with MMM, under which the voters could cast only one ballot. (The Republic of Korea shifted to a two-ballot system in 2004). Unfortunately for this volume, South Korea's electoral reform took place at the same time that this country transitioned to democracy, making it difficult to untangle the effects of electoral reform and democratization. For details, please see Brady and Mo (1992) and Mo and Brady (1999). In addition to the three East Asian cases, Afghanistan, Vanuatu, and Jordan have also had experience with SNTV for their national elections.

3. Sometimes the ruling party has an effective majority when it is just a few seats away from holding the majority of seats and can cooperate with the independent legislators to pass bills. If the ruling parties are unable to create an effective majority, the typical solution is to form a coalition government controlling the majority of seats in the HR.

4. There is also empirical evidence showing that presidential regimes are much more likely to appoint nonpartisan ministers than their parliamentary counterparts, with semipresidential regimes in between (Neto and Samuels 2010, 14).

5. The number of ministers from parties allied with the president is negligibly small. Additionally, Taiwan's ministers cannot concurrently hold a legislative position, which gives the president a strong justification to handpick the nonpartisans.

6. Coalition government is a normal practice in a parliamentary system. Although some cabinet positions are kept for nonpartisan ministers, most ministers are either from the prime minister's party or the parties of the coalition partners.

7. The president's role in the original constitution is close to a symbolic head of state. The highest administrative organ, the Executive Yuan, is headed by the premier rather than the president (Art. 53). The presidential appointment of the 
premier should have the consent of the Legislative Yuan (Art. 55); a premier failing to veto a legislative resolution "shall either accede to the Legislative Yuan's view or tender his (her) resignation" (Art. 57). The president appoints the cabinet ministers on the recommendation of the premier and cannot attend the weekly meetings of the Executive Yuan.

8. These designs did not fully realize the proclaimed goals, as the high threshold of constitutional amendments required cross-partisan collaborations.

9. Due to Taiwan's authoritarian history, many people formally joined the Nationalist Party (Kuomintang, KMT) but later allowed their membership to lapse. We thus define party membership by one's active position in the party hierarchy. Party members are those who had a seat in the central committee, held a paid job in the party bureaucracy, or represented the party in an election.

10. The president's approval rate can be another factor affecting the appointment of ministers. Presidents with high popularity are less likely to face obstruction from the legislature (Neustadt 1990; Kernell 1997). Both President Chen and President Ma saw severe declines in their approval ratings over their time in office. The percentage of nonpartisan ministers has steadily increased under $\mathrm{Ma}$ as his ratings declined. Chen appointed a significant number of nonpartisan members after he was elected in 2000 to ease worries about Cross-Strait stability. As these fears eased, the number of nonpartisan members increased, but it decreased during his second term as his approval ratings dropped. Relative to his two successors, President Lee enjoyed much higher approval ratings, and the percentage of nonpartisan ministers in his cabinets was much lower.

11. Premier Jiang Yi-Huah (2013-), the successor of Chen Chun, did not renew his KMT membership until he was about to be appointed premier. Very few of Jiang's ministers are active KMT members.

12. Batto, Kim, and Matukhno (chapter 10, this volume) make a similar argument about how presidential races contaminate legislative elections.

13. For detailed examinations of Duvergerian logic, see chapter 1 and chapter 7 , this volume.

14. All Japanese cabinets have nonpartisan ministers. Since we count nonpartisans as a group, whether they are seen as a constituent part of the cabinets makes no statistical difference.

15. The U.S. base on Okinawa has been controversial because the military base is close to a populated area and creates noise pollution. The base is also a reminder that, when the Second World War came to an end, Okinawa suffered from the most deadly strike launched by the United States.

\section{REFERENCES}

Brady, David, and Jongryn Mo. 1992. "Electoral Systems and Institutional Choice: A Case Study of the 1988 Korean Elections." Comparative Political Studies 24 (4): 405-29.

Brennan, Geoffrey, and Alan Hamlin. 1992. "Bicameralism and Majoritarian Equilibrium." Public Choice 74 (2): 169-80.

Budge, Ian, and Michael Laver. 1986. "Office Seeking and Policy Pursuit in Coalition Theory." Legislative Studies Quarterly 11 (4): 485-506. 
Cox, Gary W. 1997. Making Votes Count. New York: Cambridge University Press.

Druckman, James N., and Michael F. Thies. 2002. "The Importance of Concurrence: The Impact of Bicameralism on Government Formation and Duration." American fournal of Political Science 46 (4): 760-71.

Duverger, Maurice. 1964. Political Parties: Their Organization and Activity in the Modern State. 3rd ed. London: Methuen.

Guoshiguan Zhengjiaochu. 1994. Zhonghua minguo xingxian zhengfu zhiminglu Vol. 3 [Directory of government officials in the ROC since the implementation of the Constitution, vol. 3]. Taipei: Guoshiguan.

Guoshiguan Zhengjiaochu. 1998. Zhonghua minguo xingxian zhengfu zhiminglu Vol. 4 [Directory of government officials in the ROC since the implementation of the Constitution, vol. 4]. Taipei: Guoshiguan.

Guoshiguan Zhengjiaochu. 2001. Zhonghua minguo xingxian zhengfu zhiminglu Vol. 5 [Directory of government officials in the ROC since the implementation of the Constitution, vol. 5]. Taipei: Guoshiguan.

Hammond, Thomas H., and Gary J. Miller. 1987. "The Core of the Constitution." American Political Science Review 81 (4): 1155-74.

Heller, William B. 2001. "Political Denials: The Policy Effects of Intercameral Partisan Differences in Bicameral Parliamentary Systems.” Fournal of Law, Economics, and Organization 17 (1): 34-61.

Hicken, Allen. 2009. Building Party Systems in Developing Democracies. New York: Cambridge University Press.

Jou, Willy. 2009. "Electoral Reform and Party System Development in Japan and Taiwan: A Comparative Study." Asian Survey 49 (5): 759-85.

Kernell, Samuel. 1997. Going Public: New Strategies of Presidential Leadership. Washington, DC: CQ-Roll Call Group Books.

Kyofu, Utsu. 1996. Saishin rekidai naikaku soran [A compendium of the updated chronicle of cabinets]. Tokyo: Kabushiki kaisha jepi tsushinsha.

Lijphart, Arend, and Bernard Grofman, eds. 1984. Choosing an Electoral System: Issues and Alternatives. New York: Praeger.

Lin, Jih-wen. 2011. "The Rules of Electoral Competition and the Accountability of Semi-Presidential Governments." In Semi-Presidentialism and Democracy, ed. Robert Elgie, Sophia Moestrup, and Yu-Shan Wu. London: Palgrave Macmillan.

Liu, Guoming. 2006. Zhongguo Guomindang Bainian Renwu Quanshu [A complete directory of important figures in one hundred years of the Kuomintang]. Beijing: Tuanjie Chubanshe.

Liu, Weikai. 1994. Zhongguo Guomindang Zhiming Lu [A directory of Kuomintang party officials]. Taipei: Zhongguo guomin dang zhongyang weiyuanhui dangshi weiyuanhui.

Mo, Jongryn, and David Brady. 1999. "The SNTV and the Politics of Electoral Systems in Korea." In Elections and Campaigning in Japan, Korea, and Taiwan: Toward the Study of Embedded Institutions, ed. Bernard Grofman, Sung-Chull Lee, Edwin A. Winckler, and Brian Woodall. Ann Arbor: University of Michigan Press.

Naikaku seido hyakujunen kinen shi henshu iinkai. 1996. Naikaku seido byakunen shi, II tsuiroku [The cabinet system in one hundred years, appendix II]. Tokyo: Okura sho insatsu kyoku. 
Neto, Octavio Amorim, and David J. Samuels. 2010. "Democratic Regimes and Cabinet Politics: A Global Perspective." Revista Ibero-americana de Estudos Legislativos 1 (1): 10-23.

Neustadt, Richard E. 1990. Presidential Power and the Modern Presidents: The Politics of Leadership from Roosevelt to Reagan. New York: Free Press.

Rae, Douglas W. 1971. The Political Consequences of Electoral Laws. New Haven: Yale University Press.

Rei, Shiratori. 1986. Shinpan: Nibon no naikaku III [A new edition: The cabinets of Japan III]. Tokyo: Kabushiki kaisha shin hyoron.

Rei, Shiratori. 1987. Shinpan: Nibon no naikaku II [A new edition: The cabinets of Japan II]. Tokyo: Kabushiki kaisha shin hyoron.

Reilly, Benjamin. 2007a. "Electoral Systems and Party Systems in East Asia." Fournal of East Asian Studies 7 (2): 185-202.

Reilly, Benjamin. 2007b. "Democratization and Electoral Reform in the AsiaPacific Region.” Comparative Political Studies 40 (11): 1350-71.

Riker, William H. 1962. The Theory of Political Coalitions. New Haven: Yale University Press.

Riker, William H. 1992. “The Justification of Bicameralism.” International Political Science Review 13 (1): 101-16.

Shugart, Matthew Søberg. 1995. "The Electoral Cycle and Institutional Sources of Divided Presidential Government." American Political Science Review 89 (2): $327-43$.

Shugart, Matthew Søberg. 2005. "Semi-Presidential Systems: Dual Executive and Mixed Authority Patterns." French Politics 3 (3): 323-51.

Shugart, Matthew Søberg, and John M. Carey. 1992. Presidents and Assemblies: Constitutional Design and Electoral Dynamics. New York: Cambridge University Press.

Tavits, Margit. 2008. Presidents with Prime Ministers: Do Direct Elections Matter? Oxford: Oxford University Press.

Toshio, Otaka. 1990. Seijika jinmei jiten [A dictionary of politician names]. Tokyo: Nichigai asoshietsu kabushiki kaisha.

Tsebelis, George, and Jeannette Money. 1997. Bicameralism. New York: Cambridge University Press.

Yu, Keli, and Xianlong Zhu. 2001a. Zhongguo guomindang quanshu I [A complete directory of the Kuomintang I]. Xian: Shaanxi Renmin Chubanshe.

Yu, Keli, and Xianlong Zhu. 2001b. Zhongguo guomindang quanshu II [A complete directory of the Kuomintang II]. Xian: Shaanxi Renmin Chubanshe. 


\title{
LDP Factions under SNTV and MMM
}

\author{
Yoshiaki Kobayashi and Hiroki Tsukiyama
}

The Liberal Democratic Party (LDP) of Japan is notable as one of the most factionalized parties in modern democracies. For a long time, many scholars have discussed why LDP legislative factions ( $h a b a t s u$ ) appeared and why they are highly institutionalized. The literature offers two different explanations for the basis of LDP factions (Kohno 1992; Cox, Rosenbluth, and Thies 2000). One stresses the uniqueness of Japanese political culture including the affinity for patron-client relationships (oyabun-kobun kankei) between senior bosses and young followers (Thayer 1969; Richardson and Flanagan 1984; Baerwald 1986); the other stresses the rational incentives of LDP members (Sato and Matsuzaki 1986; Kohno 1992; Ramseyer and Rosenbluth 1993; Cox and Rosenbluth 1993, 1996; Cox, Rosenbluth, and Thies 2000). Over the last two decades, the rational choice school has become the dominant explanation.

The rational choice explanation for LDP factionalism particularly focuses on the old electoral system of Japan's lower house, the single nontransferable vote system. Under SNTV, multiple seats are open in a single district but each voter can cast only a single vote, so parties seeking governmental power have to nominate multiple candidates in districts and candidates affiliated with the same party have to scramble for that single vote. Some scholars argue that LDP factions are nothing more than an instrument to help their members in this intraparty struggle. Specifically, factions have supplied their members with some electoral resources: endorsements, financial support, and cabinet and party posts. 
In return, their members have sworn loyalty to the faction leaders in the party's presidential election (Sato and Matsuzaki 1986; Ramseyer and Rosenbluth 1993).

In terms of electoral systems, legislative factionalism should be transformed by electoral reform. In the Japanese case, the SNTV system used in lower house general elections was replaced with a mixed-member majoritarian (MMM) system in 1994. Japan's MMM is the combination of 300 seats elected from single-member districts (SMDs) and 180 seats $^{1}$ elected from a closed-list proportional representation (PR). ${ }^{2}$ Under MMM, which centers on a single member plurality system, parties nominate a single candidate in each district and they are no longer threatened by friendly fire from within the same party, so the electoral presence of factions should fall off. Hence, LDP factionalism should theoretically be reduced due to the electoral change from SNTV to MMM in 1994.

Unlike the theoretical expectation, however, old factionalism in the LDP still exists after the electoral reform. Why didn't LDP factions immediately fade away? The recent literature suggests that the reason for the continuing existence of LDP factions is that they remain influential in allocating posts, even if they have lost power in selecting candidates and the LDP presidency (Cox, Rosenbluth, and Thies 1999; Park 2001; Reed and Thies 2001b; Krauss and Pekkanen 2004, 2010). We roughly follow this argument, but the previous studies have overlooked one side of the close relationship between the decay (and persistence) of factions and the leadership of the party headquarters. Our findings suggest that the reasons for and consequences of factional decline and persistence must be understood in the context of the party president's leadership within Japan's parliamentary system.

In this chapter, we examine the long-term transition of LDP factions in the lower house under SNTV and MMM. Specifically, we investigate the change of two functions of factions from 1973 to 2009: (1) recruitment of new Diet members, and (2) allocation of cabinet posts. Our analyses show that the electoral and personnel importance of factions have weakened, and that these roles have been centralized in the LDP president; but that the power of the president has been unstable depending on fluctuations in his popularity. Finally, we discuss the fluidity of the president's leadership in terms of the constitutional system in Japan, a parliamentary system in which a prime minister always has to maintain a majority in the Diet. 


\section{Previous Studies}

\section{LDP Factions under SNTV}

We begin by reviewing the previous studies of LDP factions under SNTV. The prevailing view of the causes of LDP factionalism is based on the rational choice model, which attributes the institutionalization of factions to the rational choices of their members. In particular, the electoral incentives of both LDP candidates and seekers of the LDP presidency are crucial. Under the old SNTV electoral system, the LDP nominated more than one candidate in districts. However, their candidates were not supported by the LDP itself on a large scale. Hence, factions, rather than party headquarters, played a substantial role in national elections. On the other hand, presidential aspirants had powerful incentives to institutionalize their own factions, because the LDP president is elected by votes of LDP Diet members and local chapters (Sato and Matsuzaki 1986, 53).

Factions supplied their members with some resources under the old electoral system. First, factions had been the influential actor for the endorsement of LDP candidates. "For politician-hopefuls seeking LDP endorsement, factional backing is virtually indispensable. Faction members get first priority when the party leadership hammers out its endorsement list" (Ramseyer and Rosenbluth 1993, 69). Indeed, each faction competed for the endorsement of its own faction members during the long rule of the LDP. So-called mainstream factions ${ }^{3}$ managed the LDP endorsement policy for their own candidates (Cox and Rosenbluth 1996).

Second, factions furnished their members with financial support. Japanese politics is often related to money politics, and the important part of LDP fund-raising rested with factions. Whereas faction leaders once directly distributed their money to their followers, at the end of the 1955 System the main function of factions changed to providing "credit" and opening financial networks to their members such as fund-raising parties (Sato and Matsuzaki 1986, 61). Cox and Rosenbluth (1993) argue that interfactional differences in electoral fate in the 1960 and 1970s stemmed from differences in fund-raising success, but the electoral differences disappeared in the 1980s due to the decentralization of factional fund-raising.

Third, LDP factions won cabinet and party posts from the LDP president and allocated them to their members. It is known that cabinet and party posts were distributed among factions roughly in proportion to their number in the Diet. ${ }^{4}$ The factional proportionality system for personnel management (babatsu kinko jinji) started in the early 1970s-during 
the third Sato cabinet (Sato and Matsuzaki 1986)—or in the mid or late 1970s-the Miki or Ohira cabinets (Kawato 1996). When conservative and progressive strengths in the Diet became balanced in the 1970s, the LDP shifted the personnel system from mainstream overrepresentation to factional proportionality in order to maintain the interfactional coalition as a minimal winning coalition (Kawato 1996).

Under SNTV, LDP factions offered these three resources, which were adequate to satisfy the rational needs of members, particularly reelection (Mayhew 1974). By outsourcing election campaigns to factional organizations, the LDP solved the difficult problem of dividing votes (byo-wari). At the same time, by allocating cabinet and party posts to factions fairly, the LDP avoided critical splits in the party (Ramseyer and Rosenbluth 1993). During the SNTV era, factions persisted by performing these essential functions.

\section{LDP Factions under MMM}

If SNTV shaped LDP factions, the electoral reform should have reorganized the factional structure. Many scholars of Japanese politics argued that Japan's electoral reform in 1994 would break the importance of factions. Next, we review the previous studies on the transformation of LDP factions under MMM. First, factions clearly lost importance in elections after the reform. Under MMM, which centers on a single-member system, parties need not engage in intraparty competition within each district nor outsource election campaigns to factions. One Diet member interviewed by Krauss and Pekkanen (2004) observed changes following the electoral reform, explaining that "ultimately things are different than in the multimember district system" as "nobody looks after you in elections anymore" (15). In the 1996 election, factions already lost visible roles in nominating candidates in both SMDs and PR lists (Cox, Rosenbluth, and Thies 1999). Asano (2006) finds that the importance of factions has declined in the LDP endorsement process under MMM and the discretion of the party headquarters has clearly increased as a result.

Second, although the fund-raising activity of factions had already been decentralized in the 1970s (Cox and Rosenbluth 1993), the LDP's financial capacity has become vulnerable following the Political Funds Control Act reform. The reform in 1994 also included political finance reform, which prohibits politicians, their fund management organization (shikin kanri dantai), and other political organizations (including factions) from receiving contributions from companies. Under the new political finance law, 
only parties ${ }^{5}$ can receive contributions from companies, so the financial power is centralized to the headquarters. Reed and Thies (2001b) refer to an article in a Japanese national newspaper that said, "LDP Diet members have been heard complaining that the new system gives the party secretary-general ${ }^{6}$ too much power because he controls the flow of the party subsidies" (398). On the subject of campaign funding, some scholars report that factions have virtually stopped offering funds to their members but the secretary-general has been known to prop up feeble candidates with monetary support (Ohtake 2003, 63-67). ${ }^{7}$

Third, the voice of factions for allocating posts has weakened after the electoral reform; however, compared to its other functions, this change has come more slowly. With the declining electoral influence of factions, the party headquarters need not heed the voice of factions as they used to, so one can expect that the headquarters will allocate cabinet and party posts with less regard to the wishes of factions. We can find striking evidence in the formation of cabinets following the reform. The factional proportionality system for allocating cabinet posts has obviously been shaken under MMM. For example, Keizo Obuchi, the prime minister from 1998 to 2000, used his own discretion in appointing candidates to four ministerial posts in forming his first cabinet (the so-called sosai-waku). Although Obuchi allocated other ministerial posts in proportion to each factional power, he partly ignored the recommendation lists of factions (Takenaka 2006, 156). Junichiro Koizumi, the prime minister from 2001 to 2006, attempted a much more radical change. Koizumi completely ignored the recommendation lists of factions, and he decided the ministerial personnel on his own in forming his first cabinet (Takenaka 2006, 156). In contrast to the radical change in ministerial personnel, however, the literature shows that factions remain influential in allocating other positions after the electoral reform. Krauss and Pekkanen (2010, chap. 5) show that the rigid seniority system and the discrimination against nonfaction members for posts, for example Diet committee executive positions and Policy Affairs Research Council executive positions, still exist under the new electoral system, although they are now weaker than before. Park (2001) explains the matter in terms of organizational management. Indeed, as he pointed out, it is hard for the party leader to manage several hundred Diet members as a single unified group. After all, the relationship between the electoral reform and the party management is indirect, so the change comes slower than other functions.

Finally, factions have no longer been an indispensable key to decide the presidency. Under MMM, elections revolve around interparty competition, and the fate of the party is directly connected with the talent of party 
leaders. As a result, not only Diet members but also local members and supporters come to have a strong incentive to participate in the presidential election (Uekami 2010). In fact, seven of eleven LDP presidential elections from 1994 to 2009 after the reform have involved the popular vote from party members (toin tobyo) (Uekami 2010, 29). Recently, the popular vote has played an important role in selecting the president. It is symbolic that Koizumi, who was not a faction leader at the time, defeated Ryutaro Hashimoto, then the leader of the largest faction, due to a huge advantage in popular votes in the 2001 presidential election. Moreover, the decay of factions has reduced factional loyalty. Faction leaders now cannot always control their member votes, as can be observed, for example, in the 2007 presidential election (Krauss and Pekkanen 2010, 140-41).

In sum, the recent literature concludes that LDP factions cannot select candidates and the LDP presidency as they used to due to the electoral reform from SNTV to MMM. However, they can still influence personnel management appointments except ministerial posts, which is one of the reasons for the continuing existence of factions.

\section{Hypotheses}

The presence of LDP factions in elections has weakened, but they still retain their power in personnel management. While we basically follow this argument, some questions remain. The previous studies are relatively indifferent to the consequence of the decline of LDP factionalism, especially the reciprocal relation between the decay (and persistence) of factions and the leadership of the headquarters. If the importance of factions has declined and their power has been centralized in the party, then the party headquarters should use the power for their own benefit. Because the previous studies are aimed at the decline of factions themselves, they do not sufficiently answer the question how the decay of factions results in the ascendancy of the party headquarters, specifically the party president. ${ }^{8}$

To address this question, we examine the long-term transition of the president's success, especially in the recruitment of new Diet members and in the allocation of cabinet posts, two of the central functions of factions. We begin with the primitive hypothesis: the power of factions is centralized with the president due to the electoral reform from SNTV to MMM. Assuming that the president desires the rise of his own faction to enhance his power, we can rephrase the hypothesis as follows: the power of factions is centralized with the president's faction due to electoral reform. 
First, one can expect that the faction recruitment of new Diet members not only has decreased but also has been centralized to the president's faction after the electoral reform. Under SNTV, each faction normally did not nominate more than one candidate in each district, so the number of factions converged to below the maximum number of seats in multimember districts (Kohno 1992). This means that the faction recruitment of new Diet members would have been carried out roughly equally among the main factions before 1994. ${ }^{9}$ On the other hand, under MMM the LDP only has to nominate a single candidate in each SMD, so the president would try to find and support candidates on his own. Furthermore, because the new political finance law deprives factions of their financial resources, factions are unable to counter the discretion of the president in selecting and supporting candidates. If so, under the new electoral system, the president's faction will get priority for the recruitment of new members. Hence, we offer the first hypothesis as follows:

$\mathbf{H}_{1}$ : After electoral reform, the president's faction will be more successful than other factions in recruiting new members.

Second, one can expect not only that the factional proportionality system for the allocation of cabinet posts has broken down but also that cabinet posts have been allocated to favor the president's faction members. As stressed above, the electoral importance of factions should decline due to the electoral reform, and this should also cause their influence over personnel management decisions to wane. As can be seen from the cases of Obuchi and Koizumi, the president's discretion for the allocation of ministerial posts has obviously increased. If so, it is no wonder that the party president uses the discretion in order to benefit his own followers. Hence, we offer the second hypothesis as follows:

$\mathbf{H}_{2}$ : After electoral reform, the party president will appoint a disproportionate number of his own faction members to ministerial positions.

\section{Data}

We built two datasets of LDP members of the lower house: (1) the number of new members and all members of all LDP factions from 1973 to 2009; and (2) the list of cabinet posts and their faction affiliation from the same 
period (our data includes 45 cabinets from second Sato to Aso) ${ }^{10} \mathrm{With}$ data from the 1970s, when the LDP factional structure became stable, to the 2000s, when the LDP regime ended, we can examine the changes in the LDP factional structure before and after the electoral reform in 1994. The data are gathered from various issues of Kokkai Binran (The Diet handbook) ${ }^{11}$ (Nihon Seikei Shimbunsha 1972-2009). ${ }^{12}$

\section{Results}

\section{Recruitment of New Members}

To test the first hypothesis, we examine the long-term transition of the faction recruitment of new Diet members from 1973 to 2009. We expect that the president's faction would gain the largest number of freshmen members among all factions under MMM but not under SNTV. Figure 3.1 shows the number of new lower house members who joined the president's faction and other major factions. ${ }^{13}$

As we can see, the recruitment success of the president's faction under the two electoral systems differs widely. Under SNTV, the president's faction was not at a distinct advantage over other major factions except for the two elections in 1979 and 1980 when Masayoshi Ohira was the president. ${ }^{14}$ On the other hand, in all elections under MMM, except the 2009 election when the LDP was defeated by the Democratic Party of Japan, ${ }^{15}$ the president's faction achieved the most successful recruitment by a wide margin. The president's (Obuchi) faction gained double the number of newcomers compared to the second most successful (Mori) faction in the 1996 and 2000 elections, ${ }^{16}$ and the president's (Mori) faction gained double or triple the number of newcomers compared to the second most successful (Hashimoto) faction in the 2003 and 2005 elections. Dividing the recruitment number of the president's faction by that of the other most successful faction, the average of this rate is 1.22 under SNTV but it is 2.17 under MMM.

We also test the first hypothesis statistically using OLS estimation. In the analysis, we estimate the effect of the factional status in the election at period $t-1$ on the recruitment just before the election at period $t{ }^{17}$ The results, which are displayed in table 3.1, demonstrate that the president's faction under MMM has a distinct advantage for the recruitment of new Diet members even while controlling for the effects of factional size and the overall success of the LDP. This advantage is statistically unclear under SNTV.

Figure 3.2 also shows the sizes of the president's factions and other 


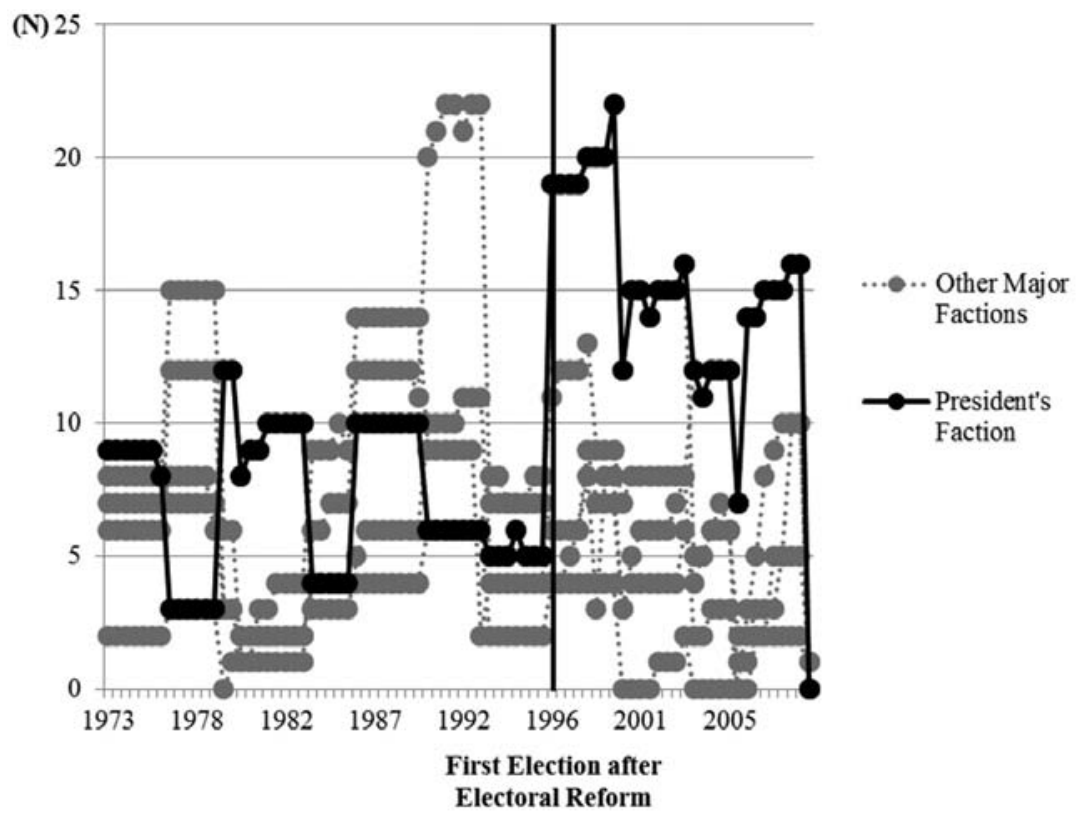

Fig. 3.1. Faction recruitment of new lower house members

major factions. As we can see, the faction controlling the party presidency clearly succeeded in developing its power under MMM but not under SNTV. Although there were some successes under SNTV for the president's faction, such as Ohira in 1979 and 1980, the power of major factions (except the smaller Miki-Kono faction) was basically balanced regardless of which faction controlled the presidency. In contrast, the president's faction was the consistent winner in developing its power under MMM. The size of the president's faction was distinctly larger than other major factions after the electoral reform.

Where did the advantage of the president under MMM come from? The keys are in the two changes after the electoral reform: the party endorsement process and the party election strategy headquarters. Table 3.2 is reproduced from Asano $(2006,65)$ and shows the number and rates of LDP endorsement under SNTV and MMM. ${ }^{18}$ Under both systems, almost all incumbent candidates were endorsed by the LDP, so the best indicator of factional power in the endorsement process is whether the nonincumbent candidates supported by each faction were endorsed by the LDP. There is 


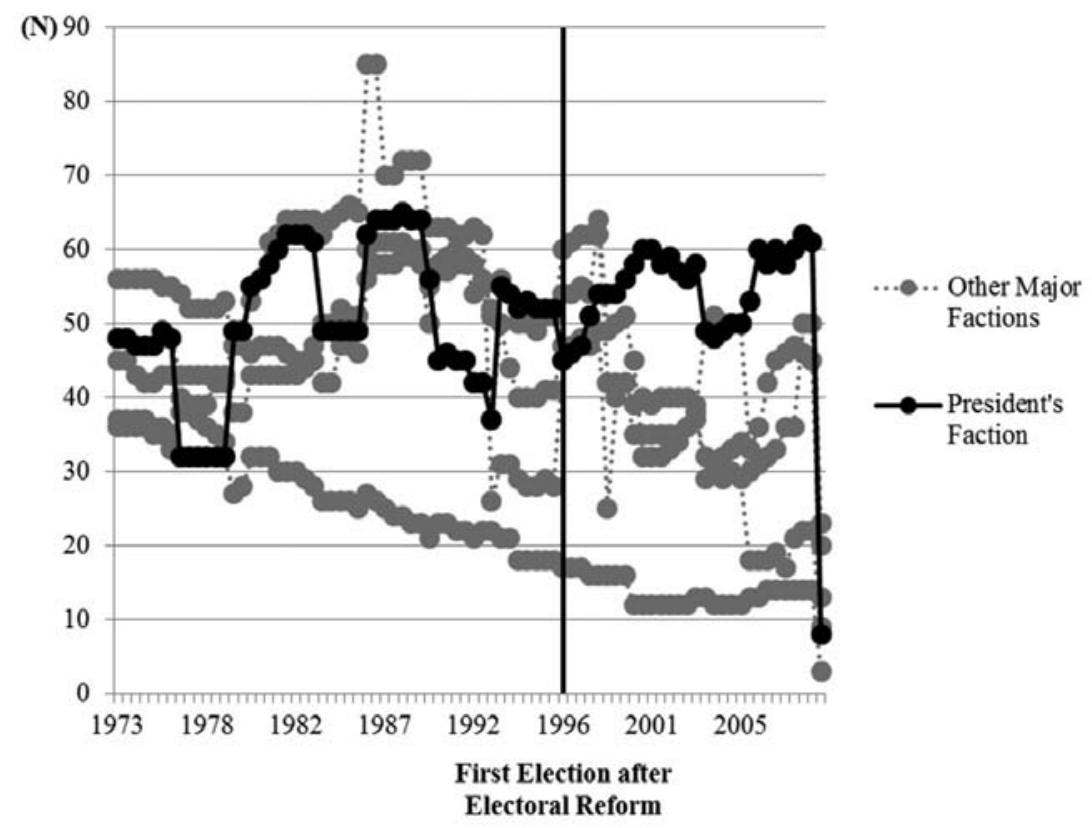

Fig. 3.2. Faction size: All lower house members

a clear difference in the advantage enjoyed by the president's faction after reform. Under SNTV, the president's faction won 133 endorsements. This number is only 0.94 times as large as that of the secretary-general, 1.27 times that of the chairman of the general council, and 1.13 times that of the chairman of the policy research council. By contrast, under MMM, the president's faction won 62 endorsements. This number is 1.32 times that of the secretary-general, 1.82 times the chairman of the general council, and 2.58 times the chairman of the policy research council. That is to say, the advantage of the president's faction in the endorsement process has grown stronger under $M M M,{ }^{19}$ causing the rise of the president's faction (Asano 2006, 90-94).

In addition, the other key to understanding the centralization of LDP recruitment is the change of the election strategy headquarters. ${ }^{20}$ Table 3.3 shows the history of the election strategy headquarters members. ${ }^{21}$

The LDP election strategy is mainly determined by the president, secretary-general, and director-general of the election bureau (DGEB). At 
one point, the LDP had stipulated that the secretary-general could not be selected from the president's faction (so-kan bunri). ${ }^{22}$ Since the Miki cabinet, this rule had only been broken once, by the first Ohira cabinet. Junichiro Koizumi, however, evidently abolished this custom, because he appointed fellow Mori faction member Shinzo Abe as secretary-general in 2003-4. Although Koizumi also appointed Yamasaki faction leader Taku Yamasaki in 2001-3 and Yamasaki faction member Tsutomu Takebe in 2004-6 to the secretary-general post, the Yamasaki faction was not one of the five major factions but instead one of the newer factions that had emerged since 1998. Moreover, in the Koizumi presidency, the DGEB position was allocated to the president's Mori faction, the smaller emerging Nikai faction, and the emerging Yamasaki faction. Probably, Koizumi intended to construct a president-centered election strategy headquarters.

Finally, we also examine emerging factions after the electoral reform. Figure 3.3 shows the number of new lower house members who joined

TABLE 3.1. OLS Estimates Predicting Faction Recruitment

Dependent Variable $=$ Faction Recruitment ${ }_{i, t}$

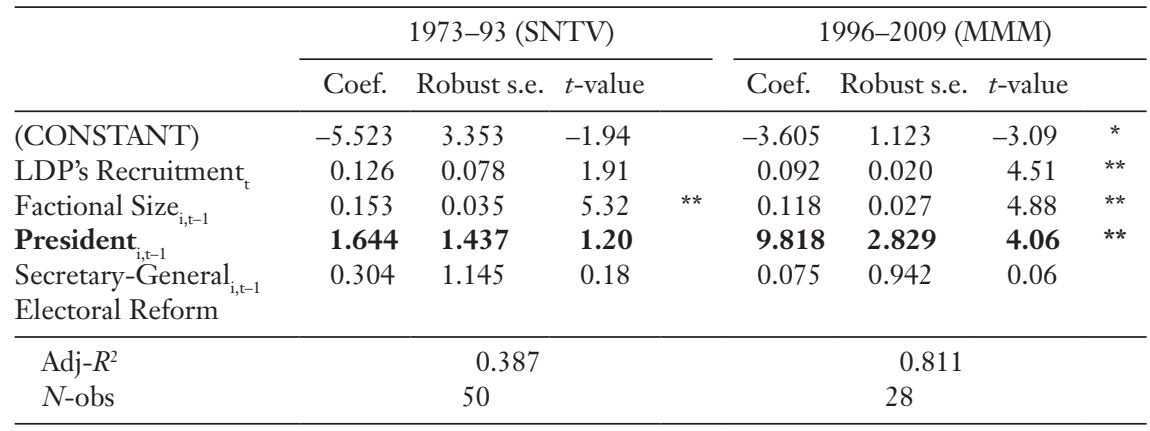

\begin{tabular}{lrrrr} 
& \multicolumn{4}{c}{$1973-2009($ SNTV-MMM) } \\
\cline { 2 - 5 } & Coef. & Robust s.e. & $t$-value & \\
\hline (CONSTANT) & -5.020 & 1.113 & -4.45 & $* * *$ \\
LDP's Recruitment $_{\mathrm{t}}$ & 0.105 & 0.025 & 4.16 & $* *$ \\
Factional Size $_{\mathrm{i}, \mathrm{t}-1}$ & 0.151 & 0.028 & 6.97 & $* * *$ \\
President $_{\mathrm{i}, \mathrm{t}-\mathrm{1}}$ & $\mathbf{4 . 2 5 4}$ & $\mathbf{1 . 7 9 4}$ & $\mathbf{2 . 7 0}$ & $*$ \\
Secretary-General $_{\mathrm{i}, \mathrm{t}-1}$ & 0.178 & 0.597 & 0.16 & \\
Electoral Reform & 0.451 & 0.941 & 0.51 & \\
\hline
\end{tabular}

\begin{tabular}{lc}
\hline Adj- $R^{2}$ & 0.499 \\
$N$-obs & 78
\end{tabular}

${ }^{* * *} p<0.001,{ }^{* *} p<0.01,{ }^{*} p<0.05,+p<0.1$. 
emerging factions after the electoral reform. As we can see, the Yamasaki faction controlling the secretary-general (2001-3; 2004-6)/DGEB (2006) and the Nikai faction controlling the DGEB (2004-5) had a relative advantage for the recruitment of freshmen members among emerging factions. In particular, the Nikai faction gained a large number of new members in proportion to its size after the 2005 election. Figure 3.4 shows the sizes of

TABLE 3.2. LDP Endorsement of Conservative Candidates, 1960-2005

\begin{tabular}{|c|c|c|c|c|}
\hline Faction & Endorsement & $\begin{array}{c}\text { Non- } \\
\text { Endorsement }\end{array}$ & Total & $\begin{array}{c}\text { Rates of } \\
\text { Endorsement }\end{array}$ \\
\hline \multicolumn{5}{|l|}{ Under SNTV/MMD (1960-1990) } \\
\hline \multicolumn{5}{|l|}{ Incumbent } \\
\hline President's & 415 & 4 & 419 & $99.0 \%$ \\
\hline Secretary-General's & 443 & 4 & 447 & $99.1 \%$ \\
\hline General Council Chair's & 379 & 3 & 382 & $99.2 \%$ \\
\hline Policy Research Council Chair's & 358 & 1 & 359 & $99.2 \%$ \\
\hline Other (Including Nonfaction) & 1166 & 15 & 1,181 & $99.7 \%$ \\
\hline Total & 2,761 & 27 & 2,788 & $\begin{array}{l}(99.8 \%) \\
\text { (average) }\end{array}$ \\
\hline \multicolumn{5}{|l|}{ Non-Incumbent } \\
\hline President's & 133 & 36 & 169 & $78.7 \%$ \\
\hline Secretary-General's & 141 & 38 & 179 & $78.8 \%$ \\
\hline General Council Chair's & 105 & 38 & 143 & $73.4 \%$ \\
\hline Policy Research Council Chair's & 118 & 68 & 186 & $63.4 \%$ \\
\hline Other (Including Nonfaction) & 423 & 943 & 1,366 & $31.0 \%$ \\
\hline Total & 920 & 1,123 & 2,043 & $\begin{array}{c}(45.0 \%) \\
\text { (average) }\end{array}$ \\
\hline \multicolumn{5}{|l|}{ Under MMM (1996-2005) } \\
\hline President's & 131 & 0 & 131 & $100 \%$ \\
\hline Secretary-General's & 138 & 0 & 138 & $100 \%$ \\
\hline General Council Chair's & 138 & 1 & 139 & $99.3 \%$ \\
\hline Policy Research Council Chair's & 108 & 1 & 109 & $99.1 \%$ \\
\hline Other (Including Nonfaction) & 192 & 50 & 242 & $79.3 \%$ \\
\hline Total & 707 & 52 & 759 & $\begin{array}{l}\text { (93.1\%) } \\
\text { (average) }\end{array}$ \\
\hline \multicolumn{5}{|l|}{ Non-Incumbent } \\
\hline President's & 62 & 1 & 63 & $98.4 \%$ \\
\hline Secretary-General's & 47 & 1 & 48 & $97.9 \%$ \\
\hline General Council Chair's & 34 & 8 & 42 & $81 \%$ \\
\hline Policy Research Council Chair's & 24 & 1 & 25 & $96 \%$ \\
\hline Other (Including Nonfaction) & 229 & 255 & 484 & $47 \%$ \\
\hline Total & 396 & 266 & 662 & $\begin{array}{r}(59.8 \%) \\
\text { (average) }\end{array}$ \\
\hline
\end{tabular}

Source: Asano $(2006,65)$. 
emerging factions. Again, the Yamasaki faction and the Nikai faction succeeded in steadily increasing their power, while other emerging factions (the Kono-Aso faction and the Ozato-Tanigaki faction) relatively failed to increase their power. We can see that not only controlling the presidency but also controlling the secretary-general and DGEB would be directly connected with the fate of emerging factions under MMM. By delegating power to the smaller emerging factions, Koizumi may have cleverly avoided the rise of the other five major factions.

\section{Allocation of Cabinet Posts}

To test the second hypothesis, we examine the allocation of cabinet posts from 1973 to $2009 .{ }^{23}$ We expect to observe not only that the faction proportionality system for ministers has been broken after the electoral reform but also that the presidents have come to allocate a disproportionate number of ministerial positions to their own faction. Thus, in this section, we test the two questions: whether or not the faction proportionality system exists; and whether or not the president's faction is overrepresented.

Figure 3.5 shows the faction disproportionality of 44 cabinets during the period in question (1973-2009). ${ }^{24}$ The value for each cabinet is measured as follows: (1) subtracting a seat share of a faction from its cabinet share; (2) adding up the absolute values of the share distance of all factions. ${ }^{25} \mathrm{In}$ figure 3.5 , the faction disproportionality has dramatically increased since $2000 .{ }^{26}$ The disproportionality of the reshuffled second Mori cabinet is 37.45 , the value of the first Koizumi cabinet is 52.06 , and the value of the first Koizumi cabinet (the first reshuffled) is 69.92, respectively. These values are clearly higher than previously experienced, because the average of the cabinets under SNTV was only 23.74.

Although it is reasonable to suggest that the high disproportionality of the Koizumi cabinet was caused by his personnel discretion (as explained above), we have to find another explanation for the rise of the disproportionality in the reshuffled second Mori cabinet. ${ }^{27}$ There are two causes. The first is the central government reform in 2001. This reform, which was approved during the second Hashimoto cabinet, reduced the number of ministries and government offices from one office and 22 ministries and agencies to one office and 12 ministries and agencies. The reshuffled second Mori cabinet was the first cabinet after the adoption of this system. Because of the reduction of ministerial posts, the disproportionality of the reshuffled second Mori cabinet increased.

The second cause is the rise of emerging factions. Since 1998, the intra- 
TABLE 3.3. LDP Election Strategy Headquarters, 1973-2009

\begin{tabular}{|c|c|c|c|c|c|c|}
\hline \multirow[b]{2}{*}{ Ed. } & \multirow[b]{2}{*}{ Yr. } & \multirow[b]{2}{*}{ Mo. } & \multirow[b]{2}{*}{ Cabinet } & \multicolumn{3}{|c|}{ LDP election strategy headquarters } \\
\hline & & & & President & Sec.-Gen. & DGEB \\
\hline 46 & 1973 & 2 & 2nd Tanaka & STT-OHT & STT-OHT & STT-OHT \\
\hline 47 & 1973 & 8 & 2nd Tanaka & STT-OHT & STT-OHT & STT-OHT \\
\hline 48 & 1974 & 2 & 2nd Tanaka (1st R) & STT-OHT & STT-OHT & STT-OHT \\
\hline 49 & 1974 & 8 & 2nd Tanaka (1st R) & STT-OHT & STT-OHT & STT-OHT \\
\hline 50 & 1975 & 2 & Miki & MK-K & KNW-KI & KNW-KI \\
\hline 51 & 1976 & 2 & Miki & MK-K & KNW-KI & KNW-KI \\
\hline 52 & 1976 & 8 & Miki & MK-K & KNW-KI & $\mathrm{KNW}-\mathrm{KI}$ \\
\hline 53 & 1977 & 2 & Fukuda.T & KFA-MMM & IMOM-KHK & NON \\
\hline 54 & 1977 & 8 & Fukuda.T (R) & KFA-MMM & IMOM-KHK & $\mathrm{NON}$ \\
\hline 55 & 1978 & 2 & Fukuda.T (R) & KFA-MMM & IMOM-KHK & FUNADA \\
\hline 56 & 1978 & 8 & Fukuda.T (R) & KFA-MMM & IMOM-KHK & FUNADA \\
\hline 57 & 1979 & 2 & 1st Ohira & IMOM-KHK & IMOM-KHK & IMOM-KHK \\
\hline 58 & 1979 & 8 & 1st Ohira & IMOM-KHK & IMOM-KHK & IMOM-KHK \\
\hline 59 & 1979 & 11 & 2nd Ohira & IMOM-KHK & KNW-KI & IMOM-KHK \\
\hline 60 & 1980 & 2 & 2nd Ohira & IMOM-KHK & KNW-KI & IMOM-KHK \\
\hline 61 & 1980 & 8 & Suzuki & IMOM-KHK & KNW-KI & KFA-MMM \\
\hline 62 & 1981 & 2 & Suzuki & IMOM-KHK & KNW-KI & KFA-MMM \\
\hline 63 & 1981 & 8 & Suzuki & IMOM-KHK & KNW-KI & KFA-MMM \\
\hline 64 & 1982 & 2 & Suzuki (R) & IMOM-KHK & STT-OHT & IMOM-KHK \\
\hline 65 & 1982 & 8 & Suzuki (R) & IMOM-KHK & STT-OHT & IMOM-KHK \\
\hline 66 & 1982 & 12 & 1st Nakasone & KNW-KI & STT-OHT & (Omitted) \\
\hline 67 & 1983 & 2 & 1st Nakasone & KNW-KI & STT-OHT & STT-OHT \\
\hline 68 & 1983 & 8 & 1st Nakasone & KNW-KI & STT-OHT & STT-OHT \\
\hline 69 & 1984 & 2 & 2nd Nakasone & KNW-KI & IMOM-KHK & IMOM-KHK \\
\hline 70 & 1984 & 8 & 2nd Nakasone & KNW-KI & IMOM-KHK & IMOM-KHK \\
\hline 71 & 1985 & 2 & 2nd Nakasone (1st R) & KNW-KI & STT-OHT & STT-OHT \\
\hline 72 & 1985 & 8 & 2nd Nakasone (1st R) & KNW-KI & STT-OHT & STT-OHT \\
\hline 73 & 1986 & 2 & 2nd Nakasone (2nd R & KNW-KI & STT-OHT & KNW-KI \\
\hline 74 & 1986 & 8 & 3rd Nakasone & KNW-KI & STT-OHT & KNW-KI \\
\hline 75 & 1987 & 2 & 3rd Nakasone & KNW-KI & STT-OHT & KNW-KI \\
\hline 76 & 1987 & 8 & 3rd Nakasone & KNW-KI & STT-OHT & KNW-KI \\
\hline 77 & 1987 & 12 & Takeshita & STT-OHT & KFA-MMM & KFA-MMM \\
\hline 78 & 1988 & 2 & Takeshita & STT-OHT & KFA-MMM & KFA-MMM \\
\hline 79 & 1988 & 8 & Takeshita & STT-OHT & KFA-MMM & KFA-MMM \\
\hline 80 & 1989 & 2 & Takeshita (R) & STT-OHT & KFA-MMM & KFA-MMM \\
\hline 81 & 1989 & 8 & 1st Kaifu & MK-K & STT-OHT & STT-OHT \\
\hline 82 & 1990 & 2 & 2nd Kaifu & MK-K & STT-OHT & IMOM-KHK \\
\hline 83 & 1990 & 8 & 2nd Kaifu & MK-K & STT-OHT & IMOM-KHK \\
\hline 84 & 1991 & 2 & 2nd Kaifu (R) & MK-K & STT-OHT & KFA-MMM \\
\hline 85 & 1991 & 8 & 2nd Kaifu (R) & MK-K & STT-OHT & KFA-MMM \\
\hline 86 & 1992 & 2 & Miyazawa & IMOM-KHK & STT-OHT & STT-OHT \\
\hline
\end{tabular}


TABLE 3.3.-Continued

\begin{tabular}{|c|c|c|c|c|c|c|}
\hline \multirow{2}{*}{\multicolumn{3}{|c|}{$\begin{array}{l}\text { Data Source: } \\
\text { Kokkai Binran }\end{array}$}} & \multirow[b]{3}{*}{ Cabinet } & \multicolumn{3}{|c|}{ LDP election strategy headquarters } \\
\hline & & & & & & \\
\hline Ed. & Yr. & Mo. & & President & Sec.-Gen. & DGEB \\
\hline 87 & 1992 & 8 & Miyazawa & IMOM-KHK & STT-OHT & STT-OHT \\
\hline 88 & 1993 & 2 & Miyazawa (R) & IMOM-KHK & STT-OHT & IMOM-KHK \\
\hline 89 & 1993 & 8 & Hosokawa & IMOM-KHK & KFA-MMM & IMOM-KHK \\
\hline 90 & 1994 & 2 & Hosokawa & IMOM-KHK & KFA-MMM & IMOM-KHK \\
\hline 91 & 1994 & 8 & Murayama & IMOM-KHK & KFA-MMM & IMOM-KHK \\
\hline 92 & 1995 & 2 & Murayama & IMOM-KHK & KFA-MMM & IMOM-KHK \\
\hline 93 & 1995 & 8 & Murayama (R) & IMOM-KHK & KFA-MMM & IMOM-KHK \\
\hline 94 & 1996 & 2 & 1st Hashimoto & STT-OHT & IMOM-KHK & IMOM-KHK \\
\hline 95 & 1996 & 8 & 1st Hashimoto & STT-OHT & IMOM-KHK & IMOM-KHK \\
\hline 96 & 1996 & 12 & 2nd Hashimoto & STT-OHT & IMOM-KHK & IMOM-KHK \\
\hline 97 & 1997 & 2 & 2nd Hashimoto & STT-OHT & IMOM-KHK & IMOM-KHK \\
\hline 98 & 1997 & 8 & 2nd Hashimoto & STT-OHT & IMOM-KHK & IMOM-KHK \\
\hline 99 & 1998 & 2 & 2nd Hashimoto (R) & STT-OHT & IMOM-KHK & IMOM-KHK \\
\hline 100 & 1998 & 8 & Obuchi & STT-OHT & KFA-MMM & KFA-MMM \\
\hline 101 & 1999 & 2 & Obuchi (1st R) & STT-OHT & KFA-MMM & KFA-MMM \\
\hline 102 & 1999 & 8 & Obuchi (1st R) & STT-OHT & KFA-MMM & KFA-MMM \\
\hline 103 & 2000 & 2 & Obuchi (2nd R) & STT-OHT & KFA-MMM & STT-OHT \\
\hline 104 & 2000 & 8 & 2nd Mori & KFA-MMM & STT-OHT & STT-OHT \\
\hline 105 & 2001 & 2 & 2nd Mori (2nd R) & KFA-MMM & IMOM-KHK & STT-OHT \\
\hline 106 & 2001 & 5 & 1st Koizumi & KFA-MMM & $\mathrm{Y}$ & KFA-MMM \\
\hline 107 & 2001 & 8 & 1st Koizumi & KFA-MMM & $\mathrm{Y}$ & KFA-MMM \\
\hline 108 & 2002 & 2 & 1st Koizumi & KFA-MMM & $\mathrm{Y}$ & KFA-MMM \\
\hline 109 & 2002 & 8 & 1st Koizumi (1st R) & KFA-MMM & $\mathrm{Y}$ & KFA-MMM \\
\hline 110 & 2003 & 2 & 1st Koizumi (1st R) & KFA-MMM & $\mathrm{Y}$ & KFA-MMM \\
\hline 111 & 2003 & 8 & 1st Koizumi (1st R) & KFA-MMM & Y & KFA-MMM \\
\hline Other & 2003 & 9 & 1st Koizumi (2nd R) & KFA-MMM & KFA-MMM & KFA-MMM \\
\hline 112 & 2003 & 12 & 2nd Koizumi & KFA-MMM & KFA-MMM & KFA-MMM \\
\hline 113 & 2004 & 2 & 2nd Koizumi & KFA-MMM & KFA-MMM & KFA-MMM \\
\hline 114 & 2004 & 8 & 2nd Koizumi & KFA-MMM & KFA-MMM & KFA-MMM \\
\hline 115 & 2005 & 2 & 2nd Koizumi (R) & KFA-MMM & Y & $\mathrm{N}$ \\
\hline 116 & 2005 & 8 & 2nd Koizumi (R) & KFA-MMM & $\mathrm{Y}$ & $\mathrm{N}$ \\
\hline 117 & 2005 & 10 & 3rd Koizumi & KFA-MMM & $\mathrm{Y}$ & $\mathrm{N}$ \\
\hline 118 & 2006 & 2 & 3rd Koizumi (R) & KFA-MMM & $\mathrm{Y}$ & $\mathrm{Y}$ \\
\hline 119 & 2006 & 8 & Abe & KFA-MMM & KFA-MMM & KNW-KI \\
\hline 120 & 2007 & 2 & Abe & KFA-MMM & KFA-MMM & KNW-KI \\
\hline 121 & 2007 & 8 & Fukuda.Y & KFA-MMM & KNW-KI & IMOM-KHK \\
\hline 122 & 2008 & 2 & Fukuda.Y & KFA-MMM & KNW-KI & IMOM-KHK \\
\hline 123 & 2008 & 8 & Fukuda.Y (R) & KFA-MMM & $\mathrm{KA}$ & IMOM-KHK \\
\hline 124 & 2009 & 2 & Aso & $\mathrm{KA}$ & KFA-MMM & IMOM-KHK \\
\hline
\end{tabular}

Notes: Horizontal lines indicate lower house general elections. Because of the restriction of the information source, this table does not include all cabinets and all election strategy headquarters. 


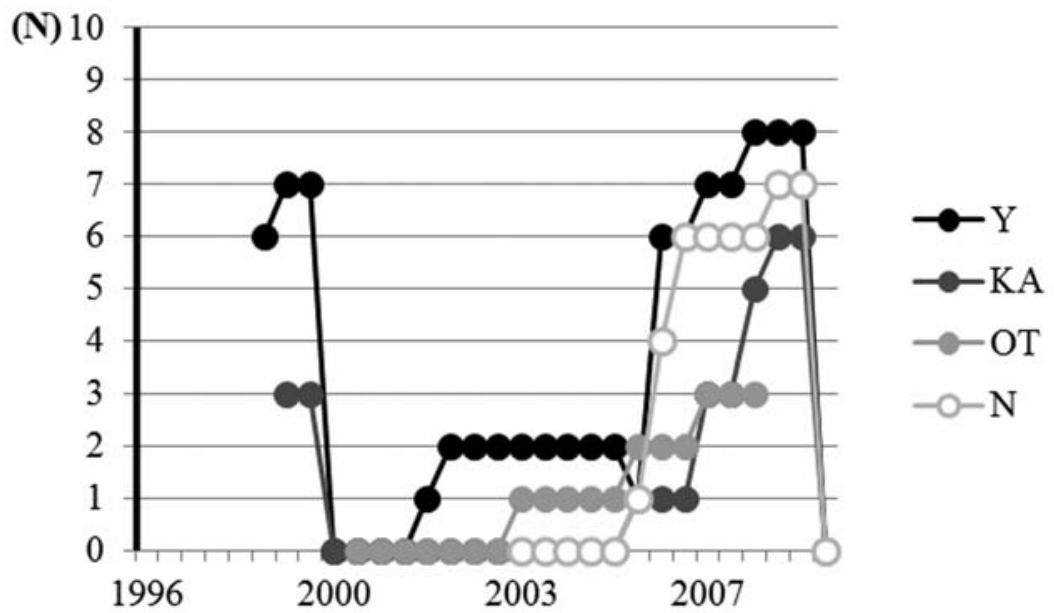

\section{First Election after}

\section{Electoral Reform}

Fig. 3.3. Faction recruitment of new lower house members (emerging factions)

(Note: See the appendix for information on LDP factions' acronyms.)

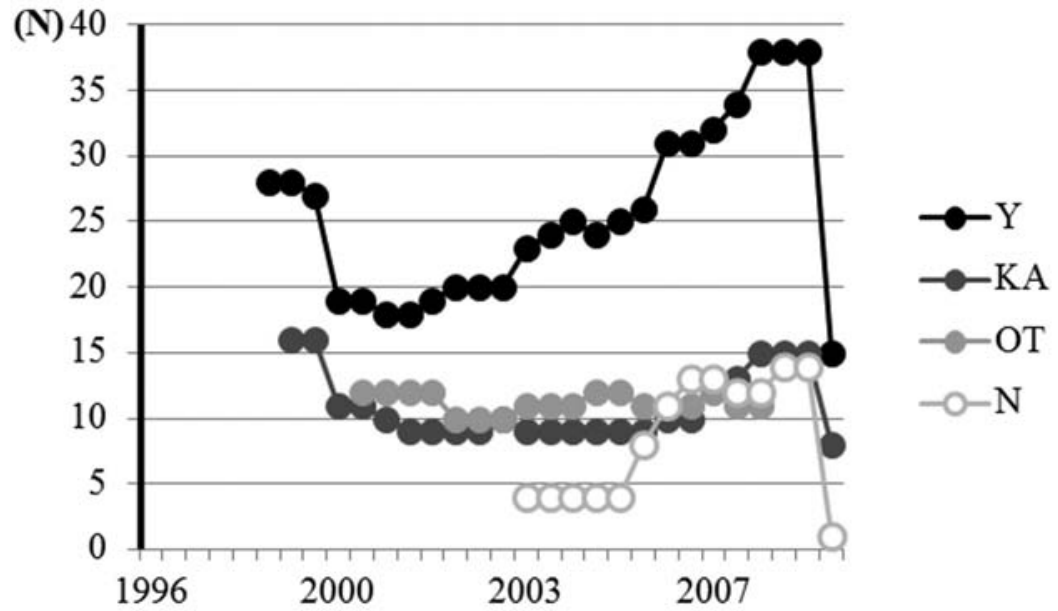

\section{First Election after}

\section{Electoral Reform}

Fig. 3.4. Faction size: All members (emerging factions) 


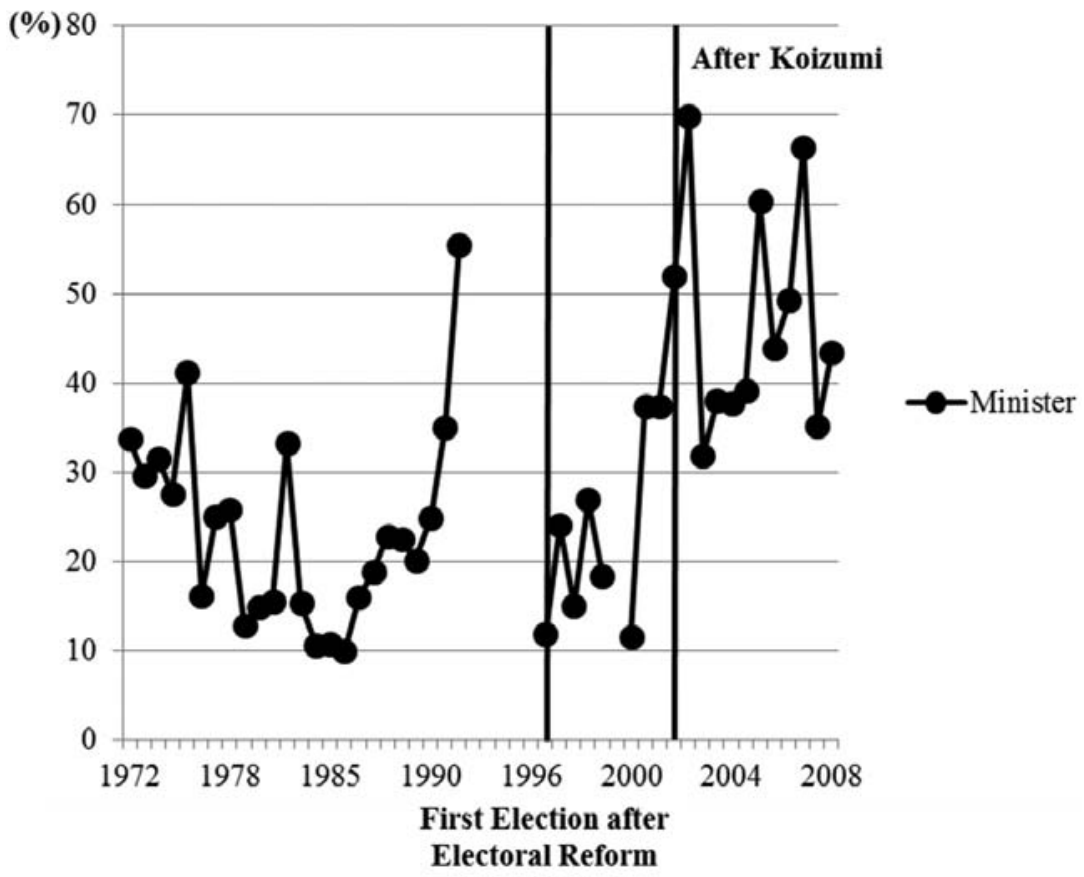

Fig. 3.5. Faction disproportionality for minister

factional strife within LDP factions has become obvious, and this strife led to the secession of emerging factions in the LDP. For example, the Yamasaki faction seceded from the Watanabe faction in November 1998, the Kono group seceded from the Miyazawa faction in December 1999, and the Horiuchi faction seceded from the Kato faction in January 2001.28 With the reduction of allocable cabinet posts, the increase of the number of factions complicates the observance of the faction proportionality system. Because the solidarity of factions has been weakened by MMM, it is reasonable to understand the new factions as indirect effects of the electoral reform.

Next, figure 3.6 shows the cabinet shares of the president's faction from 1973 to 2009. If the faction proportionality system exists, then the cabinet share of the president's faction should correspond to its seat share in the Diet. As we can see, the cabinet share of the president's faction has 


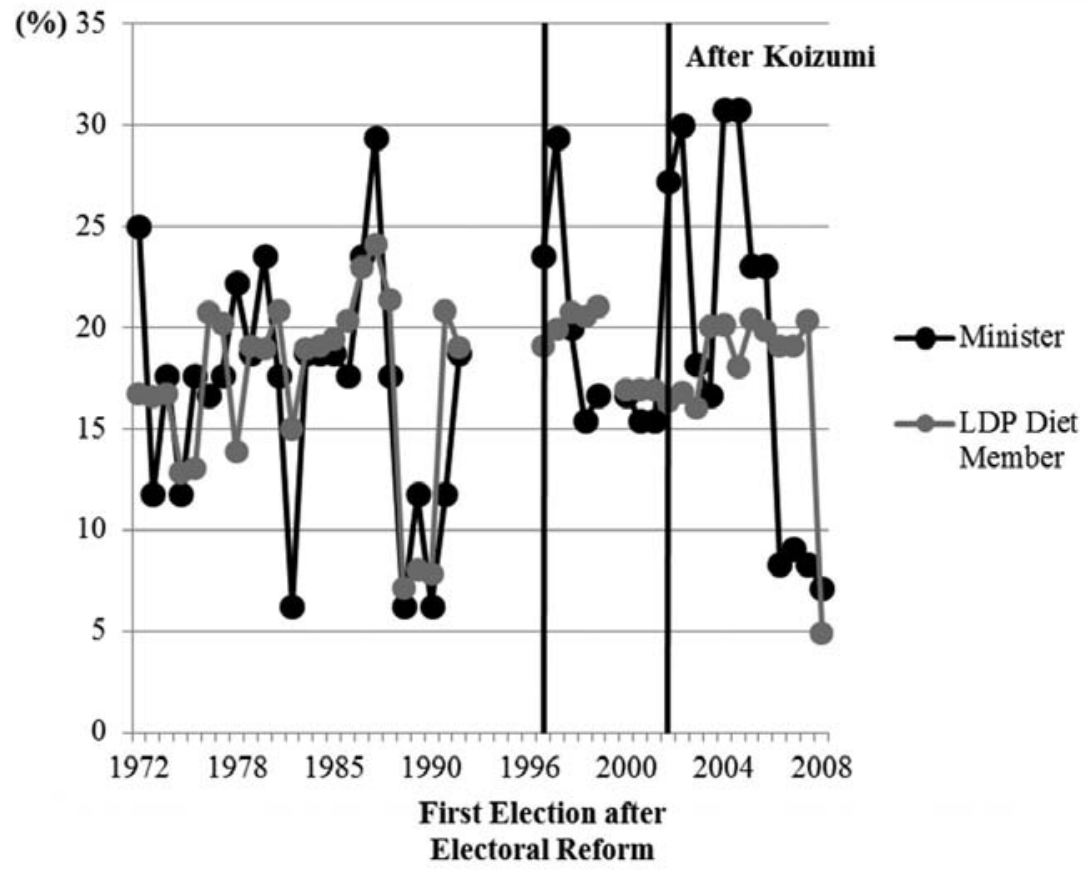

Fig. 3.6. Cabinet shares of president's faction

been disconnected from that faction's seat share following electoral reform, especially after Koizumi. Under SNTV, the seat share of the president's faction has relatively corresponded to its cabinet share. On the other hand, under MMM presidents have more often overrepresented their own faction members in the cabinet. ${ }^{29}$

However, it is contrary to our theoretical expectation that the presidents under MMM have not always disproportionally allocated ministerial posts to their own faction members. Some presidents failed not only to reap a surplus profit but even to secure a proportional number of cabinet posts for their faction. If the president's discretion for personnel management has been strengthened by electoral reform, why doesn't the president always form the best cabinet for him? To answer this new question, we must revise the second hypothesis and reanalyze our data. 


\section{Additional Analyses}

\section{Hypothesis}

Our findings in the preceding section suggest that the faction proportionality system for ministers has been broken and the president's discretion for the allocation of cabinet posts has strengthened, but the president has not always executed the overrepresentation strategy for his own faction. This runs contrary to our original expectation.

Here, we introduce a new variable to our research: the popularity of the president (prime minister). Recently, some scholars have highlighted the importance of the popularity of the prime minister under MMM (Ito 2006; Takenaka 2006). Ito $(2006,28)$ argues that under MMM the prime minister becomes the party's public face, and Diet members understand that a high cabinet approval rating is a public good shared by all members of the party. When Koizumi formed his cabinet, most members went along with him and even faction leaders refrained from lodging direct criticism against him. ${ }^{30}$ We agree with this sentiment entirely, but the argument has not been examined statistically. Therefore, according to the explanation, we revise the second hypothesis as follows: ${ }^{31}$

$\mathbf{H}_{2}{ }^{*}$ : After electoral reform, the party president with high popularity will appoint a disproportionate number of his own faction members to ministerial positions.

We employ two control variables to predict the overrepresentation of the president's faction. Kawato $(1996,126)$ argues that the LDP is more likely to employ a proportional system when it is a minimum winning coalition than when it is an oversized coalition because the withdrawal of any faction from the party could cause the LDP to lose its majority in the former situation but not in the latter. Thus, we employ two variables: (1) the size of the LDP in the lower house, and (2) the effective number of factions. ${ }^{32}$

\section{Data}

Here, we added new data for cabinet approval rates from 1973 to 2009. The information source is various issues of Fiji Seron Chosa Tokubo [Jiji public opinion poll special bulletin] (Jiji Tsushinsha 1991-2009) and its compilations (Jiji Tsushinsha 1981, 1992). 


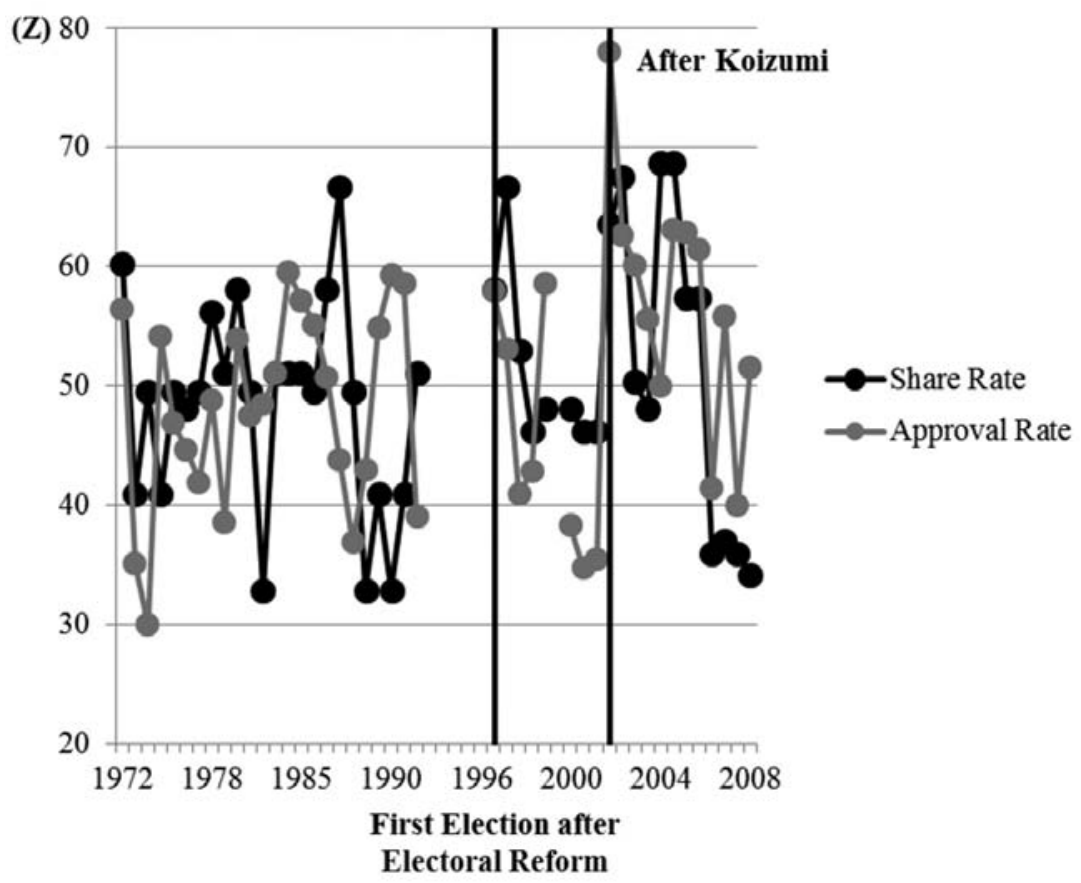

Fig. 3.7. Cabinet shares and cabinet approval rates

\section{Results}

Figure 3.7 shows the transition of the president's overrepresentation rates and the cabinet approval rates in the month when a cabinet is formed. The overrepresentation rate is measured by subtracting the seat share of the president's faction from its cabinet share. Both variables are standardized in figure 3.7. We can confirm the rough correspondence between both variables under MMM, but the relationship is unclear under SNTV. For example, in the first Koizumi cabinet and the first reshuffled first Koizumi cabinet, Koizumi, bolstered by high popularity, formed a bold cabinet that clearly advantaged his Mori faction members. In the second reshuffled first Koizumi cabinet, however, he came to restrain the overrepresentation of his own followers. The change from the first Abe cabinet to the reshuffled first Abe cabinet is a similar case..$^{33}$

We test the revised second hypothesis statistically using OLS estimation. ${ }^{34}$ We estimate the effect of the cabinet approval rate on the cabinet 
share of the president's faction controlling its seat share. ${ }^{35}$ The results are shown in table 3.4. The results demonstrate that the prime minister with the high (low) cabinet approval rate allocates a large (small) number of ministerial positions to its own faction members under MMM, but this mechanism is not statistically significant under SNTV. Moreover, the seat share of the president's faction has a weaker relation with its cabinet share under MMM than under SNTV. In general, the electoral reform has shifted the resource of the president's power from his power base within the party to his popularity among the nation. The findings in figure 3.7 are also examined statistically.

In addition, we also investigate the causes of the faction disproportionality for ministers statistically using OLS estimation. ${ }^{36}$ The results in the analysis are displayed in table 3.5. The results demonstrate that the prime minister with a large number of factions and high popularity is likely to deviate from the faction proportionality system under MMM but not under SNTV.

TABLE 3.4. OLS Estimates Predicting Cabinet Share

\begin{tabular}{|c|c|c|c|c|c|c|c|c|}
\hline \multicolumn{9}{|c|}{ Dependent Variable $=$ Disproportionality for Minister $_{t}$} \\
\hline & \multicolumn{4}{|c|}{ 1972-1993 (SNTV) } & \multicolumn{4}{|c|}{ 1996-2009 (MMM) } \\
\hline & Coef. & Robust s.e. & $t$-value & & Coef. & Robust s.e. & $t$-value & \\
\hline (CONSTANT) & -13.734 & 26.767 & -0.51 & & 38.315 & 13.141 & 2.92 & * \\
\hline LDP's Size & 0.065 & 0.280 & 0.23 & & -0.400 & 0.243 & -1.64 & \\
\hline Number of Factions & 1.683 & 2.357 & 0.71 & & -2.633 & 2.286 & -1.15 & \\
\hline Seat Share ${ }_{(\%) t}$ & 0.891 & 0.200 & 4.46 & $* * *$ & 0.449 & 0.226 & 1.99 & $\dagger$ \\
\hline $\begin{array}{l}\text { Approval Rates } \\
\text { Electoral Reform }\end{array}$ & 0.056 & 0.105 & 0.53 & & 0.300 & 0.057 & 5.22 & $* * *$ \\
\hline Adj- $R^{2}$ & & 0.340 & & & & 0.490 & & \\
\hline \multirow[t]{3}{*}{$N$-obs } & & 24 & & & & 20 & & \\
\hline & \multicolumn{4}{|c|}{ 1972-2009 (SNTV-MMM) } & & & & \\
\hline & Coef. & Robust s.e. & $t$-value & & & & & \\
\hline (CONSTANT) & 22.582 & 11.529 & 1.96 & $\dagger$ & & & & \\
\hline LDP's Size $_{(\%) t}$ & -0.312 & 0.186 & -1.67 & & & & & \\
\hline Number of Factions & -1.324 & 1.419 & -0.93 & & & & & \\
\hline Seat Share ${ }_{\%) t}{ }^{t}$ & 0.755 & 0.172 & 4.39 & $* * *$ & & & & \\
\hline Approval Rates $_{(\%) \mathrm{t}}$ & 0.179 & 0.057 & 3.12 & $* *$ & & & & \\
\hline Electoral Reform & 1.567 & 1.844 & 0.85 & & & & & \\
\hline $\operatorname{Adj}-R^{2}$ & & 0.358 & & & & & & \\
\hline$N$-obs & & 44 & & & & & & \\
\hline
\end{tabular}

${ }^{* * *} p<0.001,{ }^{* *} p<0.01,{ }^{*} p<0.05, \dagger p<0.1$ 
To summarize, the faction proportionality system has not been maintained under MMM. The president's discretion for the allocation of cabinet posts has clearly strengthened, especially after Koizumi. The personnel power of the president under MMM, however, depends on his national popularity at that time.

Ultimately, this effect stems from Japan's constitutional system. Although the importance of factions has declined under MMM, they are still latent actors. This is because prime ministers always have to control a majority in the Diet and factions can extract some resources from unpopular prime ministers by threatening to hold a vote of no confidence or to leave the party outright.

\section{Conclusion}

In this paper, we examined the transformation of LDP factions under SNTV and MMM. Under MMM, in which interparty competition is the focus, the presence of factions declines because factions are primarily ori-

TABLE 3.5. OLS Estimates Predicting Disproportionality

Dependent Variable $=$ Cabinet Share of the President's Faction $n_{t}$

\begin{tabular}{|c|c|c|c|c|c|c|c|}
\hline & \multicolumn{3}{|c|}{ 1972-1993 (SNTV) } & \multicolumn{4}{|c|}{ 1996-2009 (MMM) } \\
\hline & Coef. & Robust s.e. ${ }^{(1)}$ & $t$-value & Coef. & Robust s.e. & $t$-value & \\
\hline (CONSTANT) & -52.055 & 50.639 & -1.03 & -86.273 & 21.759 & -3.96 & ** \\
\hline LDP’s Size $_{(\%) t}$ & 0.618 & 0.523 & 1.18 & 0.576 & 0.491 & 1.17 & \\
\hline Number of Factions $_{t}$ & 8.147 & 4.771 & 1.71 & 11.714 & 2.657 & 4.41 & $* * *$ \\
\hline $\begin{array}{l}\text { Approval Rates } \\
\text { Electoral Reform }\end{array}$ & -0.162 & 0.192 & -0.85 & 0.398 & 0.165 & 2.41 & * \\
\hline $\operatorname{Adj}-R^{2}$ & \multicolumn{3}{|c|}{0.054} & \multicolumn{4}{|c|}{0.485} \\
\hline$N$-obs & \multicolumn{3}{|c|}{24} & \multicolumn{4}{|c|}{20} \\
\hline
\end{tabular}

\begin{tabular}{|c|c|c|c|}
\hline & \multicolumn{3}{|c|}{ 1972-2009 (SNTV-MMM) } \\
\hline & Coef. & Robust s.e. & $t$-value \\
\hline (CONSTANT) & -87.013 & 19.683 & $-4.420 * * *$ \\
\hline LDP's Size & 0.684 & 0.348 & $1.960 \dagger$ \\
\hline Number of Factions & 11.419 & 2.029 & $5.630^{* * *}$ \\
\hline Approval Rates $_{(\%) t}$ & 0.198 & 0.137 & 1.450 \\
\hline Electoral Reform & 4.693 & 3.344 & 1.400 \\
\hline Adj- $R^{2}$ & \multicolumn{3}{|c|}{$\begin{array}{l}0.451 \\
44\end{array}$} \\
\hline$N$-obs & \multicolumn{3}{|c|}{44} \\
\hline
\end{tabular}

${ }^{* * *} p<0.001,{ }^{* *} p<0.01,{ }^{*} p<0.05, \dagger p<0.1,(1)$ Newey-West standard errors with one lag. 
ented toward intraparty competition. The diminution of their electoral importance also weakens their voice in personnel management. Moreover, the decay of factions leads to the relative ascendancy of the president. Indeed, we confirmed that two of a faction's main functions-recruiting new members and allocating cabinet posts-have not only declined but also been centralized to the president (or the president's faction) after the electoral reform in 1994.

Under MMM, by controlling the party endorsement policy and the election strategy headquarters, the president has succeeded in recruiting freshmen members and expanding their power within the LDP. The fall of the electoral presence of factions also has indirectly caused the weakening of factions' influence on personnel management. Although once the LDP had adopted the rigid faction proportionality system, the system has broken down following the electoral reform, especially after Koizumi.

While the president's discretion over personnel management has increased, he cannot always form cabinets at will. Under MMM, there is a close relationship between the overrepresentation of the president's faction in the cabinet and the national popularity of the president. This can be understood in terms of the interaction between MMM and Japan's parliamentary system. Under a parliamentary system, the prime minister always has to control a majority in the Diet. On the other hand, under MMM, elections focus on interparty competition, so the popularity of the party president becomes directly connected with the fate of the party. While a prime minister who enjoys high popularity enjoys considerable discretion and can largely ignore factions, factions can draw concessions from less popular prime ministers by threatening a vote of no confidence or separation from the party. MMM has significantly reduced the importance of factions, but they continue to exist because they remain latent actors, especially for personnel management, under the parliamentary system. 
- STT-OHT:

Sato-Tanaka-Takeshita-Obuchi-Hashimoto-Tsushima

- KFA-MMM:

Kishi-Fukuda-Abe-Mitsuzuka-Mori-Machimura

- IMOM-KHK:

Ikeda-Maeo-Ohira-Miyazawa-Kato-Horiuchi-Koga

- KA:

Kono-Aso

- OT:

(Kato-)Ozato-Tanigaki

- KNW-KI:

Kono-Nakasone-Watanabe-(Eto-Kamei)-Kamei-Ibuki

$\mathbf{Y}$ :

Yamasaki

- MK-K:

Miki-Komoto-Komura

- $\mathbf{N}:-[$ Predecessor: New Conservative Party]

Nikai

- Five Major Factions

- Emerging Factions 
NOTES

1. Prior to the 2000 election, there were $200 \mathrm{PR}$ seats.

2. See Reed and Thies (2001a) on the history of the electoral reform in 1994.

3. This term simply indicates "factions which had supported the winning candidate in the most recent party presidential contest" (Cox and Rosenbluth 1996, 263).

4. More strictly, Sato and Matsuzaki (1986, 63-66) distinguish three types of LDP personnel systems: (1) faction power proportionality method, (2) factional representation method, and (3) all members participation method. Krauss and Pekkanen (2010, 113-14) explain the three systems in English (the English equivalents also follow them). According to Sato and Matsuzaki, for example, the first method is applied to ministers, the second method to deputy secretary-generals, and the third method to parliamentary vice-ministers.

5. Including local chapters of parties and political fund organization (seiji shikin dantai), of which each party can establish only one.

6. The secretary-general (kanji-cho) is the second highest party post in the LDP. It administers (1) the raising and distribution of party funds, (2) the allocation of party posts and advising the president on the allocation cabinet posts, and (3) decisions on election strategies on the whole (Ohtake 2003, 66).

7. The financial distribution within factions, however, has not completely disappeared after the electoral reform. For example, the Yomiuri Shimbun reported that the Obuchi faction and Eto-Kamei faction distributed three million yen per capita to their members for immediate use in campaigning before the 2000 election (Yomiuri Shimbun, May 6, 2000, 4; cited in Asano [2006, 43]).

8 . Our research on faction recruitment, however, was greatly influenced by Asano's (2006) pioneer work on the changes in the LDP endorsement process following the electoral reform.

9. In reality, four large factions and one small faction shared candidates of each district depending on their size, because only about a third of all districts under SNTV were maximum (five) member districts (Kohno 1992, 390).

10. Five cabinets from the Hosokawa to the 1st Hashimoto in 1993-6, however, are excluded from our analysis, because four cabinets were not dominated by the LDP and one cabinet was the special case of the LDP regime during the party realignment period. The first Mori cabinet (2000) is also excluded, because this cabinet is the provisional cabinet that took over all ministers and parliamentary vice-ministers from the reshuffled Obuchi cabinet (the so-called inuki naikaku).

11. Kokkai Binran (The Diet handbook) gives information about the factional affiliation of all LDP members of the Diet.

12. We secondarily referred to Hata's work (Hata 2001).

13. There are five major factions in the LDP. They come from the factions of five leaders: Eisaku Sato, Nobusuke Kishi, Hayato Ikeda, Ichiro Kono, and Takeo Miki. All leaders except Kono became the prime minister. See the appendix to this chapter for information on the series of five major factions.

14. It is known that the first and second Ohira cabinets were faced with fierce conflict between mainstream and nonmainstream factions. Ohira's election strategy for the expansion of mainstream factions was strongly criticized by nonmainstream factions (for example, Yomiuri Shimbun, October 4, 1979, 2; October 14, 1979, 2). In 
the 1980 election (Ohira died suddenly just before the poll), the relative advantage of the Ohira faction may have been caused by the sudden dissolution of the Diet in which most factions were not ready to find fresher candidates (for example, Yomiuri Shimbun, June 3, 1980, 3).

15. In the 2009 election, the number of LDP newcomers-elect was only five.

16. Although the president Yoshiro Mori (the Mori faction) contested the 2000 election, we coded the Obuchi faction as the president's faction only in the 2000 election, because the first Mori cabinet (April-July 2000) was substantially the provisional government from the sudden death of Obuchi. Of course, in the same way, we can understand this election as the special case that the former president's faction (which controlled the secretary-general at that time) wielded the power over recruitment against the "provisional" president.

17. The dependent variable is Faction Recruitment (the number of new lower house members of the faction $n_{\mathrm{i}}$ ) just before the $t$ election. There are five independent variables: (1) LDP's Recruitment (the total number of new lower house members in the whole LDP at period t); (2) Factional Size (the number of all lower house

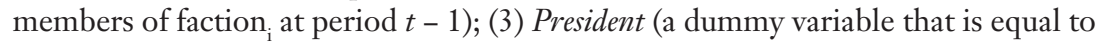

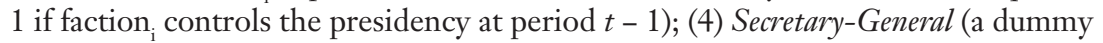

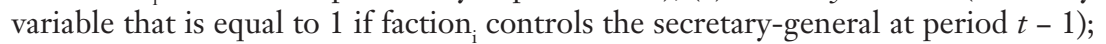
and (5) Electoral Reform (a dummy variable that is equal to 1 if the faction contests the $t-1$ election after 1994).

Our observations are 78 factions (including the same individuals) that existed from period $t-\mathrm{I}$ through period $t$. We tested the three methods: pooled OLS model; fixed effects model; and random effects model, using F test, Breusch-Pagan Lagrangian multiplier test, and Hausman test. The results of the three tests supported a pooled OLS model in all equations. Robust standard errors in table 3.I are adjusted for clustering at the faction level.

18. We have to be careful about the difference between our and Asano's data coding of the 2000 election. As stated above, we coded the factional status in the 2000 election based on the data of the reshuffled Obuchi cabinet, but Asano coded it based on the data of the first Mori cabinet. However, we can basically obtain the same results, even if Asano's data is modified according to our data coding.

19. In the 2005 election the ascendancy of the president's faction waned because Koizumi endorsed a large number of nonfaction candidates as so-called assassin candidates (shikaku koho) (Asano 2006, 88-90). Although our research with this chapter has had to omit this effect, it should be understood as an example of party centralization.

20. The LDP's organization of its election strategy is rather complicated. We focus on three positions controlling the election strategy: the president, secretarygeneral, and director-general of the election bureau (senkyo taisaku kyokucho, or soumu kyokucho).

21. See the appendix for information on the LDP factions' acronyms.

22. The system started with the Shiina decision (Shiina saitei) in 1974, which decided Tanaka's successor (then president Kakuei Tanaka lost his presidency because of a scandal). The party headquarters, including Etsusaburo Shiina, the vice-president of the Tanaka cabinet (1972-74), decided that Takeo Miki be appointed as the next president. At the same time, they also "reached a consensus 
on five points, including the principle that the secretary general, finance committee chairman, and accounting bureau chief would not be selected from among the party president's faction" (Masumi 1995,161).

23. In this chapter, we observe only ministerial positions. Although the allocation pattern of parliamentary vice-minister, senior vice-minister, and vice-minister positions is also an interesting theme, these positions have less importance in elections than ministerial positions. For example, it is known that the LDP applies an "all members participation" method (the position is allocated to all LDP members who achieve two or three reelections) to the parliamentary vice-minister (Sato and Matsuzaki 1986, 63-66). And, here, we do not consider the career pattern and relative importance of each ministerial post (Kobayashi 2012; Ono 2012).

24. We investigated 44 cabinets from the second Tanaka cabinet to the Aso cabinet (except the Hosokawa, Hata, Murayama, reshuffled Murayama, first Hashimoto, and first Mori cabinets). Strictly speaking, the second Tanaka cabinet started on December 22, 1972, so some figures in this section start from "1972."

25 . Both include only faction members in the lower house.

26. The upturn in the reshuffled Miyazawa cabinet (1992) was caused by the secession of the Hata faction from the Takeshita faction. Because the Hata faction failed in gaining positions in the cabinet, it extended the whole of the disproportionality.

27. Indeed, at that time, the opposition parties criticized the faction proportionality personnel of the reshuffled second Mori cabinet (Yomiuri Shimbun. December $6,2000,4)$.

28. Actually, major members of the Kato faction accompanied the Horiuchi faction, so we coded the Horiuchi faction as one of five major factions in this paper.

29. The average of the absolute distances between the cabinet share of the president's faction and its seat share in each cabinet is 3.36\% under SNTV, while that is $6.07 \%$ under MMM.

30. Krauss and Pekkanen (2004) offer a similar view on Koizumi's discretion in forming a cabinet: "Moreover, as Koizumi's popularity waned, his ability to disregard factions in selecting even cabinet members disappeared" (16).

31. Taking a similar view, Ono (2012) offers a sophisticated analysis of the LDP portfolio allocation. He argues that LDP presidents with a weaker power base within the party or lower popularity among the nation had surrendered more cabinet posts to other factions from 1960 to 2007, but he finds that the electoral reform in 1994 had no effect. In contrast, our analysis demonstrates that the close relationship between the cabinet share of the president's faction and the popularity of the president is statistically unique or more remarkable to the MMM era (at least in comparison with the 1970-90s' SNTV era when the LDP intraparty system was stable).

32. The effective number of factions is calculated by Laakso and Taagepera's formula (Laakso and Taagepera 1979).

33. When Koizumi and Abe formed cabinets that treated other factions more fairly, a national newspaper emphasized a stereotype of "party unity" (kyoto taisei) (Yomiuri Shimbun, September 23, 2003, 4; August 29, 2007, 4). This phrase demonstrates one side of the relationship between the prime minister's leadership and his popularity. 
34. The Breusch-Godfrey LM test indicates the absence of first-order serial correlation in each model.

35. The dependent variable is Cabinet Share of the President's Faction (the cabinet share of the president's faction in the lower house). There are five independent variables: (1) LDP's Size (the seat share of the LDP in the lower house); (2) Number of Factions (the effective number of LDP factions in the lower house); (3) Seat Share (the seat share of the president's faction in lower house faction members of the LDP); (4) Approval Rates (the cabinet approval rating in the month when the cabinet is formed); (5) Electoral Reform (a dummy variable that is equal to 1 after 1994).

36. The Breusch-Godfrey LM test indicates the absence of first-order serial correlation in each model, except the model of the STNV era. Therefore, we report the Newey-West standard errors for first-order serial correlation in this model.

The dependent variable is Disproportionality for Minister (the sum of the absolute distances between the cabinet share and its seat share for each faction in the lower house). The independent variables are the same as in table 3.4, except (3).

\section{REFERENCES}

Asano, Masahiko. 2006. Shimin Shakai ni okeru Seido Kaikaku: Senkyo Seido Kaikaku to Kohosha Rikuruto [Institutional reform in civil society: Electoral system and candidate recruitment]. Tokyo: Keio Daigaku Shuppankai.

Baerwald, Hand H. 1986. Party Politics in Fapan. Boston: Allen \& Unwin.

Cox, Gary W., and Frances M. Rosenbluth. 1993. "The Electoral Fortunes of Legislative Factions in Japan." American Political Science Review 87:577-89.

Cox, Gary W., and Frances M. Rosenbluth. 1996. "Factional Competition for the Party Endorsement: The Case of Japan's Liberal Democratic Party." British Fournal of Political Science 26:259-69.

Cox, Gary W., Frances M. Rosenbluth, and Michael F. Thies. 1999. "Electoral Reform and the Fate of Factions: The Case of Japan's Liberal Democratic Party." British Fournal of Political Science 29:33-56.

Cox, Gary W., Frances M. Rosenbluth, and Michael F. Thies. 2000. "Electoral Rules, Career Ambitions, and Party Structure: Comparing Factions in Japan's Upper and Lower Houses." American Fournal of Political Science 44:115-22.

Hata, Ikuhiko, ed. 2001. Nibon Kanryosei Sogo Fiten 1868-2000 [Japanese bureaucracy general encyclopedia 1868-2000]. Tokyo: Tokyo Daigaku Shuppankai.

Ito, Mitsutoshi. 2006. "Kantei Syudogata Seisaku Kettei to Jiminto: Koa Eguzekuteibu no Syukenka" [The LDP and the centralization of the core executive under the Koizumi cabinet]. Revaiasan [Leviathan] 38:7-40.

Jiji Tsushinsha, ed. 1981. Sengo Nibon no Seito to Naikaku: Fiji Seron Chosa ni yoru Bunseki [Political parties and cabinets of postwar Japan: Analysis with Jiji public opinion poll]. Tokyo: Jiji Tsushinsha.

Jiji Tsushinsha, ed. 1992. Nibon no Seito to Naikaku 1981-91: Fiji Seron Chosa ni yoru Bunseki [Political parties and cabinets of Japan 1981-91: Analysis with Jiji public opinion poll]. Tokyo: Jiji Tsushinsha.

Jiji Tsushinsha. 1991-2009. Fiji Seron Chosa Tokuho [Jiji public opinion poll special bulletin]. Various Issues. Tokyo: Jiji Tsushinsha.

Kawato, Sadafumi. 1996. "Shinioritei Ruru to Habatsu: Jiminto ni okeru Jinji Hai- 
bun no Henka" [The seniority rule and factions: The change in post allocation of the LDP]. Revaiasan [Leviathan] special issue: 52-77.

Kobayashi, Yoshiaki. 2012. Malfunctioning Democracy in Japan: Quantitative Analysis in a Civil Society. Lanham, MD: Lexington Books.

Kohno, Masaru. 1992. "Rational Foundations for the Organization of the Liberal Democratic Party in Japan.” World Politics 44:369-97.

Krauss, Ellis S., and Robert Pekkanen. 2004. "Explaining Party Adaptation to Electoral Reform: The Discreet Charm of the LDP." Fournal of Fapanese Studies 30:1-34.

Krauss, Ellis S., and Robert Pekkanen. 2010. The Rise and Fall of Japan's LDP: Political Party Organizations as Historical Institutions. Ithaca: Cornell University Press.

Laakso, Markku, and Rein Taagepera. 1979. "Effective Number of Parties: A Measure with Application to West Europe." Comparative Political Studies 12:3-27.

Masumi, Junnosuke. 1995. Contemporary Politics in Japan. Trans. Lonny E. Carlile. Berkeley: University of California Press.

Mayhew, David R. 1974. Congress: The Electoral Connection. New Haven: Yale University Press.

Nihon Seikei Shimbunsha. 1972-2009. Kokkai Binran [The Diet handbook], 45125. Tokyo.

Ohtake, Hideo. 2003. Nihongata Popyurizumu: Seiji be no Kitai to Genmetsu [Japanese populism: Hopes and disillusionments in politics]. Tokyo: Chuko Shinsho.

Ono, Yoshikuni. 2012. "Portfolio Allocation as Leadership Strategy: Intraparty Bargaining in Japan." American fournal of Political Science 56:553-67.

Park, Cheol Hee. 2001. "Factional Dynamics in Japan's LDP since Political Reform." Asian Survey 41:428-61.

Ramseyer, Mark J., and Frances M. Rosenbluth. 1993. Fapan's Political Marketplace. Cambridge: Harvard University Press.

Reed, Steven R., and Michael F. Thies. 2001a. "The Causes of Electoral Reform in Japan.” In Mixed-Member Electoral Systems: The Best of Both Worlds?, ed. Matthew S. Shugart and Martin P. Wattenberg. Oxford: Oxford University Press.

Reed, Steven R., and Michael F. Thies. 2001b. "The Consequences of Electoral Reform in Japan." In Mixed-Member Electoral Systems: The Best of Both Worlds?, ed. Matthew S. Shugart and Martin P. Wattenberg. Oxford: Oxford University Press.

Richardson, Bradley M., and Scott C. Flanagan. 1984. Politics in Fapan. Boston: Little, Brown.

Sato, Seizaburo, and Tetsuhisa Matsuzaki. 1986. Fiminto Seiken [The LDP regime]. Tokyo: Chuo Koron Sha.

Takenaka, Harukata. 2006. Sbusho Shibai: Nibon Seiji no Henbo [The prime minister ruling: Japanese politics transformed]. Tokyo: Chuko Shinsho.

Thayer, Nathaniel B. 1969. How the Conservatives Rule Fapan. Princeton: Princeton University Press.

Uekami, Takayoshi. 2010. "Senkyo Seido Kaikaku to Jiminto Sosai Sensyutsu Katei no Henyo: Ridashippu wo Umidasu Kozo to Kosei no Sokoku" [Electoral reform and the transformation of LDP presidential elections: Leadership, structure, and personality]. Senkyo Kenkyu [Japanese Journal of Electoral Studies] 26 (1): 26-37. 


\title{
Executive Competition, Electoral Rules, and Faction Systems in Taiwan
}

\author{
Nathan F. Batto and Hsin-ta Huang
}

It is sometimes assumed that politics in Taiwan mirrors politics in Japan. Taiwan is a former Japanese colony, and it inherited much of its present institutional structure from the Japanese who were largely copying their own Meiji-era institutions back home. During the latter half of the 20th century, both countries experienced a long period of single-party dominance, electoral reform from SNTV to MMM, the rise of a longtime opposition party to power, and fast economic growth. Further, the KMT is often assumed to be a mirror of the LDP, and both were longtime ruling parties with strong clientelistic proclivities. Thus it is not unreasonable to expect KMT factions to operate in a similar manner to the LDP factions described by Kobayashi and Tsukiyama in chapter 3 of this volume. However, the KMT's internal factions have not mirrored the LDP's. Instead of national factions, the KMT factions are primarily local. Further, instead of multiple factions, there are usually two KMT factions in each area. Finally, while the LDP factions competed primarily for top party positions and parliamentary seats in SNTV elections, KMT factions are focused primarily on winning control of local governments. Surprisingly, it is the longtime opposition DPP's factions that look much more like the LDP's.

Taiwanese factions have been shaped primarily by executive competition. However, factions have not necessarily organized to capture the national executive. Rather, they have competed over the most desirable 
post that was attainable to them at the time. KMT local factions have always been oriented around control of local governments, and this has led to bifactional systems. DPP factions were initially shaped for winning control of the national party bureaucracy as well as winning seats in the legislature, and multiple factions flourished. Since the presidency became a viable goal, DPP factions have undergone significant upheavals, and most of them have been related to competition over the presidency.

Electoral reform from SNTV to MMM has had a limited impact on Taiwan's factions. For one thing, KMT local factions maintained bifactionalism in spite of SNTV, not because of it. MMM has done little to upset the preexisting faction systems. For another, the reform covered the national legislature only and did not extend to local assemblies or internal party elections. Just as the presidency is not always the critical executive post around which factions compete, the rules used to elect the national legislature are not necessarily the only pertinent important electoral rules.

In this chapter, we examine the recent evolution of KMT local factions and DPP national factions. For the KMT, we focus extensively on the Taichung County Red and Black factions, which have dominated local politics since the 1950s. For the DPP, we retrace the twists and turns of the factional struggle, as various factions are born, form alliances, fight bitterly, splinter, and disintegrate altogether. The discussion of the KMT is informed by extensive interviews with local politicians in Taichung, ${ }^{1}$ while the section on the DPP relies heavily on newspaper accounts.

\section{KMT Local Factions}

There are multitudes of local factions in Taiwan, and it is consequently extremely difficult to make statements that apply to all of them. However, we can make a few generalizations about the characteristics and goals of almost all local factions. ${ }^{2}$ First, local factions are geographically bounded. They are formed along local administrative boundaries, and their activities are confined within this geographical area. The largest factions operate within the boundaries of a single county, while smaller factions appear in smaller administrative districts, such as townships. Second, most factions grew out of competition among local elites over political posts, such as township mayor, county assembly seats, and especially for the county magistrate. ${ }^{3}$ This competition created two or more local factions that have been defined, in part, by their competition with and opposition to each other. Third, factions are informal structures. However, factional affiliations for 
faction bosses and other prominent politicians are usually widely known. Interviews reveal very little ambiguity among insiders about who belongs to which faction. Fourth, the overriding goal that motivates factions is to secure political, economic, and social interests. This can be done by taking as many political posts as possible and by cooperating with the KMT. Fifth, the factions currently compete for political posts in both the public and quasi-public sectors. The latter includes farmers, fishers, and irrigation associations, which are valuable both for their contacts with large numbers of farmers and fishers and also for the financial clout of their affiliated credit unions. However, the single most important prize is the county magistrate's seat.

\section{The Nature of KMT Factions}

There are two distinct understandings of KMT factions. One set of scholars sees factions as being constructed in a guided, top-down process through patron-client relationships. A second set of scholars understand factions as founded on a set of social relationships. In this view, factions form in a natural, bottom-up process.

The first school sees factions as built on a series of unequal and hierarchical bilateral relationships cultivated from the top down. In a patronclient relationship, a patron provides instrumental benefits to a client of lower status in return for general support or personal services (Scott 1972, 92). The relationship is unequal, with a large pool of potential clients competing for a small pool of potential patrons. In the KMT factions, the KMT sits atop four tiers of hierarchical relationships. The party acts as a patron to the faction core, who act as patrons to electoral cadres, who are patrons to faction followers. In each tier, the patron provides protection and privileges, such as nomination to particular political posts, monopolistic economic interests, or constituency service, to the client in exchange for political loyalty and support in elections (Wang and Huang 2010).

In this view, local factions were deliberately created to satisfy the KMT's need for stable government. Local political elites, who had first come onto the scene during the Japanese era, gained increased prominence at the inception of KMT rule through local elections for posts in local governments or councils. The KMT did not interfere much in local politics during these early years, and the elites began to form horizontal and vertical alliances with other local politicians. As the KMT solidified its rule in Taiwan, it began to cultivate these local elites to ensure long-term stability under the guiding principles of localizing political participation, balanc- 
ing competing forces, and offering economic privileges (M. Chen 1995, $150 ;$ N. Wu 1987, 301-34). The new local factions were thus absorbed into the KMT's political structure, relying on the KMT for their existence and operation. The KMT resided at the top tier of this structure as the sole patron to all local factions. They could compete with each other only for the patronage of the KMT. If they went against the will of the KMT, they could be shoved aside or even be put out of existence.

In this structure, the faction bosses (or core members) were usually local gentry or members of prominent families. They typically held more economic resources and had stronger motives to be politically involved. Both attributes made them desirable targets for the KMT. Faction bosses acting as patrons handled political and economic resources, distributing them to the faction's electoral cadres, their clients. Electoral cadres intermediated between local politicians and their supporters, mobilizing supporters to vote in elections in return for local political and economic resources such as low-level political posts or uncompetitive contracts for small public works projects. Electoral cadres patronized their own followings. These faction followers traded their votes for help in dealing with the government. Moreover, faction followers were generally alienated from politics due to the prevailing authoritarian political environment and did not have strong opinions about which candidate deserved their votes. At election time, they often deferred to a trusted electoral cadre for guidance, and the election cadre, as a savvy and connected observer of local politics, served as an opinion leader.

The second school sees factions as the political manifestation of social relationships (Chao 1997; Kao 2004). These relationships can be based on a variety of relationships, including blood, marriage, language, local proximity, religious, education, occupation, or other ties. These ties are collectively known as "guanxi," which is individualistic, specific, and nonideological (Jacobs 1979, 81). In this relationship of mutual loyalty, there is no master or servant. Rather guanxi relationships reflect interpersonal trust and define the lines of friendships or enmity (Kao 2000, 57). These social networks extend to different parts of the political arena. Chen ChiehHsuan sees three distinct levels arranged in concentric circles. Core faction networks form among those most clearly identified with and participating in local politics. They, however, cannot mobilize followers without a wider network of electoral cadres, who are often motivated by symbolic and economic factors in addition to naked politics. Election cadres, in turn, mobilize votes from a civil network (C. Chen 1997, 33-48). Jacobs also notes the role of guanxi in mobilizing votes. He observes that voters tend to vote for 
candidates who are closest to them. Indeed, guanxi even underlies practices such as vote-buying (Jacobs 1979).

The vision of factions as an expression of social relationships implies limits and challenges to the factions. If a faction grows too large, the relationships that undergird it may be weaker. There is a limit to the number of intense social relationships that any single person can maintain, and a successful faction almost necessarily has to be based in a specific geographic location to ensure sufficient density of these guanxi networks. Moreover, any societal change that shakes guanxi networks is a direct threat to the survival of local factions. For example, economic development, deepening urbanization, the passing of the traditional agricultural lifestyle, and a generational shift from one set of faction bosses to the next all constitute serious challenges to faction structures built on interpersonal relationships (Huang 2010, 232-33; Wang 2004).

\section{Bifactionalism}

All local factions have been confined to a single county. This is partially due to the limitations imposed by social networks. In addition, the KMT did not want any political force to grow large enough to challenge its rule. As the top-tier patron, it could and did cut off the lifeline of patronage benefits flowing to any politician who tried to expand his network across county lines. Moreover, there was little incentive for faction politicians to try to construct wider networks. During the authoritarian era, the highest level positions open to elections were all elected at the county level. There were no elections for provincial governor, much less president, so no politician ever had a need to appeal to the national electorate. Some local politicians were recruited into the central government, but these promotions were always based on the politician's personal performance and never on his factional identity. Once a faction politician was promoted into the central government, he was expected to leave his factional priorities behind and work for the KMT regime. Central-local faction linkages were not allowed during the authoritarian era.

If the KMT was careful to limit factions' power by limiting their geographic scope, it also limited their power by preventing them from monopolizing power within that area. In almost all counties, the KMT cultivated a bifactional system and ensured the stability of this system with a rotation of power policy. After one faction had held a particular post for two terms, the KMT nominated a politician from the other faction. Moreover, different posts were distributed among the two factions. The key position is 
the county magistrate, which controls far more resources than the other positions. In Taiwan's centralized political system, the county assemblies have very little legislative power. Assemblies can supervise the county budget, but they cannot demand increases in spending. Assembly members have access to a small pool of resources through each county's Small Public Works Projects Coordinated Fund, but all expenditures from this fund require the assent of the county magistrate. ${ }^{4}$ Overall, the county magistrate had more resources at hand and more leeway in distributing them than any other local officeholder. As a result, factions wanted first and foremost to win control of the county government. The KMT was always careful to make sure that neither faction could hold this post for more than two four-year terms. The bifactional system with rotation of power benefitted the factions by preventing the rise of new factions, giving them periodic access to the county magistrate, and ensuring a steady, if smaller, stream of resources even when they were out of power. It benefitted the KMT because the factions checked each other's power and no single faction could stay in power long enough to achieve absolute local dominance (Jen 2006).

Taichung County is a nice example of this bifactional system. Prior to its incorporation into Taichung City in 2010, Taichung County's politics had been dominated by the Red and Black factions since the beginning of the ROC era. ${ }^{5}$ In the 1950 s, the two major competitors for county magistrate, Lin He-nian and Chen Shui-tan, organized the Red and Black factions, respectively, to support their political ambitions. ${ }^{6}$ In some counties, faction systems reorganize when founders fade from active politics. For example, each new county magistrate in Yunlin County tends to build a new faction. In other counties, like Taichung, the old factions are durable enough to survive a leadership transition. ${ }^{7}$

In table 4.1, we can see that neither the Red faction nor the Black faction ever held the county magistrate for more than two terms. The faction out of power usually held the speaker's chair. In fact, the KMT tried to give the faction out of power the speaker's seat regardless of whether or not that faction had more assembly members than the other faction. During the authoritarian era, the KMT's dominant position made it unwise for factions to challenge the system. The most notable failure came in 1997, after democratization had weakened the KMT's absolute control. The Black faction magistrate had somewhat neglected grassroots operations during his two terms in the 1980s. The Red faction further starved Black faction politicians while they held power over the next two terms. By 1997, the Black faction had been significantly weakened, and the Red Faction did not want to yield power. Both factions ran a candidate for the county magis- 
trate and threw the race to the DPP. Chastened by four years out of power, the two factions cooperated in 2001 to elect a Black Faction politician.

Interestingly, the bifactional system was challenged during this period by a third contender, the Yang faction. The Yang faction was led by business tycoon Yang Tien-sheng, who had risen as part of the Red faction. However, Yang was always on the periphery of the Red faction, and in the early 1990s he and his allies (who came from both major factions) began to call themselves the Third Force. The Yang faction reached its high point in 1994 when his son was elected vice-speaker of the Provincial Assembly. However, in 1998 the Provincial Assembly was abolished, and Yang's son moved over to the legislature where he was just one of 225 members. Moreover, in making this move, he displaced the Yang faction's other major source of power, a two-term incumbent who had to yield his seat. The Yang faction lost this seat in 2004, and it subsequently faded away as a political force. When the Black faction waned in strength in the 1990s, the KMT stepped in to nominate a Black faction member for county magistrate in 1997 and 2001 and thus ensure the continuing viability of the faction. In contrast, the KMT did nothing to help the Yang faction survive. ${ }^{8}$

TABLE 4.1. Rotation of Power between Factions in Taichung County

\begin{tabular}{|c|c|c|c|c|c|c|c|}
\hline \multicolumn{4}{|c|}{ Taichung County Magistrate } & \multicolumn{4}{|c|}{ Taichung County Council } \\
\hline Year & Magistrate & Party & Faction & Year & Speaker & Party & Faction \\
\hline 1951 & Lin He-nian & KMT & Red & 1951 & Li Chen-chung & KMT & Red \\
\hline 1954 & Chen Shui-tan & KMT & Black & 1953 & Li Chen-chung & KMT & Red \\
\hline 1956 & Liao Wu-hu & KMT & Black & 1955 & Chiu Hsiu-sung & KMT & Black \\
\hline 1957 & Lin He-nian & KMT & Red & 1957 & Wang Ti & KMT & Red \\
\hline 1960 & Ho Chin-sheng & KMT & Black & 1961 & Wang Tzu-kuei & KMT & Black \\
\hline 1964 & Lin He-nian & KMT & Red & 1964 & Wang Tzu-kuei & KMT & Black \\
\hline 1968 & Wang Tzu-kuei & KMT & Black & 1968 & Tsai Chiang-yin & KMT & Red \\
\hline 1972 & Chen Meng-ling ${ }^{\mathrm{a}}$ & KMT & Red & 1973 & Hsieh Yu-ho & KMT & Black \\
\hline 1978 & Chen Meng-ling ${ }^{\mathrm{a}}$ & KMT & Red & 1978 & Hsieh Yu-ho & KMT & Black \\
\hline 1981 & Chen Keng-chin & KMT & Black & 1982 & Huang Cheng-yi & KMT & Red \\
\hline 1985 & Chen Keng-chin & KMT & Black & 1986 & Huang Cheng-yi & KMT & Red \\
\hline 1989 & Liao Liao-yi & KMT & Red & 1990 & Lin Min-lin & KMT & Red \\
\hline 1993 & Liao Liao-yi & KMT & Red & 1994 & Lin Min-lin & KMT & Red \\
\hline 1997 & Liao Yung-lai & $\mathrm{DPP}$ & New Tide & 1998 & Yen Chin-piao & IND & Black \\
\hline 2001 & Huang Chung-sheng & KMT & Black & 2002 & Chang Ching-tang & KMT & Red \\
\hline 2005 & Huang Chung-sheng & KMT & Black & 2005 & Chang Ching-tang & KMT & Red \\
\hline 2010 & Jason C. $\mathrm{Hu}^{\mathrm{b}}$ & KMT & none & 2010 & Chang Ching-tang & KMT & Red \\
\hline
\end{tabular}

${ }^{a}$ Chen Meng-Ling was nominated in the first stage of the KMT's faction replacement policy (Chen 1995, 185). But after he was elected, he cooperated closely with the Red faction. We here mark him as Red faction.

bJason C. Hu had been the mayor of Taichung City from 2001 to 2010 prior to the merger of Taichung County and City in 2010. 
The faction never was able to secure the resources of a township government or farmers association, much less the county government. Even with the financial backing of Yang's corporation, it simply could not maintain a viable third faction with the resources from one legislative seat. The Yang faction example is a vivid illustration of just how high the barriers to entry were in the bifactional system.

\section{SNTV Elections and Faction Competition}

A variety of assemblies have elected seats under SNTV rules in Taiwan, including the Legislative Yuan, National Assembly, Provincial Assembly, county assemblies, and township councils. Factions competed for all of these posts, though in the democratic era the legislative and county assembly seats have been the most important positions. These offices are critical to a faction's ability to commandeer resources from various levels of government and provide constituency service to supporters, especially for the faction out of power. Factions also use these elections to maintain their mobilization machinery. However, the SNTV elections are not as crucial as those for the county magistrate.

With multiple seats available, the KMT could choose from several different nomination strategies depending on the strength of the local factions and the strength of other parties. In districts where the factions were strong and the KMT's grip was firm, the KMT might nominate a full slate of candidates, one for each seat available. The nominations would be apportioned to each faction according to their relative strength. In other districts, the KMT might leave one or two seats open for friendly independents who often were faction members. In those districts in which the opposition parties had more support than the KMT, the KMT might nominate candidates for only half the seats and then also support friendly independents (C. Wu 2002, 89). This strategy aimed at "sandwiching" the anti-KMT politicians, with various candidates each taking a bite out of the anti-KMT candidates' support. In some contests in which the factions could not internally determine who should receive a nomination, the KMT would open the race up so that the contestants could have a free fight. However, these free fights were generally carried out when the faction could be sure that one of the two would win; factions were wary of allowing free fights that might harm the faction's overall interests. Overall, the KMT frequently nominated multiple candidates from the same faction in a particular district. To put it another way, the county magistrate elections shape the bifactional system; the two factions then nominate the 
best they can in SNTV elections. This is quite unlike the Japanese LDP's factional system, which has taken shape according to the logic of SNTV competition and the need to control a majority in the national legislature in order to form a government. ${ }^{9}$

The two factions in Taichung County usually nominated multiple candidates in county assembly elections. Table 4.2a shows nominees and seats won for each faction in 2005 and 2010. If we look only at the eight districts with two or more seats, the Black faction ran multiple candidates in nine of the sixteen races while the Red faction was represented by multiple candidates in all sixteen races. In fact, it was not unusual for a faction to have three or four candidates in a single race. Table $4.2 \mathrm{~b}$ shows the party affiliations of the candidates in 2005. From this table, we can see that the factions are affiliated with but also a bit separated from the KMT. All 29 of the KMT winners in 2005 belonged to one of the factions. However, there were also 10 other faction members who ran and won as independents. Table $4.2 \mathrm{c}$ shows that the same pattern appears in 2010. Ten of the $13 \mathrm{KMT}$ winners were faction members, and nine of the 19 winning faction members ran as independents in 2010. Some of these ran with the tacit approval of the KMT, but others were not nominated and ran on their own. During the democratic era, faction members have become increasingly likely to defy party orders. One specific manifestation of this is that the KMT has a harder and harder time controlling the number of candidates competing for the Pan-Blue pool of voters. The local KMT is still dominated by the factions and the factions are still associated with the KMT, but the KMT can no longer demand absolute obedience to party discipline.

Table 4.3 shows the relevant data for legislative elections. Taichung County was a single election district, electing 11 seats in the three SNTV elections in 1998, 2001, and 2004. In these, we also find that each faction regularly nominated multiple candidates and won multiple seats. The Red faction ran four candidates in each of the three elections, while the Black faction had five, six, and three. Seventeen of the 26 candidates from the two big factions were KMT members, but four were independents, two ran (unsuccessfully) under the banner of the People First Party, and one Black faction member even went over to the Green camp, running (and losing) twice under the Taiwan Solidarity Union label.

If the number of candidates indicates that factions were not organized to nominate optimally for SNTV elections, there is also another way in which the Taichung experience demonstrates the primacy of competition over the local executive seat. The Red faction has arguably been Taiwan's most successful faction in terms of producing speakers. A Red faction mem- 


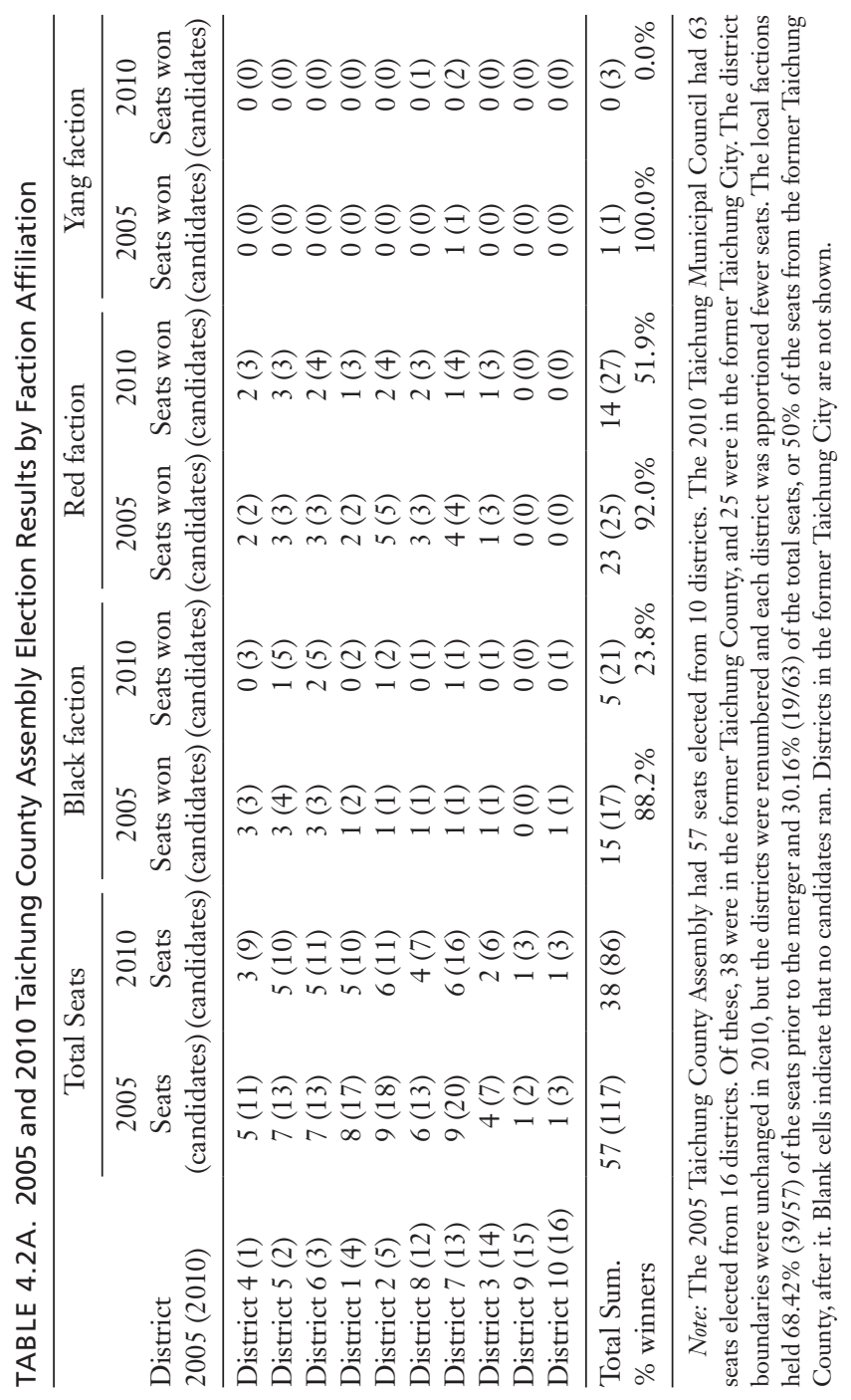


ber, Tsai Hung-wen, was speaker of the Provincial Assembly from 1972 to 1981 , when that position was commonly considered the highest position open to elected politicians. His protégé, Liu Sung-pan, was speaker of the Legislative Yuan from 1992 to 1999, by which time the legislature had surpassed the Provincial Assembly in importance. With such prominent figures, if any local faction were to reorganize itself to support a leader running in SNTV elections, it arguably should have been the Red faction. However, even Tsai and Liu had to contend with other Red faction nominees. ${ }^{10}$ Tsai and Liu had tremendous national prestige, but the Red faction county magistrates of the 1970s and 1990s, with their control of the local treasury, were arguably the real faction leaders.

\section{The Effect of Electoral and Administrative Reform}

In 2008, the MMM system was used for the first time in legislative elections. This proved to have very little effect on the KMT's local factions. On the one hand, we have already seen that the KMT's factions are organized around county magistrate elections, not legislative elections. Further, only the legislature used the new system. The county assembly and township council elections continued to be elected under SNTV rules. On the other

TABLE 4.2B. 2005 Taichung County Assembly Election Results by Party Affiliation

\begin{tabular}{|c|c|c|c|c|c|c|}
\hline District & $\begin{array}{l}\text { Total seats } \\
\text { (candidates) }\end{array}$ & $\begin{array}{c}\text { KMT } \\
\text { Seats won } \\
\text { (candidates) }\end{array}$ & $\begin{array}{c}\text { DPP } \\
\text { Seats won } \\
\text { (candidates) }\end{array}$ & $\begin{array}{c}\text { PFP } \\
\text { Seats won } \\
\text { (candidates) }\end{array}$ & $\begin{array}{c}\text { TSU } \\
\text { Seats won } \\
\text { (candidates) }\end{array}$ & $\begin{array}{c}\text { All others } \\
\text { Seats won } \\
\text { (candidates) }\end{array}$ \\
\hline District 4 & $5(11)$ & 3(3)R2B1 & $0(2)$ & & & 2(6)B2 \\
\hline District 5 & $7(13)$ & 3(5)R2B1 & $0(2)$ & & $0(1)$ & 4(5)R1B2 \\
\hline District 6 & $7(13)$ & 5(6)R2B3 & $1(2)$ & & & 1(5)R1 \\
\hline District 1 & $8(17)$ & 3(5)R2B1 & $3(3)$ & $1(1)$ & $1(1)$ & $0(7)$ \\
\hline District 2 & $9(18)$ & 5(8)R4B1 & $3(4)$ & $0(1)$ & $0(1)$ & 1(4)R1 \\
\hline District 8 & 6(13) & 3(4)R2B1 & 2(3) & $0(1)$ & $0(1)$ & 1(4)R1 \\
\hline District 7 & $9(20)$ & 5(6)R4Y1 & 2(4) & $1(1)$ & $0(1)$ & 1(8)B1 \\
\hline District 3 & $4(7)$ & 2(4)R1B1 & $1(1)$ & $0(1)$ & & $1(1)$ \\
\hline District 9 & $1(2)$ & $0(1)$ & & 1(1) & & \\
\hline District 10 & $1(3)$ & & & & & 1(3)B1 \\
\hline \multirow[t]{2}{*}{ Total } & $57(117)$ & $29(42)$ & $12(21)$ & $3(6)$ & $1(5)$ & $12(43)$ \\
\hline & & R19B9Y1 & & & & R4B6 \\
\hline$\%$ winners & & $69.0 \%$ & $57.1 \%$ & $50.0 \%$ & $20.0 \%$ & $27.9 \%$ \\
\hline Seats share & & $50.9 \%$ & $21.0 \%$ & $5.3 \%$ & $1.8 \%$ & $21.0 \%$ \\
\hline
\end{tabular}

Notes: abbreviations = B: Black faction; R: Red faction; Y: former Yang faction. The table should be read as follows: in District 4, "3(3)R2B1" means the KMT nominated 4 candidates and won 3 seats; of the 3 winners, 2 belong to the Red faction and 1 belongs to the Black faction. " $0(2)$ " means the DPP nominated 2 candidates and won no seats. "2(6)B2" means 6 candidates ran with no party affiliation, and 2 of them won. More important, the winners both belong to the Black faction. Blank cells indicate that no candidates ran. 
hand, the single-seat districts available to the local factions under MMM should push toward bifactionalism. ${ }^{11}$ Since the KMT already had a bifactional system in most counties, it would be strange to expect the new electoral system to bring about significant change.

Taichung County was apportioned five seats under the new system. Instead of competing for each nomination, the factions decided to continue the collaboration they had practiced since the 2001 county magistrate election. The six faction incumbents divided up the five districts among themselves. The KMT cemented this bargain by giving the sixth incumbent a place on the KMT party list and by agreeing not to nominate a candidate against the Black faction incumbent running as an independent in District 2. The candidates even traded support across district lines by exchanging election cadres (Huang, Wang, and Wang 2009). This strategy was a complete success, as the factions won all five districts. In a certain sense, the new electoral system seemed to strengthen the local factions by placing all of Taichung County's legislative seats in their hands. In 2012, the DPP managed to take two of the five seats, but the blame for these defeats should go primarily to the KMT, not to the factions. In District 1 the Red faction incumbent retired, and the factions were unable to come to a consensus on a new candidate. A local high school principal loosely associated with the Black faction was the only person to register for the

TABLE 4.2C. 2010 Taichung Municipal Council Election Results by Party Affiliation

\begin{tabular}{|c|c|c|c|c|c|c|}
\hline District & $\begin{array}{l}\text { Total Seats } \\
\text { (candidates) }\end{array}$ & $\begin{array}{c}\text { KMT } \\
\text { Seats Won } \\
\text { (candidates) }\end{array}$ & $\begin{array}{c}\text { DPP } \\
\text { Seats Won } \\
\text { (candidates) }\end{array}$ & $\begin{array}{c}\text { PFP } \\
\text { Seats Won } \\
\text { (candidates) }\end{array}$ & $\begin{array}{c}\text { TSU } \\
\text { Seats Won } \\
\text { (candidates) }\end{array}$ & $\begin{array}{c}\text { All others } \\
\text { Seats Won } \\
\text { (candidates) }\end{array}$ \\
\hline District 1 & $3(9)$ & 1(2)R1 & 1(1) & & & 1(6)R1 \\
\hline District 2 & $5(10)$ & 1(2)B1 & $1(2)$ & & & 3(6)R3 \\
\hline District 3 & $5(11)$ & 3(3)R1B2 & $1(2)$ & & & 1(6)R1 \\
\hline District 4 & $5(10)$ & 1(4)R1 & 2(3) & & $1(1)$ & $1(2)$ \\
\hline District 5 & $6(11)$ & 3(4)R2 & 2(3) & & & 1(4)B1 \\
\hline District 12 & $4(7)$ & 1(3)R1 & $2(2)$ & & & 1(2)R1 \\
\hline District 13 & $6(16)$ & $0(4)$ & $3(3)$ & 1(1) & & 2(8)R1B1 \\
\hline District 14 & $2(6)$ & 1(2)R1 & 1(1) & & & $0(3)$ \\
\hline District 15 & 1(3) & $1(3)$ & & & & \\
\hline District 16 & $1(3)$ & $1(3)$ & & & & \\
\hline Total & $38(86)$ & $\begin{array}{l}\text { 13(30) } \\
\text { R7B3 }\end{array}$ & $13(17)$ & 1(1) & 1(1) & $\begin{array}{l}10(37) \\
\text { R7B2 }\end{array}$ \\
\hline$\%$ winners & & $36.4 \%$ & $76.5 \%$ & $100.0 \%$ & $100.0 \%$ & $27.0 \%$ \\
\hline Seats share & & $34.2 \%$ & $34.2 \%$ & $2.6 \%$ & $2.6 \%$ & $26.3 \%$ \\
\hline
\end{tabular}

Note: For instructions on how to read this table, please refer to the note in table $4.2 \mathrm{~b}$.

In the full Taichung Municipal Council (including the former Taichung City), the KMT won 27 seats, the PFP won 1 seat, the DPP won 24 seats, the TSU won 1 seat, and independents won 10 seats. 
KMT's nomination. The factions did not take him seriously and continued to negotiate, but to everyone's surprise the principal managed to pass the threshold of approval in the KMT's noncompetitive telephone surveys ${ }^{12}$ and was duly nominated. The DPP thrashed this very weak nominee. In District 7 (formerly District 3), the 2008 winner was convicted of vote buying and stripped of his seat. The DPP then won the seat in a by-election. In 2012, the KMT chose to parachute in a candidate from Taipei with no local connections. She was beaten soundly by a DPP candidate with deep local roots. In the other three districts, however, the factions proved their continuing strength.

Overall, factions have adapted to the new legislative electoral system

TABLE 4.3. Taichung County Legislative Election Results, 1998-2012

\begin{tabular}{|c|c|c|c|c|c|}
\hline $\begin{array}{l}\text { Year } \\
\text { (Blue : Green) }\end{array}$ & KMT & DPP & New & TSU & Others \\
\hline \multicolumn{6}{|l|}{$1998(9: 2)$} \\
\hline Nominees & $8(\mathrm{R} 3, \mathrm{~B} 4, \mathrm{Y} 1)$ & 4(N1,ND1,nf2) & 1 & & $\mathrm{R} 1$ \\
\hline Seats won & $7(\mathrm{R} 3, \mathrm{~B} 3, \mathrm{Y} 1)$ & $2(\mathrm{~N} 1, \mathrm{ND} 1)$ & 1 & & $\mathrm{R} 1$ \\
\hline \multicolumn{6}{|l|}{$2001(7: 4)$} \\
\hline Nominees & $6(\mathrm{R} 3, \mathrm{~B} 2, \mathrm{Y} 1)$ & $5(\mathrm{~N} 3, \mathrm{ND} 1, \mathrm{NE} 1)$ & 1 & 4(R1,B1,nf2)1(B1) & B2 \\
\hline Seats won & $5(\mathrm{R} 3, \mathrm{~B} 1, \mathrm{Y} 1)$ & $5(\mathrm{~N} 3, \mathrm{ND} 1)$ & 0 & $1(\mathrm{nf} 1) \quad 0$ & B1 \\
\hline \multicolumn{6}{|l|}{$2004(7: 4)$} \\
\hline Nominees & $5(\mathrm{R} 4, \mathrm{~B} 1)$ & $6(\mathrm{~N} 3, \mathrm{~W} 1, \mathrm{GFA} 1, \mathrm{nf} 1)$ & & 2(B1,nf1) & B1 \\
\hline Seats won & $5(\mathrm{R} 4, \mathrm{~B} 1)$ & $4(\mathrm{~N} 2, \mathrm{~W} 1, \mathrm{nf} 1)$ & & $1(\mathrm{nf} 1)$ & B1 \\
\hline \multicolumn{6}{|l|}{$2008(5: 0)$} \\
\hline District 1 & $1(\mathrm{R} 1) \bullet$ & $1(\mathrm{~N} 1)$ & & & \\
\hline District 2 & & 0 & & & $1(\mathrm{~B} 1) \bullet$ \\
\hline District 3 & $1(\mathrm{R} 1)$ & $1(\mathrm{~N} 1)$ & & & \\
\hline District 4 & $1(\mathrm{R} 1)$ & 0 & & $1(\mathrm{nf} 1)$ & \\
\hline District 5 & $1(\mathrm{R} 1) \bullet$ & $1(\mathrm{~N} 1)$ & & & \\
\hline \multicolumn{6}{|l|}{$2012(3: 2)$} \\
\hline District 1 & 1(B1) & $1(\mathrm{~N} 1) \bullet$ & & & 1(nf1) \\
\hline District 2 & & $1(\mathrm{nf} 1)$ & & & $1(\mathrm{~B} 1)$ \\
\hline District 7(3) & $1(\mathrm{nf} 1)$ & $1(\mathrm{nf} 1)$ & & $1(\mathrm{nfl})$ & $1(\mathrm{nf} 1)$ \\
\hline District 8(4) & $1(\mathrm{R} 1)$ & $1(\mathrm{~N} 1)$ & & $1(\mathrm{nf})$ & $2(\mathrm{~B} 1, \mathrm{nf} 1)$ \\
\hline District 3(5) & $1(\mathrm{R} 1)$ & $1(\mathrm{nf} 1)$ & & $\mathrm{Na}$ & $1(\mathrm{~F} 1)$ \\
\hline \multicolumn{6}{|c|}{$\begin{array}{l}\text { Notes: abbreviations for KMT factions are B: Black faction; R: Red faction; Y: former Yang faction; abbrevia- } \\
\text { tions for DPP factions are N: New Tide; W: Welfare; ND: New Dynamic; NE: New Era; GFA: Green Friend- } \\
\text { ship Alliance; for Others, nf: no faction affiliation. Blank cells indicate no candidate nominated. } \\
\text { The table should be read as follows: the cell " } 8(\mathrm{R} 3, \mathrm{~B} 4, Y 1) \text { " means the KMT nominated } 8 \text { candidates, includ- } \\
\text { ing } 3 \text { Red faction members, } 4 \text { Black faction members, and } 1 \text { Yang faction member. } \\
\text { Under SNTV, Taichung County was one electoral district and elected } 11 \text { seats. After the shift to MMM in } \\
2008 \text {, Taichung County was divided into } 5 \text { single-seat districts. The mark "•" shows the winning candidate in } \\
\text { MMM elections. The district boundaries were not altered in } 2012 \text {, but they were renumbered. For example } \\
\text { "District } 7(3) \text { " indicates that the } 2012 \text { District } 7 \text { was District } 3 \text { in } 2008 \text {. }\end{array}$} \\
\hline
\end{tabular}


with a minimum of disruption. Administrative reform is a much more serious threat to the KMT's local factions.

In 2010, Taichung City and County were combined to form Taichung Municipality, one of four new direct municipalities. ${ }^{13}$ Direct municipalities differ from counties and county-level cities in a number of ways. Municipality mayors have much larger budgets with much more discretionary spending, and they can appoint many more positions within the municipal government. Counties have elected township mayors and councils. In direct municipalities, townships are converted into administrative districts, and the executives and councils are appointed ${ }^{14}$ and politically irrelevant. From the perspective of local factions, there were far fewer offices available,${ }^{15}$ and, to win the biggest prize, the municipal mayor's seat, they had to compete not only with each other and the opposition party but also with all the politicians and factions from the other city or county.

Since the only useful positions left, other than the five legislative seats, were in the municipal council, the 2010 election was particularly intense. With fewer seats available, many incumbents were unable to secure a nomination from the KMT. Rather than accept the death of their political careers, many faction members ran as independents. The result was a bloodbath. The KMT did terribly, with only 13 of its 30 nominees winning. The Red faction had a miserable performance, as only 14 of its 27 candidates won. The Black faction was devastated; only 5 of its 21 members won. To put this in perspective, in 2005 the two factions had elected 38 of their 42 candidates. The main reason for the electoral disaster of 2010 was that the factions simply had too many candidates running. Another reason is that they now needed to win more votes. Compared to 2005, successful candidates in 2010 needed $70-100 \%$ more votes. Many politicians had built their machines focusing on particular areas or constituencies to fit the old system. Their networks were the right size to deliver the old number of votes, but when factions are built on personal relationships, it is no small task to scale up to a meet the new, higher threshold.

With no township governments and without control of the municipal government, both factions are left without direct control over any local government resources. They are not entirely powerless, of course. Since the mayor came from Taichung City, the KMT helped Taichung County win control of the municipal council. The new speaker is from the Red faction, while the vice-speaker is from the Black faction. Moreover, while the two factions have less than one-third of the total seats, this should be sufficient for them to guide the council's agenda if they cooperate. Within the KMT, the two factions have 10 of 27 seats, but if one looks at the 
broader Blue camp, the two factions combine for 19 of 38 seats. However, it remains to be seen if the factions will try to cooperate with each other, look for allies from the former Taichung City, or simply fade from prominence as they are starved of patronage resources.

\section{KMT Local Factions: Summary}

In the KMT's authoritarian regime, elected politicians were effectively locked out of competition for national power. In a sense, whether the national executive was presidential or parliamentary was irrelevant to KMT local factions. Instead, factions organized around the most desirable post within their grasp, in this case local executive office. As these posts were elected by the plurality rule, competitors had to form preelectoral coalitions, and these formed the basis of two stable factions. The KMT reinforced this structure by actively intervening to ensure that two, and only two, factions remained viable. These factors were sufficient to maintain bifactionalism even when all assembly seats were elected under SNTV rules. The shift to MMM in legislative elections does little to change this calculus. In fact, the factions have collaborated more often than they have competed, yielding seats to one another instead of directly fighting one another for each seat. Looking forward, the factor with the greatest potential to shake up the system is administrative reform, which has deprived the local factions of most of their patronage resources.

\section{DPP National Factions}

In contrast to the KMT's factional structure, the DPP's internal factions are structured more similarly to those of the Japanese LDP. Throughout the democratic era, the DPP has usually had around four major factions, all of them national in scope. Until 2006, the factions were formal organizations, with bylaws, regular meetings, and membership rosters. In 2006, the DPP formally abolished its factions, and the factions have been informally organized since then.

The DPP's factional system arose in the era before the presidency became a reasonable goal. When the presidency did eventually come into play, it placed considerable pressure on the factional system to evolve. Indeed, most of the major upheavals of the past 15 years have been directly related to presidential politics, as factions have allied and reshuffled to try 
to win the presidential nomination and risen or fallen with their leaders' prospects.

\section{Arenas of Competition}

While KMT factions are designed to capture and distribute patronage resources at the county level, the major goal of DPP factions is to help their members gain control of the national party machinery and national elected offices. While the presidency has become a focal point of competition in recent years, factions originally competed in three primary arenas. Even with the increasing focus on the presidency, these three arenas remain important in shaping the DPP factional system. First, they compete for nominations to elected office. Like the KMT's local factions, DPP factions try to win local executive offices. However, since they are national in scope, there is not simply one big prize. DPP factions can win some nominations while losing others without facing an existential crisis. In fact, DPP factions place a higher priority on winning large numbers of legislative seats, and the size of a faction's legislative delegation is the clearest measure of a faction's strength and influence. Factions can help members win nominations and elections by providing financial or human resources, coordinating among aspiring candidates, and mobilizing party member or regular voters in primaries. The DPP's nomination rules have changed considerably over the years (see chapter 5), but factions have always played a central role in deciding nominations.

Second, the factions compete for positions within and control of the party machinery. The most important of these positions are seats in the Central Standing Committee (CSC), the body that makes most of the critical decisions. The CSC is indirectly elected. Party members elect representatives to the National Party Congress, which meets only once a year. The National Party Congress elects 30 of its members to the Central Executive Committee (CEC), and the Central Executive Committee elects 10 of its members to the CSC. ${ }^{16}$ All of these elections are conducted by SNTV. Needless to say, a well-organized group can do quite well in this threestage indirect election. Indeed, factions often house their members in specific hotels for the weekend, with each faction based in a different hotel. This allows the faction leaders to give members voting instructions and, more important, to keep them away from other factions who might seek to poach their votes. Factions try to maximize their power by enrolling party members, directing them how to vote, and using extra votes to support 
allies. No faction has held a majority of seats in the CSC since the earliest years of the party. Instead, the factions form postelectoral coalitions within the CSC. Until 1996, these coalitions elected the party chair. The chair has been directly elected since 1998, and even though this yields some independent stature, party chairs have had to come to an accommodation with a majority in the CSC in order to lead the party effectively.

The third and least important arena of competition is for the three floor leaders of the DPP legislative caucus. The DPP elects new floor leaders for each six-month session, and these elections have generally been contested along factional lines. Again, these elections use SNTV, so it is not necessary to have a majority to win a caucus leader position.

Prior to electoral reform, nominations to the legislature, elections to the CSC, and floor leader elections were all conducted under SNTV. With multiple seats available, multiple factions could survive. After electoral reform, CSC and floor leader elections continue to be held under SNTV. Moreover, the CSC remains an arena in which coalitional, not majoritarian, politics hold sway. In addition, multiple factions can compete for two or three legislative seats each in the party list tier. While the electoral reform has eliminated one of the major institutional foundations of the multifactional system, it has not eliminated all of them.

\section{Characteristics of the Individual DPP Factions}

When the DPP was founded in 1986, it had two major factions: Formosa and New Tide. Formosa members tended to be bound together by personal, rather than ideological, ties, and they tended to be quite pragmatic, interested first and foremost in winning office (Rigger 2001, 72; Cheng and Hsu 1996). With only one exception, all other DPP factions also adopted a similarly pragmatic orientation. DPP factions are not noted for clear positions on specific issues or distinct ideological positions. Factions tend to focus on maximizing power and leave the policy decisions to individual officeholders. Perhaps because the glue holding them together is relatively weak, the factions tend to have loose discipline. Members usually vote with their faction, but often they do not. When they defect, there are few repercussions. Because of this weak discipline, faction leaders have weak bargaining power. The leader may make a promise, but he cannot always commit the full strength of his faction to that promise.

The New Tide faction is the exception. New Tide is highly organized and highly disciplined. It is organized along Leninist lines and considers itself a vanguard organization (Cheng 2004, 149). Members are carefully 
screened before being accepted into the faction, and they participate in regular training and education meetings. During elections, the faction provides campaign staff and funds for its candidates. In the 1980s and 1990s, New Tide was considered to have clear ideological stances favoring Taiwan independence and social welfare, though these distinctions have become murkier over the last decade. New Tide members also take militant positions against corruption. The faction practices democratic centralism, and all members are expected to obey faction decisions. Violators are almost always expelled from the faction. New Tide's discipline allows it to exert much more influence than its numbers imply. Faction leaders are credible negotiators, since counterparts know they can deliver on their promises. Moreover, New Tide can make standing commitments of support not just today on a particular question but also in the future on unspecified questions. This makes New Tide particularly attractive as a coalition partner. However, New Tide's discipline and disproportional influence arouse powerful emotions among other DPP members. Other factions can be jealous of New Tide's power, they grumble about New Tide's voting brigades, and they have at times worried that New Tide's militant political positions might hurt the DPP at the ballot box. No other faction arouses such passions, and New Tide always has to worry about the potential of an "everyone-against-New Tide" coalition.

The Welfare State Alliance and Justice Alliance formed in the early 1990s. With democratization, all the seats in the legislature were up for election, creating space for more than two factions. Justice was centered on Chen Shui-bian and included a few of his political allies. In the early 1990s, Justice was the smallest of the four main factions. Welfare was nominally led by Frank Hsieh, but it was more accurately understood as a coalition of everyone not in Formosa, New Tide, or Justice. Welfare had several prominent leaders, and they were not likely to follow orders from each other. ${ }^{17}$

\section{A Brief History of DPP Factional Politics in the Presidential Election Era}

In this subsection, we present a rough history of DPP factional politics over the past decade and a half. During this period, the DPP's factions underwent substantial changes, and most of these changes can be traced, at least in part, to conflicts over the presidency.

If the 2000 presidential election was the first one that the DPP had a chance of winning, then the first major change to the factional system in the era of competitive presidential politics was the splintering of the For- 
mosa faction. Formosa's leader and presidential aspirant, Hsu Hsin-liang, argued that if the DPP wanted to win power, it should be more open to economic integration with China. This stance put many Formosa members in an uncomfortable position with their supporters (UDN, December 20, 1998). Taking advantage of dissatisfaction with Hsu's leadership, his top lieutenant, Chang Chun-hung, usurped control of the faction. By the July 1998 CEC and CSC elections, the Chang faction and the Hsu faction had effectively split, with each organizing its own vote rationing scheme. Most of the Formosa faction ended up in Chang's new group, New Era. ${ }^{18}$ Hsu's supporters renamed themselves New Dynamic. Already small, New Dynamic was further crippled by a lack of leadership, as Hsu withdrew from the DPP to focus on his unsuccessful presidential bid (UDN, June 7, 1999). New Era and New Dynamic continued to exist until about 2004, but neither was able to exert much influence in the party. With no charismatic leaders and no patronage to offer, both slowly dwindled in size. Around 2004, a small new faction, the Green Friendship Alliance, absorbed most of the remnants of New Era and New Dynamic. However, in terms of influence, the Green Friendship Alliance was merely an echo of the old Formosa faction. The disintegration of Formosa was a direct result of Hsu's unsuccessful pursuit of the presidency.

Chen Shui-bian won the presidency in March 2000, and his faction, Justice, grew quickly (see tables 4.4 and 4.5). In the past, pragmatic politicians who wanted to be on the winning side might have joined Formosa; now they joined Justice. Justice moved quickly to try to put together an even bigger coalition. In April and May, leaders of the Justice, Welfare, New Dynamic, and Taiwan Independence Alliance factions had meetings to discuss cooperation and even merger. On May 20, they announced they would form the Mainstream Coalition, which included around 40 legislators from all factions except New Era and New Tide (UDN, April 19, 2000; UDN, May 5, 2000; UDN, May 13, 2000; UDN, May 20, 2000). This Mainstream Coalition certainly looked like the first step in reorienting the system into a bifactional system, but it was not to be. The Mainstream Coalition never expanded its activities from within the legislative caucus to other arenas, such as competition for nominations or CSC seats. Moreover, many of the members, especially those from Justice, quietly withdrew from Mainstream Coalition activities, and the coalition quickly became a small, marginalized group dominated by Welfare members.

Instead of Welfare, President Chen chose the larger and more reliable New Tide as the main coalition partner for his Justice faction. Chen put several New Tide leaders into important positions in the executive branch. 
TABLE 4.4. Size of Each DPP Faction in the Legislative Yuan

\begin{tabular}{lrrrrrr}
\hline & 1995 & 1998 & 2001 & 2004 & 2008 & 2012 \\
\hline Formosa & 14 & & & & & \\
New Tide & 11 & 15 & 19 & 22 & 4 & 7 \\
Welfare & 13 & 12 & 15 & 12 & & \\
Justice & 11 & 13 & 34 & 20 & & \\
TIA & 4 & 5 & 4 & 1 & & \\
New Era & & 14 & 5 & & & \\
New Dynamic & & 6 & 4 & 5 & 1 & 1 \\
GFA & & & & 5 & 1 & 3 \\
Su & & & & & 5 & 4 \\
Hsieh & & & & & 5 & 3 \\
Chen & 2 & 4 & 6 & 29 & 9 & 19 \\
Yu & & & & & & 1 \\
Grandparents & 55 & 69 & 87 & 89 & 27 & 40 \\
No faction & & & & & & \\
Total DPP delegation & 55 &
\end{tabular}

Note: Factional affiliations for 1995, 1998, and 2001 are taken from Cheng (2004, 563-76). Factional affiliations for 2004, 2008, and 2012 were compiled by the authors from newspaper reports.

TABLE 4.5. Size of Each DPP Faction in the Central Standing Committee

\begin{tabular}{lccccccccc}
\hline & 1994 & 1996 & 1998 & 2000 & 2002 & 2004 & 2006 & 2008 & 2010 \\
\hline Formosa & 4 & 3 & & & & & & & \\
New Tide & 2 & 3 & 2 & 2 & 3 & 2 & 2 & 2 & 3 \\
Welfare & 3 & 3 & 2 & 4 & 3 & 1 & 1 & & \\
Justice & 1 & 2 & 3 & 3 & 2 & 1 & 2 & & \\
TIA & 1 & & & & & & & & \\
New Era & & & 1 & 1 & & & & & \\
New Dynamic & & & 2 & 1 & 2 & & & 1 & 1 \\
GFA & & & & & & 2 & 2 & 1 & 1 \\
Su & & & & & & 1 & 1 & 1 & 1 \\
Hsieh & & & & & & & & 2 & 0 \\
Chen & & & & & & & & 1 & 1 \\
Yu & & & 1 & & & 1 & 1 & 1 & 2 \\
Grandparents & 11 & 11 & 11 & 11 & 10 & 10 & 10 & 10 & 10 \\
No faction/other & & & & & & & & & \\
Total CSC seats & 11 &
\end{tabular}

Note: Factional affiliations for 1994-2002 are taken from Cheng (2004, 214-17). Factional affiliations for 2004-2010 were compiled by the authors from newspaper reports. Only directly elected seats are included; seats automatically awarded to mayors and legislative floor leaders are not included in this table. 
In fact, because Justice members were relatively junior and not yet qualified for such important posts, New Tide was more successful than Chen's own Justice faction at placing its members into the government bureaucracy. The Chen-Justice-New Tide axis dominated the DPP throughout Chen's first term. While Justice had more members, its internal discipline was dismal, and Chen often had to rely on New Tide to get what he wanted.

Chen's choice of coalition partners was likely the most important reason that the DPP maintained a multifactional system. If Chen had supported the Mainstream Coalition and encouraged its various members to merge into one new faction, he likely would have been able to reshape the system into a bifactional Mainstream vs. New Tide system. Instead, he chose to cooperate with New Tide. The very internal cohesiveness that made New Tide such an attractive coalition partner also ensured that it would remain a separate entity outside of Chen's direct control. Moreover, because New Tide retained its independence, it had the capacity to terminate the coalition.

New Tide began to distance itself from Chen in the early months of his second term. As public outrage at Chen's mounting corruption scandals grew, New Tide moved into open attacks on President Chen. By June 2006, Chen had been so severely weakened ${ }^{19}$ that he was forced to announce he would step back from the first line of politics and devolve power to Premier Su Tseng-chang. New Tide continued to apply pressure. When the DPP declined to ask Chen to resign or to recommend sending his case to the government anticorruption agency, two New Tide leaders resigned their seats in the legislature, an action they claimed was designed to shock the DPP into self-reflection (CT, November 14, 2006). By the end of 2006, New Tide was in open revolt against President Chen.

As Chen stumbled toward the end of his tenure, the battle to succeed him as president intensified, and this contest reshaped the DPP's factions. The two leading candidates, Su Tseng-chang and Frank Hsieh, both had roots in the Welfare faction, but Welfare had ceased to be a coherent organization by Chen's second term. Within weeks after Chen's reelection, the media started referring to the Su faction and the Hsieh faction. At first, these were merely a few of Su or Hsieh's closest political allies, and many of them maintained membership in one of the traditional factions. The Su and Hsieh factions would quickly grow into larger groupings, and these factions would contest power in multiple arenas. Unlike the traditional factions, the Hsieh and Su factions were never formal organizations. They might have eventually moved to formalize their networks, but another major shock rocked the DPP's factional ecology. 
In July 2006, the DPP's National Party Congress voted to dissolve all factions. ${ }^{20}$ This was not a new proposal; it had been discussed at several previous party congresses but had never won much support. In 2006, however, conditions were ripe for the motion to pass. Once again, many of the tensions were directly related to presidential politics. The motion was an attack on New Tide, which had grown steadily in size and influence over the past decade. Most people in the party felt that New Tide benefitted most from being organized so it would lose the most if it were forced to disband. Moreover, anti-New Tide passions were running high. New Tide had profited from its alliance with President Chen in his first term and had then turned on him. This could not help but infuriate other people in the party who remained loyal to Chen. The motion may also have gotten a boost from the upcoming presidential race. New Tide had formed an alliance with $\mathrm{Su}$, and Hsieh was beginning to form an anti-New Tide coalition. Because of this, Hsieh's supporters were enthusiastic about the motion not only because it hit directly at New Tide, but also because it indirectly weakened their principal rival for the presidential nomination (CT, July 3, 2006). ${ }^{21}$

Cheng argues that, in addition to injuring New Tide, the DPP may have had two other reasons for dissolving its factions. First, President Chen may have been trying to avoid blame for his own myriad woes by focusing attention on the DPP's factions. Second, electoral reform had just passed, and the DPP may have felt that multiple factions were no longer needed for legislative elections using single-member districts (Cheng 2010). This latter point is especially relevant to our purposes. However, the electoral system did not play a prominent part in the actual public debates over the merits of dissolving the factions. If factions simply were not useful under the new electoral system, they would simply have faded away. Alternatively, the multiple factions might have simply consolidated into two factions. There would have been no need to actively abolish them. In fact, multiple factions were still useful in contests for CEC, CSC, party list, and city and county council seats. Electoral reform is not a convincing explanation for the dissolution.

Factions did not cease to exist simply because the motion passed. ${ }^{22}$ There had been some worries that New Tide might collectively quit the DPP if such a motion passed, but all factions announced that they would comply with the letter of the new rules. Within a short time, it became apparent that the other factions had been the primary victims of the motion. Without formal offices, rules, and meetings, the other factions had very little to hold them together and quickly withered away. New Tide, in 
contrast, was bound together with much stronger glue and continued to operate as a relatively coherent faction. The names of the other factions disappeared almost immediately from media reports following the party congress. In contrast, the media reported regularly on the activities of the "former New Tide" faction. ${ }^{23}$

With the dissolution of all the traditional factions except for New Tide, most DPP members were suddenly free to form new alliances, and they coalesced around the two major presidential contenders and the incumbent president. After the 2006 party congress, the Su and Hsieh factions grew quickly in size and influence. The Su, Hsieh, and Chen factions were not simply a renaming of the old factions. For one thing, while many of the former Justice members now identified as Chen loyalists, several took this opportunity to switch their allegiance to Su or Hsieh. For another, Su and Hsieh had both originally belonged to the Welfare faction, so there were no obvious cues that might help the old faction members switch en masse to one side or the other. Instead, there was a fairly thorough reshuffling of allegiances. Because this reshuffling occurred in the context of a fierce battle for the presidential nomination, the new factions consolidated rather quickly.

By the end of President Chen's second term in 2008, a new faction system had taken shape. In addition to the old New Tide faction, there were three other major factions, the Su, Hsieh, and Chen factions. There were also a few smaller factions organized around somewhat less prominent leaders. These new factions were different from the old factions in that they were not formally organized. They did not have formal rosters, rules, or meetings. Membership was not clearly defined, and a particular individual might have good relations with multiple faction leaders. Moreover, they were much more centered around a single leader than the previous factions had been. Where the old factions had been physically centered in a legislative office and measured by the size of their legislative delegations, the new factions were more focused on presidential contenders than on legislative delegations. However, the new factions continued to organize their members to contest nominations and party offices, just as the old factions had.

The factional system has seen relatively minor changes during Ma Ying-jeou's presidency. A new faction may be starting to form around Tsai Ing-wen. Tsai, who was not affiliated with any faction, served as party chair during Ma's first term and eventually became popular enough to win the 2012 presidential nomination. During Ma's first term, she received support from all the major factions. However, after losing the presidential election and resigning as party chair, she established a think tank and has begun 
cultivating allies in the legislature and the party. If Tsai's influence is rising, former president Chen's is waning. There has been quite a bit of pressure for the DPP to draw a clear line between Chen and itself, and the Chen faction has fought to resist this. Chen's faction had some success in the 2010 city council elections, conducted under SNTV rules, but far less in the 2012 single-seat legislative races. Moreover, in the 2010 CEC and CSC elections, the Chen faction was unable to win any CSC seats. ${ }^{24}$ With Chen's health deteriorating in prison and the battles of Chen's presidency fading from the present, the Chen faction faces a struggle to retain its size and influence within the DPP.

Throughout this discussion, one can see again and again how competition over the presidency has molded the DPP's system of factions. The most important events, including the splintering of Formosa, the formation and dissolution of the alliance between Justice and New Tide, the formal abolition of all factions, and the emergence of the Su and Hsieh factions, were all results of competition to control the presidency or efforts by the president to reshape the factional system.

\section{Number of Faction Nominees per District}

Masaru Kohno argues that the number of LDP factions was heavily influenced by the SNTV electoral system. As a general rule, factions only nominated one candidate per district. Because the LDP nominated multiple candidates in almost all districts, this created space for multiple factions. Ideally, a faction would grow large enough to nominate one candidate in every district nationwide. In practice, they did not grow quite that large, and there were four large factions that nominated in most districts and one smaller faction that nominated candidates only in larger districts (Kohno 1992).

Almost all Japanese districts have between three and five seats, so the LDP factions faced a fairly similar challenge across districts. Taiwan's districts vary much more, ranging from 1 to 17 seats. Moreover, Taiwan's factions have also competed for 30 Central Executive Committee seats, 10 or 11 Central Standing Committee seats, around 15 party list seats, and around 3 Overseas Representatives seats. These very different challenges make it much harder to construct factions of exactly the right size such that a faction can always nominate one and only one candidate.

Even so, DPP factions have exhibited tendencies to avoid multiple nominees. To illustrate this, we first considered all DPP district nominations worth fighting for in SNTV legislative elections from 1995 to 2004 (table 4.6). ${ }^{25}$ The DPP nominated 304 candidates in these districts, of whom 256 
were affiliated with a faction. Of these faction candidates, $176(68.8 \%)$ did not have to run against another nominee from their faction. However, this overall number hides differences across district sizes. As might be expected, multiple nominees from a single faction were much more common when the DPP nominated more candidates. When the DPP only nominated one or two candidates, $95.3 \%$ of the faction nominees did not run against a fellow faction member. When the DPP nominated three or four, this percentage fell to only $74.4 \%$. In districts with five or more DPP nominees, half had to face at least one other nominee from their faction. There were also significant differences among the various factions. Multiple nominations were almost exclusively the province of the three biggest factions. Among

TABLE 4.6. Number of DPP Faction Nominees in SNTV Legislative Elections

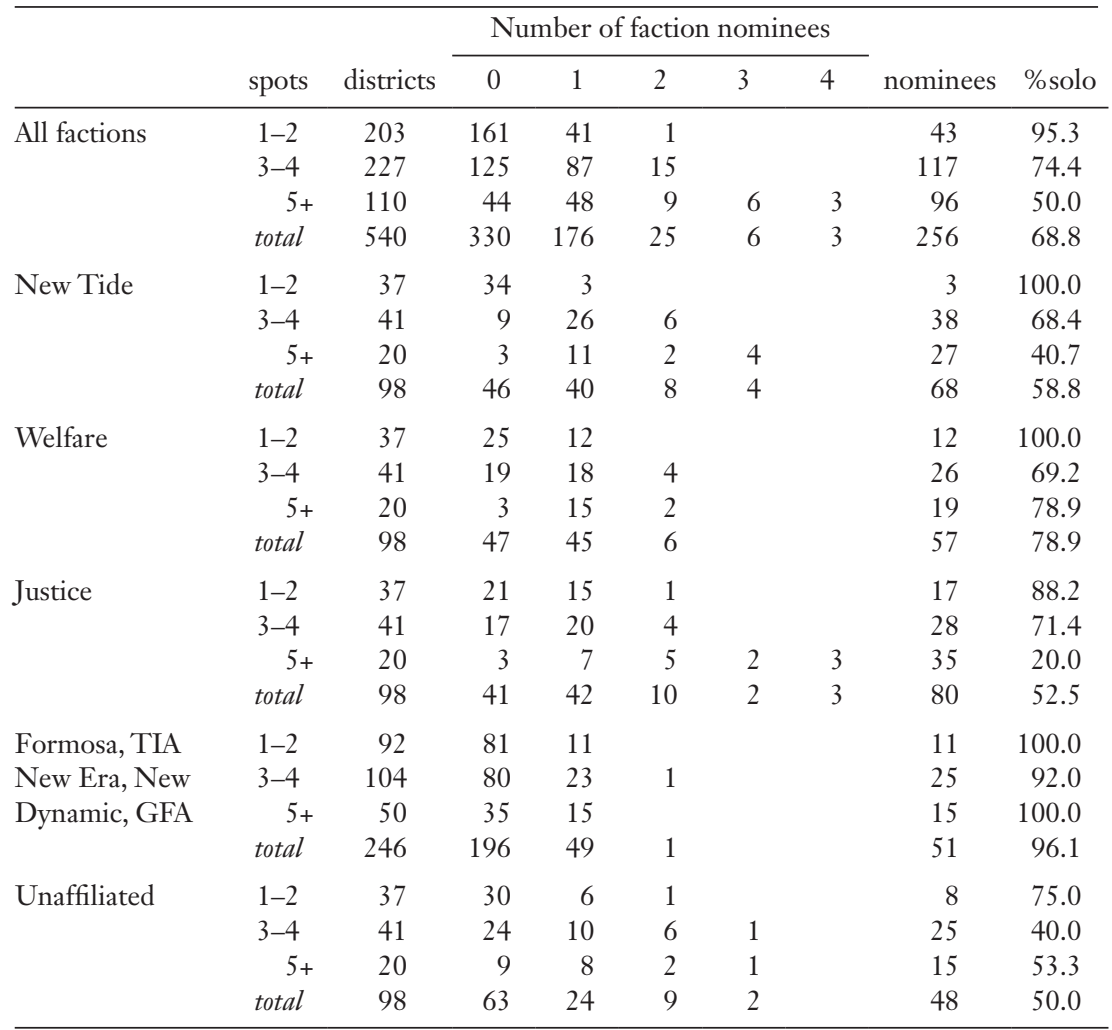

Note: These data cover the 1995-2004 legislative elections. The following districts are excluded: Taitung County, Penghu County, Jinmen County, Lienchiang County, Plains Aborigines, Mountain Aborigines, Party List, and Overseas Representatives. Factional affiliations for 1995, 1998, and 2001 are taken from Cheng (2004, 563-76). Factional affiliations for 2004 were compiled by the authors from newspaper reports. 
Formosa, Taiwan Independence Alliance, New Era, New Dynamic, and Green Friendship Alliance, there was only one case of a multiple nominees. However, among Welfare, New Tide, and Justice, $21.1 \%$, 41.2\%, and $47.5 \%$ of nominees, respectively, had to run against a fellow faction member. It is especially striking that in the biggest districts, a majority of New Tide $(59.3 \%)$ and Justice $(80.0 \%)$ nominees had to deal with challenges from other faction members.

In general, factions usually nominated a single candidate, but the larger factions were not afraid to nominate multiple candidates in larger districts. Even so, there is anecdotal evidence that they viewed nominating multiple candidates as a challenge. For example, in the 2004 election, New Tide originally had multiple candidates in Taipei County 2 and Taichung City. However, four months before the election, it held a meeting in which the extra candidates were encouraged to withdraw from the faction (CT, August 11, 2004). It is probably no coincidence that the two factions that were able to grow large enough to consistently nominate multiple candidates and navigate the resultant coordination problems were New Tide and Justice. The former is famous for its internal discipline, and both had ample resources from the executive branch. This last point brings us back to the importance of the executive. If the electoral system created pressures for factions to remain small enough that they would not need to nominate multiple candidates in a district, competition over the executive created both the incentive for bigger factions and the resources to sustain them.

\section{DPP National Factions: Summary}

This section draws attention to important parallels between the DPP and LDP factions. Like the LDP, the DPP has multiple factions competing for control of the national party. Even though the DPP party chair is directly elected, chairs need to forge a working majority in the CSC to be effective. Since no faction has had an outright majority since the very early days of the party, this has required building a coalition of multiple factions. To use the terminology of the introductory chapter, a postelectoral strategy is viable, so there is no need to consolidate into two big factions. Like the LDP, the DPP's factions were born in a SNTV environment, and multifactionalism helped both parties nominate multiple candidates with differentiated power bases. However, neither the LDP's nor the DPP's factions were completely dependent on the SNTV system, and both managed to adapt and survive after electoral reform.

If there are similarities between the LDP and DPP factions, there are 
also notable differences. The LDP is a party of power, while the DPP has traditionally been an opposition party. The LDP's factions collect and distribute enormous sums of money, and this money is often used by individual MPs to sustain a koenkai (personal support organization). These sorts of resources have generally not been available to the DPP, and collecting and distributing money plays an extremely limited role in the DPP's factional politics. The koenkai help LDP politicians reach out to ordinary voters to win general elections; DPP factions connect politicians with party members to win primaries.

Overall, the theories constructed to understand LDP factions are far more useful for understanding DPP factional politics than for deciphering KMT factions.

\section{Conclusion}

Our discussion of both KMT and DPP factions points to the centrality of executive competition. However, this was not necessarily competition over the national executive. For KMT local factions and DPP factions until the late 1990s, the presidency was not a viable goal. Rather, the factions organized themselves around the most attainable executive positions. KMT local factions are designed to win control of the local government, and the result is bifactionalism. DPP national factions were originally formed to win control of the national party, and building a minority faction and then constructing a coalition with other minority factions proved a viable strategy. When the presidency became a possibility, the DPP's faction system also changed. All the major changes of recent years, including the disintegration of the Formosa faction, the push toward a bifactional system in the early years of the Chen presidency, and the evolution from legislativecentered factions to factions centered on presidential contenders, were all intimately related to competition over the presidency. The introduction reminds us that executive competition plays an important role in shaping party and faction systems. This chapter builds on that notion by pointing out that the critical competition may not always be over the national executive but may instead be over a local executive post, a party leadership post, or some other post that is both desirable and attainable.

Another lesson is that the electoral system used for the national legislature may be less important than we previously believed. The change from SNTV to MMM forced factions to rethink their legislative electoral strategies, but it did not affect them in other critical arenas. After elec- 
toral reform, KMT local factions continued to place most of their focus on the single-seat-plurality county magistrate elections. Their secondary arena was arguably in the county assemblies, which continued to be elected by SNTV. Legislative elections were more central to the DPP's nationally oriented factions. However, all the DPP's party positions as well as elections for the legislative caucus floor leaders continue to be elected by SNTV. With multiple arenas of competition, it is simplistic to expect that reforming the electoral system in just one arena will completely transform the factional system.

Finally, the different paths of the KMT and DPP draw attention to the historical context during the period of faction development. The KMT local factions were created in an authoritarian context in which they were not allowed to compete for national power or espouse controversial political ideas. The KMT used factions to co-opt local elites and prevent them from coalescing into a force that could threaten its grip on national power. The result was locally oriented factions aimed at distributing patronage. DPP factions grew up in a very different context. Coming out of the democratization movement, DPP politicians were always focused on national politics. Even if winning power was not a viable short-term goal in the late 1980s and early 1990s, the DPP leaders who formed factions were nationally oriented politicians who forged alliances with similar colleagues from different areas. This led to a party with multiple power centers and a collective leadership. Today's environment is different still from either the authoritarian era or the period of transition to democracy. The factions have evolved to meet current challenges, but the legacy of yesterday remains powerful.

\section{NOTES}

1. These data are based on a research project subsidized by the National Science Council research program entitled "The Relationship between Local Factions and Political Parities after the Consolidation of Taichung County and Taichung City." Project No. NSC 99-2410-H-029-061.

2. For more detail on the theoretical foundations, historical evolution, and everyday operations of Taiwan's local factions, see Chao (1997); C. Chen (1997); M. Chen (1995); Huang (2010, 2011); Wang and Huang (2010).

3. Administratively, Taiwan is divided into direct municipalities, counties, and county-level cities. For simplicity, we will often simply refer to both counties and city-level counties as counties. The executives for these are commonly called mayors and magistrates, respectively. For simplicity, we call them all magistrates. Below the cities and counties are a group of administrative districts including cities, towns, villages, and districts that we will collectively call townships. Township executives 
will be called mayors. All these executive posts are elected by the single-memberplurality rule.

4. Similarly, members of the Provincial Assembly and national legislature had access to funds for subsidies to local governments. However, even if the assembly members or legislators could help secure these funds, the money was dispersed by the provincial or central governments instead of the politicians themselves.

5. There are other factions in Taiwan called the Red and Black factions. However, the Taichung County Red and Black factions are not allied with these other Red and Black factions. When Taichung County Red faction members enter the national legislature, for example, they do not necessarily cooperate with Changhua County Red faction legislators or Kaohsiung County Red faction legislators. All three Red factions are independent entities confined to specific counties, and there is no national Red faction.

6. The faction names are drawn from the colors used for campaign materials in the 1950s. Lin He-nian favored red flags, leaflets, and name cards, while Chen Shui-tan used black or dark blue (Hung 1996). These colors may have been chosen to indicate the candidates' social status and perhaps even their attitudes toward traditionalism. In those early days, many of the elites were doctors or teachers. Doctors wore Western-style black suits, and were often considered to be more westernized. Teachers tended to be more conservative and often dressed in red. Chen was a prominent doctor, while Lin was an intellectual from the famous Wufeng Lin clan, which had produced several degree holders (see Meskill 1979).

7. The Red and Black factions do not have any clear policy differences. Individual members may take different positions on particular policies, but these stances do not represent the entire faction.

8. In fact, the KMT actively hastened the decline of the Yang faction. Yang Tien-sheng found himself on the wrong side of the power struggle between Lee Teng-hui and James Soong in the late 1990s, and Yang's business interests suddenly found that government regulators became very hostile.

9. Conventional accounts of the LDP's factions almost never mention local executive races, focusing heavily on legislative races and competition over party leadership and cabinet positions. See Thayer (1969); Curtis (1988); Fukui (1970); Ramseyer and Rosenbluth (1993); and Kobayashi and Tsukiyama (chapter 3, this volume).

10. Even the common story about money does not fit. The usual legislaturecentric story involves the legislator building up support by bringing large amounts of public money back to the district. In contrast, Hung and Liu were not particularly noted for their ability to extract pork from the provincial or central governments. Rather, both were famous for their ability to penetrate local farmers associations (Hung 1996). Controlling a farmers association does not necessarily mean that a politician is especially pro-farmer. While the conduit to farming votes is useful, the main advantage to controlling farmers associations is being able to command the financial assets of their affiliated credit unions. However, it is important to remember that local governments offer far more discretionary resources than farmers associations and have always been considered a far bigger prize.

11. For an explanation of this logic, see Batto and Cox, introduction, this volume. 
12. For an explanation of telephone primaries, see $\mathrm{Yu}, \mathrm{Yu}$, and Shoji, chapter 5 , this volume.

13. The name of the new direct municipality is actually Taichung City. To avoid confusion with the old, smaller, county-level Taichung City, we call the new entity Taichung Municipality.

14. Appointees must meet the civil service employment qualifications. Most local politicians do not meet these qualifications, so a municipal mayor cannot simply stuff these posts with faction cronies.

15. Taichung County lost 21 township mayor positions, 19 county assembly seats, and 282 township council seats. Taichung County also effectively lost its executive seat, since the new Taichung Municipality mayor was the incumbent from Taichung City. In all, 323 elected positions were eliminated.

16. In addition, the party chair, any mayors of direct municipalities, and the three legislative caucus floor leaders are automatically members of the CSC. Mayors of county-level cities and counties are automatically members of the CEC, and they may choose one of their members to sit on the CSC. This system has been used since 2002. Prior to 2002, there were no automatic seats, and there were $31 \mathrm{mem}$ bers of the CEC who elected 11 members of the CSC.

17. In addition to the four major factions, there were also some smaller and less influential factions in the 1990s. The most famous of these was the Taiwan Independence Alliance, which had its roots in the overseas independence movement during martial law.

18. Press reports differ, but New Era was generally reported with 15 or 16 legislators, while New Dynamic only had about 8 or 9 (see CNA, January 6, 1990; CNA, June 7,1990$)$.

19. Not all the pressure came from New Tide. For example, Vice President Annette Lu publicly mooted the possibility of Chen's resignation, and some in the Justice faction urged Chen to hand over power before his term expired. However, New Tide led many of the attacks, and defenders of the president focused their rage on New Tide.

20. The motion ordered factions to dissolve and including five clarifying provisions: (1) factions could not maintain offices; (2) factions could not recruit new members; (3) factions could not accept dues from members or raise money; (4) factions could not hold official faction meetings or hear reports from government officials; (5) all party members holding public or party offices should publicly announce they have withdrawn from any factions (LT, July 12, 2006).

21. Money may also have played a role, an interesting possibility given the Japanese experience. Raising money has been stressed as one of the main functions of Japanese LDP factions, and one of the main thrusts of 1994 Political Funds Control Act was to prohibit individual factions from directly seeking corporate funds (Reed and Thies 2001; Kobayashi and Tsukiyama, chapter 3, this volume). In the DPP, there was concern that New Tide had been absorbing a disproportionate share of money. Critics pointed to a New Tide leader's position as chair of the Taiwan Stock Exchange Corporation and the leverage over the financial system that this position bestowed on him. However, there are reasons to doubt that money was really the crucial factor. The other factions also had rainmakers, and many of 
them were among the motion's most ardent supporters (CT, July 7, 2006). Moreover, New Tide allies proposed an alternate motion that would have prohibited raising money but allowed the factions to continue to exist. The fact that New Tide was willing to sacrifice its fund-raising capacity and that opponents rejected this alternative suggests fund-raising was not the central point.

22. Somewhat comically, immediately after the motion dissolving factions passed, the party congress turned to the last item on the agenda: electing the new CEC and CSC. These elections featured factional politics in all their glory, with factions organizing vote rationing schemes. Of course, the media reported these elections in terms of which factions did well and which ones did not.

23. This does not mean that the dissolution did not affect New Tide at all. Over the final two years of Chen's presidency, observers began to differentiate between the Northern Tide and the Southern Tide. The Northern Tide was far more critical of President Chen and far more vocal about the need for a reform movement within the DPP. Some New Tide members blamed this internal divergence on the fact that they were not able to hold regular meetings and hammer out a common position as they had in the past (CT, May 18, 2007). New Tide only fully reestablished an organizational foundation in October 2008 when it founded the New Society for Taiwan think tank.

24. However, two CSC seats were won by factions that are loosely allied with the Chen faction, the Grandparents faction and former Premier Yu Hsi-kun's faction.

25. The DPP has historically not been competitive in several districts, and we considered nominations in these districts to be far less valuable. As such, we do not consider nominations in the following districts: Taitung County, Penghu County, Jinmen County, Lienchiang County, Plains Aborigines, and Mountain Aborigines. Party List and Overseas Representatives are also excluded from this table.

\section{REFERENCES}

Chao, Yung-mau. 1997. Taiwan Difang Zhengzhi de Bianqian yu Tezhi [The change and characteristics of political ecology on Taiwan's local autonomy]. Taipei: Han Lu Book \& Publishing.

Chen, Chieh-Hsuan. 1997. "Faction Network, Electoral Cadre Network, and Civil Network: The Social Meaning of a Local Faction's Initiation" [in Chinese]. In Difang Shebui [Local Society], ed. Institute of East Asian Societies and Economies, Tunghai University. Taipei: Linking Book Press.

Chen, Ming-Tong. 1995. Paixi Zhengzhi yu Taiwan Zhengzhi Bianqian [Faction politics and political change in Taiwan]. Taipei: Yue-dan.

Cheng, Ming-teh. 2004. Yi Mai Zong Xiangcheng: Paixi Zhengzhi zai Minjindang [Faction politics in the DPP]. Taipei: Shiying.

Cheng, Ming-teh. 2010. "Why Did the DPP National Party Congress Dissolve the Factions?" [in Chinese]. Meilidao Dianzi Bao [Formosa] April 30. http://www. my-formosa.com/article. aspx? cid=5\&id=4006 (accessed March 26, 2012).

Cheng, Tun-jen, and Yung-ming Hsu. 1996. "Issue Structure, the DPP's Factionalism, and Party Realignment." In Taiwan's Electoral Politics and Democratic Transition: Riding the Third Wave, ed. Hung-mao Tien. Armonk, NY: M. E. Sharpe. 
Curtis, Gerald L. 1988. The Japanese Way of Politics. New York: Columbia University Press.

Fukui, Haruhiro. 1970. Party in Power: The Zapanese Liberal-Democrats and PolicyMaking. Berkeley: University of California Press.

Huang, Hsin-ta. 2010. "An Analysis of the Possible Effects on the Local Political Ecology of the New Taichung Municipality" [in Chinese]. In Gonggong Zhengce yu Difang Zhili: Difang Zizhi Lunwenji [Public policy and local governance: Autonomy in local government], ed. Hsing-chou Sung and Chien-jen Chen. Taipei: AIRITI.

Huang, Hsin-ta. 2011. "A Study of the Relationships between Local Factions and Political Parties after the Taichung County-City Consolidation" [in Chinese]. Zhengzhi yu Zhengce [Asian Journal of Politics and Policy] 1 (2): 91-140.

Huang, Hsin-Ta, Yeh-Lih Wang, and Chien-Hsiung Wang. 2009. "The Impact of Electoral Reform on Local Politics: A Case Study of Taichung County." Paper presented at the International Conference on Elections in Taiwan, Japan, and Korea under the Mixed-Member Electoral System, NCCU University, Taipei City, Taiwan, May 24.

Hung, Chun-mu. 1996. "Taichung County: The Continuing Lin-Chen Rivalry and the Rise of the Third Force" [in Chinese]. In Difang Paixi yu Taiwan Zhengzhi [Local factions and Taiwan politics], ed. Kun-shan Chang and Cheng-hsiung Huang. Taipei: Lianjing.

Jacobs, J. Bruce. 1979. "A Preliminary Model of Particularistic Ties in Chinese Political Alliances: Kan-ch'ing and Kuan-bsi in a Rural Taiwanese Township." China Quarterly 78:237-73.

Jen, Yu-te. 2006. "The Establishment and Development of KMT's Electoral Machine and Mobilization System during the 1950s" [in Chinese]. Zhengzhi Daxui Lishixue Bao [Journal of History] 25:71-116.

Kao, Yuang-Kuang. 2000. "Disparities of Urban-Suburban Development and Political Factions: A Case Study to Local Elections of Taipei County in 1998" [in Chinese]. Xuanju Yanjiu [Journal of Electoral Studies] 7 (1): 53-86.

Kao, Yuang-Kuang. 2004. "An Analysis to the Interactive Pattern of Political Factions and Gangsters in Taipei County" [in Chinese]. Xuanju Yanjiu [Journal of Electoral Studies] 11 (1): 33-72.

Kohno, Masaru. 1992. "Rational Foundations for the Organization of the Liberal Democratic Party in Japan.” World Politics 44:369-97.

Meskill, Johanna M. 1979. A Chinese Pioneer Family: The Lins of Wufeng, Taiwan, 1729-1895. Princeton: Princeton University Press.

Ramseyer, J. Mark, and Frances McCall Rosenbluth. 1993. Japan's Political Marketplace. Cambridge: Harvard University Press.

Reed, Steven R., and Michael F. Thies. 2001. "The Consequences of Electoral Reform in Japan." In Mixed-Member Electoral Systems: The Best of Both Worlds?, ed. Matthew Søberg Shugart and Martin P. Wattenberg. New York: Oxford University Press.

Rigger, Shelley. 2001. From Opposition to Power: Taiwan's Democratic Progressive Party. Boulder: Lynne Rienner.

Scott, James, C. 1972. "Patron-Client Politics and Political Change in Southeast Asia." American Political Science Review 66 (1): 91-113. 
Thayer, Nathaniel B. 1969. How the Conservatives Rule Japan. Princeton: Princeton University Press.

Wang, Chin-shou. 2004. "Returning to Feng-mang County: The Success and Failure of the Kuomintang Political Machine" [in Chinese]. Taiwan Zhengzhixue Kan [Taiwan Political Science Review] 8 (1): 99-146.

Wang, Yeh-lih, and Hsin-ta Huang. 2010. "Local Factions after Twin Transitions of Government in Taiwan: Decaying or Transforming?" Paper presented at the Annual Meeting of the American Political Science Association in Washington, DC, September 2-5.

Wu, Chung-li. 2002. "Controversy about the Research on Taiwan's Faction Politics: Learning from the Analytical Approaches of American Machine Politics" [in Chinese]. Zhengzhixue Luncong [Political Science Review] 17:81-106.

Wu, Nai-teh. 1987. "The Politics of a Regime Patronage System: Mobilization and Control within an Authoritarian Regime." PhD diss., Department of Political Science, University of Chicago.

Newspaper articles are cited by source and date:

CNA: Zhongyang She (Central News Agency)

CT: Zhongguo Shibao (China Times)

LT: Ziyou Shibao (Liberty Times)

UDN: Lianbe Bao (United Daily News) 


\title{
Innovations in Candidate Selection Methods
}

\author{
Eric Chen-bua Yu, Kaori Shoji, and Nathan F. Batto
}

This chapter focuses on how major parties adjusted their candidate selection methods (CSMs) to meet the challenges brought about by the new electoral regimes in Taiwan and Japan, respectively. Specifically, it investigates two innovative ways to select district-level candidates adopted by the major parties in each country. ${ }^{1}$ In Taiwan, the polling primary became the default system that the two major parties, the Kuomintang (KMT) and the Democratic Progressive Party (DPP), used to nominate their candidates for the Legislative Yuan elections. In Japan, both of the major parties, the Democratic Party of Japan (DPJ) and the Liberal Democratic Party (LDP), have turned to the kobo (public recruitment) system to select candidates. The new CSMs were designed to address different concerns. The polling primary was intended to identify the strongest candidate and resolve intraparty competition. In contrast, the initial purpose of the kobo system was not to resolve intraparty clashes among ambitious and powerful contenders. Rather, in the late 1990s and early 2000s the DPJ used kobo for the purposes of party-building. In more recent years, both the DPJ and LDP have increasingly used it to legitimize party decisions.

\section{Candidate Selection Methods, Electoral Reform, and Constitutional Systems}

The determinants of CSMs is an important topic for scholars interested in political parties (Ranney 1981; Gallagher and Marsh 1988). Recent work 
on the extent to which electoral systems affect the choice of CSMs has not pointed to a consensus. While some comparative case studies argue that electoral institutions should have substantial impacts on choices of CSMs, particularly in terms of ballot structure and district magnitude (Norris 1997; Kasapovic 2001), other recent large- $N$ studies show that the empirical evidence is meager at best (Lundell 2004; Shomer 2012). From the perspective of level of analysis, Hazan and Voerman (2006) point out that electoral systems are a country-level variable that may not account for intracountry, cross-party variation in CSMs. Gallagher and Marsh (1988) are perhaps correct in positing that electoral systems do not, by themselves, completely determine CSMs, yet it is certainly possible that electoral systems exert some degree of influence. Decades of research on electoral systems has clearly indicated that parties do, in fact, vary their strategies according to the different incentive schemes produced by different electoral systems. CSMs are an important element of overall party electoral strategies, and we should expect to see some impact of the electoral incentives on the choice of CSMs. In the particular cases of Taiwan and Japan, although both the polling primary and kobo had been initiated prior to the introduction of electoral reforms, we argue that the electoral and constitutional systems helped facilitate the consolidation of both innovative institutions.

Changing from SNTV to MMM may push parties to adjust their CSMs. For one thing, such a change increases the importance of managing intraparty competition in the nomination stage (Wu and Fell 2003; Krauss and Pekkanen 2004). Under SNTV, much of the intraparty competition takes place in the general election stage, as parties routinely nominate multiple candidates in the same district. While the optimal strategy is for a party to nominate the "right" number of candidates and then distribute its support evenly among them (Cox and Rosenbluth 1993; Cox and Thies 1998; Cox and Niou 1994; Browne and Patterson 1999), overnomination is not always a disaster. If more than the appropriate number of candidates insists on running and no compromise can be found, the party can sometimes simply let them all run and let the electorate decide which is the weakest. That is, the party can opt for a less optimal solution in which no candidate is unfairly denied a nomination. Sometimes this will lead to a worse outcome, but sometimes the party will still manage to avoid losing a winnable seat. In contrast, in single-member districts (SMDs), parties must nominate a single candidate to have any chance to win. A second candidate in an SMD race almost always portends disaster. Thus, any intraparty clashes that appear during the nomination process have to be dealt with at that stage and cannot be pushed off until the general election. 
Another way in which the shift to MMM could affect nominations involves the increased number of districts. Under SNTV, each district elects multiple seats. Any party wishing to give every voter a chance to support it has merely to nominate one candidate in every district. With the change to MMM, the number of districts increases markedly, and parties wishing to give all voters an option to support them have to nominate a much larger number of candidates. Even for established parties, this is not an easy task. For smaller and newer parties without deep pools of potential candidates, simply finding enough competent candidates to run in every district can be a daunting challenge. Especially in weaker districts, newer and smaller parties have to struggle to present a roster of credible candidates.

Japan's parliamentary system creates a different set of problems than Taiwan's semipresidential system does. Batto and Cox (introduction, this volume) and Lin (chapter 2, this volume) argue that executive posts are the ultimate goal for many politicians. In Japan, cabinet posts are determined by negotiations among party leaders in the House of Representatives. Almost all of the key figures, including the party leaders and the MPs who receive ministerial posts, are legislators who have accumulated years and years of seniority. The typical career path is well documented. An MP is elected at a young age and slowly works his way up through a series of posts. After being reelected several times, he or she might finally accumulate sufficient seniority and experience to be eligible for a ministerial post. Party leaders are generally drawn from this same group of senior MPs. In short, seniority is a prerequisite for securing powerful posts. Taiwan's semipresidential system works differently. Cabinet posts are allotted unilaterally by the president, not negotiated by legislative leaders. Moreover, since a legislator must resign his or her seat to assume a post in the executive branch, presidents are reluctant to appoint legislators to the cabinet. Ambitious legislators must thus look elsewhere if they hope to hold executive power. In fact, ambitious legislators typically seek to win local executive seats as city mayors or county magistrates. National leaders generally have proven their mettle by winning a highly competitive mayoral race and successfully administering a city government for several years. The legislators who remain in the legislature and accumulate seniority are generally less energetic, charismatic, and politically talented than those who move on to other challenges. The result of this is that legislative seniority is much more important in Japan than in Taiwan. Most important Japanese politicians are senior legislators, while few Taiwanese leaders are.

The differing importance of seniority has significant implications for nomination strategies. Consider a district in which a party is very strong. The nomination in this party is a very valuable commodity, since nomina- 
tion almost certainly means winning in the general election. Such a valuable commodity is certainly worth fighting over, even if it means taking on an entrenched incumbent. In Japan, all of the senior figures in the party have accumulated seniority, and they all have an interest in protecting that precious asset. To this end, Japanese parties have written the rules to favor incumbents. In particular, Japanese parties typically automatically renominate incumbents. In Taiwan, the decision makers in the party do not usually have strong personal interests in protecting seniority. They would generally prefer to see the strongest candidate emerge. In fact, party leaders may actually prefer to see energetic challenges to ensure that incumbent legislators work hard and actively stay in touch with their constituents.

As a result, Taiwanese and Japanese CSMs have evolved to address very different challenges. For Taiwanese parties, the most important problem is how to choose nominees in the strongest and most desirable districts. The polling primary has emerged as the best solution for this task. As parties cannot always easily resolve intraparty clashes, they have an incentive to delegate the power to the general public to make the decision. Public opinion surveys are seen as an objective test of strength in which everyone gets a fair shot. Surveys have the added advantage of communicating a quantifiable measure of strength and weakness to the general public. Voters who support the loser not only have to face evidence that their favored candidate has lost in a fair process but also that if he ran a renegade campaign in the general election he would have to face the prospect of widespread strategic voting toward the party nominee.

Japanese parties have a different problem. The most desirable districts are almost all occupied by incumbents, and intraparty challenges for these nominations are simply disallowed. Instead, Japanese parties worry about nominating candidates for districts without incumbents. Many of these districts are hopeless and undesirable to ambitious politicians. Nevertheless, big parties generally wish to run candidates in all or almost all districts, so they try to find someone to represent the party. ${ }^{2}$ In the years just after the electoral reform, this was a particular challenge for the DPJ. The old primary opposition, the Japan Socialist Party (JSP), disintegrated in the new electoral system as it was unable to win pluralities in many districts. The DPJ rose to fill this void, but, as a new party, it did not have deep pools of candidates ready to run in every district. The DPJ turned to kobo to recruit new politicians and ensure that it could run a full slate of candidates. At first, the DPJ used kobo primarily as a party-building mechanism. As the DPJ matured and finding enough candidates to run nationwide became less of a problem, the nature of kobo began to shift. Many districts with no 
incumbents were worth fighting for. Local power holders or national faction leaders might maneuver to nominate their most favored candidate into these spots, but concerns over fairness spurred them to try to cloak their influence. Increasingly kobo was used to publicly legitimize decisions made by party leaders. That is, kobo was presented to the public as an open and fair decision-making process. In practice, it was anything but open. Even the LDP, a well-established party with an entrenched local party organization, shared some similarities to the DPJ in the incentives for adopting kobo. Below, we look into the development of new CSMs in each country.

The Polling Primary in Taiwan

\section{The Evolution of Taiwanese CSMs and the Emergence of the Polling Primary}

The KMT implemented an authoritarian regime after retreating to Taiwan in 1949 and institutionalized different types of elections in order to facilitate its control at the grassroots (Cheng 1989; Wu 2001). To solidify its authority in elections, the KMT adopted a top-down CSM. During the authoritarian era, local party members were informally consulted in the candidate selection process, but the overall CSM was characterized by centralization.

During the transition to democracy in the mid-1980s, Taiwan saw a series of important political markers, such as the establishment of the main opposition party, the DPP, in 1986, the dismantling of martial law in 1987, and the death of President Chiang Ching-kuo in 1988. These events signaled the decline of the KMT's authoritarian rule and the emergence of competitive party politics (Wu 2001). In response to the inevitable trend of democratization, the KMT adopted and started transforming its Leninist party structure to compete in the new democratic structure. One of the starting points was to open and decentralize its CSM.

In 1989, the KMT adopted a closed primary system. This was the first time that the party's rank-and-file members could formally participate in the candidate selection process and marked a major decentralization of authority. While the central party headquarters continued to retain the right to make the final decisions, it generally respected the primary results. However, this new system did not produce an entirely favorable outcome. One of the KMT's goals was to reduce the power of local factions, and this new system led to more nominees who were not associated with local factions 
(Huang 1996). The KMT share of elected seats fell by $9.5 \%$ from 1986, and the new CSM, which many argued had produced a weak slate of candidates, was commonly cited as one of the reasons for this poor performance.

The KMT revised its CSM for the 1992 elections to include party member primaries followed by evaluations from party cadres. While this new system was somewhat less decentralized than the 1989 system, the KMT did not return to a fully centralized CSM. Rather, the 1992 system confirmed the power shift from the center to localities, and local party members and party officials have exercised significant influence in determining nominations in all subsequent elections.

In the 1993 county magistrates and city mayoral elections, the KMT further adjusted its CSM to include three factors: party member opinion responses, evaluations by cadres, and public opinion polls (Wu 2001). This marked the first time that the KMT incorporated polling results in its candidate selection process. However, the results from these three processes were not binding, as higher party officials reserved the right to make the final nomination decisions.

Although the KMT was the first party to use polls to assess aspirants, the DPP was the first party to incorporate polling results into a binding formula to determine nominations. In the early years after its founding in 1986, the DPP's leadership was not composed as a unified group but came from various anti-KMT individuals or factions that occupied offices at the local representative bodies. This unique preparty history gave the DPP a decentralized pattern of power distribution that was reflected in its CSM. Negotiations and compromises among party factions became the major tool for nominating candidates. If party leaders were unable to reach any consensus, party members were to be asked to cast votes to determine final nominations. In practice, the leadership of the DPP tried to reach consensus through compromise, and it was rare to see party members voting in the 1980s. The above two-stage process characterized the DPP's candidate selection from its founding until the early 1990s, though it was not officially codified until the 1992 legislative election.

In 1995, the DPP revised its CSM to give party cadres more power. ${ }^{3}$ If the party failed to settle on a consensus, votes of party members and party cadres each accounted for $50 \%$ of the final decision. The introduction of voting for party cadres signaled the increasing importance of local party branches and a deemphasis on party members in the nomination process. One reason for this was to address an increasing tendency for aspirants to register large numbers of new party members. The aspirant would typically pay the party dues and control the votes of these "head voters" (rentou 
dangyuan), and many DPP leaders and supporters saw this as a growing form of corruption or vote buying (Wang 2006). Others worried that DPP factions were becoming too powerful, and it was increasingly impossible for aspirants not affiliated with a faction to win a nomination. In fact, the addition of party cadres did little to reduce the influence of factions, as most of the cadres were themselves deeply embedded in the faction system.

The DPP strategy for avoiding these negative repercussions was to decentralize their nominations. Instead of relying on the small number of formal party members or an even smaller number of party leaders to make decisions, the DPP attempted to empower the much larger number of party supporters and sympathizers in the general public. Aspirants could manipulate the outcomes inside the party by registering easily controlled "head voters" or by factional maneuvering, but the hope was that these strategies would not be feasible in the much larger population of party supporters. This new strategy was first attempted in the contest for the 1996 presidential nomination. The DPP used a closed primary to winnow the field to the top two contestants, and then these two toured the country in a series of debates in which the general public was allowed to vote to determine the nominee. Unfortunately, the attendance at these open primary events was still fairly low, so the DPP continued to look for a better process.

This led to the incorporation of telephone polling in the 1998 legislative nomination process. The DPP scrapped voting by party cadres and instead gave $50 \%$ weights to both party member votes and telephone poll results. This marked the first time that either of the two major parties had included polling results in the nomination process in a binding, not merely an advisory, role.

During the 1980s and 1990s, the two main parties' CSMs evolved in very different ways. The KMT's main concern was to devolve power from the center to localities in order to compete more effectively in the new democratic system, while the DPP moved from an elite-dominated CSM to one that drew on a much larger selectorate in an attempt to mitigate manipulation of its internal party processes. However, once the polling primary was introduced and its advantages became apparent, the 2000s saw the two parties converge on relatively similar CSMs.

In the 2001 Legislative Yuan election, the KMT imitated the DPP by adopting polling results in its nomination process. The KMT's CSM included two parts: voting by local party members and telephone polling, each given equal weights. Local party branches tabulated and combined the results of the two parts and forwarded them to the central party headquarters, which generally respected the local results. 
TABLE 5.1. Evolution of CSMs for Legislative Yuan Elections, 1969 to 2012

\begin{tabular}{|c|c|c|}
\hline Year & KMT & DPP \\
\hline 1969 & $\begin{array}{l}\text { Candidates produced by consultations with } \\
\text { local party members, then reviewed by } \\
\text { the provincial party headquarter, and } \\
\text { finally decided by the central party } \\
\text { headquarters }\end{array}$ & N/A \\
\hline 1972 & $\begin{array}{l}\text { Candidates produced by consultations with } \\
\text { local party members, then decided by the } \\
\text { central party headquarters }\end{array}$ & N/A \\
\hline 1975 & Same as 1972 & N/A \\
\hline 1980 & $\begin{array}{l}\text { Candidates produced by consultations } \\
\text { with local party members and reviews of } \\
\text { local party officials, then reviewed by the } \\
\text { provincial party headquarter, and finally } \\
\text { decided by the central party headquarters }\end{array}$ & N/A \\
\hline 1983 & $\begin{array}{l}\text { Candidates produced by consultations with } \\
\text { local party members and reviews of local } \\
\text { party officials, then the provincial party } \\
\text { headquarter doubled the number of } \\
\text { nominee, and finally decided by the } \\
\text { central party headquarters }\end{array}$ & N/A \\
\hline 1986 & Same as 1983 & N/A \\
\hline 1989 & $\begin{array}{l}\text { Candidates produced by party member } \\
\text { primary, then decided by the central } \\
\text { party headquarters }\end{array}$ & $\begin{array}{l}\text { Candidates produced by consensus; } \\
\text { otherwise by party member vote }\end{array}$ \\
\hline 1992 & $\begin{array}{l}\text { Candidates produced by party member } \\
\text { primary }(50 \%) \text {, and reviews of local party } \\
\text { officials }(50 \%) \text {, then decided by } \\
\text { the central party headquarters }\end{array}$ & $\begin{array}{l}\text { Candidates produced by consensus; } \\
\text { otherwise by party member vote }\end{array}$ \\
\hline 1995 & $\begin{array}{l}\text { District candidates produced by } \\
\text { consultation with local party members, } \\
\text { or by opinion polls, or by reviews of } \\
\text { local party officials, then decided by the } \\
\text { central party headquarters }\end{array}$ & $\begin{array}{l}\text { Candidates produced by consensus; } \\
\text { otherwise by party member vote }(50 \%) \\
\text { and party cadres vote }(50 \%)\end{array}$ \\
\hline 1998 & Same as 1995 & $\begin{array}{l}\text { Candidates produced by compromises } \\
\text { (consensus), otherwise by party member } \\
\text { vote }(50 \%) \text { and opinion polls }(50 \%)\end{array}$ \\
\hline 2001 & $\begin{array}{l}\text { Candidates produced by party member } \\
\text { primary }(50 \%) \text {, and opinion polls }(50 \%)\end{array}$ & $\begin{array}{l}\text { Candidates produced by compromises } \\
\text { (consensus), otherwise by party member } \\
\text { vote }(30 \%) \text { and opinion polls }(70 \%)\end{array}$ \\
\hline 2004 & $\begin{array}{l}\text { Candidates produced by party member } \\
\text { primary }(30 \%) \text {, and opinion polls }(70 \%)\end{array}$ & Same as 2001 \\
\hline 2008 & Same as 2004 & Same as 2001 \\
\hline 2012 & Candidates produced by opinion polls & Candidates produced by opinion polls \\
\hline
\end{tabular}

Source: Data before 2012 were adopted and revised from Wang (2008, 143-70).

Note: The nomination of party list candidates is not included. All nomination decisions, even those after parties began using polling primaries, had to be ratified by the national party headquarters. 
The importance of polling results continued to increase. The DPP adjusted its formula to make telephone polling account for $70 \%$ of the final outcome, with party members voting reduced to only $30 \%$. The KMT followed suit in 2004, and both parties used the 70-30 rule to determine their district-level nominees for the 2004 and 2008 Legislative Yuan elections. ${ }^{4}$ In 2012, both parties completed the evolution toward the polling primary by eliminating voting by party members and determining nominations solely by the results of telephone polls. ${ }^{5}$

While the polling primary evolved in the SNTV era, it arguably is even better suited to nominations for the single-seat districts employed in MMM. In a large SNTV district, a party wishing to nominate four candidates might have to adjudicate between its fourth and fifth strongest aspirants. These aspirants might not be strong enough to cause problems if not nominated, and the party always has the option to simply overnominate. In MMM, the clash is between the two strongest aspirants and overnomination is not a feasible option. Resolving the conflict in a fair way is imperative. Moreover, SNTV elections are characterized by intraparty competition, so finding a balanced roster of nominees that appeal to various factions within the party is important. Internal party processes, such as a closed primary, are useful for ensuring that no single faction monopolizes nominations. In contrast, internal party balance is less urgent in MMM. Single-seat elections are characterized more by interparty competition, and the strongest candidates are those that appeal to broad swaths of the population. Polls are particularly adept at identifying these politicians. In fact, while this chapter focuses on legislative nominations, both parties have used polling primaries extensively for single-seat executive elections. It is thus not surprising that the parties responded to electoral reform by intensifying their use of the polling primary.

\section{The Mechanics of the Polling Primary}

This section describes the CSMs used by KMT and DPP in the 2012 legislative election. Both the KMT and DPP started their candidate selection procedure with candidate registration. All aspirants had to register, including incumbents. In general, incumbents were not given any special status in the competition for nominations, and sitting legislators often faced competition from challengers within the party. Even when only one candidate registered, he or she still needed to demonstrate electability through public opinion polls. The KMT required that unopposed aspirants must pass a $30 \%$ threshold of support to win a nomination, while the DPP head- 
quarters reserved the right to reject weak aspirants and search for stronger alternatives.

If more than two aspirants registered for nomination selection, the process proceeded into the second phase-negotiation. Both parties preferred to resolve conflicts behind closed doors rather than by engaging in open and potentially explosive intraparty competition. During the negotiation period, parties sometimes did nonbinding polling to see who had a better chance to win and who should be encouraged to yield. Additionally, the party headquarters sometimes sent a senior party official to handle the negotiation process. In some cases, such negotiation processes was successful and the party was able to nominate a candidate without intense and direct intraparty conflict. For example, in 2012 in New Taipei City 4th District, the KMT's incumbent Lee Hung-chun faced a challenge from Hsu Bing-kuan, who had a strong local organization and significant grassroots support. Lee and Hsu had known each other for 30 years and were close friends. In the beginning of the negotiation process, Lee expressed a willingness to withdraw and let Hsu represent the KMT in the general election. Yet, the KMT leadership favored Lee due to both his performance in the legislature and his broad popularity in the very competitive 4th District. Thus, at the end of the day, Hsu agreed to withdraw and wait on the sideline for future opportunities. ${ }^{6}$

Most negotiations did not go as smoothly as the previous example. Quite often, contenders refused to step aside and the negotiation process broke down. For example, in New Taipei City 2nd District, the DPP incumbent Lin Shu-fen was challenged by Huang Chien-hue, a former legislator who had lost to Lin in the 2008 DPP primary. Soon after the deadline for registration, the DPP headquarters sent a senior party leader to initiate the negotiation process. Yet, the negotiations fell apart quickly as Huang, who was strongly supported by one of the DPP's major factions, made it clear that he would never withdraw from the competition. ${ }^{7}$ In short, although Lin seemed to be a very strong DPP incumbent candidate, a polling primary was still necessary since a quality contender insisted on challenging her.

When negotiations broke down, the process moved into one of two third phases. In stronger districts, parties held a polling primary, while in weaker districts the party headquarters tended to directly select a nominee. In weaker districts, the party had little chance of winning and the challenge was more commonly to simply recruit any quality candidate rather than to mediate between multiple competent aspirants. In these more difficult districts, the party headquarters sometimes unilaterally decided who the 
nominee would be. For example, the DPP deemed all districts in which it had received less than $42.5 \%$ of the vote in 2008 as "difficult," and the party headquarters was given the authority to unilaterally decide nominations in these districts.

Where parties were stronger, the nominations were more valuable, intraparty conflict was potentially more explosive, and parties were more likely to end up with the polling primary. Table 5.2 shows that in nine of the 11 districts in which the KMT held a polling primary in 2012, it eventually won the seat. The DPP was only slightly less successful when it held polling primaries, winning nine of 13 districts.

Incumbents were not immune from challenges. Twelve incumbents were forced to face a polling primary, and three lost. Fifty KMT and DPP incumbents were eventually nominated without resorting to a polling primary. However, this should not be interpreted as 50 unchallenged nominations. In many cases, other aspirants registered or considered registering but were eventually persuaded to yield before or during the negotiation phase.

There were many similarities and a few clear differences in the protocols

TABLE 5.2. Use of Polling Primaries in the 2012 Legislative Yuan Election

\begin{tabular}{|c|c|c|c|c|}
\hline & \multicolumn{2}{|c|}{ KMT } & \multicolumn{2}{|c|}{ DPP } \\
\hline & Number of seats & $\%$ of total & Number of seats & $\%$ of total \\
\hline Total single-seat districts ${ }^{a}$ & 73 & $100.0 \%$ & 73 & $100.0 \%$ \\
\hline Districts nominated & 71 & 97.3 & 71 & 97.3 \\
\hline $\begin{array}{l}\text { Districts won in } 2012 \\
\text { election }\end{array}$ & 44 & 60.3 & 27 & 37.0 \\
\hline $\begin{array}{l}\text { Districts held prior to the } \\
2012 \text { election }^{\text {b }}\end{array}$ & 50 & 68.5 & 19 & 26.0 \\
\hline $\begin{array}{l}\text { Districts using a polling } \\
\text { primary }\end{array}$ & 11 & 15.1 & 13 & 17.8 \\
\hline $\begin{array}{l}\text { Polling primary winners } \\
\text { who also won the seat }\end{array}$ & 9 & 12.3 & 9 & 12.3 \\
\hline $\begin{array}{l}\text { Incumbents nominated } \\
\text { without a polling primary }\end{array}$ & 39 & 53.4 & 11 & 15.1 \\
\hline $\begin{array}{l}\text { Incumbents participating } \\
\text { in a polling primary }\end{array}$ & 7 & 9.6 & 5 & 6.8 \\
\hline $\begin{array}{l}\text { Incumbents winning a } \\
\text { polling primary }\end{array}$ & 5 & 6.8 & 4 & 5.5 \\
\hline
\end{tabular}

anly single-seat districts are considered in this table.

${ }^{\mathrm{b}}$ This is slightly different from the 2008 election result because there were several by-elections between the two general elections.

cFor this table, an incumbent is defined as a legislator who won the district in the 2008 election or an intervening by-election. Legislators who won their seat in a different district or on the party list are not considered incumbents. 
used by the two parties (table 5.3). Both parties contracted with outside polling companies to do random sample surveys. The DPP had a list of eligible polling organizations, including its own internal survey unit, and randomly selected three of these for each different race. The KMT adopted a more decentralized method, allowing any two polling organizations to be selected in any race upon the aspirants' agreement. The two parties applied different scheduling of the surveys, and the KMT employed in-house sampling $^{8}$ while the DPP did not. These two differences reflected the different priorities of the two parties. The KMT placed the highest priority on getting an accurate reading of public opinion, and its protocols were designed to ensure a representative sample. The KMT prescheduled its surveys to be held over three days, usually including both weekdays and weekends, and it further used in-house sampling rather than simply asking whoever answered the phone in order to eliminate as much as possible any distortions in the sample. The DPP, in contrast, saw the polling primary as a way to test the mobilization capacity of its contenders. ${ }^{9}$ Rather than trying to eliminate any distortions, the DPP encouraged its contestants to try everything possible to affect the outcome. The scheduling, in particular, was designed specifically to test mobilization. The headquarters only prescheduled a period of time for a list of district primaries without specifying the order. Thus, no one knew which primary would take place on what particular date. Then every morning during the primary period, the headquarters randomly selected one district from the list for a polling primary that night. The contenders were immediately informed, usually around 10:00 a.m. Once the primary date was announced, contenders rushed to mobilize their supporters, encouraging them to be in their homes between 6:00 and 10:00 p.m. that night to wait for possible phone calls. The DPP did not adopt inhouse sampling for the same reason. In households with split preferences,

TABLE 5.3. Key Features of KMT and DPP Polling Primaries in 2012

\begin{tabular}{lll}
\hline & \multicolumn{1}{c}{ KMT } & \multicolumn{1}{c}{ DPP } \\
\hline $\begin{array}{l}\text { Overseen by: } \\
\text { Method: }\end{array}$ & Local party branch & National party headquarters \\
$\begin{array}{l}\text { Days to complete survey: } \\
\text { Survey organizations: }\end{array}$ & Telephone survey & Telephone survey \\
$\begin{array}{l}\text { Interviews completed by each } \\
\text { organization: }\end{array}$ & At least 1,068 & 1 \\
Questionnaire: & & 3 \\
& Interparty matchup: $85 \%$ & About 1,200 \\
Date: & Intraparty matchup: 15\% & (can be changed by consensus) \\
In-bouse sampling: & Prescheduled & Random \\
\hline
\end{tabular}


who answered the phone became an important factor in determining the results. Contenders had just a few hours to phone, text, or otherwise contact as many people as possible to ensure that a disproportionate number of their supporters were at home ready to answer the phone.

Finally, the questions put to respondents varied across parties. The DPP's default question in strong districts was an interparty comparison. ${ }^{10}$ For example, if there were two DPP contestants (A and B), respondents were typically asked a pair of questions, whether the respondent preferred A or the KMT candidate and whether the respondent preferred B or the KMT candidate. However, if the contestants agreed on some alternate format or if the KMT candidate had not yet been determined, ${ }^{11}$ the DPP was willing to allow other question formats. Unlike the scheduling, which the party headquarters kept under tight control, the question format was open to revision. One common complaint about the interparty comparison was that it did not allow sincere party loyalists to express their preferences for one or the other contestant. Since many loyalists prefer any DPP candidate to any KMT candidate, sincere respondents would express support for both A and B and thus have no impact on the outcome. Only those who strategically answered that they would support the KMT candidate over the less favored DPP contestant affected the outcome, and this led to complaints that the system forced respondents to lie if they wished to have any impact. The KMT system addressed this concern by including both interparty and intraparty comparisons. In addition to pitting the contestants against the DPP nominee, ${ }^{12}$ respondents were further asked which of the KMT contestants they preferred. The interparty comparison was still the more important, accounting for $85 \%$ of the final score, but the $15 \%$ weight given to the intraparty comparison allowed KMT supporters to show their preference for a specific KMT contestant.

Table 5.4 shows an example of a polling primary. In 2010, the DPP had won the seat in Taitung County in a by-election, and the incumbent, Lie Kuen-cheng, wanted to run for reelection. He was opposed by the former deputy head of the county government, Liu Chao-hao. Negotiations did not yield any compromises, so a polling primary was conducted. Since the KMT had already settled on a candidate, Yao Ching-ling, the standard interparty questions were used. On the morning of April 6, 2011, the DPP headquarters randomly drew the Taitung County district for that day's polling primary. At the same time, it randomly drew three survey organizations to carry out the polls. Between 6:00 and 10:00 that night, each organization conducted 1,200 interviews. The DPP issued a press release on the morning of April 7 announcing that Liu had defeated Lie and would be 
nominated. Liu's nomination was confirmed later that week at the weekly meeting of the DPP's Central Standing Committee. Two points about the results are worth noting. First, the results from the three organizations were very similar. This was almost always the case, and similar results from different organizations helped to assuage any suspicions of manipulation. Second, no consideration was given to ideas about margin of error. Results were reported with an unrealistic degree of precision, and there was no requirement that the margin of victory be over a certain threshold.

\section{Discussion}

There are several reasons that the two main parties have turned to the polling primary as the default CSM. First, the polling primary controls costs for parties. Commissioning several polls costs money, but it is cheaper than organizing party member primaries. ${ }^{13}$ Second, polling primaries identify the candidate who is the most popular among the general public and thus most likely to win in the general election. Previous CSMs relied on more narrow segments of the electorate to decide nominations, and this left them open to the charge that they were not selecting the best candidates. For example, in the early 1990s the KMT leadership "parachuted" several candidates with no local ties into districts, and these were often attacked as outsiders and easily defeated. With the polling primary, parachute candidates whose national fame did not translate into local popularity were rejected while those who did enjoy substantial local support were legitimized.

Third and most important, the polling primary is seen as a much fairer system than any other alternative. Polls produce hard numbers and a clear decision rule: candidates with support from more respondents win. The fact that the poll results are usually very similar across multiple survey organizations gives them added credibility. Moreover, poll results are much

TABLE 5.4. Polling Primary for DPP's 2012 Legislative Nomination in Taitung County

\begin{tabular}{lccccccccc}
\hline & \multicolumn{1}{c}{$\begin{array}{c}\text { All Dimension } \\
\text { Survey organization } \\
\end{array}$} & \multicolumn{2}{c}{$\begin{array}{c}\text { Center } \\
\text { CPP Survey }\end{array}$} & \multicolumn{2}{c}{$\begin{array}{c}\text { Master Survey \& } \\
\text { Research }\end{array}$} & \multicolumn{2}{c}{$\begin{array}{c}\text { Survey } \& \\
\text { Research }\end{array}$} & Average \\
\hline Candidate & DPP & Yao & DPP & Yao & DPP & Yao & DPP & Yao \\
Liu & .4175 & .2368 & .4195 & .2481 & .4487 & .2332 & .4286 & .2394 \\
Lie (incumbent) & .3823 & .2799 & .3905 & .2913 & .4198 & .2876 & .3975 & .2863 \\
\hline
\end{tabular}

Source: DPP website (http://www.dpp.org.tw/news_content.php? \&sn=4844), accessed July 2, 2013.

Notes: The surveys were conducted on April 6, 2011. Results were announced on April 7. Respondents were asked a pair of questions, whether they preferred Liu or Yao (the KMT candidate) and whether they preferred Lie or Yao. 
harder to manipulate than closed primaries or negotiations by party elites behind closed doors.

The KMT was particularly worried about the influence of local factions in its nomination process. Factions were extremely effective in closed-room negotiations and could often control the recommendations forwarded to the national party by local party branches. This ability to control the process was seen as somewhat illegitimate by the general public, as the factions appeared to simply be dividing up spoils among themselves, and opportunities for regular people to influence nominations were limited. By moving the locus of competition from party elites to the general public and forcing contestants, including faction members, to compete in a transparent process, the KMT was able to credibly claim that faction-affiliated contestants had no unfair advantages.

The DPP was also concerned about the influence of its factions, which were also seen as somewhat illegitimate by many party supporters. In the DPP, the question of faction power was closely related to the number of phantom party members. Most powerful DPP figures controlled a certain number of "head voters," and they relied on these votes both in internal party elections and in nomination fights. Indeed, DPP factions all had large numbers of head voters in their pockets. Since the formal membership of the DPP was relatively small, factions or individual politicians could decide the outcome of closed primaries by recruiting more head voters, and this was widely seen as a perversion of democracy. The polling primary rendered the "head voter strategy" obsolete. More generally, one can see these phantom party members as a type of vote-buying strategy, and, by dramatically increasing the size of the selectorate, the polling primary made votebuying extremely inefficient. In fact, given the low payoff, the negative consequences resulting from being publicly exposed as a vote-buyer, and the high probability that one's opponents would uncover and expose any such activity, the polling primary arguably transformed vote-buying from a beneficial strategy into a harmful one. ${ }^{14,15}$

There are some criticisms of the polling primary (Wu 2008, 115-45). One popular normative argument is that parties have a responsibility to nominate good people, and by adopting the polling primary and delegating decisions to the general public, parties are abdicating this duty. ${ }^{16} \mathrm{~A}$ related argument is that allowing the general public to make the decision leaves no important role for ordinary party members. Why should a person formally join a party if he or she has no say in its most important decisions? According to this argument, the polling primary could negatively affect party-building. 
Another criticism is that the polling primary encourages politicians to be overly concerned with public opinion. Some Taiwanese commentators have suggested that the polling primary makes potential aspirants (including incumbent candidates) care more about their public image than anything else. As such, politicians expend too much effort seeking media exposure and building name recognition and not enough energy working on mundane but important policy questions.

A quite different line of criticism is more technical, arguing that survey results may not accurately reflect popular opinion. On the one hand, it takes quite a bit of expertise to conduct a random sample survey. Surveys include many different components, such as sampling technique, questionnaire wording and ordering, data processing, and so on. Each component is subject to manipulation, and slight variations may produce different outcomes. In the worst case scenario, an unrepresentative sample or an intentional distorted outcome might give a victory to the wrong person. Less dramatically, surveys produce estimates with statistical errors. Any victory, no matter how small, is sufficient to win the nomination. In close races, the margin of victory may be within the statistical error, but the parties do not consider this.

On the whole, however, the polling primary is generally viewed as a positive innovation. Even if it is not perfect, it has produced substantial benefits to the DPP and KMT by institutionalizing a system that resolves intraparty conflict in a fair and transparent manner.

The Kobo System in Japan

\section{The Evolution of Japanese CSMs and the Emergence of the Kobo System}

The Japanese term kobo literally means public advertisement of a post. The opening of a position is publicly announced, and anyone who is interested and qualified can apply. The term only suggests that the entry to the selection process is open to public, but other important aspects could vary (and are often left unspecified), such as what level in the party organization will make the decision, how much outside participation will be allowed, and what the criteria for the decision will be. This method, which merely declared that anyone could enter the nomination race, was regarded as an innovative CSM only in comparison to the closed and informal traditional Japanese nomination practice. 
Prior to the appearance of kobo in the 1990s, there was no formal structure for candidate selection adopted by major political parties in Japan. Each party would recruit its candidates through its internal networks, the opening was never officially announced, and the entry to the selection was never made open to the public. For example, prior to the 1994 electoral reform, the LDP typically delegated recruiting candidates to each of its factions (chapter 3, this volume; Krauss and Pekkanen 2011). The supply of human resources came mainly from local and national electable officeholders, national-level bureaucrats, and the heirs of MPs. For other smaller parties, it was the norm to recruit candidates from affiliated organizations, such as trade unions, or from within the hierarchy of party organizations.

By the early 1990s, the prevalence and evils of seshu (hereditary succession of electoral turf within bonds of kinship, typically from a father to his son) under the LDP regime became widely criticized (Inada 2009; Uesugi 2009). The media repeatedly questioned the quality of the MPs of the ruling parties, claiming that Japanese politics was hopelessly chaotic largely because it was filled with hereditary MPs, and the path to the Diet was closed to talented people who would have been able to offer solutions.

With the electoral reform from SNTV to MMM in 1994, the parties faced new challenges in their nomination strategies. Under the old system where factions took responsibility for candidate recruitment (chapter 3, this volume), conservative contestants who failed to win an LDP nomination often ran in the general election as independents. If they were able to win, the LDP usually allowed them to join the party. In effect, the LDP deferred difficult coordination decisions to the general election, allowing the electorate to sort things out. In the SMDs used in MMM, this strategy was no longer an option, since having two conservative candidates in the same district was a recipe for disaster. Thus, nominations became more critical, and party leaders were legitimized to take a more active role and exert more power in determining who would be nominated. The new opposition parties faced a different problem, that of finding enough qualified candidates to run in every district. The electoral reform increased the number of nominal districts from 129 to 300. Moreover, under the old system, even a locally weak party could hope to win one seat in most districts, and the possibility of winning attracted quality candidates. Under the new system, many of the districts were hopeless and thus unappealing to ambitious politicians. The difficulty in finding enough qualified candidates was exacerbated by the fact that opposition parties had never done well in prefectural assembly elections and did not have large numbers of established local politicians trying to move up to the national legislature 
(Scheiner 2006). Electoral reform thus created a need for opposition parties to explore new strategies to find new pools of talent.

With many vacant seats to fill, the opposition parties naturally were the pioneers to try out kobo. ${ }^{17}$ In 1990 , the JSP, then suffering from a shortage of candidates, was the first of the major national parties to recruit candidates for elected positions through kobo, although the practice was limited to the city/ward levels. It is widely recognized that the first political party to adopt kobo for national elections was the Nihon Shinto (People's New Party, 1992-94). It fielded three candidates recruited through kobo in the 1993 HR election. One of them was Yukio Edano, who later became a leading figure in the DPJ. The Shinshinto (New Frontier Party, 1994-97) used kobo extensively for candidate recruitment and managed to field candidates in 235 SMDs in the first election under MMM in 1996. It was the first time the largest opposition party fielded candidates for over half of the district seats in an HR election since the JSP did so in the 1958 general election. The DPJ was the first major party to conduct kobo repeatedly over an extended period of time. The party conducted large-scale national kobo five times from 1999 to 2009. The LDP also tried out kobo on a much smaller scale as early as in 1994, but it did not fully embrace kobo until after the party's defeat in 2009..$^{18}$

The precise institutional design of kobo differs from party to party, but they can be broadly grouped into two categories: centralized and decentralized. The national headquarters of the party manages the centralized type, and the prefectural branches and the district chapters play dominant roles under the decentralized type. The former became well known for its use by the DPJ, mainly for the elections for the HR from 2000 to 2009. Other relatively new third parties, such as the Minna no To (Your Party, 2009-), the Genzei Nippon (Tax Cut Japan, 2010-), and the Nohon Ishin no Kai (Japan Restoration Party, 2012-) also adopted similar forms of centralized kobo. The latter was implemented widely by the LDP for the 2012 HR election. While the LDP adopted the decentralized version because it was more conducive to its entrenched local organization, parties with relatively short histories and less developed organization typically had no choice but to employ the centralized form.

The initial goal of adopting kobo was to recruit potential candidates who the parties could not reach to through their traditional internal networks and to find candidates to run in weak districts. This was especially the case with the DPJ. Gradually, however, insider aspirants started to use the DPJ kobo path to take advantage of its legitimacy. The LDP also 
used kobo to fill in weak districts, but its decentralized version of kobo, its entrenched local organization, and its more uniform application of kobo to open seats led the system to develop into a mediating device for intraparty competition.

\section{The DPJ Kobo System}

The current DPJ was formed in 1998 by absorbing three smaller parties ${ }^{19}$ into the old DPJ, which had been established in 1996. The members of the new DPJ came from different backgrounds: some of its leading figures originally belonged to the LDP, while others came from the Democratic Socialist Party, which had been established by the conservative wing of the old JSP. Right before the 2003 HR election, another major conservative force, the Liberal Party, dissolved, and joined the DPJ. As a relatively new and small party with underdeveloped local organizations, the DPJ suffered from an inadequacy of candidates, and this was the background for the adoption of kobo.

Within the DPJ, incumbents were given priority over others and were renominated automatically in most cases. Candidates who lost in the previous election were renominated once, but those who lost two elections in a row were not nominated for a third time. Only when the district had no incumbent or held-over candidate from the previous election did the party look for a new candidate. In such a case, the regular candidate selection process was initiated at the district level. The HR district chapter worked with the kenren (prefecture branch) in finding a candidate via the traditional internal network. The kenren then asked the national headquarters for the endorsement of their choice. The national headquarters reserved the final say. When the district chapter and the kenren failed to field or agree on a candidate, the headquarters sent in a kobo-selected candidate. The SMDs where this happened were typically very weak. However, the party also attempted to use kobo as a public relations tool for enhancing its image by putting flashy ads in major newspapers with national circulation.

The DPJ kobo was not conducted independently for each vacant district. Instead, the party held nationwide general kobo five times between 1999 and $2009 .{ }^{20}$ All of these were conducted in a similar manner, and each kobo supplied candidates to districts all over the country for the five HR elections for the Diet from 2000 to 2012. ${ }^{21}$ There were 74 kobo-selected candidates who debuted between 2000 and 2012 under the DPJ banner (table 5.5). The DPJ kobo for the Diet elections were directly managed by 
the national headquarters. The headquarters had to take charge because the party used kobo to find candidates to run in vacant districts when the kenrens could not find anyone on their own.

A kobo applicant had to pass three hurdles in order to become an official DPJ candidate: passing the kobo screening at the headquarters (Stage 1), securing an informal nomination for a specific district from the district chapter and the kenren (Stage 2), and getting this district-designated nomination officially approved by the national headquarters (Stage 3). Technically, the kobo system covered only the first stage, and both kobo and nonkobo candidates had to go through the latter two stages.

The Stage 1 screening was handled by the national headquarters office. The applicants submitted curricula vitae and essays, and those who passed the initial document screening advanced to the in-person interview sessions. A few MPs joined the party staff in interviewing each applicant for about 20 minutes on what he or she wanted to do as an MP and in which district he or she wished to run. Interviewers focused on personality rather than policy orientation because the DPJ, being a hodgepodge of groups with different backgrounds, had no official policy positions it could enforce on its candidates. The total number of applicants for the DPJ national kobo increased from 564 in 1999 to nearly 2,000 in 2009. However, the odds of passing this first stage of screening remained constantly about one to nine.

Those kobo-screenees who passed Stage 1 were eligible to advance to Stage 2-seeking district nomination. The headquarters served as an intermediary by matching these screenees and the kenrens with vacant districts. During the matching process, the applicants' personal roots in the districts or prefectures counted heavily. Finding districts to run in was often the toughest hurdle for the kobo screenees. Most of the better seats had been already taken, and the remaining seats often looked hopeless. Less than

TABLE 5.5. Number of Kobo Candidates Who Ran and Won in HR Elections

\begin{tabular}{lrrrrr}
\hline & \multicolumn{2}{c}{ DPJ } & & \multicolumn{2}{c}{ LDP } \\
\cline { 2 - 3 } \cline { 5 - 6 } Year & Ran & Elected & & Ran & Elected \\
\hline 2000 & 17 & 3 & & 0 & 0 \\
2003 & 9 & 3 & & 0 & 0 \\
2005 & 18 & 1 & & 26 & 22 \\
2009 & 29 & 28 & & 6 & 0 \\
2012 & 1 & 0 & & 83 & 76 \\
Total & 74 & 35 & & 115 & 98 \\
\hline
\end{tabular}

Source: Compiled by authors from party records. 
$20 \%$ of these district-seekers were eventually embraced by district chapters and the kenrens and ran in elections as official party candidates.

Stage 3, approval by the national headquarters, was not an automatic rubber stamp process. The person was not officially regarded as a DPJ candidate until after obtaining final endorsement from the headquarters. Although the national headquarters normally tried to respect local selections and most of the local choices were endorsed, the headquarters would suspend approval or even replace candidates if kenren-chosen candidates looked too weak in the polls or did not seem to be campaigning hard enough.

Overall, only $2 \%$ of the initial kobo applicants ended up running in the HR elections. We should note, however, that it is difficult to determine the quality of the applicants because the party never released any detailed information about the kobo applicants except for those who were officially nominated. The names of competitors had to be kept secret because running for a public office in Japan almost always meant that one had to quit his or her current job before the election. No one wanted to quit before knowing whether he or she would get the party's nomination and could actually run in an election. Few people would apply for kobo if their names were not kept confidential.

The use of kobo helped the DPJ prepare to take over power in 2009 by finding nontraditional outsider types of candidates to run in the weak districts. However, the party gradually started to ask those who used to be recruited through traditional paths to apply for kobo, as well, in order to add legitimacy to their nominations. For example, those members of prefecture assemblies who used to join the selection process at Stage 2 were often considered to have "stolen" the nomination by disgruntled koboqualified applicants. By the 2009 election, in order to avoid the impression of manipulation, the DPJ encouraged all candidates, including those from traditional career paths, to apply for kobo.

Even though it was increasingly used to confer legitimacy on nominees, the kobo system was still fundamentally a nontransparent process. Decisions at each stage were made behind closed doors. The general public did not know exactly how the kobo selection process worked, who the kobo applicants were, which of them passed the screening stage or the matching stage, or what the bases were for the decisions at each stage. No official records were kept for the decision making at the matching stage. The only way the voters knew that the candidates were selected through kobo was through the label of kobo attached to them when they were presented as the nominated candidates. This opaque process allowed national and 
local faction bosses to exert influence behind closed doors during the selection processes. As a result, the DPJ kobo came to function more as a black box convenient for various actors within the party in contrast to its public image as an open and fair CSM (Shoji 2013).

\section{The LDP Kobo System}

The earliest kobo practice by the LDP was observed in 1994 by the Ishikawa kenren for the 1995 House of Councillors election. After the 1994 electoral reform, several kenrens tried kobo in some districts in preparation for the 1996 HR election. Yet the LDP did not widely conduct kobo for national offices until it suffered heavy losses in the 2003 House of Councillors election. Encouraged by a few kobo successes in special elections, the LDP conducted kobo in about 20 districts before it conducted a special emergency national kobo right before the 2005 HR election. For the latter, 868 applications were submitted in four days. Twenty-four kobo-selected candidates ran in the 2005 HR election, and twelve won in the SMDs. A further nine lost their district race but were elected on the PR list (Asano 2006). For the 2009 HR election, the LDP nominated only six candidates through district-level kobo. ${ }^{22}$ After the defeat in the 2009 HR election, the LDP attracted fewer candidates, and the party started to use kobo extensively to fill in the vacant districts.

Facing new challenges as an opposition party and continuing public complaints over seshu, the LDP made it mandatory to conduct kobo for any open HR district. Right after the 2009 HR election, the thenopposition LDP was no longer as attractive to ambitious new politicians and had some difficulties in recruiting satisfactory candidates through its traditional paths. In response, the LDP once again turned to kobo. As the popularity of the party recovered, the competition for LDP nominations intensified, and the LDP responded by further institutionalizing the use of kobo. In this section, we focus on the LDP's practices in preparation for the 2012 HR election.

The party heavily protected its incumbents and renominated them automatically, as it had done throughout its history. After the 2009 HR election, the candidates who lost were automatically renominated if they were 65 years old or younger and had lost in the SMD but won at least $70 \%$ as many votes as the district winner. The party only began the candidate selection process when there was neither an incumbent nor a heldover candidate in the district.

Although the national headquarters had the final say, the candidate 
selection processes of the LDP were bottom-up, starting at the district level. A district chapter worked with its kenren in recruiting and selecting a candidate. Because the party made it a rule to hold kobo for any open district nomination after the 2009 HR election, kobo was conducted not just in weak districts but also in strong districts such as those where strong incumbents had just retired. During this period, the party attempted to bar the sesh $u$ practice, but it had to give up after facing strong resistance. The party justified this by insisting that anyone, seshu or not, who was selected through kobo was fairly chosen and thus qualified. The LDP fielded 83 candidates through kobo for the 2012 HR election.

The largest difference from the DPJ kobo was that the LDP kobo was always conducted at the prefecture or district level. In most cases, each kobo was held specifically for a certain district, and the kenren would determine the specific kobo procedures. Thus, there was a wide variety in the LDP kobo practices observed across the country. Typically, a selection committee of 20 or fewer people was set up at the district or kenren level for each kobo. Outside experts or prominent local figures representing the interests of local industry were often invited into the committee. The selection processes normally entailed paper-screening and interview sessions. Applicants were always asked to submit essays, and, in a majority of cases, the public announcement listed some connection to the district as a prerequisite or at least as highly desirable. Complete outsiders with no connection to the district or the prefecture were usually not welcome.

In some cases, the selection committee required applicants to fill in survey sheets on policy preferences. The LDP witnessed the DPJ's travails stemming from the lack of policy coherence within the party and attempted to avoid the same problem by screening the ideological leanings of kobo candidates. The party occasionally asked applicants to sign a pledge that they would not run against the LDP nominee if they were not nominated. While most of the kobo selection took place in closed-door meetings, there were some instances in which the applicants were asked to compete by giving speeches in public or in which the party used opinion polls to identify the most attractive candidate. There were even some kobo cases where party members voted to decide the outcome. These closed primaries did not necessarily lead to more open or fair selections, however, since the competitors with a longer history of local party activities had usually cultivated more supportive members and the newcomers were put at a severe disadvantage.

Broadly speaking, there were three observed patterns in the actual competition under the LDP kobo. The first was districts with a single likely 
winner, such as those that would previously have been determined by seshu. Under this category, kobo functioned to justify the predetermined outcome. The second category included districts with two or three major contestants. Those contestants were often well-established local politicians in the district, and the party had a hard time mediating a compromise among them. Kobo helped to justify the final outcome and persuade the losers to accept the result. In this case, kobo worked as a vehicle of conflict resolution. The third category included districts with no strong competitors known prior to kobo. These cases typically involved districts where the party was extremely weak and potential quality candidates were reluctant to run. The party had to recruit complete amateurs from outside the internal network who would dare to run against the strong incumbents of another party.

\section{Discussion}

Although they were called with the same name, kobo, and they shared a similar function at the early stage of fielding candidates in the weak districts, the centralized and decentralized versions adopted by the DPJ and the LDP, respectively, evolved in very different ways. The contrast is summarized in table 5.6. The headquarters-led DPJ kobo process remained extremely nontransparent in its selection criteria and the decision-making protocol. At the district assignment stage, where the negotiation process remained completely informal and hidden, anything was possible.

Not unaware of these drawbacks, many DPJ staff and MPs testified they never perceived kobo as an ideal CSM. The centralized form of kobo left parties vulnerable to collapse in more difficult times. New parties had to use it because they had underdeveloped party organization and suffered an inadequate supply of candidates. In turn, this dependence on kobo led to negligence in building internal recruitment and training systems. The

TABLE 5.6. Characteristics of DPJ and LDP Kobo

\begin{tabular}{lll}
\hline & \multicolumn{1}{c}{ DPJ kobo } & \multicolumn{1}{c}{ LDP kobo } \\
\hline Unit of kobo & At-all (national) & Mostly by district \\
Implementation of kobo & Headquarters & Prefectures/districts \\
Scope of participation & Very limited & Relatively broad \\
Final say & Headquarters & Headquarters \\
Period of intensive kobo practice & For 2000-2009 HR elections & For 2012 HR election \\
State of party & Opposition & Opposition \\
Primary initial motivation & Filling vacancy & Improving public image \\
Use of closed primary & None & Several \\
\hline
\end{tabular}


DPJ kobo was used by ambitious aspirants who wanted to become MPs while bypassing an unappealing apprenticeship in local politics. These candidates had no loyalty to the party and were prone to leave the party when they did not like the policy decisions made by the leaders. The number of kobo applicants plummeted as the popularity of the party dropped, which revealed that how well kobo functioned depended heavily on whether the party's electoral prospects looked promising. The quick rise and fall of the Japan Restoration Party, which was completely dependent on the charisma of a single leading figure and an extensive use of centralized kobo, illustrates both the advantages and dangers of this CSM. The structure of centralized kobo left the parties with little space for improvement in terms of intraparty democracy. It merely opened the door to the smoke-filled room to outside aspirants, but the decision-making processes were left exclusive and nontransparent.

The decentralized kobo that the LDP experimented with presented different possibilities. The kenrens tried different ideas, and good examples were copied by others. Some examples of policy debate in public, formal use of polling surveys, and even closed primaries were observed in the course. While many kenrens preferred to remain secretive and exclusive about nomination processes when possible, the LDP experience suggests that kobo might serve as a venue for CSM democratization if implemented by a party with strong local party organization. Although much of the decision-making processes of the LDP kobo remained nontransparent to most voters, the institutionalization of kobo that took place at the prefecture and district levels helped improve the fairness and legitimacy of the nominations. The LDP kobo reform is even showing some signs of being nonreversible. With an increase in the kobo practices, it has become harder for the party to reject holding kobo when demanded by competitors.

While it is hard to measure the impact of kobo on factions within the DPJ, which started to use kobo right after its inception, it should be fair to say that kobo did not help factions within the LDP. If the introduction of SMD had already made things harder for the factions (chapter 3, this volume), opening competition to outsiders in each district made it almost impossible for the factions to coordinate across districts and prefectures.

Some studies investigate the impact of kobo on the type of candidates who won nominations. Smith, Pekkanen, and Krauss (2013) examined DPJ nominations through the 2009 HR election and found that kobo nominees tended to be lower quality on average than nonkobo nominees. DPJ kobo candidates tended to have less connection to the district, and aside from the female-only kobo in 1999 , kobo was actually less likely to recruit 
female candidates. Overall, the kobo candidates had a higher probability of winning, but the impact of kobo disappears after controlling for the party strength in the district and candidate quality.

As for the LDP kobo, specifically in the run-up to the $2012 \mathrm{HR}$ election when kobo became the default CSM for the party, Smith (2013) argues that it did not significantly change the backgrounds of candidates who were nominated. Kobo helped to push down the average age of first-time nominees, but the backgrounds of those kobo candidates remained largely similar to the traditional pools: local politicians, MP aides, and national-level bureaucrats. We should also note that, although decreasing in number over time, sesh $u$ was not wiped out by kobo.

\section{Conclusion}

This chapter has analyzed new innovations in CSMs for legislative elections in Taiwan and Japan. While the origins of the polling primary in Taiwan and kobo in Japan both predate electoral reform, we argue that the shifts from SNTV to MMM created pressures for parties in both countries to intensify the use of these two institutions. Further, the effects of the changing electoral rules on CSMs need to be addressed in the context of the different constitutional systems of the two countries. Specifically, Taiwan's semipresidential system deemphasizes legislative seniority while Japan's parliamentary system always relies on senior MPs to form the government. Such contextual variance leads to the different purposes and scopes of the CSM reforms adopted by major parties in the two countries.

In Taiwan, where seniority is less valuable and incumbents are not protected, the parties converged on the use of the polling primary in strong districts. The polling primary has proven useful to the parties by successfully mediating intraparty conflict, and it is also beneficial to the general public to the extent that it is a disincentive to corruption. In Japan, where seniority is more valuable and incumbents are heavily protected, both major parties adopted kobo in weak districts. This allowed them access to a wider pool of potential candidates and helped to defuse charges that insiders were illegitimately monopolizing nominations.

Of course, the CSMs continue to evolve. In Taiwan, many worry that the polling primary harms intraparty democracy and party-building by leaving no role for party members to influence nominations. After the 2012 elections, there was discussion in both parties about reinstating some mix of closed primaries and polling primaries. Though neither party has opted 
for a change from the 2012 rules as of this writing, the parties continue to search for a CSM that will give party members a bigger role while still resolving conflict and discouraging corruption. In Japan, there are serious concerns about the effects of centralized kobo, which has proven useful for young and popular parties but has also hindered efforts to develop party institutions that can survive when a party's fortunes decline. The decentralized version may prove more sustainable. It shows signs of taking root and has demonstrated some potential for intraparty democratization.

\section{NOTES}

1. In the new electoral regimes in both Taiwan and Japan, the nominal tier plays the dominant role in shaping incentives. In both countries, a relatively large proportion of seats are determined in single-member districts. Further, in Japan the practice of dual candidacy results in SMD candidates taking up most of the space on PR lists, thus leaving relatively few spots for PR-only candidates. This chapter thus focuses on the linkage between electoral rules for the nominal tier and CSMs. Nemoto and Tsai take up the topic of list tier nominations in chapter 6, this volume.

2. This has been less of a problem in Taiwan than in Japan for three main reasons. First, Taiwan has only 73 SMDs compared to Japan's 300. Parties simply have fewer districts to worry about. Second, as part of Taiwan's electoral reform, the total number of seats was cut in half. That meant that Taiwan had large numbers of incumbents chasing a relatively small number of seats. Third and most important, like the LDP and unlike the DPJ, both of Taiwan's major parties were well established and had already amassed reservoirs of ambitious potential candidates within their ranks.

3. DPP cadres include party members of the Legislative Yuan, National Assembly, Taiwan Provincial Assembly, as well as Taipei and Kaohsiung city councils.

4. Both parties utilize more centralized methods to determine their candidates for party list vote. For more on party list nominations, see chapter 6 by Nemoto and Tsai in this volume.

5. Officially, the KMT nomination rules still include the clause allowing party members' votes to account for $30 \%$ of the decision. However, aspirants may agree to skip this stage, and in 2012 all KMT aspirants chose to use only polling results to determine nominations.

6. Interview with Lee Hung-chun, November 16, 2011.

7. Interview with Lin Shu-fen, November 16, 2011.

8. In-house sampling refers to a protocol used to determine which member of the household should respond to the survey. Typically, the interviewer determines how many adult males and females live in the residence. Based on these numbers and a predetermined schedule, the interviewer will ask to speak to, for example, the second-oldest female. On in-house sampling, see Hung 1996.

9. Interview with deputy secretary general Hung Yao-fu, November 14, 2011.

10. The interparty comparison was used when the DPP candidate's support was higher than the KMT candidate's. Where the KMT candidate was more popular 
than any of the DPP candidates, an intraparty head-to-head question was used. However, most of the districts that required a polling primary were those in which the DPP was more popular, so we consider the interparty comparison to be the default.

11. The DPP finished its nomination process before the KMT, so the KMT candidate was not always known. However, because of the KMT's landslide victory in 2008, most districts, including many of the DPP's stronger districts, had a KMT incumbent that the DPP assumed would be renominated in 2012 .

12. The KMT intentionally waited until the DPP had completed its nomination process so that it could choose the best candidate to match up with that specific DPP opponent. (Interview with a member of the KMT's think tank, Dr. Hsieh Hsian-chin, November 16, 2011.)

13. Interview with deputy secretary general Hung Yao-fu, November 14, 2011.

14. The fear over vote-buying was an important factor in the DPP's decision to move to a $100 \%$ polling primary in 2012. In November 2007, the KMT-dominated legislature revised the election law and made it illegal to buy votes in party primaries, not just in the general election. The DPP worried that the KMT would use its control over the bureaucracy to subject its nominees to intense scrutiny and might be able to disqualify some of them. Rather than fight the election with a roster of tainted candidates, the DPP simply eliminated the party-member voting section of its CSM.

15. Many people also worry that their party's CSM is vulnerable to manipulation by the other party. For example, KMT supporters might participate in the DPP's polling primary and express support for the weakest DPP candidate. These fears are probably overblown, and DPP deputy secretary general Hung Yao-fu even identified the low vulnerability of the polling primary to manipulation from the other party as one of its major advantages (interview, November 14, 2011). On the one hand, the closed party primaries were probably more vulnerable since the other party could strategically launch a registration drive and send large number of its supporters to vote in the other party's primary. In contrast, since polls are random, this action would need to be individually undertaken by large numbers of otherparty supporters who would further have to agree on who the weakest contestant was. The polling primary simply makes the coordination costs very high. On the other hand, anecdotal evidence suggests that the same people who are worried about the other party manipulating their nominations tend to be disinterested in manipulating the other party's nominations.

16. A common sarcastic jab is that DPP no longer stands for Democratic Progressive Party (minjindang); now it stands for Democratic Polling Party (mindiaodang).

17. A nonpartisan civic movement emerged in 1990 to use kobo to cultivate and promote fresh candidates without party stigma for local executive offices. The movement originated in the mayoral election in Asahikawa City, Hokkaido, and it gradually spread to other prefectures around the country over the next few years. The popularity of this movement and the media attention it drew might have had some impact on the decision of parties to try kobo.

18. No party has used kobo for the selection of PR-only candidates.

19. The three smaller parties were Minsei To (Good Governance Party, 1998), 
Shinto Yuai (New Fraternity Party, 1998), and Minshu Kaikaku Rengo (Democratic Reform Party, 1989-98).

20. In addition to these general ones, the DPJ headquarters conducted a femalefocused kobo in 1999 and a district-specified kobo in 2005. The latter was special in the sense that vacant districts were listed in advance; they had remained available because they were all extremely difficult for the DPJ.

21. We located in newspapers nine cases of kobo conducted by the DPJ kenrens at the prefecture level for the HR elections between 2000 and 2009, and there might have been more. However, these cases were not recognized by the national headquarters, and no systematic records have been kept for them. For this paper, we focus on the national kobo conducted by the headquarters.

22. The number of kobo candidates differs across studies due to the way of counting. More than a few cases of kobo were observed that were called kobo by the kenrens but were not recognized by the national headquarters. Here in this chapter, we focus on those that were officially recognized by the national headquarters.

\section{REFERENCES}

Asano, Masahiko. 2006. Shimin Shakai ni Okeru Seido Kaikaku: Senkyo Seido to Koubosha Rikuruto [Institutional reform in civil society: Electoral system and candidate recruitment]. Tokyo: Keio University Press.

Browne, Eric, and Dennis Patterson. 1999. "An Empirical Theory of Rational Nominating Behavior Applied to Japanese District Elections.” British Fournal of Political Science 29:259-89.

Cheng, Tun-jen. 1989. "Democratizing the Quasi-Leninist Regime in Taiwan." World Politics 41 (4): 471-99.

Cox, Gary W., and Emerson Niou. 1994. "Seat Bonuses under the Single Nontransferable Vote: Evidence from Japan and Taiwan." Comparative Politics 26:221-36.

Cox, Gary W., and Frances Rosenbluth. 1993. "The Electoral Fortunes of Legislative Factions in Japan.” American Political Science Review 87 (3): 577-89.

Cox, Gary W., and Michael F. Thies. 1998. "The Cost of Intraparty Competition: The Single Non-transferable Vote and Money Politics in Japan." Comparative Political Studies 31 (3): 267-91.

Gallagher, Michael, and Michael Marsh, eds. 1988. Candidate Selection in Comparative Perspective: The Secret Garden of Politics. London: Sage.

Hazan, Reuven Y., and Gerrit Voerman. 2006. "Electoral System and Candidate Selection." Acta Politica 41:146-62.

Huang, Teh-fu. 1996. "Elections and the Evolution of the Kuomintang." In Taiwan's Electoral Politics and Democratic Transition: Riding the Third Wave, ed. Tien Hung-mao. Armonk, NY: M. E. Sharpe.

Hung, Yung-tai. 1996. Huzhong Xuanyang zhi Yanjiu [In-house sampling]. Taipei: Shihying.

Inada, Shigeru. 2009. Seshu Giin: Kozo to Mondaiten [Hereditary MP: Background and problems]. Tokyo: Kodansha.

Kasapovic, Mirjana. 2001. "Nominating Procedures in Democratic Polities." En: Politicka Misao 38 (5): 3-17.

Krauss, Ellis S., and Robert Pekkanen. 2004. "Explaining Party Adaptation to Elec- 
toral Reform: The Discreet Charm of the LDP?" Fournal of Japanese Studies 30 (1): $1-34$.

Krauss, Ellis S., and Robert Pekkanen. 2011. The Rise and Fall of Japan's LDP: Political Party Organizations as Historical Institutions. Ithaca: Cornell University Press.

Lundell, Krister. 2004. "Determinants of Candidate Selection: The Degree of Centralization in Comparative Perspective." Party Politics 10 (1): 25-47.

Norris, Pippa. 1997. Passages to Power: Legislative Recruitment in Advanced Democracies. Cambridge: Cambridge University Press.

Ranney, Austin. 1981. "Candidate Selection." In Democracy at the Polls: A Comparative Study of National Elections, ed. David Butler, Howard R. Penniman, and Austin Ranney, 75-106. Washington, DC: American Enterprise Institute.

Scheiner, Ethan. 2006. Democracy without Competition in Fapan: Opposition Failure in a One-Party Dominant State. Cambridge: Cambridge University Press.

Shoji, Kaori. 2013. "DPJ Kobo on the Ground: Opening Candidate Nominations without Democratization" [in Japanese]. Gakushuin Diagaku Hougakkai Zasshi [Gakushuin Review of Law and Politics] 49 (1): 181-210.

Shomer, Yael. 2012. "What Affects the Candidate Selection Process? A CrossNational Examination." Party Politics, published online, April 11. http://dx.doi. org/10.1177/1354068811436060.

Smith, Daniel M. 2013. "Candidate Recruitment for the 2012 Election: New Parties, New Methods . . . Same Old Pool of Candidates?” In Fapan Decides 2012: The Fapanese General Election, ed. Robert Pekkanen, Steven R. Reed, and Ethan Scheiner. Hampshire, NY: Palgrave.

Smith, Daniel M., Robert J. Pekkanen, and Ellis S Krauss. 2013. "Building a Party: Candidate Recruitment in the Democratic Party of Japan, 1996-2012.” In Fapan under the DPF: The Politics of Transition and Governance, ed. Kenji E. Kushida and Phillip Y. Lipscy. Stanford: Walter H. Shorenstein Asia-Pacific Research Center.

Uesugi, Takashi. 2009. Seshu Giin no Karakuri [Tricks of hereditary MPs]. Tokyo: Bungei-Shunju.

Wang, Yeh-Lih. 2006. Bijiao Xuanju Zhidu [Comparative electoral systems]. Taipei: Wunan Book.

Wu, Chung-li. 2001. "The Transformation of the Kuomintang's Candidate Selection System." Party Politics 7 (1): 103-18.

Wu, Chung-li. 2008. Zhengdang yu Xuanju: Lilun yu Shijian [Political parties and elections: Theory and practice]. Taipei: Sanmin.

Wu, Chung-li, and Dafydd Fell. 2003. "Taiwan's Primaries in Comparative Perspective." Japanese Fournal of Political Science 2 (1): 23-45. 


\title{
Post Allocation, List Nominations, and Preelectoral Coalitions under MMM
}

\author{
Kuniaki Nemoto and Chia-bung Tsai
}

A theory of electoral systems (Shugart 2001) predicts that the move from SNTV to MMM should produce a trend away from personal politics and toward party-centered politics. The literature on the recent elections in Japan suggests that party labels and the leadership's popularity now significantly influence candidates' electoral fortunes (McElwain 2012; Patterson and Maeda 2007) and clientelism is now being replaced by programmatism (Rosenbluth and Thies 2010). Furthermore, in 2009 Japan had a government turnover through elections for the first time in more than 60 years, because the combination of the DPJ's potential and disillusionment with the LDP government's policy performance convinced most swing voters: a poll on the 2009 turnover, for example, showed that $61.2 \%$ of voters thought party reputations were important in making voting decisions, compared to $29.0 \%$ who considered individual candidates' personal traits as important (Akarui Senkyo Suishin Kyōkai 2010). Reed, Scheiner, and Thies (2012) argue that the swings in Japan's recent elections are built on coherent party images and in particular parties' programmatic policy manifestoes, showing that "candidates' party affiliation mattered more for their chances of victory than their individual résumés" (373).

This record high importance attached to party label is a flip side of the fact that the importance of individual candidates has been declining over time. Surveys conducted in the mid-1960s found $60.4 \%$ of the vot- 
ers in Japan voted on the basis of the candidate, compared to $43.3 \%$ in the United States, 32.5\% in Canada, 23.8\% in Germany, and 5.4\% in the United Kingdom (Rochon 1981). This candidate-based voting was dominant until the 1993 elections, the last elections before the electoral reform, with nearly a half (49.1\%) of the voters still voting based on the candidate (Akarui Senkyo Suishin Kyōkai 2010).

Against this background, this chapter investigates how parties strategically adapted themselves to the new electoral environment. Specifically, it compares what parties do between and during election periods in order to maximize votes and seats, how this has changed compared to the prereform SNTV period, and how the two countries differ. A simple prediction is that parties should concentrate their efforts on appealing to voters with their policymaking abilities and attractive public policy pledges.

Beyond this simple prediction, however, there should be many more vote mobilization strategies that parties can adopt. Their choice from among these strategies should depend on the institutional contexts in which parties compete and the institutional resources available for the party leadership to utilize. The basic argument throughout this chapter is that, as articulated by Batto and Cox in their introductory chapter, the transition from SNTV to MMM should simplify the intraparty bargaining process for leaders to utilize such resources. This is because, compared to SNTV, which systematically generates intraparty fragmentation and factionalism (Grofman 1999), MMM increases the importance of party reputations, policy platforms, and leaders' popularity in electoral competition (Shugart 2001). Consequently, MMM centralizes the power of the party leadership against intraparty factional bosses, to the extent that parties should use available tools and resources more strategically to maximize votes and seats.

Among the many strategies, we focus on three areas: post allocation, list nomination, and candidate coordination. Along with the main argument briefly articulated above, party leaders should be now expected to (1) allocate cabinet positions and other privileges more autonomously from intraparty factions to members; (2) nominate candidates with clean and fresh images at the top of party lists, such as women and professionals who are widely known across the country; and (3) form preelectoral coalitions in the nominal SMD tier to solicit small party supporters. We generally find that parties in both Japan and Taiwan are moving toward these expected directions, suggesting that they are indeed strategically adapting themselves to the new electoral environment.

However, we also argue that nuanced but very important rules- 
the constitution and the dual candidacy with the best loser provisioninstitutionally constrain parties' strategies to the extent that these naïve expectations do not hold under certain contexts. First, compared to a parliamentary system, where appointing legislators to cabinet positions serves as institutional bonding for the cabinet to maintain the confidence of the legislature, semipresidentialism implies much more independence between the president and ruling party members. Therefore in Taiwan, promoting and demoting legislators cannot be as effective as in parliamentary Japan. Second,Japan's somewhat unique "best loser provision"-dually nominated candidates can have the same ranks and their actual ranks are determined by their performance in their SMDs-makes it difficult for leaders to give favorable positions to quality candidates. Rather, leaders now simply put almost all the SMD candidates on a level playing field. Meanwhile, the absence of such a provision enables Taiwanese leaders to be more strategic in selecting and rank-ordering list candidates. Third, the presence of the list tier, on which small parties rely for their electoral survival, makes candidate coordination rather complicated in mixed-member systems. Large parties in parliamentary Japan can credibly commit not to exploiting small parties by appointing ministers and forging coalition agreements, but the presence of presidential coattails and interbranch independence in Taiwan can make coordination between parties for candidate entry rather difficult.

This chapter is organized in three sections. First, we will discuss how parties allocate posts for electoral purposes in Japan and Taiwan. Second, we will discuss how they nominate candidates on the list tier, where parties' images and reputations matter greatly. Third, we will investigate how they coordinate candidates and form preelectoral coalitions to maximize the chance of winning SMD seats.

\section{Post Allocation Strategy}

This section focuses on how parties strategically allocate posts in the government to incumbents for electoral purposes. As Kobayashi and Tsukiyama show in chapter 3, prior to reform SNTV's intraparty fragmentation effects made the bargaining process for post allocation rather complicated. Since factional heads vied for the limited number of lucrative positions in the government, the prime minister needed to allocate cabinet positions proportionally to each of the factions according to their sizes (Ramseyer and Rosenbluth 1993). In addition to this norm of the factional balance ( habatsu kinko), promotion of backbenchers to legislative committee chairs, 
vice ministers, and ministers was strictly determined based on seniority (nenko joretsu). These party rules were effective methods to contain ambitious factions and keep the party united (Nemoto, Krauss, and Pekkanen 2008), but significantly constrained the leadership.

The transition to MMM should simplify this intraparty game for two reasons: first, factional heads' influence should become weaker; and second, the leadership can exercise greater influence based on the everincreasing importance of party labels and leaders' image. Thus, the leadership should more freely and strategically target certain members when giving out the government's privileges. Thus Kobayashi and Tsukiyama show that the prime minister's faction now receives disproportionately more posts in the cabinet.

This section further explores how this centralized control over posts now enables the leadership to utilize post allocation for electoral purposes, in line with Pekkanen, Nyblade, and Krauss (2006). They show that marginal members, such as zombies who were defeated in SMDs but still elected by PR, were more likely to assume posts connected to private and particularistic goods, so that they could improve name recognition in their districts and return to the Diet in the next election. They also show that senior and famous figures were assigned to high-policy posts, such as ministers for security and treasury, so that the party could improve its policymaking reputations.

However, the temporal trend shown in figure 6.1 suggests that parties give fewer positions to electorally marginal members (i.e., zombies) over time. Rather, being elected on the SMD tier has become nearly a necessary condition for a member to become a full minister since 2005. Zombies and PR members are now less likely to assume lower-level positions (vice ministers and legislative committee chairs) than in 1996, 2000, and 2003. The DPJ governments avoided electorally marginal members in assigning new Diet committee chairs and party posts after the 2009 election: the then secretary-general of the DPJ, Ichiro Ozawa, prioritized SMD winners and made it clear that the party wouldn't give important posts to those elected on PR (Asabi Shimbun, October 15, 2009, 4). Rather, he ordered first-term members and zombies to go back to their local districts often and expand their supporter bases (Asabi Shimbun, October 30, 2009, 4). This appears to be somewhat incompatible with what Pekkanen, Nyblade, and Krauss (2006) find, especially given that now Japanese parties make the most use of dual candidacy and there are more and more zombies that the leadership needs to take care of.

We suggest that Pekkanen, Nyblade, and Krauss (2006) might have 


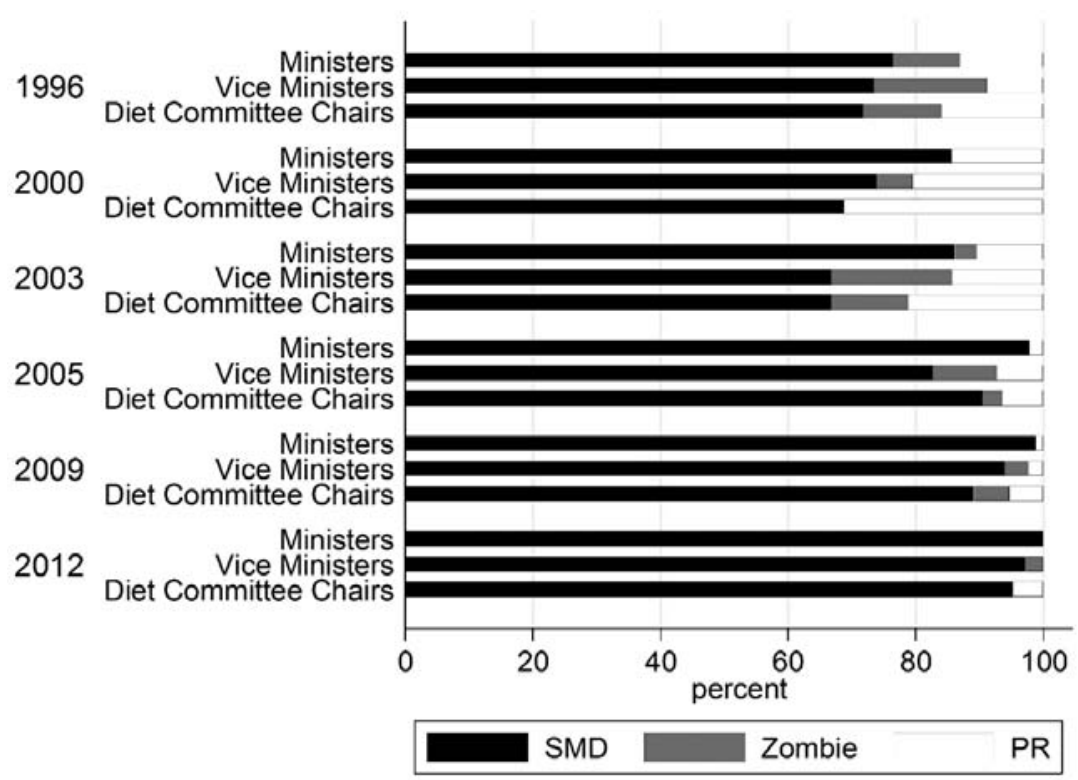

Fig. 6.1. Lower-house members in government and Diet posts by different types

ignored two things. One is a counterintuitive consequence from their model: if you want to increase the chance of getting good positions, you need to lose in the nominal tier. Thus, appointing marginal members to good positions should result in the problem of moral hazard, although it is somewhat unrealistic to assume that some SMD candidates might want to lose. The second thing is the change that the electoral reform could bring about: the decline of particularism and clientelism (Noble 2010). Thus, over time, the idea of having backbenchers use posts to allocate subsidies and other private goods to their districts should have become untenable, especially given the shrinking budgets of the Japanese government.

These factors combined lead us to suspect the leadership gradually changed its appointment patterns from posts as "carrots to marginal members" to posts as "sticks to tame backbenchers." We argue that, as party reputations become more important than ever, the leadership now needs able and efficient ministers to lead bureaucrats, respond to tough questions from the opposition in the Diet, and implement the party's policy platforms. The LDP leadership gradually appointed loyal and able lawmakers, while intentionally ignoring the factional balance and seniority norms (Nibon Keizai Shimbun, September 19, 2006, 14; also see Nemoto, Krauss, 
and Pekkanen 2008). Therefore, it could be hypothesized that, as long as posts in the government and the Diet are valued by members in getting attention from the media and exerting influence over the policy-making process, the leadership can encourage backbenchers to work harder in their local districts by appointing more SMD winners to these posts. This whipping strategy should look more appropriate under MMM than the compensation strategy.

As one rough test for this hypothesis, we divided LDP members in 2000-2009 into four groups according to their SMD performance in two consecutive elections (1996-2000, 2000-2003, and 2003-5): (1) those who won SMDs in the first elections but won in the second as zombies (SMDZombie); (2) those who won as zombies for the two consecutive elections (Zombie-Zombie); (3) those who won as zombies in the first but won SMDs in the second (Zombie-SMD); and (4) those who won SMDs continuously (SMD-SMD). If Pekkanen, Nyblade, and Krauss's (2006) compensation story is correct, we should find more members promoted in the SMDZombie category. Meanwhile, if the leadership instead uses promotion to whip lazy members and reward hard workers, then those who lost their seats (SMD-Zombie) should be punished and those who regained their seats (Zombie-SMD) should be promoted. Here, in line with the literature (Ramseyer and Rosenbluth 1993, 86), we coded a member's promotion as his/her moving up the career ladder of (I) no post; (II) vice minister; (III) Diet committee chair; (IV) minister; and (V) second-time (or higher) minister. $^{1} \mathrm{~A}$ note of caution is required in interpreting the results in figure 6.2 , as by its nature the sample here excludes those who didn't run in the nominal tier for the two consecutive elections, and most (87.0\%) of the 508 observations are concentrated in the upper-left "SMD-SMD" cell.

Interestingly, the figure suggests that, contrary to the compensation story, the "SMD-Zombie" category in the upper-right cell is the least likely to get promoted. This implies that they are punished for losing their seats. On the other hand, consistent with the whipping story, the "Zombie-SMD" category in the lower-left cell is the most likely to get rewarded, suggesting that those who ousted opposition district incumbents were seen as making the biggest contributions to the party. The lower-right "Zombie-Zombie" cell looks slightly puzzling as nearly half of them were promoted, but six out of the 11 in this entry were in fact "favorably ranked" (discussed in the next section) hopeless candidates who continuously challenged invincible opposition party leaders. Excluding these loyal hard workers, only one (20\%) of the five in the "Zombie-Zombie" category was promoted.

Moving on to the case of Taiwan, we expect that in contrast to parlia- 


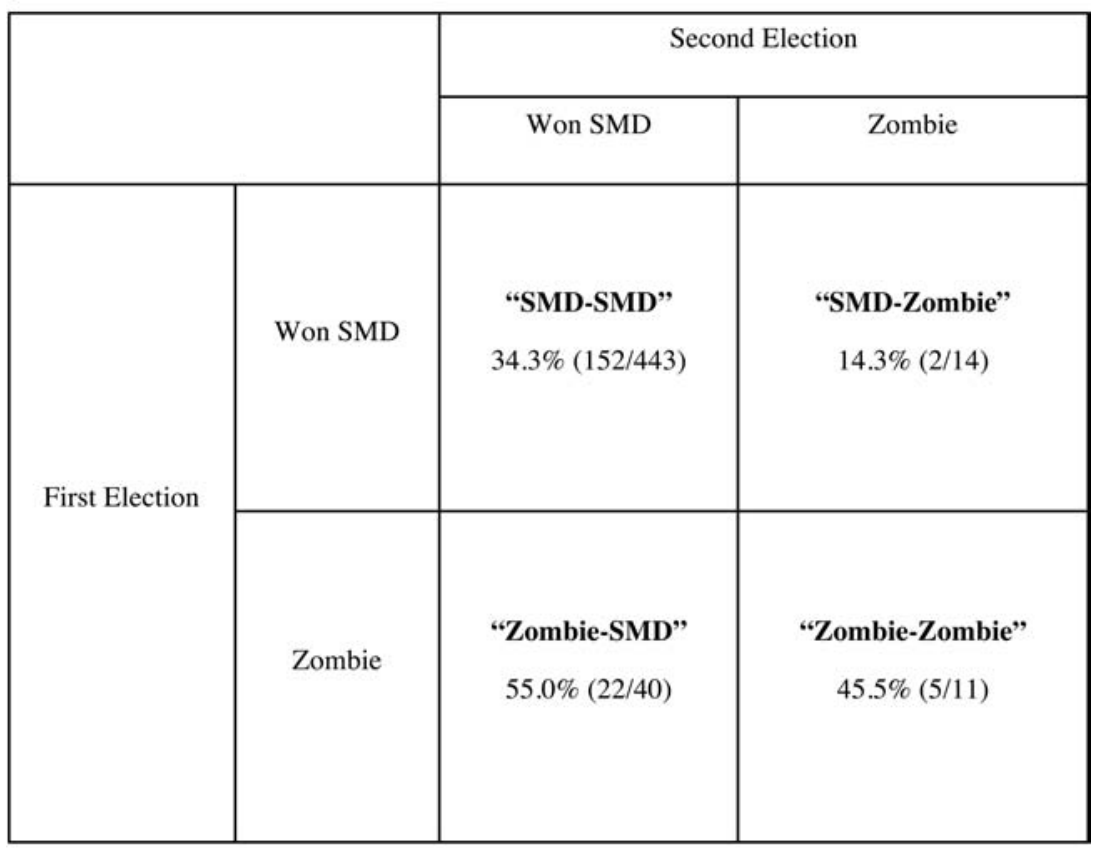

Fig. 6.2. LDP members' promotion, 2000-2009

mentary Japan, the same logic should not hold under the semipresidential regime, as Lin shows in chapter 2. In parliamentary Japan, the stakes are high for backbenchers to win their seats and expand the party's size in the legislature, as it will directly increase their chance of becoming ruling party members and getting promoted in the government. In other words, legislative confidence results in a much closer alignment between appointments and vote-seeking incentives. Meanwhile, even though the Taiwanese president may be able to appoint legislators as ministers, he or she does not really have to do so, as he or she is independently elected by the people and his or her survival does not rely on legislative confidence. And legislators' reelection incentives should only be weakly tied to their office-seeking incentives-when they are appointed as ministers, they have to resign their legislative seats, which are won independently from the president.

However, some recent anecdotes suggest that a somewhat similar story applies to the Taiwanese context. For example, a former cable TV news anchor, Chen Yi-chen, was picked directly by the KMT's central headquarters to run in Chiayi, one of the DPP's strongholds in southern Taiwan 
(Taipei Times, August 8, 2011, 3). She also helped President Ma Ying-jeou organize his campaigning office in the south (Taipei Times, August 21, 2011, 3 ) and reportedly, rather than winning seats in the Legislative Yuan, Chen and the other KMT candidates running in the opposition's strongholds were expected to shore up support for $\mathrm{Ma}$ in the presidential election to be held on the same day (Taipei Times, September 20, 2011, 3). Although Chen lost, Ma still valued her efforts highly, as they helped the party deepen its ties with supporters (China Post, January 20, 2012), and he appointed her to be National Youth Commission minister after the election (China Post, February 1, 2012). In total, after the 2012 legislative elections, the KMT used cabinet positions as carrots when it rewarded five losers who had run against very strong opponents by appointing two as ministers, one as a deputy minister, one as head of a party branch, and one as spokesperson for the Executive Yuan.

In addition to compensating losers with positions in the cabinet, the KMT is also using these positions to develop winnable candidates to compete with the DPP, especially in southern Taiwan. Reportedly the Executive Yuan was to restructure the administration by the end of 2012 and planned to have Chen Yi-chen, the aforementioned minister appointed right after the 2012 elections, lead a regional branch office in Chiayi City (Taipei Times, June 26, 2012, 1). The DPP criticized the KMT government over the move, as she was rumored to be preparing to run for the 2014 mayoral election in the city, a Pan-Green stronghold. The DPP even speculated that she might leverage the regional administration position to improve her local name recognition for the upcoming election (Taipei Times, July 14, 2012, 3). Similarly, when Lin Yi-shih had to step down as minister because of corruption charges, the media reported that it was a major loss for President Ma, who had been grooming Lin, a southern Taiwan native, as the KMT's candidate in the next Kaohsiung mayoral election. Lin had been given him the positions of head of the party's youth corps, vice chair of the party, chief executive of the party's Policy Coordination Committee, and cabinet secretary-general (China Times, June 30, 2012, 4).

The flip side of all this is that the leadership can use cabinet appointments as sticks: it can demote members when they do not conform to its expectations. For example, in the 2008 elections, Wang Yu-ting represented the KMT in Tainan's 1st District, one of the DPP's strongholds, and lost. In exchange for her campaigning efforts, the president gave her the cabinet-level position of chairperson for the National Youth Commission, with an eye toward using the Tainan native again in future elections to expand the party's support bases in the south. The chance came in 2011, 
when a seat in Tainan was made vacant and a by-election was scheduled, but she chose not to accept the KMT's request. The KMT's secretarygeneral, King Pu-tsung, said, "[She was] nurtured by the party, but refused to step up when needed. . . A A warrior does not have the right to choose the battles" (China Post, January 18, 2011), implying the party would punish Wang for her insubordination. Together with another KMT cabinet member, Kao Su-po, who also declined to go back to his district and run in the by-elections, Wang was summarily fired from her cabinet post. ${ }^{2}$

These anecdotes about cabinet appointments present an interesting contrast to the SNTV period. When SNTV was in place, the president chose to appoint his own followers inside the party, while not considering the optimal use of right talents with appropriate skills in the right places. For example, when President Chen Shui-bian reshuffled his cabinet in January 2002, the media reported that, by assigning his own people and some political moderates to key posts, Chen eliminated all DPP leaders who had made contributions to his presidential election victory, to the extent that the newly appointed ministers lacked professional expertise (China Post, January $25,2002,19)$. The DPP's intraparty factional struggles went on and resulted in a series of party reform attempts to eliminate factionalism (Taipei Times, June 21, 2004, 4). ${ }^{3}$

But a crucial difference from Japan should be noted. Despite the episodes above, which suggest that the Taiwanese party leadership can sometimes strategically use cabinet positions for electoral purposes, it is still rare that former legislators are appointed to the cabinet, as figure 6.3 shows. Of the 503 ministers appointed since the late 1990s, only $11.3 \%$ had experience serving in the legislature, ${ }^{4}$ suggesting that only on rare occasions were cabinet posts used as carrots for hard workers. Instead, as in other presidential democracies, cabinet posts usually went to technocrats, academics, and others from nonlegislative backgrounds, whereas in Japan it is rather rare to appoint nonlegislators to the cabinet. ${ }^{5}$

Party members using cabinet positions as stepping-stones for electoral positions are also still rare. For example, of the 68 cabinet members appointed by President Ma between 2008 and 2012, only five (7.4\%) ran for election, and their performance was not impressive. Four of them ran in the 2012 Legislative Yuan elections: Yang Chih-liang and Yin Chi-ming were unsuccessful list-tier candidates, while Chiang Chi-chen and Su Junpin ran for SMDs in Taichung and Tainan, respectively, with only Chiang being successful. Chu Li-lun stepped down as deputy premier in 2010 to defeat the DPP's eventual 2012 presidential candidate, Tsai Ing-wen, in the New Taipei City mayoral election. 


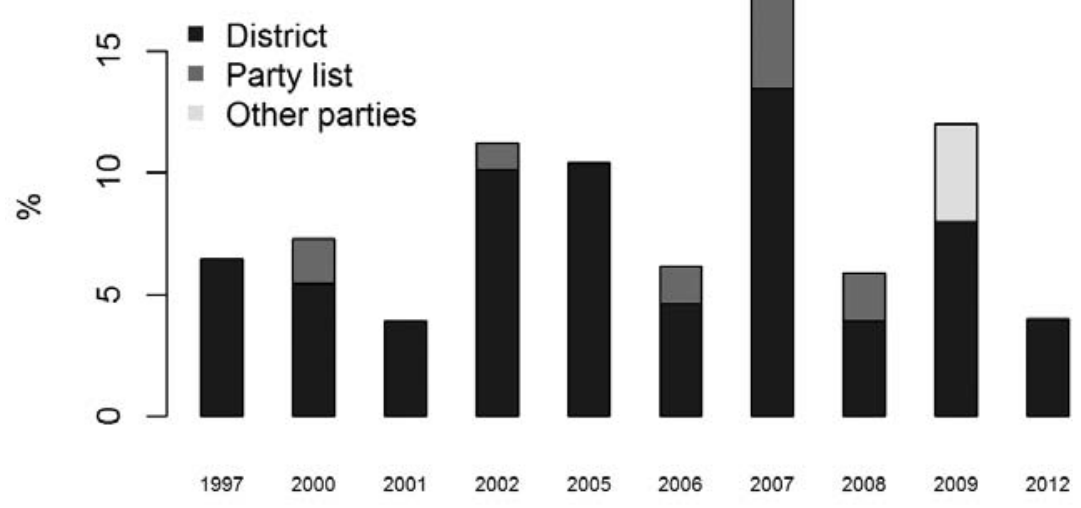

Cabinets

Fig. 6.3. Proportion of former legislators as cabinet ministers in Taiwan, 1997-2009

(Note: Percentage is the number of incumbent district or party-list legislators divided by the total number of cabinet ministers. Because the premiers may appoint more than one person to a cabinet post, the denominators could be different from period to period. The KMT formed the cabinets between 1997 and 2000, and from 2008 to present.)

Ultimately, these differences are the result of the constitutional differences between Japan and Taiwan. In contrast to parliamentary Japan, where cabinet appointments are much more closely aligned with a party's vote-seeking incentives, the president's survival in semipresidential Taiwan does not rely on legislative confidence, and therefore the incentive to strategically use government positions to tame backbenchers is substantially weaker. Indeed, the Taiwanese president can appoint anyone to the cabinet, including an opposition party member. For instance, President Chen appointed a retired air force general and KMT member Tang Fei as his first premier in 2000. In 2008, President Ma chose a former Taiwan Solidarity Union (TSU) legislator, Lai Shin-yuan, as the chair of the Mainland Affairs Council, even though KMT backbenchers demanded that the president give priority to the party's loyal members when making cabinet appointments (Taipei Times, April 30, 2008, 5).

In sum, the evidence we offer here suggests that parties in both Japan and Taiwan are now gradually making the strategic use of positions in the government for electoral purposes. This stands out in contrast with the SNTV period, when the leadership had a much smaller voice in allocating posts because of the intraparty factional constraints. By promoting those 
who are loyal and demoting those who are disloyal, parties use government posts as carrots and sticks, although the decline of particularism caused by MMM seems to have made cabinet appointments less attractive as carrots. Nevertheless, the constitutional difference explains why Taiwanese presidents' use of these important governmental resources is still limited.

\section{List Nomination Strategy}

Candidate selection and nomination is also one of the party strategies to win more votes, as the nature of electoral systems systematically determines what types of candidates are more popular. Therefore, we should observe how parties adjust their candidates accordingly (Hazan and Rahat 2010; Siavelis and Morgenstern 2008). As discussed by Yu, Shoji, and Batto in chapter 5, under Japan's SNTV incumbents were given endorsements as long as they wanted to run, as they were proven to be electorally powerful enough to win seats. When a member announced his or her retirement and an open seat was created, factional heads would engage in some bargaining but most often the retiring member's close relative (most often his or her son) was picked up to fill the vacancy for that faction (Ishibashi and Reed 1992). This is because koenkai were very costly to maintain and it was very difficult for the other factions to challenge those inherited seats from scratch. Thus, beyond giving nominations to incumbents or second- (or even third- or fourth-) generation hereditary candidates, parties' roles in the candidate recruitment and selection process were very minimal.

The change to MMM should be expected to simplify this intraparty bargaining process among factions and therefore bring about some changes in parties' nomination strategies. One such change is the diminished influence of factions. As Kobayashi and Tsukiyama show in chapter 3, now the leadership exercises more centralized power in nominating candidates in favor of its faction members. Another consequence is that the leadership can more strategically select those who would fit best into the new institutional environment. For instance, as Yu, Shoji, and Batto show in chapter 5 , Japan's major parties now utilize the public recruitment ( $k o b o)$ system to select attractive candidates on the nominal tier. In this section, we primarily focus on the list tier on which voters cast party votes. We expect that parties will try to nominate new candidates with fresh images, such as women or professionals who are well known nationwide, on the PR list in order to mobilize more party votes.

In Japan, there are some signs that parties try to entice the voter with 
attractive PR lists. When the LDP lost in the 1993 elections, it started discussing the introduction of an age limit for list candidates so that its PR lists would have a new image that could appeal to voters (Asabi Shimbun, September 8, 1993, 8). Although it took a couple of years for the leadership to convince veteran members, the party finally decided in 1995 to impose an age limit of 73, although when to actually impose it was made unclear (Asabi Shimbun, May 24, 1995, 2). After rounds of discussions, the LDP imposed this age limit beginning in the 2000 elections to all the candidates desiring to run on the list tier, except for the two former prime ministersYasuhiro Nakasone and Kiichi Miyazawa-who were guaranteed the top ranks in the list tier for life (Asahi Shimbun, January 28, 2000, 6). In 2003, these exceptions were finally dumped by Prime Minister Junichiro Koizumi, as the LDP needed to appeal to voters with "how the party was trying to transform itself" (Asabi Shimbun, October 15, 2003, 4). According to opinion polls, a great majority (77\%) of voters supported this abolishment of the exceptions (Asabi Shimbun, November 2, 2003, 2). The DPJ followed the move in 2004, when it decided to impose the age limit at 70 to show the voters that it was more reform-minded than the LDP (Asabi Shimbun, February 16, 2004, 2). At the same time, the DPJ also decided to demote candidates' ranks in the list if they lost two consecutive elections in the nominal tier, while banning any relative within the third degree from inheriting a retiring member's district (Asabi Shimbun, May 2, 2004, 1), ${ }^{6}$ as this seat inheritance practice looks to the Japanese voter very undemocratic and unfair.

Introducing the age limit was also designed to replace top-rank PR candidates with more attractive ones, as who sits atop a party's PR lists symbolizes whom the party is really meant to represent. In 2005, the LDP nominated 10 eye-catching female candidates with diverse career backgrounds at the top in most of the lists (Asabi Shimbun, August 30, 2005, 2). Described as "lipstick ninjas" armed with "blood-red lipstick and a killer smile" by the foreign media (Washington Post, September 3, 2005, 28), most of them were political amateurs without previous experience in the Diet. They were picked directly by Prime Minister Koizumi and his aides, so that they could give the voter the impression of change in the traditionally male-dominated party. Most of them (8 of 10) were also dually nominated at the nominal tier to compete with those who defected from the LDP to oppose Koizumi's postal reform agenda, giving the voter a choice of the old LDP vs. the new LDP. ${ }^{7}$

But some important institutional settings-dual candidacy and list ranking based on margins with the winner (sekihai ritsu)—somewhat constrain 
the leadership's list nomination strategies in Japan. The dual candidacy in Japan is unique in that candidates can be listed on the PR list at the same rank and their actual rankings are determined by how they perform in their SMDs, or, to be more precise, their vote margins with SMD winners. This dual candidacy at the same rank, or what is usually called the "best loser" provision, gives candidates the incentive to win as many votes as possible in their local SMDs, which is also compatible with parties' collective goal of seat maximization. But this provision makes it difficult to decide who should be prioritized in the list, as list-only candidates at safe ranks looked to SMD candidates as though they were free riders on the party (Asabi Shimbun, March 14, 2003, 4). For the same reason, it is also difficult to recruit high-profile professionals and celebrities as top-rank list candidates or to have a wide variety of list candidates recruited from different regions, different professions, and different genders, compared to Taiwan.

Let us illustrate this problem with a typical party list shown in table 6.1. In this Tohoku PR bloc, the LDP won six seats. Four of the 28 candidates were given favorable positions, while 23 candidates were given the same fifth rank. Note that eight candidates lost in their SMDs. However, of the eight losers, three were revived as zombies: Tokuichiro Tamazawa was favorably ranked in fourth place so that he got a sure win, even though he was unpopular in his district, having secured less than $40 \%$ of the votes relative to the invincible opposition leader, Ichiro Ozawa. Koji Futada and Atsushi Watanabe were also revived as they were close enough to the SMD winners compared to the other SMD losers from the LDP: for example, Masami Saito was also close, but unfortunately, his sekibai ritsu, or his votes relative to the winner, was lower than Futada's.

This combination of a few favorably ranked candidates with a clump of same-rank candidates was a typical LDP strategy until the early 2000s. However, now this practice is increasingly rare, as it is difficult to convince other LDP candidates why, in the example shown in table 6.1, the four (Sakamoto, Nakano, Sato, and Tamazawa) should be prioritized over the rest. Now it is less common to give discrete ranks near the top of the list, where a party can guarantee a sure win to the candidates without their having to perform well in the nominal contest. ${ }^{8}$ As shown in figure 6.4, by 2005 and 2009, large parties' nomination and list-ranking strategies seemed to converge, as SMDs became more competitive.

In Taiwan, the prohibition of dual candidacy on the single nationwide list tier with a district magnitude of 34 allows parties to more strategically use list candidates. The first strategy can be called a "regional reach-out strategy": parties can compensate for SMD outcomes with candidates from 
certain regions, given the regional divide between the KMT-dominant north and the DPP-dominant south. Figure 6.5 shows that $48 \%$ of list legislators the DPP nominated were from the KMT's strongholds in the north: Taipei City, New Taipei City, Keelung City, Taoyuan County, Hsinchu City and County, and Miaoli County, where the DPP expected uphill battles with the KMT. Although the DPP's party list in 2008 included only one former legislator from northern Taiwan (Ker Chien-ming), in 2012 its list included, in addition to Ker, Tuan Yi-kang, Wu Ping-jui, and Yu Tian, all of whom had been elected in the districts of northern Taiwan and therefore had some supporters in the region. Yu was the highest-ranked loser, while the other three all won list seats. In addition, Su Tseng-chang, the former premier, was listed at the marginal rank of 18 , and party offi-

TABLE 6.1. LDP's List for Tohoku Bloc, 2005, as a Typical Party List

\begin{tabular}{|c|c|c|c|c|c|}
\hline Won & Rank & Name & Incumbent & Gender & $\begin{array}{c}\text { Dually nominated / } \\
\text { Best loser's ratio } \\
\text { (where applicable) }\end{array}$ \\
\hline Yes & 1 & Goji Sakamoto & Yes & Male & \\
\hline Yes & 2 & Masashi Nakano & Yes & Male & \\
\hline Yes & 3 & Tatsuo Sato & Yes & Male & \\
\hline Yes & 4 & Tokuichiro Tamazawa & Yes & Male & Yes / 38.6\% \\
\hline Yes & 5 & Atsushi Watanabe & & Male & Yes / $92.7 \%$ \\
\hline Yes & 5 & Koji Futada & Yes & Male & Yes / 88.8\% \\
\hline Yes (in SMD) & 5 & Akinori Eto & Yes & Male & Yes \\
\hline Yes (in SMD) & 5 & Tadamori Oshima & Yes & Male & Yes \\
\hline Yes (in SMD) & 5 & Taro Kimura & Yes & Male & Yes \\
\hline Yes (in SMD) & 5 & Shun'ichi Suzuki & Yes & Male & Yes \\
\hline Yes (in SMD) & 5 & Toru Doi & & Male & Yes \\
\hline Yes (in SMD) & 5 & Ken'ya Akiba & Yes & Male & Yes \\
\hline Yes (in SMD) & 5 & Akihiro Nishimura & Yes & Male & Yes \\
\hline Yes (in SMD) & 5 & Shintaro Ito & Yes & Male & Yes \\
\hline Yes (in SMD) & 5 & Itsunori Onodera & Yes & Male & Yes \\
\hline Yes (in SMD) & 5 & Nobuhide Minorikawa & Yes & Male & Yes \\
\hline Yes (in SMD) & 5 & Toshiaki Endo & Yes & Male & Yes \\
\hline Yes (in SMD) & 5 & Takehiko Endo & Yes & Male & Yes \\
\hline Yes (in SMD) & 5 & Koichi Kato & Yes & Male & Yes \\
\hline Yes (in SMD) & 5 & Yoshitami Kameoka & & Male & Yes \\
\hline Yes (in SMD) & 5 & Takumi Nemoto & Yes & Male & Yes \\
\hline \multirow[t]{7}{*}{ Yes (in SMD) } & 5 & Masayoshi Yoshino & Yes & Male & Yes \\
\hline & 5 & Masami Saito & & Male & Yes / $87.6 \%$ \\
\hline & 5 & Atsushi Oikawa & & Male & Yes / $68.5 \%$ \\
\hline & 5 & Hidenori Hashimoto & & Male & Yes / $68.1 \%$ \\
\hline & 5 & Takaki Ono & & Male & Yes / $66.1 \%$ \\
\hline & 5 & Susumu Hasumi & Yes & Male & Yes / $45.9 \%$ \\
\hline & 28 & Takao Sato & & Male & \\
\hline
\end{tabular}




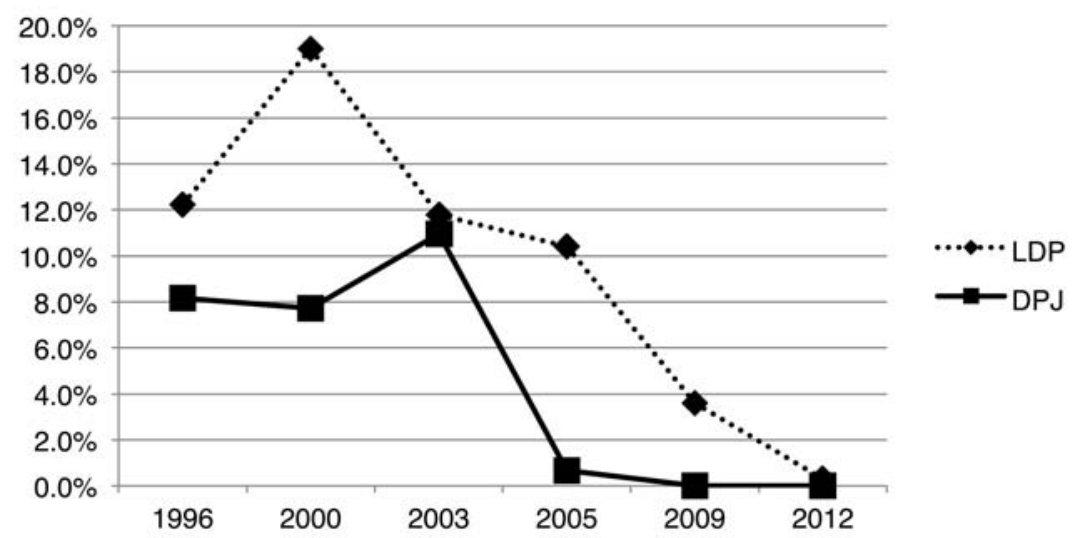

Fig. 6.4. Favorably ranked candidates from the LDP and DPJ

cials said that the very influential figure inside the party was strategically placed just outside the safe zone because he was expected to mobilize his supporters in New Taipei City, where he had previously headed the local government (Taipei Times, June 30, 2011).

To further explore how (dis)proportionally the two major parties nominate regional candidates on the list tier, we group the KMT's and DPP's list members in 2008 and 2012 by six regions and then put them in a scatter plot shown in figure 6.6. It is apparent that both parties did not recruit their list members in proportion to the population, with the exception of Taipei City and its suburban area. The DPP drew six list members from the least populated area-Yilan, Hwalien, and Taitung — while the KMT found 12 list members in Kaohsiung, Pingtung and Penghu, part of southern Taiwan. Compared to figure 6.5, which counts all of the list members after 1992, the result implies that the KMT has targeted southern Taiwan since the electoral reform.

In contrast to this regional strategy, a party can also choose what can be called a "group reach-out strategy": it can step up efforts to attract votes from a wide range of social segments by nominating a variety of representatives from disadvantaged and special interest groups. Compared to 2008, when the KMT's list candidates were mostly those incumbents who had to find places to run because of the downsizing of the Legislative Yuan (Taipei Times, November 8, 2007), the party in 2012 ambitiously tried to reach out to different minority groups. Seeing how the DPP reserved the second 


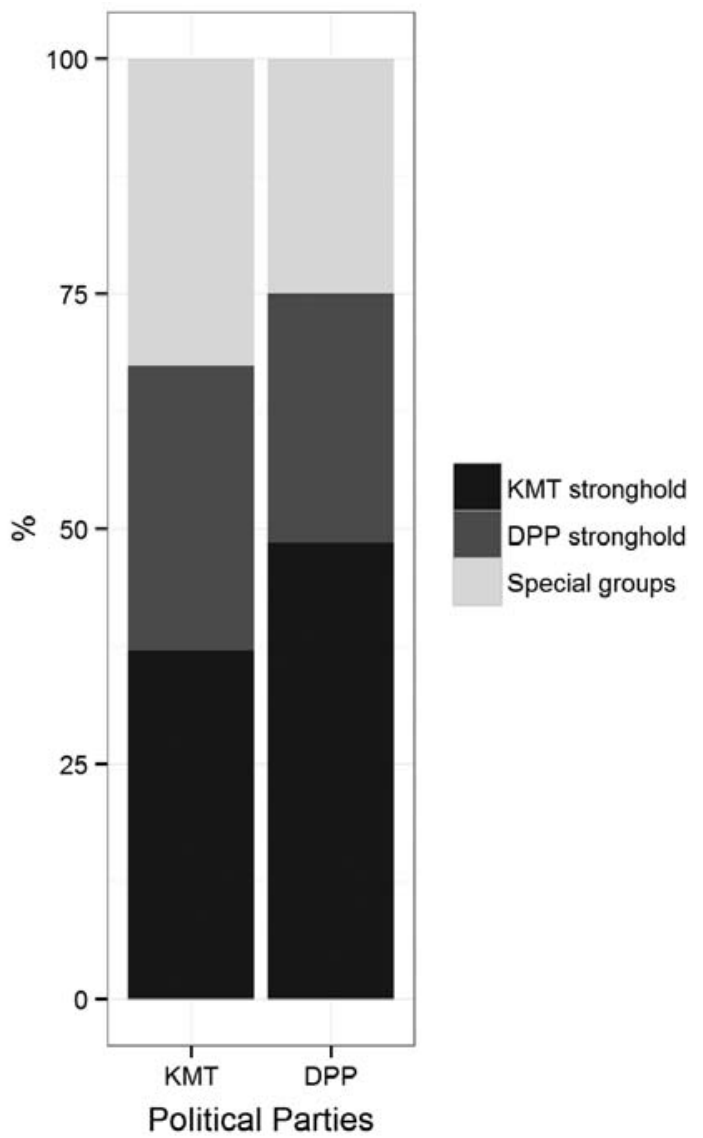

Fig. 6.5. Percentages of KMT's and DPP's list members from their own strongholds, their rival's strongholds, or special groups, 1992-2012 (Note: List members who have run in elections or served in the party organizations in the city/ county, or have been associated with the place, are considered influential in their own locale. The KMT's strongholds are defined as the city/county where the DPP's vote share is lower than the DPP's average national vote share. The DPP's strongholds are defined as the city/county where the DPP receives a higher vote share than its national one. Special groups refer to military, teachers, judges and social groups. $N=157$.)

spot for Chen Chieh-ju, president of the Yu-Cheng Social Welfare Foundation, and the third spot for Wu Yi-chen, a women's rights lawyer, the KMT reserved the second, third, and fourth spots for Wang Yu-min (the executive officer of the Child Welfare League Foundation), Tseng Chu-wei (a well-known public finance scholar), and Yang Yu-hsin (the secretarygeneral of the Taiwan Foundation for Disadvantaged Patients), respectively. The media and even the DPP's presidential candidate Tsai Ing-wen 


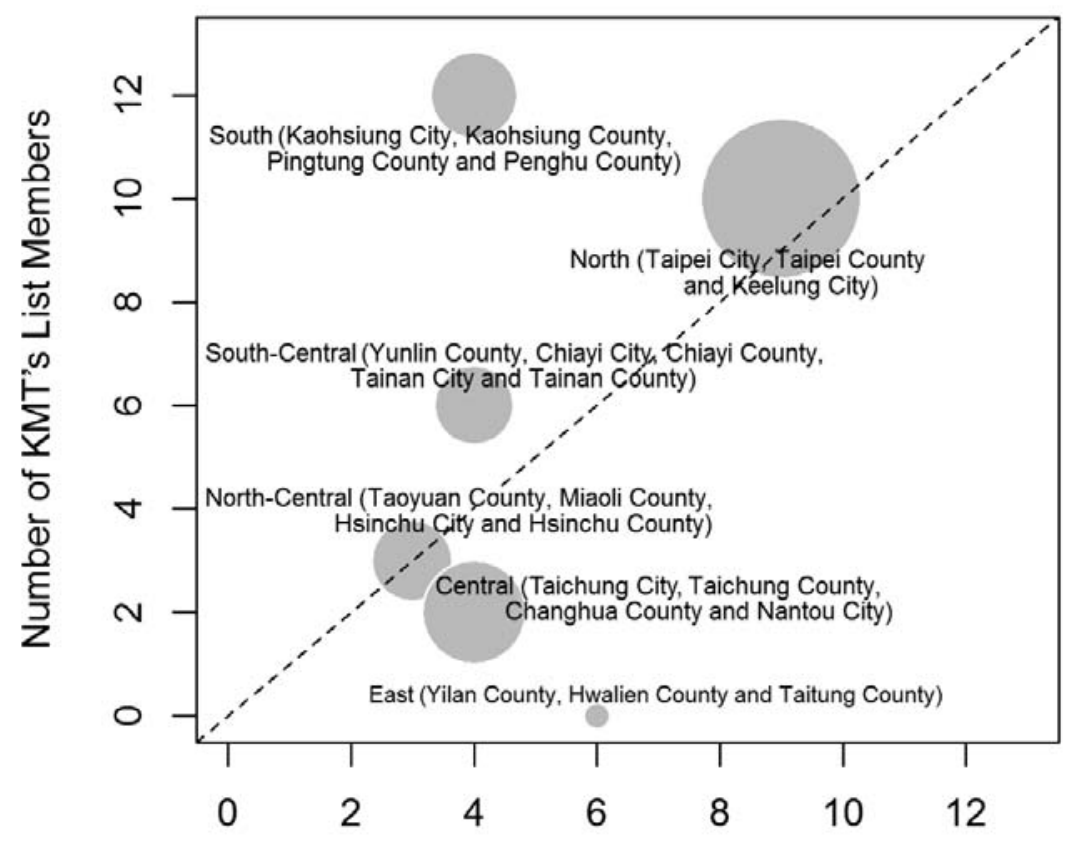

Number of DPP's List Members

Fig. 6.6. Number of two parties' list members clustered by regions, 2008 and 2012

(Note: Circles are in proportion to the population of each region, 2010.)

highly praised this aggressive recruitment: for example, the China Post (November 18, 2011) reported Tsai as saying: "It is good to see the [KMT] come up with a more diverse list of candidates for the at-large legislative seats, including activists representing underprivileged groups.... We do hope that the KMT nominations are more than just an election gimmick. Let's hope that it really marks a change of the party's mentality."

Note that these ambitious list nomination strategies cannot be expected to occur in Japan now, where major parties simply dually nominate on their lists SMD candidates, most of whom are from their local districts. One clear illustration of this is how parties treat women in Japan and Taiwan. As most of the list candidates are dually nominated now and male candidates are still dominant in the nominal tier, significantly fewer female candidates are nominated in Japan than in Taiwan: between 1996 and 2012, females accounted for only $5.1 \%$ and $11.3 \%$ of the LDP's and the DPJ's list can- 
didates, respectively. Meanwhile in Taiwan, even before the Constitution was amended in 2005 to require that half of list legislators must be women, political parties attempted to increase the share of female party-list legislators to improve their image. In the 2004 election for instance, the DPP allocated six out of 16 seats to women. ${ }^{10}$

In sum, with the transition to MMM, parties now have strategic reasons to offer attractive sets of candidates in the list tier. In light of this, Japanese parties started adopting age limits and installing fresh-image candidates and widely known professionals at the top. But with the best loser provision, Japan's parties now just choose to use the list tier only as a safety net for SMD candidates, by dually nominating almost all of them simply at the same rank so that they can maximize votes and seats on the nominal tier. This has resulted in the declining number of favorably ranked candidates. In contrast, parties in Taiwan can strategically nominate females, nationally well-known figures, and even candidates from the main opponent's strongholds to boost votes across the country.

\section{Candidate Coordination Strategy}

The third among various party strategies for vote mobilization that we discuss in this chapter is about candidate coordination, or preelectoral coalitions. Under SNTV, it is usually difficult for preelectoral coalitions to emerge for two reasons. First, if $M$ is large enough—say, five-then all a party needs to do to maintain one seat is to secure a small fraction of the votes $(16.7 \%)$, so even a small party winning only $10-15 \%$ of the votes has a good chance to be competitive and will not easily give up running candidates. Second, intraparty factionalism accentuated by SNTV necessarily increases the interparty bargaining complexities. This is because even if a leader chooses to withdraw a candidate from a district, the leader needs to convince one of the factional bosses to give up running. Thus, we expect that, with the transition to MMM, the mechanical and psychological effects of Duverger's Law and the simplified intraparty bargaining process for candidate nomination should help party leaders to directly bargain with the other parties over candidate entry. Large parties take advantage of the majoritarian nature of MMM to nominate candidates in almost all the SMDs while convincing smaller parties to join preelectoral coalitions. ${ }^{11}$ Therefore the effective number of electoral parties in each district should converge to two over time. This is our general expectation.

However, there are several theoretical caveats to this general expecta- 
tion. One is about the presence of the list tier. If joint lists are not allowed, then preelectoral coalition partners would need to compete on the list tier. LDP candidates, for example, usually ask their own personal supporters to cast their list votes for the party's coalition partner, the Clean Government Party (Komeito, CGP), to make sure that CGP supporters would vote for them in exchange (Asabi Shimbun, September 7, 2000, 4). However, this is nothing more than lip service. Because joint lists are not allowed in Japan, unlike in Taiwan, there is really no way to go about ordering voters to split their tickets at the booths: the exit polls in 2003, for example, suggest that only $6 \%$ of LDP supporters voted for the CGP on the list tier (Asabi Shimbun, November 10, 2003, 3). One former CGP legislators lamented: "The coalition should be 'give and take' but we only give in to the LDP" (Nibon Keizai Shimbun, August 27, 2005, 2). This is consistent with the empirical evidence presented in chapter 7 by Wang, Lin, and Hsiao.

In addition to this fear of being exploited by large parties, minor parties want to improve their performance on the list tier by using hopeless SMD candidates and "contaminating" the list tier (Herron and Nishikawa 2001). In Japan, the Communists nominated hopeless SMD candidates in almost all the SMDs except in 2009, even though it could win only a couple of SMD seats back in 1996. In addition to this extreme case, the Social Democratic Party (SDP) in 2009 also had to compete with the DPJ in nearly half of the 31 SMDs where it ran candidates. ${ }^{12}$ This limited coordination is partially the result of the SDP's reliance on the list tier for its survival: "The SDP was agonized over how to distance itself from its larger partner, because it might end up encouraging more voters to cast PR votes for the DPJ by supporting the DPJ's SMD candidates" (Asabi Shimbun, August 30, 2009, 2).

Thus, in a mixed-member system, preelectoral coalition partners face a commitment problem: smaller parties fear that their larger partners might exploit votes, while larger parties cannot be sure if their smaller partners' activists will be really collaborative in local districts. Of course, this commitment problem should be omnipresent under any single-member system, but the presence of the list tier, on which small parties rely for their electoral survival, somewhat aggravates the problem. Thus, there must be some credible commitment mechanisms, and we argue that Japan's institutional arrangements-parliamentarism and bicameralism-somehow helped to solve, if not perfectly, the commitment problem. That is why we see the gradual convergence of the effective number of electoral parties to two, as shown in figure 6.7, although the case of the 2012 elections looks very anomalous.

As shown by Lin in chapter 2, parliamentarism can help coalition part- 


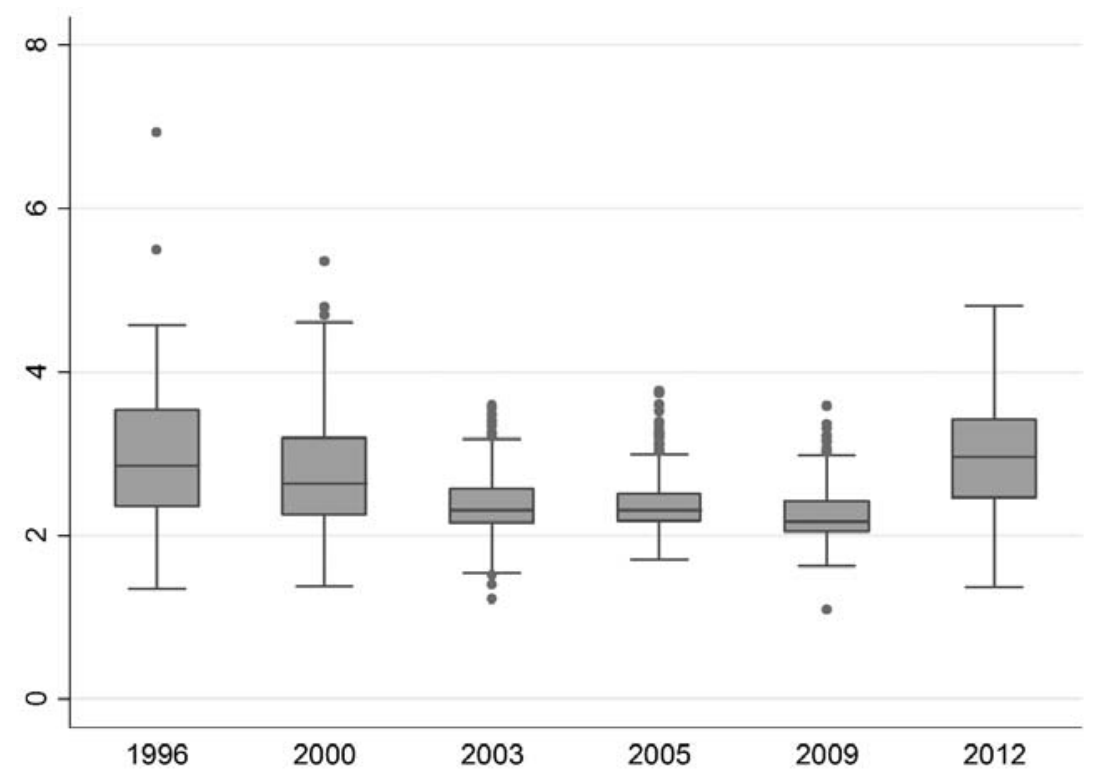

Fig. 6.7. Effective number of electoral parties in each district in Japan, 19962012

ners become united as a single team by taking mutual hostages. Small parties can offer support for the confidence vote and the government's survival on the one hand, while they can influence policy making and implementation through positions in the government on the other. Thus, in every cabinet after Obuchi's second reshuffle in 1999, the LDP appointed one minister and several vice ministers from the CGP, and when it did so, it incorporated the CGP's demands for positions (Asabi Shimbun, September $28,2004,3)$. Another solution is to forge detailed policy agreements before the election to make sure everyone signing the agreement will join the government after a turnover. Before the 2009 elections, the DPJ had rounds of policy negotiations with two potential coalition partners (the SDP and the People's New Party [PNP]) to develop common policy platforms (Nibon Keizai Shimbun, May 28, 2009, 2). In an interview before the 2012 elections, the CGP's leader, Natsuo Yamaguchi, emphasized that, although his party and the LDP might have had some policy differences, "the two parties share the history of forming coalition governments.... So we can reach policy agreements that the people can rely on" (Asabi Shimbun, November 30, 2012, 4).

Bicameralism in Japan also helped to make these coalitions more stable. 
Japan's upper house, the House of Councillors (HC), has equal lawmaking power with the lower house except over the budget and the investiture vote. The HC features a more proportional and therefore fragmented $M M M$, in which the list tier uses a nationwide open-list PR district with $M$ around 50 . No party has won a single-party majority in the HC since 1989. Thus, even when the LDP retained a single-party majority in the lower house from 1997 to 2009, it always needed legislative support from the CGP. Similarly, the SDP and the PNP had a considerable bargaining advantage with their 11 seats in the HC.

Therefore, except in 2012, small parties strategically coordinated candidates where possible with two of the major parties (the LDP or the DPJ), resulting in the Duvergerian convergence shown in figure 6.7. The LDP and the CGP first formed a coalition government in 2000, and this coalition spread to district-level cooperation. Although the two coalition partners competed against each other in some of the districts in the 2000 elections, they stopped doing so after 2003 in any of the 300 SMDs. Where the LDP is traditionally strong, the CGP refrained from running candidates, and the LDP's SMD candidates can expect votes from a large majority of the CGP supporters (Asabi Shimbun, June 26, 2000, 3). Meanwhile, the LDP avoids sending candidates to the CGP's strongholds, where the CGP's loyal supporters, based on a religious group Soka Gakkai, are geographically concentrated. ${ }^{13}$ Beginning with the 2007 upper-house elections, the DPJ also coordinated candidates with some minor parties (the SDP and the PNP) to maximize the possibility of a government turnover through elections. Unlike the LDP-CGP coalition, this opposition coalition could not perfectly coordinate candidates as described above, but it was still successful in gradually reducing the number of contested districts from 41 (13.7\% of 300 SMDs) in 2003 to $30(10.0 \%)$ in 2005 , and then down to $14(4.7 \%)$ in 2009 . Where the DPJ decided not to run in 2009 , it officially backed the smaller partner's candidates (Asabi Shimbun, July 22, 2009, 4).

It is still yet to be seen whether the fragmentation in 2012 will continue or not. In a sense, this is something one should expect under a parliamentary regime: as Batto and Cox's introductory chapter in this volume argues, a party might choose to independently run as a third party and try to join the cabinet by engaging in postelectoral bargaining with one of the major parties if no party wins a majority. In line with this view, the results of 2012 were mainly caused by the rise of minor parties, the so-called third forces (daisankyoku) seeking votes by disassociating themselves from the existing parties and attracting nonpartisan voters disillusioned with the very unsatisfactory performance of the three-year DPJ administration. One of 
them, the Japan Restoration Party (Nippon Ishin no Kai, JRP), was quite successful with 54 seats $(11.3 \%)$, while others were moderately successful: The Your Party (Minna no To) and the Tomorrow Party of Japan (Nippon Mirai no To) won 18 (3.8\%) and 9 seats (1.9\%), respectively. Many of the SMDs were marked by three- and even four-way competition, disturbing the trend toward the Duvergerian equilibrium as shown in figure 6.7.

But we would also like to note that, although the parliamentary postelection bargaining story as posed by Batto and Cox may explain well the rise of third parties in 2012, it has some difficulties in explaining the gradual decline in the number of parties until 2009. In fact, most of the third parties, except the ideologically extreme Communists, were merged into one of the two major camps led by the LDP and the DPJ by $2003 .{ }^{14}$ And, even in 2012, the minor parties themselves stepped up their efforts to form the united front against the LDP-CGP coalition: in fact, the JRP and the Tomorrow Party of Japan were born when even smaller parties decided to merge, ${ }^{15}$ while the JRP and Your Party tried to coordinate their candidates in as many districts as possible until the last minute (Asabi Shimbun, December 1, 2012, 4). So it might be the case that the 2012 elections were just a temporal outlier. Several of the minor parties might be merged or join either of the two large camps before too long, but as of this writing it is still very unclear.

Let us move to the case of the MMM system in semipresidential Taiwan, which similarly indicates that in most of the districts, Duverger's Law is working: the average effective number of candidates stood at 2.09 and 2.18 in 2008 and 2012, respectively. However, this masks how preelectoral coalitions work in reality. In 2008, the small parties in the Pan-Blue coalition refrained from nominating SMD candidates, but the TSU competed with the DPP in 13 districts (17.8\% of the 73 districts) although no candidate from the TSU could win. In 2012, it was the opposite: The Pan-Blue coalition was split, as the People's First Party nominated SMD candidates in 10 districts (13.7\%) to challenge the KMT, and no candidate could win seats, just like the TSU in 2008. This stands out in stark contrast to Japan, where, at least until 2009, the two large camps were successful in coordinating candidates so that less than $5 \%$ of the districts observed intracamp competition.

This could be because of the heavy regulations on which parties can run for the list tier ${ }^{16}$ but we argue that this is because of the presence of (negative) presidential coattails: as the presidency is the most important political prize in presidential and semipresidential democracies, the media and the general public pay the greatest attention to the presidential race and presi- 
dential candidates' performance significantly affects legislative elections as well (Golder 2006). Without viable presidential candidates to start with, the small parties have a very strong incentive to associate themselves with a major party in the same coalition when it has a very winnable candidate.

This scenario happened in 2008, when the KMT's Ma Ying-jeou looked like a sure winner well before the 2008 elections (Chu 2008; Tan 2009). The People First Party (PFP) readily formed a preelectoral coalition with the KMT and had a joint PR list-four PFP members were placed in the KMT's party list and three of them were ranked high enough to win seats. At the same time, the PFP was very collaborative on the nominal tier as well, as it did not run candidates in any SMDs (Chu 2008, 126). Similarly in 2012, the TSU was very collaborative with the DPP: learning from 2008, the TSU this time decided not to run on the nominal tier and instead yield to its Pan-Green alliance partner (Taipei Times, May 29, 2011). The TSU's spiritual leader, Lee Teng-hui, even called on voters to cast their ballots for the DPP's SMD candidates and give their party votes to the TSU (Taipei Times, December 26, 2011). This was because a series of opinion polls suggested that the DPP's presidential candidate, Tsai Ing-wen, was running neck and neck with Ma. As late as December 10, 2011, about a month before the election, a TVB super channel poll showed Tsai and Ma tied with $39 \%$ each. Another poll by a Taiwan think tank showed Tsai leading by $35.9 \%$ to $35.4 \%$ (Taipei Times, December 10, 2011). Riding the coattails of the popular presidential candidate from the same camp, the TSU won three PR seats, a breakthrough from its zero seats in the previous election.

On the other hand, small parties similarly have a very strong incentive to dissociate themselves from the major party when the coalition's presidential candidate is unpopular, and this happened to the TSU in 2008 and the PFP in 2012. Before the 2008 election, Chen Shui-bian was very unpopular as president and leader of the DPP, with the ever-worsening economy, increasing cross-strait tensions with mainland China, and a series of corruption scandals. Even the DPP leadership predicted devastating defeats in the 2008 elections (Chu 2008; Tan 2009). This created a schism in the Pan-Green coalition, with Lee Teng-hui explicitly criticizing the DPP as "incompetent, preoccupied with winning the presidential election" (Taipei Times, February 14, 2007). In an interview, Lee went on to characterize President Chen as having "no concept of democracy" and worried that Taiwan was being held hostage politically by the two main political parties (Taipei Times, December 29, 2007). As the TSU tried to dissociate itself from the unpopular president, TSU chairman Huang Kun-huei did not like the idea of withholding its candidates on behalf of the DPP (Taipei 
Times, July 20, 2007). The schism in the Pan-Green coalition was never resolved despite the common belief that "the Pan-Green Coalition will lose the elections if there is no cooperation with each other" (Taipei Times, August 4, 2007). DPP chairman Yu Shyi-kun often attempted to convince the smaller partner to "only nominate the most promising candidates for the next legislative election based upon public opinion survey results," describing the two parties as "brothers in a family" (China Post, January 31, 2007), but to no avail.

After its landslide victory in 2008, the KMT faced a similar problem. One of the key events was Typhoon Morakot in August 2009, which significantly undermined the perception of the administration's ability to prepare for a natural disaster and Ma's credibility as a leader (Gold 2010). As Ma's popularity steadily decreased over time (Taipei Times, April 21, 2011), the KMT began losing votes and seats. For example, the mayoral elections in November 2010 showed that its vote share decreased by $7.6 \%$ compared to that of 2005-6. Even though the KMT maintained some major city mayoral positions, this poor performance was an ominous bellwether for the coming presidential race (Tien and Tung 2011). Sensing the worsening situation around the Pan-Blue coalition, PFP chairman James Soong said that his party would nominate at least 10 candidates for the legislative elections as early as June 2011 (Taipei Times, June 11, 2011). Time after time the KMT tried to convince the PFP to collaborate on candidate coordination (Taipei Times, July 27, 2011) and even suggested PFP candidates could run where the KMT had not yet completed its nomination process (Taipei Times, July 30, 2011). But ultimately the PFP decided to run its own candidates for presidential, SMD, and party-list elections.

In sum, with the transition to MMM, in theory we should observe how small parties will try to form preelectoral coalitions in the nominal tier in order to survive. But coordination cannot go smoothly unless there is a commitment mechanism, because small parties fear exploitation by larger partners and want to maximize list votes with the contamination effects. Thus, Japan's larger parties (the LDP and the DPJ) offered cabinet positions to and forged coalition agreements with small parties (the CGP, the SDP, and the PNP) to make preelectoral coalitions stable. Consequently, the number of candidates at the district level gradually declined at least until 2009. Lacking such mechanisms, semipresidential Taiwan, by contrast, was marked by limited coordination. Rather, small parties (the TSU in 2008 and the PFP in 2012) challenged their larger partners when they sensed that their odds of winning improved by distancing themselves from their camps' presidential candidates. 


\section{Conclusion: Constitution, Dual Candidacy, and Beyond}

In this chapter we investigated how parties have strategically adapted themselves to the new electoral environment in Japan and Taiwan by focusing on three different issues: post allocation, list nomination, and candidate coordination. The main argument is that the simplified intraparty bargaining process over posts and candidates under MMM allows the leadership to use available tools and resources more strategically for electoral purposes than it could during the SNTV period. More specifically, in terms of post allocation, ruling parties should make more strategic use of positions in the government as carrots and sticks to control candidates. In terms of nominations, parties should strategically nominate attractive candidates on the list tier to boost party votes. And in terms of candidate coordination, parties should strategically form preelectoral coalitions to minimize wasted votes. In general, parties in both Japan and Taiwan are moving toward these expectations.

However, throughout this chapter we also find the institutional differences between the two countries-parliamentarism versus semipresidentialism and the dual candidacy provision—are so significant that they can outweigh these naivve predictions driven by the theory of electoral systems alone. First, mutual dependence between the cabinet and the legislature for survival in parliamentary Japan results in a much closer alignment between the vote-seeking incentives and cabinet appointment patterns: now the prime minister appoints fewer and fewer zombies to important positions in the government so that candidates can win more SMDs. But in Taiwan, although some signs suggest that the president rewards hard workers with cabinet positions to develop quality candidates in the opposition's strongholds, they are still rare, because constitutionally the president really does not depend on the party or the legislature for support.

Second, to maximize the strategic use of the best loser provision, Japan's parties now use the list tier only as a safety net for SMD candidates. This is because the leadership can expect to maximize its nominal-tier winners by dually nominating SMD candidates at the same top rank and letting them engage in laissez-faire competition on a level playing field. Now parties nominate very few favorably ranked candidates. In Taiwan, the single nationwide list tier without dual candidacy allows for more strategic nominating and list-ranking of candidates. Therefore party lists in Taiwan tend to include a wider variety of candidates from different regions, genders, and career backgrounds than in Japan.

Third, parliamentarism can effectively address the credible commit- 
ment problem that could otherwise make candidate coordination difficult. Japan's larger parties (the LDP and the DPJ) offered cabinet positions to and forged coalition agreements with small parties (the CGP, the SDP, and the PNP) to make preelectoral coalitions stable. Therefore Japan observed the gradual convergence to the Duvergerian equilibrium as evidenced by the declining number of candidates at least until 2009. Lacking such mechanisms, semipresidential Taiwan was, by contrast, marked by limited coordination. Rather, small parties (the TSU in 2008 and the PFP in 2012) challenged their larger partners when they did not like their camps' presidential candidates.

All of these ideas imply that the effects of electoral rules are mediated by contextual factors. It is important to look beyond district magnitude, ballot types, and seat allocation methods when understanding parties' vote mobilization strategies. Although this chapter's primary focus is on the two main institutional differences between Japan and Taiwan, one could point to other contextual differences, including but not limited to, ethnic and linguistic heterogeneity, the degrees of democratic consolidation, and the presence of a second chamber (cf. Moser and Scheiner 2012). While we did not delve into how these different contextual factors could affect parties' mobilization strategies, we believe these will open up new research opportunities for comparing Japan, Taiwan, and any other mixed-member systems from different perspectives.

\section{NOTES}

1. To this ladder one could add vice chair and chair of a Policy Affairs Research Council subdivision between (II) and (III), as the literature does (Ramseyer and Rosenbluth 1993, 86), but we do not do this since the Policy Affairs Research Council became less and less important, especially after Koizumi took power in 2001. In addition, since Japan has no clear notion of demotion, unlike in other parliamentary democracies, we focus on only promotion here.

2. The KMT finally nominated a party-list legislator from Tainan, Chen Suhui, to run in the by-election against the DPP nominee, former mayor of Tainan City, Hsu Tian-Tsair. Hsu defeated Chen by a margin of $61 \%$ to $38 \%$.

3. Also see chapter 4 by Batto and Huang in this volume for a much more detailed account of the DPP's factional struggles, especially between the New Tide faction and the other factions over cabinet positions, and its attempts to reform itself.

4. This may sound a bit contradictory with Lin's evidence in chapter 2 , but here we look at whether ministers have served as legislators before.

5. On average, the Japanese cabinet has only one or even no nonlegislator, with some exceptions including Koizumi's first cabinet (2001-2), which had three non- 
legislators (16.7\%) in 18 cabinet positions, and Fukuda's first cabinet (2007-8), which had two.

6. This means that a retiring incumbent cannot designate as a successor candidate his/her child (first degree), sibling or grandchild (second degree), or niece/ nephew or great-grandchild (third degree). In order to differentiate itself from the LDP, the DPJ in 2012 applied this strict rule to any candidate hoping to run in SMDs, including Yuichiro Hata, who showed an interest in succeeding his retiring father, former prime minister Tsutomu Hata. Denied an endorsement from the party, the younger Hata chose not to run (Nibon Keizai Shimbun, November 18, 2012, 2).

7. Of the eight dually nominated candidates, three won their SMDs, while the other five were elected on the PR list thanks to their high rankings.

8. Favorably ranking some candidates near the top of the list is more of a legacy of the old SNTV system (see Reed 1995). As the same district had more than one incumbent under SNTV and the leadership needed to deal with them under the new system, those who could not win nominations for the SMD race were given favorable ranks in the list.

9. There are two main reasons why the KMT's list was praised more than the DPP's list. The first reason is that many of the younger nominees on the DPP list had been either former cabinet ministers or legislators, while the KMT recruited many new faces from different fields and areas. Although Tsai argued that those former legislators or ministers could more effectively represent the interests of minority groups, it was a tough sell for the mass media. The second reason is that the KMT's list was completely different from the conservative-looking 2008 list. In that list, the KMT filled the first 20 spots with 17 incumbent legislators, two cabinet ministers, and one businessperson.

10. Prior to the 2005 constitutional reform, any party winning at least five seats was required to reserve at least one seat for a woman.

11. This also means that under a much more proportional MMP system, where list votes determine parties' seat shares in the parliament, preelectoral coalitions at the district level are not likely to occur. On this point, see chapter 9 by Shugart and Tan in this volume on New Zealand's MMP.

12. In these 15 districts where the DPJ and the SDP competed, the DPJ won 14 seats. In one district where the LDP won, the DPJ could not win even if hypothetically the SDP gave up running a candidate.

13. Except in 2009, when none of the CPG SMD candidates survived, the party has been remarkably successful in SMDs for a relatively small party: in 45 districts where the CPG ran candidates between 2000 and 2012, it won 33 seats (73.3\%). This is because the party has been very good at predicting the size of its supporter bases and optimizing candidate entry accordingly, using its religious-group network (Lee 1970, 507).

14. They were mainly the remnants of the second largest party in the 1996 election, the New Frontier Party, which was suddenly dissolved in 1997 into several minor ones: the New Fraternity Party (Shinto Yuai), the Good Governance Party (Minsei To), the Liberal Party (Jiyu To), and others joined the DPJ, while the Conservative Party (Hoshu To) and others chose the LDP.

15. The JRP was born in September 2012 when the populist Osaka mayor, 
Toru Hashimoto, extended his Osaka-based regional party, the Osaka Restoration Association, into a nationwide one. In addition to about a dozen MPs individually switching to the JRP, some other tiny parties tried to join the force, including the Tax Cut Japan (Genzei Nippon) and the Sunrise Party (Tachiagare Nippon), and the latter finally merged in November after rounds of negotiations. The Tomorrow Party of Japan was born in late November when several DPJ splinters- the Kizuna Party (Shinto Kiduna), People's Life First (Kokumin no Seikatsu ga Daiichi), Green Wind (Midori no Kaze), and Tax Cut Japan, which was rejected by the $\mathrm{JRP}$ - merged into a single party.

16. More specifically, a party can run its list if any of the following four conditions hold: (1) its presidential candidate got at least $2 \%$ of the votes in the most recent election; (2) it won at least $2 \%$ of the list votes in the previous three elections; (3) it has at least five legislators; or (4) it nominates at least 10 SMD candidates.

\section{REFERENCES}

Akarui Senkyo Suishin Kyōkai. 2010. Dai 45-kai Shugiin Giin Sosenkyo no fittai [The results of the 45th House of Representatives election]. Tokyo: Akarui Senkyo Suishin Kyōkai.

Chu, Yun-han. 2008. "Taiwan in 2007: The Waiting Game.” Asian Survey 48 (1): 124-32.

Gold, Thomas B. 2010. "Taiwan in 2009: Eroding Landslide." Asian Survey 50 (1): $65-75$.

Golder, Matt. 2006. "Presidential Coattails and Legislative Fragmentation." American Fournal of Political Science 50 (1): 34-48.

Grofman, Bernard. 1999. "SNTV: An Inventory of Theoretically Derived Propositions and a Brief Review of the Evidence from Japan, Korea, Taiwan, and Alabama." In Elections in Fapan, Korea, and Taiwan under the Single Non-Transferable Vote: The Comparative Study of an Embedded Institution, ed. Bernard Grofman, Brian Woodall, Sung-Chull Lee, and Edwin Winckler, 375-416. Ann Arbor: University of Michigan Press.

Hazan, Reuven Y., and Gideon Rahat. 2010. Democracy within Parties: Candidate Selection Methods and Their Political Consequences. Oxford: Oxford University Press.

Herron, Erik S., and Misa Nishikawa. 2001. "Contamination Effects and the Number of Parties in Mixed-Superposition Electoral Systems.” Electoral Studies 20 (1): 63-86.

Ishibashi, Michihiro, and Steven R. Reed. 1992. "Second-Generation Diet Members and Democracy in Japan: Hereditary Seats." Asian Survey 32 (4): 366-79.

Lee, Jooinn. 1970. "Komeito: Sokagakkai-Ism in Japanese Politics." Asian Survey 10 (6): 501-18.

McElwain, Kenneth Mori. 2012. "The Nationalization of Japanese Elections." Fournal of East Asian Studies 12 (3): 323-50.

Moser, Robert G., and Ethan Scheiner. 2012. Electoral Systems and Political Context: How the Effects of Rules Vary across New and Established Democracies. Cambridge: Cambridge University Press.

Nemoto, Kuniaki, Ellis S. Krauss, and Robert Pekkanen. 2008. "Policy Dissension 
and Party Discipline: The July 2005 Vote on Postal Privatization in Japan.” British Fournal of Political Science 38 (3): 499-525.

Noble, Gregory W. 2010. "The Decline of Particularism in Japanese Politics." Journal of East Asian Studies 10 (2): 239-73.

Patterson, Dennis, and Ko Maeda. 2007. "Prime Ministerial Popularity and the Changing Electoral Fortunes of Japan's Liberal Democratic Party.” Asian Survey 47 (3): 415-33.

Pekkanen, Robert, Benjamin Nyblade, and Ellis S. Krauss. 2006. "Electoral Incentives in Mixed-Member Systems: Party, Posts, and Zombie Politicians in Japan.” American Political Science Review 100 (2): 183-93.

Ramseyer, J. Mark, and Frances McCall Rosenbluth. 1993. Japan's Political Marketplace. Cambridge: Harvard University Press.

Reed, Steven R. 1995. "The Nomination Process for Japan's General Election: Waiting for the Heiritsu-sei." Asian Survey 35 (12): 1075-86.

Reed, Steven R., Ethan Scheiner, and Michael F. Thies. 2012. "The End of LDP Dominance and the Rise of Party-Oriented Politics in Japan." Fournal of Fapanese Studies 38 (2): 353-76.

Rochon, Thomas R. 1981. "Electoral Systems and Voting Behavior: The Case of Japan." In Parties, Candidates, and Voters in Japan, ed. John C. Campbell, 1-28. Ann Arbor: Center for Japanese Studies, the University of Michigan.

Rosenbluth, Frances, and Michael Thies. 2010. Japan Transformed: Political Change and Economic Restructuring. Princeton: Princeton University Press.

Shugart, Matthew Søberg. 2001. "Electoral 'Efficiency' and the Move to MixedMember Systems." Electoral Studies 20 (2): 173-93.

Siavelis, Peter M., and Scott Morgenstern, eds. 2008. Pathways to Power: Political Recruitment and Candidate Selection in Latin America. University Park: Pennsylvania State University Press.

Tan, Alexander C. 2009. "The 2008 Taiwan Elections: Forward to the Past?" Electoral Studies 28 (3): 502-6.

Tien, Hung-Mao, and Chen-Yuan Tung. 2011. "Taiwan in 2010.” Asian Survey 51 (1): 76-84. 


\title{
Split-Ticket Voting under MMM
}

\author{
T. Y. Wang, Chang-chib Lin, and Yi-ching Hsiao
}

Split-ticket voting has generated substantial interest in the discipline as demonstrated by the voluminous publication on the subject (Alesina and Rosenthal 1995; Bawn 1993, 1999; Beck et al. 1992; Born 1994; Brandy 1993; Cox 1990, 1997; Cox and Schoppa 2002; Duverger 1959; Feigert 1979; Ferrara, Herron, and Nishikawa 2005; Fiorina 1996; Fisher 1973; Gallagher 1998; Garand and Lichtl 2000; Gschwend, Johnston, and Pattie 2003; Herron and Nishikawa 2001; Huang 2001; Huang, Chen, and Chou 2008; Jacobson 1991; Jesse 1988; Karp et al. 2002; Kohno 1997; Lewis-Beck and Nadeau 2004; Reed 1999; Roscoe 2003). With a focus on electoral behavior in the United States where elections on executive and legislative bodies are held simultaneously, ticket-splitting is generally defined as a voting behavior where voters cast two or more than two ballots in an election to candidates of different parties competing for different positions. For instance, when elections for the presidency and for the House of Representatives in the United States take place at the same time, voters may choose to vote in the manner of a straight ticket by casting both ballots for candidates from the same party, or to split the ticket by voting for candidates from different parties on different ballots.

Split-ticket voting can also occur in countries with mixed-member systems for legislative elections (Choi 2006; Gschwend, Johnston, and Pattie 2003; Huang 2008a, 2008b; Huang, Wang, and Kuo 2008; Karp et al. 2002; Kohno 1997; Moser and Scheiner 2004, 2009; Reed 1999; Schoen 1999). 
Characterized as hybrids that combine both proportional representation (PR) and single-member district (SMD), mixed systems have been adopted in many countries including Germany, Hungary, Japan, New Zealand, and more recently, Taiwan. Depending on whether there is a linkage between votes acquired from the PR and from the SMD tier, the institutional designs can be further categorized as "nonparallel" mixed-member proportional (MMP) and "parallel" mixed-member majoritarian (MMM) systems (Bawn 1993, 1999; Cox 1997, 81-83; Cox and Schoppa 2002; Fisher 1973; Gschwend, Johnston, and Pattie 2003; Karp et al. 2002; Shugart and Wattenberg 2001, 13-14). In nonparallel MMP systems, as in Germany and New Zealand, votes acquired from the PR tier are used to balance the overall representation of parties in the legislature so that weaker parties receive a number of seats proportionate to their general performance in the election. The majoritarian boost received by a large party from the SMD tier is likely to be reduced by the proportional allocation from the party list. Because the PR votes are used to compensate for the SMD votes, the nonparallel MMP is also characterized as "compensatory" mixed system (Karp et al. 2002; see also chapter 9 by Shugart and Tan, this volume). In MMM systems, as in Japan and Taiwan, seats in the SMD and PR are allocated independently and separately with no linkage between the two tiers. They are thus characterized as "parallel" systems. Despite these differences, both types of mixed systems feature electoral rules that provide voters with two ballots. One ballot determines which candidate wins seats in SMD under plurality and the other decides which party acquires seats under PR rules. Voters in such hybrid systems are offered an opportunity to split their votes for different political affiliations. Ticket-splitting in countries with mixed-member systems is thus different from that which occurs in the American context.

Both Japan and Taiwan abandoned the time-honored single nontransferable vote electoral rules in favor of the MMM systems in 1994 and 2005, respectively. The new institutional setting of both countries provides citizens with two ballots. ${ }^{1}$ Voters in both countries may thus behave strategically as the new institutions offer voters an opportunity to split their votes for candidates of different political affiliations. Parties of similar political positions may also plan their campaigns collectively in order to maximize their overall seat shares. This study examines how voters are expected to behave under the new systems, and, in particular, how they respond to political parties' strategic moves of maximizing electoral votes.

To examine voters' electoral behavior under the new electoral rules, survey data collected in Japan and in Taiwan are employed, which include 
data of the 2008 Taiwan's Election and Democratization Study (hereafter TEDS2008L), ${ }^{2}$ fifteen waves of preelection rolling surveys conducted prior to Taiwan's 2012 combined elections, ${ }^{3}$ and Japan Election Studies (JES) III. ${ }^{4}$ This study proceeds in three parts. The next section reviews the literature on split-ticket voting, which offers a theoretical framework for analysis. In the ensuing sections, descriptive and multivariate analyses are conducted, with conclusions in the final section. The findings support the conventional wisdom that party identification is the primary determinant of electoral behavior. The institutional design of mixed-member systems, however, mitigates the effects of partisan loyalty as identifiers of minor political parties are more likely to be ticket-splitters, but they tend to support candidates of the same political coalitions/alliances. Voters' ticketsplitting behavior may be further induced by coordinated nomination strategies of political parties with similar political positions.

\section{Split-Ticket Voting in MMM System}

More than half a century ago, Angus Campbell and his associates (1964) stated that:

Few factors are of greater importance for our national elections than the lasting attachment of tens of millions of Americans to one of the parties. These loyalties establish a basic division of electoral strength within which the competition of particular campaigns takes place. . . . Most Americans have this sense of attachment with one party or the other. And for the individual who does, the strength and direction of party identification are facts of central importance in accounting for attitude and behavior. (67-68)

Generally characterized as the "Michigan model," its characterization of party identification as the primary determinant of political behavior has subsequently dominated the academic research in the discipline (e.g., Green, Palmquist, and Schickler 2002; Miller and Shanks 1996). Although a number of studies have noted an increase in "independent voters" along with split-ticket voting over the subsequent decades (Burnham 1970, 123; Keith et al. 1992; Pomper 1967), more recent analysis has shown that the argument for the "decline of parties" in American politics was exaggerated. Bartels (2000), for instance, demonstrates that the impact of partisan loyalties on presidential and congressional voting was strong in the elec- 
tions held between 1952 and 1996 in the United States. Other recent studies (Hetherington 2011; Stanley and Niemi 2010) have also shown that straight-ticket voting by Americans has increased. Although the effect of party identification on electoral choice varies by candidates' social characteristics (Campbell, Green, and Layman 2011), over time (Bartels 2000; Lewis-Beck et al. 2008), and across types of elections (Bartels 2000), party identification continues to play an important role in American electoral politics. In elections between candidates from competing parties, individuals affirm their partisan loyalties by casting ballots for the candidates who share their party labels. While this conclusion is primarily based on findings in an American setting, empirical analysis shows that it is also applicable to other democratic countries such as Taiwan (Chu 1996; Fu 1996; Ho 1994; Liu 1994; Sheng 2002; Sheng and Chen 2003; Shyu 1991, 1992; Tsai 2008; N. Wu 1999; Yu 2004) and Japan (Akuto 1971; Kohei 1972; Kuo 2011; Richardson 1988; Rochon 1981).

Although party labels serve as an important cue for individuals' voting decisions, the institutional framework within which an election operates may determine how much partisanship matters. In this context, the seminal work by Duverger (1959) becomes relevant. He argues that the SMD and the PR systems, in their pure forms, each provide different incentives to party elites and to voters. In a pure SMD election, the simple mechanics of the plurality rule create an effect of "underrepresentation" of the weaker parties because a larger party can win $100 \%$ of the seats available by winning half or even less than half of the votes cast in each district. As a result of this mechanical effect of the plurality rule, the percentage of seats of minor parties tends to be disproportionate to their percentage of the poll. Such a mechanical effect further introduces a psychological effect in voters' minds. As they realize that backing trailing candidates has a higher chance of becoming "wasted votes," supporters of these candidates in the SMD context are likely to transfer their votes to more viable candidates of major parties.

In a similar vein, party elites behave strategically in the SMD system by not wasting resources on candidates who have little chance of winning. Recognizing the mechanical and psychological effects of the SMD system, minor parties or parties of similar political positions may also strategically choose not to nominate candidates in some or all of the SMDs lest they divide the pool of support and thereby lose the election. Such strategic decisions of nomination mean that the voters' choice menu in any given SMD tier is typically more limited than the one in the PR tier, further aggravating the effects of the SMD system. This logic leads to Duverger's 
classic argument that "the simple-majority single ballot system favors the two-party system" and thus the number of parties will settle at two in a pure SMD electoral system $(1959,217)$. In a pure PR electoral system, however, there is little incentive for parties of similar political tendencies to fuse because the division does little or no harm to them. As the PR system puts a "powerful brake" to any tendency toward a two-party system, Duverger concludes that "proportional representation encourages a system of parties that are multiple, rigid, independent and stable" (1959, 204-5).

The SMD and the PR systems in their pure forms thus offer different incentives to voters. Because an MMM system is a hybrid of both PR and SMD, voters in this system may behave strategically, leading to splitticket voting. Various studies show ticket-splitting in such hybrid systems as evidence of voters' strategic reaction to electoral rules because they cast a greater number of votes for large parties in SMD races than in the PR tier (Bawn 1999; Cox 1997; Huang and Hsiao 2009; Reed 1999; Roberts 1988). ${ }^{5}$ As a result, identifiers with major parties tend to cast sincere votes in both SMD and PR segments by voting for their most preferred candidates and parties. Supporters of minor parties may act strategically in district races by voting for the more viable candidates of major parties but cast a sincere PR vote for their preferred minor parties. While partisan identification influences individuals' vote choice, the electoral context may mitigate its effects.

The tendency of ticket-splitting on the part of voters may be further induced by the strategic moves of party elites. In addition to fielding candidates in SMDs in order to boost party votes in the PR tier by generating the so-called contamination effect (Cox and Schoppa 2002; Ferrara and Herron 2005; Ferrara, Herron, and Nishikawa 2005; Herron and Nishikawa 2001; Huang 2007; Mizusaki and Mori 1998; Reed 2003), ${ }^{6}$ an approach frequently adopted by political parties in Japan and in Taiwan has been to coordinate candidate nomination in district races with other parties. Because there are no linkages between the SMD and the PR tiers in MMM systems, victory in district races directly changes the number of seats won by parties. Such electoral rules thus provide incentives to parties of similar political positions to coordinate their candidate nomination in SMDs lest they divide the pool of support (Ferrara and Herron 2005). Coordinated district races can also boost parties' $\mathrm{PR}$ votes as voters receive a clear voting cue from the electoral coalitions. Thus, parties of electoral coalitions can collectively maximize their seat shares through preelectoral pacts. Indeed, political parties in both Japan and Taiwan have coordinated their campaigns since electoral reforms were passed. In no district did 
the Liberal Democratic Party (LDP) and the Clean Government Party (Komeito, CGP) of Japan both nominate candidates in SMD races in 2003 and 2005. Similarly, Taiwan's two major political parties, the Nationalist Party (Kuomintang, KMT) and the Democratic Progressive Party (DPP), also collaborated with their junior partners in the 2008 and 2012 legislative elections. $^{7}$

The above discussion thus yields the following theoretical expectations to be examined in the subsequent sections. Specifically, it is hypothesized that partisan identification remains the primary determinant of vote choice in mixed-member systems but the framework of the electoral institutions mitigates its effect. Identifiers of major political parties are more likely to cast straight tickets while supporters for minor parties tend to split their ballots by casting a sincere PR vote and confine their defection to SMD races. As political parties may coordinate their campaign strategies, voters' ticket-splitting behavior may be further induced by such preelectoral pacts.

\section{Split-Ticket Voting in Japan and Taiwan}

Since MMM systems were adopted in the two countries, the 2003 and 2005 legislative elections were the third and fourth such contests held in Japan, whereas the 2008 and 2012 elections were the first and second held in Taiwan. The vote and seat shares by political parties in the elections are presented in tables 7.1a and 7.1b.

Data in table 7.1a show that the LDP in Japan, the ruling party since 1955 , was able to continue its domination in the legislative elections. In 2003 , the party garnered about $44 \%$ of the electoral support in SMD races and $35 \%$ of the PR votes, which were translated into a total of 237 legislative seats. The opposition Democratic Party of Japan (DPJ) also acquired a substantial numbers of votes in both tiers and became the second largest political party in the Diet with 177 seats. The LDP advanced its political domination in the 2005 elections with a landslide victory by winning 296 of the 480 total legislative seats. Along with its political partner, the LDP-CGP governing coalition commanded a two-thirds majority in the lower house. The DPJ suffered a devastating loss in 2005, acquiring only 113 seats but continuing to be the largest opposition party. Overall, the party system in Japan in the mid-2000s can be characterized as heading toward a two-party system dominated by the LDP and the DPJ, or more precisely, a "governing coalition vs. opposition coalition" system. Indeed, observers have noted that the effective number of parties in Japan has 
shown a downward trend during the postreform era but has never reached two. Smaller parties have been able to keep a presence in the Diet even though they cannot thrive (Jou 2009; Maeda 2008) and major political parties have maintained collaborative relationships with them. For instance, the CGP continued to be the partner of the LDP-dominated governing coalition even after the LDP's landslide victory in 2005. The DPJ has also maintained a loosely defined political alliance with the Social Democratic Party (SDP) through collaborative campaigns in some, but not all, SMDs. The only exception to this pattern is the Japanese Communist Party (JCP), which has continued its adherence to an unwavering political ideology and "going it alone" (Ferrara and Herron 2005) by fielding a large number of candidates in SMDs regardless of the chances of winning. ${ }^{8}$

TABLE 7.1A. Vote and Seat Shares by Political Party in Japan

\begin{tabular}{|c|c|c|c|c|c|c|c|c|}
\hline & \multicolumn{4}{|c|}{2003} & \multicolumn{4}{|c|}{2005} \\
\hline & \multicolumn{2}{|c|}{ Vote $\%$} & \multicolumn{2}{|c|}{ Number of Seats (\%) } & \multicolumn{2}{|c|}{ Vote \% } & \multicolumn{2}{|c|}{ Number of Seats (\%) } \\
\hline & SMD & PR & SMD & PR & SMD & PR & SMD & PR \\
\hline LDP & 43.9 & 35.0 & $168(56.0)$ & $69(38.3)$ & 47.8 & 38.2 & $219(73.0)$ & $77(42.8)$ \\
\hline DPJ & 36.7 & 37.4 & $105(35.0)$ & $72(40.0)$ & 36.4 & 31.0 & $52(17.3)$ & $61(33.9)$ \\
\hline $\mathrm{JCP}$ & 8.1 & 7.8 & $0(0.0)$ & $9(5.0)$ & 7.3 & 7.3 & $0(0.0)$ & $9(5.0)$ \\
\hline CGP & 1.5 & 14.8 & $9(3.0)$ & $25(13.9)$ & 1.4 & 13.3 & $8(2.7)$ & $23(12.8)$ \\
\hline SDP & 2.9 & 5.1 & $1(0.3)$ & $5(2.8)$ & 1.5 & 5.5 & $1(0.3)$ & $6(3.3)$ \\
\hline NCP & 1.3 & - & $4(1.3)$ & - & - & - & - & - \\
\hline PNP & - & - & - & - & 0.6 & 1.7 & $2(0.7)$ & $2(1.1)$ \\
\hline NPN & - & - & - & - & 0.2 & 2.4 & $0(0.0)$ & $1(0.6)$ \\
\hline NPD & - & - & - & - & 0.1 & 0.6 & $0(0.0)$ & $1(0.6)$ \\
\hline Others & 5.7 & 0.0 & $13(4.3)$ & $0(0.0)$ & 4.8 & 0.00 & $18(6.00)$ & $0(0.0)$ \\
\hline
\end{tabular}

Data source: Revised from Kuo (2011, 20-21).

TABLE 7.1B. Vote and Seat Shares by Political Party in Taiwan

\begin{tabular}{|c|c|c|c|c|c|c|c|c|}
\hline & \multicolumn{4}{|c|}{2008} & \multicolumn{4}{|c|}{2012} \\
\hline & \multicolumn{2}{|c|}{ Vote $\%$} & \multicolumn{2}{|c|}{ Number of Seats (\%) } & \multicolumn{2}{|c|}{ Vote $\%$} & \multicolumn{2}{|c|}{ Number of Seats (\%) } \\
\hline & SMD & PR & SMD & PR & SMD & PR & SMD & PR \\
\hline KMT & 53.5 & 51.2 & $57(78.1)$ & $20(58.8)$ & 48.1 & 44.6 & $44(60.3)$ & $16(47.1)$ \\
\hline DPP & 38.7 & 36.9 & $13(17.8)$ & $14(41.2)$ & 44.5 & 34.6 & $27(37.0)$ & $13(38.2)$ \\
\hline NP & - & 4.0 & - & $0(0.0)$ & 0.1 & 1.5 & $0(0.0)$ & $0(0.0)$ \\
\hline PFP & 0.1 & - & $0(0.0)$ & - & 1.1 & 5.5 & $0(0.0)$ & $2(5.9)$ \\
\hline TSU & 1.0 & 3.5 & $0(0.0)$ & $0(0.0)$ & - & 9.0 & - & $3(8.8)$ \\
\hline NPSU & 2.3 & 0.7 & $2(2.7)$ & $0(0.0)$ & 1.1 & - & $1(1.4)$ & - \\
\hline Others & 4.6 & 4.4 & $1(1.4)$ & $0(0.0)$ & 4.9 & 4.9 & $1(1.4)$ & $0(0.0)$ \\
\hline
\end{tabular}

Data source: Central Election Commission, Taiwan.

Note: The six Aboriginal seats are not included in this table. 
Taiwan's political landscape has been roughly divided into two political camps: the Pan-Blue alliance and the Pan-Green alliance, which are divided on the issues of national identity and cross-strait policy (Hsu and Lin 2009; Niou 2004; Wang and Liu 2004; Y. Wu 2004). The Pan-Blue alliance consists of the now ruling KMT, the People First Party (PFP), and the New Party (NP), while the Pan-Green alliance includes the opposition DPP and the Taiwan Solidarity Union (TSU). In the first legislative election in 2008 since the MMM system was adopted, parties of the Pan-Blue alliance entered an electoral pact to coordinate their campaign. Also included in the agreements was the Non-Partisan Solidarity Union (NPSU). The two political parties of the Pan-Green alliance, however, failed to reach an agreement. They fielded their candidates separately in both the SMD and PR tiers and competed with each other for the support of Pan-Green identifiers. As the data in table 7.1b show, the KMT and the DPP, the two largest political parties in Taiwan, garnered almost all of the legislative seats in 2008 and none of the minor parties passed the required $5 \%$ threshold to receive apportioned PR seats.

In the 2012 combined presidential and legislative elections, the KMT again collaborated with the NP and the NPSU in the legislative campaign. With a coordinated nomination strategy, the NP presented a party list in the PR tier and nominated only one SMD candidate while the NPSU nominated two SMD candidates without competing in the PR segment. The KMT fielded candidates in the remaining 71 SMDs and presented a complete party list. The PFP did not enter the 2012 Pan-Blue pact and ran its legislative campaign separately mainly due to the presidential bid by its chairman, James Soong, who ran against the incumbent president, $\mathrm{Ma}$ Ying-jeou of the KMT. On the part of the Pan-Green alliance, the DPP fielded 69 candidates for district races while the TSU only presented a party list in the PR tier without running any candidates in SMDs. Although the two parties did not enter a formal agreement, it appeared that the TSU and the DPP reached a tacit understanding on their campaign strategies as leaders of the TSU repeatedly called on Pan-Green identifiers to support DPP candidates in SMD races but back the TSU with their party votes. The DPP chairwoman, Tsai Ing-wen, also indicated publicly that she would like to see the TSU garner more than $5 \%$ of the party votes so that the party could receive apportioned PR seats (Lee 2012). Similar to the 2008 electoral outcome, the KMT and the DPP had a lion's share of the legislative seats with the former as the biggest winner. While the PFP and the TSU were able to pass the $5 \%$ threshold and acquired two and three seats in the PR tiers, respectively, the electoral results of 2008 and 2012 
demonstrate that minor political parties in Taiwan have difficulty winning SMD races without collaborating with major parties.

Interestingly, as both Japan and Taiwan are in the process of consolidating their two-party systems, the vote shares of major and minor parties in SMD races are generally different from their PR vote shares. The divergent patterns of vote distributions at the aggregate level seem to show that some electorates in both countries split their tickets in the elections. Survey data from the JES III and the TEDS appear to confirm this finding. By cross-tabulating SMD and PR votes at the individual level, table 7.2a shows that, in the 2003 elections, $37.8 \%$ of the Japanese electorate cast a straight-ticket vote for the LDP in both PR and SMD tiers, while 26.6\% of them voted sincerely for the DPJ in both segments. Even after other minor parties are included in the calculation, less than $70 \%$ of Japanese citizens were straight-ticket voters. Similar patterns can be found in the 2005 electoral results as a total of $68.5 \%$ of JES respondents supported candidates of the same political party in both the PR and SMD tiers. This means that roughly $30 \%$ of Japanese citizens were ticket-splitters in these two legislative elections. By comparison, the proportions of straight-ticket voters were higher in Taiwan's 2008 legislative elections as $77.7 \%$ of the TEDS respondents indicated that they supported the same political parties in both the PR and SMD tiers. Specifically, $55.2 \%$ and $22.5 \%$ of the electorate, respectively, were KMT and DPP straight-ticket voters in 2008. The 2012 elections, however, witnessed a 10\% increase in ticket-splitters and less than $70 \%$ of the country's citizens cast straight tickets. While some of these ticket-splitters may be "nonopportunity voters" due to a lack of SMD nominations of their preferred political parties (Benoit, Giannetti, and Laver 2006; Ferrara, Herron, and Nishikawa 2005, 87), roughly $20 \%$ to $30 \%$ of Japanese and Taiwanese voters split their tickets between their preferred parties in the PR list and candidates of other political affiliations in SMD races.

TABLE 7.2A. Straight Ticket Voters in the Electorates (in percentages)

\begin{tabular}{|c|c|c|c|c|c|}
\hline \multicolumn{3}{|c|}{ Japan } & \multicolumn{3}{|c|}{ Taiwan } \\
\hline & 2003 & 2005 & & 2008 & 2012 \\
\hline LDP & 37.8 & 38.0 & KMT & 55.2 & 50.6 \\
\hline DPJ & 26.6 & 26.4 & DPP & 22.5 & 17.0 \\
\hline CGP & 0.8 & 0.7 & TSU & 0.0 & - \\
\hline SDP & 0.8 & 0.2 & PFP & - & 0.4 \\
\hline JCP & 3.2 & 3.2 & NPSU & 0.0 & - \\
\hline All Straight Tickets & 69.2 & 68.5 & All Straight Tickets & 77.7 & 68.0 \\
\hline
\end{tabular}

Data source: JESIII, TEDS2008L, TEDS2012-T, Huang (2011), and Yu (2011). 
Comparing with ticket-splitting under the MMP systems in Germany and New Zealand, the patterns of split-ticket voting in Japan and in Taiwan are not unique. Indeed, the proportion of German ticket-splitters has increased from $4.3 \%$ in 1953 , when the country adopted the MMP system, to 22.1\% in 1998 (Gschwend, Johnston, and Pattie 2003; Kingemann and Wessels 2001). New Zealand also witnessed $37 \%$ of its voters splitting their ballots in the country's first parliamentary election under the MMP rules (Johnston and Pattie 2002; Barker et al. 2001). The extent of ticket-splitting in Japan and in Taiwan is thus comparable with that in other countries that employ mixed-member electoral systems.

It is important to note that ticket-splitters in both countries tend to vote for ideologically proximate candidates. As table $7.2 \mathrm{~b}$ shows, more than $75 \%$ of CGP and $44 \%$ to $60 \%$ of SDP supporters in the PR tier, respectively, voted for Japan's LDP and DPJ candidates in SMD races. About $90 \%$ of the NP's and $60 \%$ to $80 \%$ of the TSU's PR supporters in Taiwan

TABLE 7.2B. Vote Choices between PR and SMD Ballots

\begin{tabular}{|c|c|c|c|c|c|c|c|}
\hline \multirow{2}{*}{ Japan } & & \multicolumn{6}{|c|}{ 2003/2005 SMD Ballot } \\
\hline & & LDP & DPJ & CGP & SDP & $\mathrm{JCP}$ & $n$ \\
\hline \multirow{5}{*}{$\begin{array}{l}2003 \\
\text { PR Ballot }\end{array}$} & LDP & 82.7 & 6.5 & 2.4 & 0.5 & 0.8 & 660 \\
\hline & DPJ & 15.2 & 72.2 & 0.6 & 4.1 & 2.6 & 532 \\
\hline & CGP & 76.6 & 10.2 & 8.8 & 0 & 0.7 & 137 \\
\hline & SDP & 18.8 & 43.8 & 0 & 25.0 & 8.3 & 48 \\
\hline & $\mathrm{JCP}$ & 8.8 & 20.6 & 0 & 2.9 & 67.7 & 68 \\
\hline \multirow{5}{*}{$\begin{array}{l}2005 \\
\text { PR Ballot }\end{array}$} & LDP & 83.5 & 8.2 & 3.6 & 0.2 & 0.9 & 563 \\
\hline & DPJ & 11.6 & 82.3 & 0.3 & 0 & 1.3 & 396 \\
\hline & CGP & 78.8 & 6.6 & 6.6 & 0 & 1.5 & 137 \\
\hline & SDP & 16.7 & 60.4 & 0 & 6.3 & 12.5 & 48 \\
\hline & $\mathrm{JCP}$ & 9.7 & 16.1 & 0 & 1.6 & 64.5 & 62 \\
\hline & & \multicolumn{6}{|c|}{ 2008/2012 SMD Ballot } \\
\hline \multicolumn{2}{|l|}{ Taiwan } & KMT & DPP & TSU & PFP & NPSU & $n$ \\
\hline & KMT & 89.8 & 4.3 & 0 & - & 2.7 & 625 \\
\hline 2008 & DPP & 7.2 & 86.7 & 0.8 & - & 0.4 & 264 \\
\hline \multirow[t]{5}{*}{ PR Ballot } & NP & 90.0 & 1.7 & 0 & - & 1.7 & 60 \\
\hline & TSU & 21.9 & 62.5 & 0 & - & 3.1 & 32 \\
\hline & NPSU & 33.3 & 16.7 & 16.7 & - & 0 & 6 \\
\hline & KMT & 89.9 & 6.1 & - & 0.6 & 1.4 & 1,953 \\
\hline & DPP & 14.3 & 81.6 & - & 0.4 & 0.6 & 723 \\
\hline 2012 & NP & 89.7 & 5.1 & - & 1.3 & 0 & 78 \\
\hline \multirow[t]{2}{*}{ PR Ballot } & PFP & 62.3 & 25.2 & - & 4.3 & 1.3 & 320 \\
\hline & TSU & 14.2 & 80.9 & - & 0.3 & 0 & 325 \\
\hline
\end{tabular}

Data source: JESIII, TEDS2008L, TEDS2012-T, Huang (2011), and Yu (2011).

Note: Cells are row percentages; figures are listed for selected political parties. 
cast their SMD ballots for KMT and DPP candidates, respectively. These findings indicate that ticket-splitting in Japan and Taiwan tends to occur within coalitions rather than across coalitions. Indeed, party identification represents a psychological attachment to a political group and manifests individuals' political ideologies and positions on a host of issues. To be consistent with their partisan loyalty, ticket-splitters thus tend to back those within the partisan coalition.

That said, one cannot ignore the fact that there are a significant number of voters in Japan and Taiwan that split their tickets across coalitions. Table $7.2 \mathrm{~b}$ shows that about $6 \%$ to $8 \%$ of LDP and $12 \%$ to $15 \%$ of DPJ supporters in the PR tier, respectively, voted for DPJ and LDP candidates in SMD races. Similarly, $4 \%$ to $6 \%$ of the KMT's supporters and $7 \%$ to $14 \%$ of the DPP's supporters cast their SMD ballots for candidates of the other major party. These findings show that strategic thinking is not the only factor involved in ticket-splitting. Voters may support a candidate due to personal ties or the candidate's service record to the constituency regardless of his/ her partisan affiliation. The tendency to cast a personal vote is particularly strong in Japan and in Taiwan because both countries previously employed the single nontransferable vote system for legislative elections, which is notoriously characterized by personal ties between candidates and voters. The parallel institutional features of the MMM system discussed in chapter 1 also provide incentives for parties to encourage their district candidates to launch more personalistic campaigns (Moser and Scheiner 2004). Despite these historical and institutional factors contributing to personal votes, the overall voting patterns in both Japan and Taiwan lend support for the proposition that partisan identification is the primary determinant of vote choice but electoral institutions mitigate its effect.

Our theoretical expectations are that identifiers with major parties tend to cast sincere votes in both SMD and PR segments for their most preferred candidates and parties. Supporters of minor parties may act strategically by casting a sincere vote in the PR tier but then transferring their support to more viable SMD candidates. To test these hypotheses, tables $7.3 \mathrm{a}$ and $7.3 \mathrm{~b}$ cross-tabulate individual respondents' PR and SMD votes after their partisan loyalty is identified. The empirical results support the above theoretical expectations. Specifically, $56 \%$ to $60 \%$ of LDP supporters and about $66 \%$ of DPJ identifiers in both the 2003 and 2005 elections cast straight tickets for their preferred parties and the affiliated candidates, whereas $59 \%$ to $67 \%$ of CGP supporters and $23 \%$ to $30 \%$ of SDP identifiers were ticket-splitters. While supporters of major parties in Japan had a greater tendency to cast straight tickets, identifiers with minor parties 
are more likely to vote sincerely in the PR tier for their most preferred parties but back more viable SMD candidates of the major party of the same political coalition. Apparently, the psychological effects discussed by Duverger were in operation in the mind of Japanese voters.

The analysis of TEDS data yields similar findings in Taiwan. Because both the NP and PFP-two minor parties of the Pan-Blue allianceentered a preelectoral pact with the KMT in the 2008 elections, and thus they either did not nominate any candidates in district races or had their candidates run under the KMT banner. While almost all of the NP identifiers continued to be nonopportunity voters in the 2012 election and split their tickets in the PR and SMD tiers, some of the PFP identifiers had the opportunity to be straight-ticket voters as the PFP nominated 10 candidates in district races. Nevertheless, $35 \%$ and $15 \%$ of PFP identifiers in

TABLE 7.3A. Vote Choices between PR and SMD Ballots by Party Identification in Japan

\begin{tabular}{|c|c|c|c|c|c|c|c|c|c|c|c|}
\hline \multirow{2}{*}{$\begin{array}{l}\text { Voter's } \\
\text { party ID }\end{array}$} & \multirow[b]{2}{*}{ PR vote } & \multicolumn{5}{|c|}{2003 SMD vote } & \multicolumn{5}{|c|}{2005 SMD vote } \\
\hline & & LDP & DPJ & CGP & SDP & $\mathrm{JCP}$ & LDP & DPJ & CGP & SDP & $\mathrm{JCP}$ \\
\hline \multirow[t]{5}{*}{ LDP } & LDP & 56.0 & 3.8 & 1.7 & 0.2 & 0.4 & 60.2 & 4.3 & 2.2 & 0.2 & 0.5 \\
\hline & DPJ & 5.2 & 11.7 & 0.1 & 0.5 & 0.4 & 4.5 & 8.5 & & & \\
\hline & CGP & 5.5 & 0.2 & 0.4 & & 0.1 & 6.8 & 0.5 & 0.3 & & 0.2 \\
\hline & SDP & 0.4 & & & & & 0.6 & 0.3 & & & \\
\hline & $\mathrm{JCP}$ & 0.4 & 0.2 & & & 0.5 & 0.6 & 0.2 & & & 0.2 \\
\hline \multirow[t]{5}{*}{ CGP } & LDP & 3.5 & & & & & 3.9 & & 1.3 & & \\
\hline & DPJ & 1.1 & 2.3 & & 1.2 & & & 5.1 & & & \\
\hline & CGP & 59.3 & 9.3 & 8.1 & & & 66.7 & 6.4 & 7.7 & & \\
\hline & SDP & & & & & & & & & & \\
\hline & JCP & & 1.2 & & & & & & & & \\
\hline \multirow[t]{5}{*}{ DPJ } & LDP & 3.9 & 1.8 & & 0.3 & & 7.5 & 2.8 & 0.9 & & 0.3 \\
\hline & DPJ & 7.7 & 65.8 & 0.3 & 3.9 & 1.2 & 4.4 & 66.9 & 0.3 & & \\
\hline & CGP & & 0.3 & & & & 0.9 & 0.3 & & & 0.3 \\
\hline & SDP & 0.3 & 0.9 & & 0.9 & 0.3 & 0.6 & 4.1 & & 0.3 & 0.3 \\
\hline & $\mathrm{JCP}$ & 0.3 & 1.2 & & 0.3 & 1.2 & & 1.3 & & 0.3 & 0.9 \\
\hline \multirow[t]{5}{*}{ SDP } & LDP & 3.9 & & 1.9 & & & 6.1 & & 3.0 & & \\
\hline & DPJ & 3.9 & 19.2 & & 1.9 & 1.9 & & 27.3 & & & 3.0 \\
\hline & CGP & 1.9 & & & & & & & & & \\
\hline & SDP & 7.7 & 23.1 & & 11.5 & 1.9 & 3.0 & 30.3 & & 6.1 & 6.1 \\
\hline & JCP & & 1.9 & & & 3.9 & & & & & 6.1 \\
\hline \multirow[t]{5}{*}{ JCP } & LDP & 3.5 & & & & 1.8 & 7.4 & & & & 1.9 \\
\hline & DPJ & 1.8 & 15.8 & & & 3.5 & & 11.1 & & & 1.9 \\
\hline & CGP & & & 1.8 & & & & & & & \\
\hline & SDP & & & & & & & 1.9 & & & 5.6 \\
\hline & JCP & 1.8 & 5.3 & & 1.8 & 56.1 & & 3.7 & & & 48.2 \\
\hline
\end{tabular}

Data source: JESIII.

Note: Figures given in the cells are total percentages. Percentages are presented only for selected political parties, thus the sum of percentages does not equal $100 \%$. 
2012 decided to cross the party line and supported KMT and DPP candidates in SMD races, respectively. As in Japan, the psychological effect appeared to be in place at least in some of the PFP identifiers.

Probably the most instructive finding is the voting patterns of TSU identifiers. Recall that Pan-Green parties failed to reach a preelectoral pact ahead of the 2008 elections. As a result, the TSU fielded a number of SMD candidates with a complete PR list to compete with the DPP for the support of Pan-Green identifiers. The electoral outcome in 2008 was disastrous for the party as it did not win any district race and failed to pass the 5\% threshold in the PR tier. Recognizing the mistake they made, TSU leaders decided to collaborate with the DPP in the 2012 elections. This

TABLE 7.3B. Vote Choices between PR and SMD Ballots by Party Identification in Taiwan

\begin{tabular}{|c|c|c|c|c|c|c|c|}
\hline \multirow{2}{*}{$\begin{array}{l}\text { Voter's } \\
\text { party ID }\end{array}$} & \multirow[b]{2}{*}{ PR vote } & \multicolumn{3}{|c|}{2008 SMD vote } & \multicolumn{3}{|c|}{2012 SMD vote } \\
\hline & & KMT & DPP & TSU & KMT & DPP & $\mathrm{PFP}$ \\
\hline \multirow[t]{5}{*}{ KMT } & KMT & 82.2 & 3.6 & & 78.6 & 3.9 & 0.5 \\
\hline & DPP & 0.4 & 0.8 & & 1.0 & 2.1 & \\
\hline & NP & 4.1 & 0.2 & & 2.5 & 0.1 & 0.1 \\
\hline & PFP & - & - & - & 4.5 & 1.0 & 0.1 \\
\hline & TSU & & 0.2 & & 0.4 & 0.6 & \\
\hline \multirow[t]{5}{*}{ NP } & KMT & 28.6 & & & 52.1 & 2.1 & \\
\hline & DPP & & & & & & \\
\hline & NP & 50.0 & & & 25.0 & 4.2 & \\
\hline & PFP & - & - & - & 2.1 & & 2.1 \\
\hline & TSU & & 3.6 & & & 2.1 & \\
\hline \multirow[t]{5}{*}{ PFP } & KMT & 50.0 & 6.3 & & 14.3 & 1.4 & \\
\hline & DPP & & & & 0.7 & 3.4 & \\
\hline & NP & 18.8 & & & 2.0 & & \\
\hline & PFP & - & - & - & 34.7 & 15.0 & 6.1 \\
\hline & TSU & 6.3 & & & 2.0 & 6.1 & \\
\hline \multirow[t]{5}{*}{ DPP } & KMT & 3.1 & 0.9 & & 5.3 & 1.9 & 0.1 \\
\hline & DPP & 3.1 & 82.5 & 0.5 & 5.8 & 52.7 & 0.2 \\
\hline & NP & 0.5 & & & 0.2 & & \\
\hline & PFP & - & - & - & 1.7 & 2.3 & \\
\hline & TSU & & 2.2 & & 2.7 & 20.1 & 0.1 \\
\hline \multirow[t]{5}{*}{ TSU } & KMT & 17.4 & & & 4.4 & & \\
\hline & DPP & & 21.7 & & 6.7 & 28.9 & \\
\hline & NP & & & & & & \\
\hline & PFP & - & - & - & & 4.4 & \\
\hline & TSU & 13.0 & 17.4 & & 8.9 & 46.7 & \\
\hline
\end{tabular}

Data source: TEDS2008L, TEDS2012-T, Huang (2011), and Yu (2011).

Note: Figures given in the cells are total percentages. Percentages are presented only for selected political parties, thus the sum of percentages does not equal $100 \%$. 
strategy appeared to be working for the TSU. By not competing with an ideologically proximate major party in district races, the TSU successfully consolidated the party votes from its own followers. Interestingly, the TSU leaders' call on Pan-Green identifiers to support DPP candidates in SMD races but back the TSU in the PR also drew $20 \%$ of the DPP identifiers who transferred their party votes to the TSU. Party elites' explicit message of encouraging such ticket-split voting may be responsible for DPP identifiers' support for the TSU in the PR tier. Taiwan's single national 5\% threshold also makes this type of strategic voting likely by comparison as voters can more easily figure out if a small party is close to the threshold. ${ }^{10}$ As a result, the TSU garnered about $9 \%$ of the party vote and received three seats in the PR tier.

As shown in table $7.3 \mathrm{~b}, 29 \%$ of TSU identifiers cast a straight party vote for the DPP in the 2012 election. Unlike other minor party identifiers who split their ballots by casting sincere PR votes for their most preferred parties but voting for viable candidates in the district races, the psychological effect appeared to be in full swing here. Close to one-third of TSU identifiers worried that their votes would be wasted in the SMD as well as in the PR tiers if they supported a minor party. These voters' strategic calculation was probably due to the $5 \%$ legal threshold of Taiwan's PR segment. The TSU's disastrous outcome in 2008 might have also reinforced the Duvergerian gravity in both SMD and PR segments of the 2012 elections. Similarly, the same logic seems applicable to NP identifiers because more than half of them cast a straight party vote for the KMT in the 2012 election while only $25 \%$ of NP identifiers split their ballots and cast a sincere vote in the PR tier. The voting patterns of TSU and NP identifiers lend additional support for the hypothesis that the effect of partisan identification on electoral choice may be moderated by the institutional framework of MMM systems. More important, such a mitigation effect is more apparent to identifiers of minor parties than to those of major parties.

That said, it is important to note that some citizens in Japan's and in Taiwan's legislative elections were nonopportunity voters. As table 7.4 shows, almost all of the political parties in the two countries' elections presented a party list to compete in the PR tier. None of them, however, made nominations in all district races, except the JCP in Japan's 2003 election. The lack of district candidates was particularly acute for such minor parties as the CGP and the SDP in Japan and the NP, the PFP, the NPSU, and the TSU in Taiwan. While all voters in mixed-member electoral systems have the option of ticket-splitting, voters in these districts were forced to do so because their most preferred party failed to provide a choice on both PR 
and SMD ballots. To avoid overestimating ticket-splitting, a proper analysis of electoral behavior in Japan and in Taiwan thus requires attention to the voting patterns of these nonopportunity voters.

In general, the above analysis shows that $20 \%$ to $30 \%$ of voters split their tickets in the respective elections in Japan and in Taiwan. The voting patterns in both countries seem to be consistent with the theoretical expectations that partisan identification continues to be the primary determinant of vote choice in MMM systems but the electoral institutions mitigate its effect. Thus, identifiers of major political parties tend to cast straight tickets while supporters for minor parties are likely to be sincere in their PR votes but vote for viable candidates in SMD races. When they cross the party line and vote for candidates of different political affiliations, splitticket voting in both countries tends to occur within coalitions rather than across coalitions. As political parties may coordinate their campaign strategies, voters' ticket-splitting may be further induced by such preelectoral pacts. Because some of these ticket-splitters were nonopportunity voters due to a lack of SMD nominations of preferred political parties, a multivariate analysis of JES III and TEDS survey data is in order to ensure that the above findings are not spurious.

\section{Data and Methods}

To conduct the multivariate analyses, the dependent variable, Vote Choice, is created based on voters' responses if they cast a straight-ticket or split their ballots in the elections. Due to the different political landscapes of Japan and Taiwan, the variable is coded with different labels but each has five

TABLE 7.4. "Nonopportunity" Voters: Number of Districts with a Party Nominee

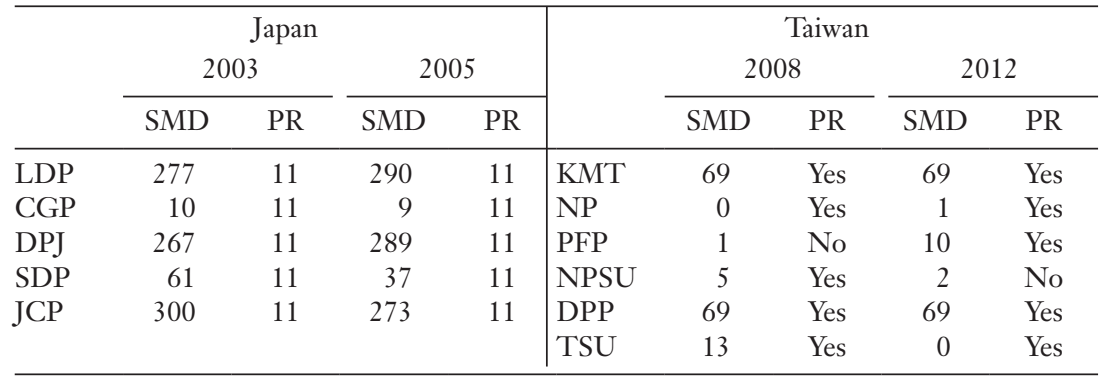

Data source: Central Election Commission, Taiwan; Elections and Citizen Participation website: http:// www.asianelections.org/cubekmcht/ezcatfiles/cust/img/img/144/196798271.pdf; http://www.asianelec tions.org/cubekmcht/ezcatfiles/cust/img/img/144/467755124.pdf.

Note: Japan has 300 SMDs and 11 PR districts. Taiwan has 73 SMDs and one PR district. 
categories. Because the Japanese political system can be roughly characterized as "governing coalition vs. opposition coalition," citizens' vote choices in Japan include (1) governing coalition straight-ticket, (2) opposition coalition straight-ticket, (3) governing coalition split-ticket, (4) opposition coalition split-ticket, and (5) other forms of split-ticket voting. ${ }^{11}$ To be consistent with Taiwan's "Pan-Blue vs. Pan-Green" political landscape, the categories of the island citizens' vote choice consist of (1) Pan-Blue alliance straight-ticket, (2) Pan-Green alliance straight-ticket, (3) Pan-Blue alliance split-ticket, (4) Pan-Green alliance split-ticket, and (5) other forms of splitticket voting. Table 7.5 presents the frequency distributions of each voting type in Japan and in Taiwan, respectively. As indicated earlier, the voting behavior of Japanese citizens appears to be more stable because there are few variations in the distributions of various vote choices. Taiwanese citizens' voting patterns appear to be more volatile as there is a $10 \%$ shift from straight-ticket to split-ticket voting. Such changes are particularly visible in the support for the Pan-Green alliance, which, as indicated earlier, was attributed to the coordinated electoral campaigns of the DPP and the TSU.

While data from Japan and Taiwan are analyzed separately, several common independent variables are created so that cross-country comparisons can be made. Because partisan attachment is considered the primary determinant of an individual's vote choice, a series of dummy variables of respondents' party identifications are created separately for each country. To assess Japanese citizens' partisan loyalties, the following variables are coded with 1 s for respondents in the relevant categories and otherwise with 0s for nonpartisan voters as the baseline group: Liberal Democratic Party (LDP), Democratic Party of Japan (DPf), Clean Government Party (CGP), Social Democratic Party (SDP), and Fapanese Communist Party (FCP). Corresponding variables of Taiwanese citizens' party identification are National-

TABLE 7.5. Distribution of Citizens' Vote Choices Typologies

\begin{tabular}{lrrlrr}
\hline & \multicolumn{2}{c}{ Japan } & & \multicolumn{2}{c}{ Taiwan } \\
\cline { 2 - 3 } \cline { 3 - 5 } & 2003 & 2005 & & 2008 & 2012 \\
\hline Governing straight & 38.6 & 38.8 & Pan-Blue straight & 55.3 & 51.0 \\
Opposition straight & 30.6 & 29.9 & Pan-Green straight & 22.6 & 17.0 \\
\hline Governing split & 9.3 & 10.4 & Pan-Blue split & 7.3 & 8.7 \\
Opposition split & 5.3 & 5.3 & Pan-Green split & 2.2 & 7.6 \\
Other split & 16.2 & 15.8 & Other split & 12.6 & 15.7 \\
Total $(n)$ & 1,445 & 1,236 & Total $(n)$ & 1,014 & 3,466 \\
\hline
\end{tabular}

Data source: JESIII, TEDS2008L, TEDS2012-T, Huang (2011), and Yu (2011). 
ist Party (KMT), Democratic Progressive Party (DPP), New Party (NP), People First Party (PFP), and Taiwan Solidarity Union (TSU).

As indicated earlier, not all political parties in Japan's and in Taiwan's past legislative elections nominated candidates competing for SMD seats. Voters in such districts where their most preferred parties did not nominate candidates would not even have the opportunity to cast straight tickets. In Taiwan's 2008 legislative elections, for instance, the DPP did not nominate candidates in four districts while the TSU did not do so in 60. In Taiwan's 2012 legislative elections, the TSU did not field any candidates in district races. Similarly, in Japan's 2003 and 2005 elections the LDP coordinated its nominations with the CGP and did not make nominations in those districts where the CGP candidates ran. The DPJ and the SDP also coordinated their nominations in some SMDs lest they compete with each other. The only political party that did not enter into electoral pacts with other parties was the JCP as its candidates ran in all 300 SMDs in the 2003 elections and in 273 SMDs in 2005. To avoid overestimating ticketsplitting, three dummy variables are incorporated to control the effect of "nonopportunity" supporters in Japan: nomination for DPF, nomination for $L D P$, and nomination for SDP. Similarly, three corresponding dummy variables are included to control the effect of "nonopportunity" supporters in Taiwan: nomination for KMT, nomination for DPP, nomination for TSU, and nomination for $P F P .^{12}$ These dummy variables are coded as $1 \mathrm{~s}$ if the relevant political parties nominated candidates in the SMDs and 0s if the parties did not field candidates.

Several demographic factors are included as control variables. Previous studies find that education increases an individual's ability to understand abstract and intangible subjects like politics. Such abilities heighten individuals' interest in politics, equip them with better knowledge of democratic norms and procedures, give them greater skills in working with complex rules, and offer them the capacity of identifying local and national leaders (Huang, Yu, and Hsiao 2011; Karp et al. 2002; Nie, Junn, and Stehlik-Barry 1996; Wolfinger and Rosenstone 1980). Well-educated voters are more likely to possess the political awareness and ability to understand the institutional design of MMM systems and the strategic payoffs of each menu choice in the PR and the SMD tiers. They are more likely to split their votes for candidates of different political affiliations due to their political sophistication. To tap respondents' education attainment, the following dummy variables are included: university degree (and above), junior college degree, and senior high school degree. They are coded as 1 s for those who are in the relevant category and 0 s otherwise, with respondents having 
a junior high school degree and below as the reference group. To control the effects of gender and age, two variables are created: Male is a dichotomous variable, which is coded as 1 according to respondents' gender, and Age is measured by the number of years since birth.

Because the dependent variable, Vote Choice, has five nonordered categories, a multinomial logit model is used (Glasgow and Alvarez 2008; Long 1997; Long and Freese 2006). Specifically, the regression model takes the form of

$$
\ln \Omega_{m \mid b}(\mathbf{x})=\ln \frac{\operatorname{Pr}(y=m \mid \mathbf{x})}{\operatorname{Pr}(y=b \mid \mathbf{x})}=x \beta_{m \mid b}, \quad \text { for } m=1 \text { to } \mathcal{f}-1,
$$

where $b$ is the base category for comparison; $\ln \Omega_{m \mid b}(\mathbf{x})$ is the conditional odds of having other responses relative to the base category; $\mathbf{x}$ is a vector of independent variables; $\beta$ is a vector of regression parameters; and $\mathcal{F}$ is the number of categories in the dependent variable.

\section{Multivariate Analysis of Split-Ticket Voting in Japan and Taiwan}

Using "governing coalition straight-ticket" and "Pan-Blue alliance straight-ticket," respectively, as the baseline for comparison in analyzing Japanese and Taiwanese citizens' voting behavior, the variable of Vote Choice is regressed on the aforementioned independent variables in a multivariate context. The results in tables 7.6a to 7.6d show that most coefficients associated with partisan identification, especially those of major political parties (the LDP and DPJ in Japan and KMT and DPP in Taiwan), are statistically significant. These findings show that partisan loyalty is the most important factor in determining citizens' electoral choice in both Japan and Taiwan even after the effects of nonopportunity voters and citizens' demographic characteristics are controlled for. Most important, data in the tables confirm the previous finding that identifiers of major parties are more likely to cast sincere straight-tickets whereas those of minor parties tend to engage in ticket-splitting voting within their respective coalitions/alliances. To illustrate, table 7.7 presents the predicted probabilities for Japanese and Taiwanese voters, respectively, with selected conditions. As table 7.7 shows, an average LDP or DPJ male identifier's predicted probabilities of casting a straight-ticket for candidates of his own coalition are between 0.7 and 0.8 when his most preferred party fielded SMD candidates in the 2003 and 2005 elections. The likelihood for this voter to split the ticket was rather small with a probability of less than 0.1 . However, an identifier of minor 
political parties like the CGP and SDP has a higher tendency of splitting the ticket within the coalition, with a probability between 0.3 and 0.7 in both elections with or without SMD nominations by his most preferred parties.

Table 7.7 reveals a similar voting pattern in Taiwan, and it is instructive regarding the effects of preelectoral pacts among political parties. First, like Japanese voters, an average male KMT or DPP identifier in the 2008 elections had a rather high probability (about 0.85 ) of casting a straightticket but a miniscule likelihood of splitting his ballots when the most preferred parties had candidates in district races. Identifiers of minor parties like the NP, which engaged in a preelectoral pact, or the PFP, which had its candidates run under the KMT banner, had higher probabilities of either splitting the ticket within the alliance or casting a Pan-Blue straight-ticket. Parties of the Pan-Green alliance did not coordinate their campaigns in 2008 and TSU identifiers apparently had a difficult time making a decision as their predicted probabilities of voting were evenly spread across various options. In the 2012 elections, the PFP dropped out of the Pan-Blue pact and PFP identifiers, like their CGP and SDP counterparts in Japan, had a higher probability of splitting the ticket with or without SMD nominations by the party as the majority of them cast their SMD ballots for KMT candidates. Probably due to the coordinated campaign by the Pan-Green alliance in 2012, an average TSU identifier had a higher probability of splitting the ticket and voting for the TSU in the PR tier and for DPP candidates in district races. For the same reason, an average DPP supporter had a lower likelihood of casting a Pan-Green straight-ticket in 2012 than in 2008 as they split their support for DPP district candidates and for the TSU in the PR tier. Along with the findings in table 7.3b, the empirical evidence thus shows that the coordinated campaign strategy in the 2012 elections by the Pan-Green alliance consolidated TSU identifiers' support in the PR tier and also drew party votes from DPP supporters. Apparently, voters' ticket-splitting behavior can be further induced by the campaign strategies of political parties.

\section{Conclusions}

Characterized as hybrids that combine both PR and SMD rules, mixedmember systems have been adopted in many countries during the past two decades. Because the institutional arrangements of such electoral systems provide citizens with an opportunity to split their votes for candidates of 


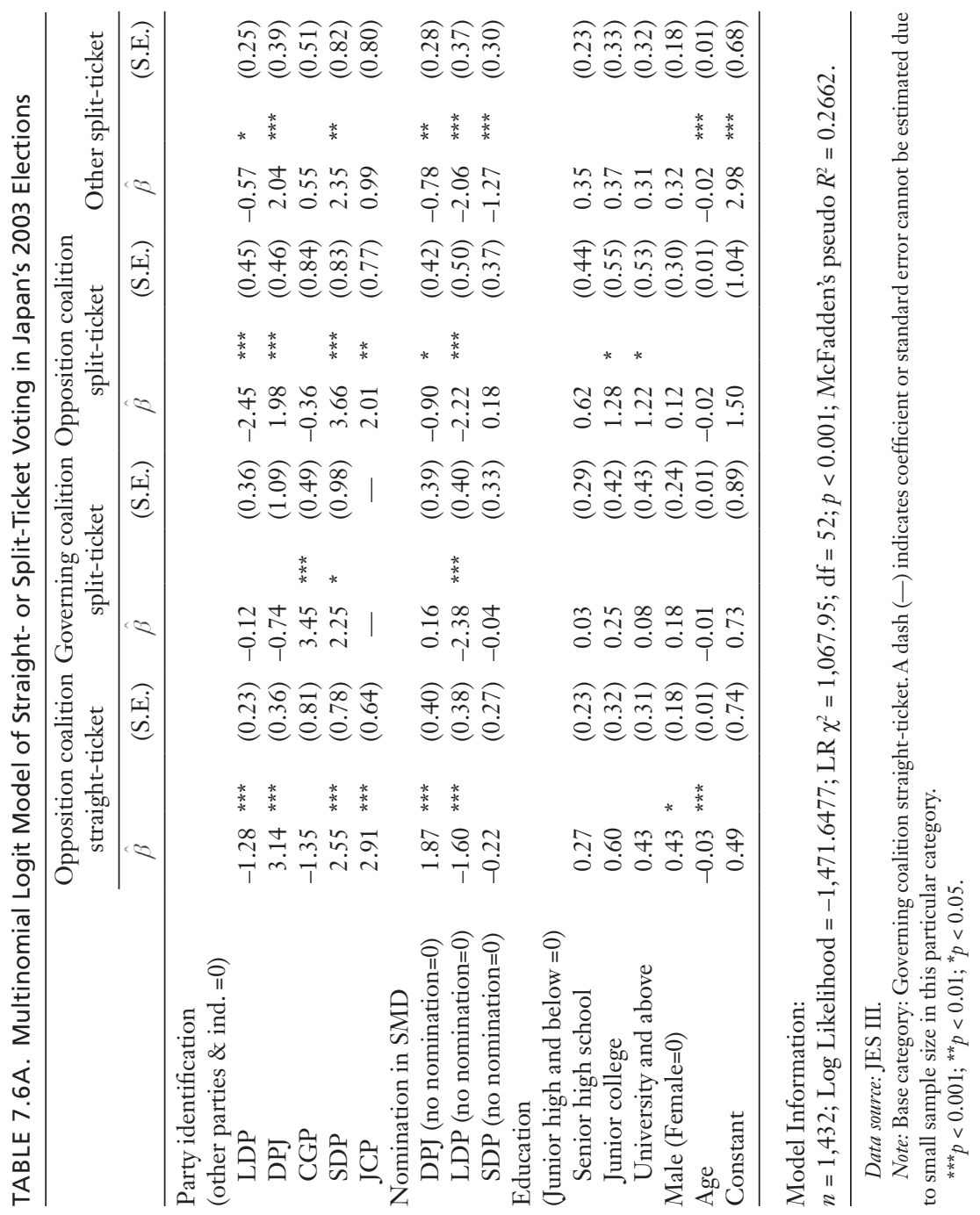




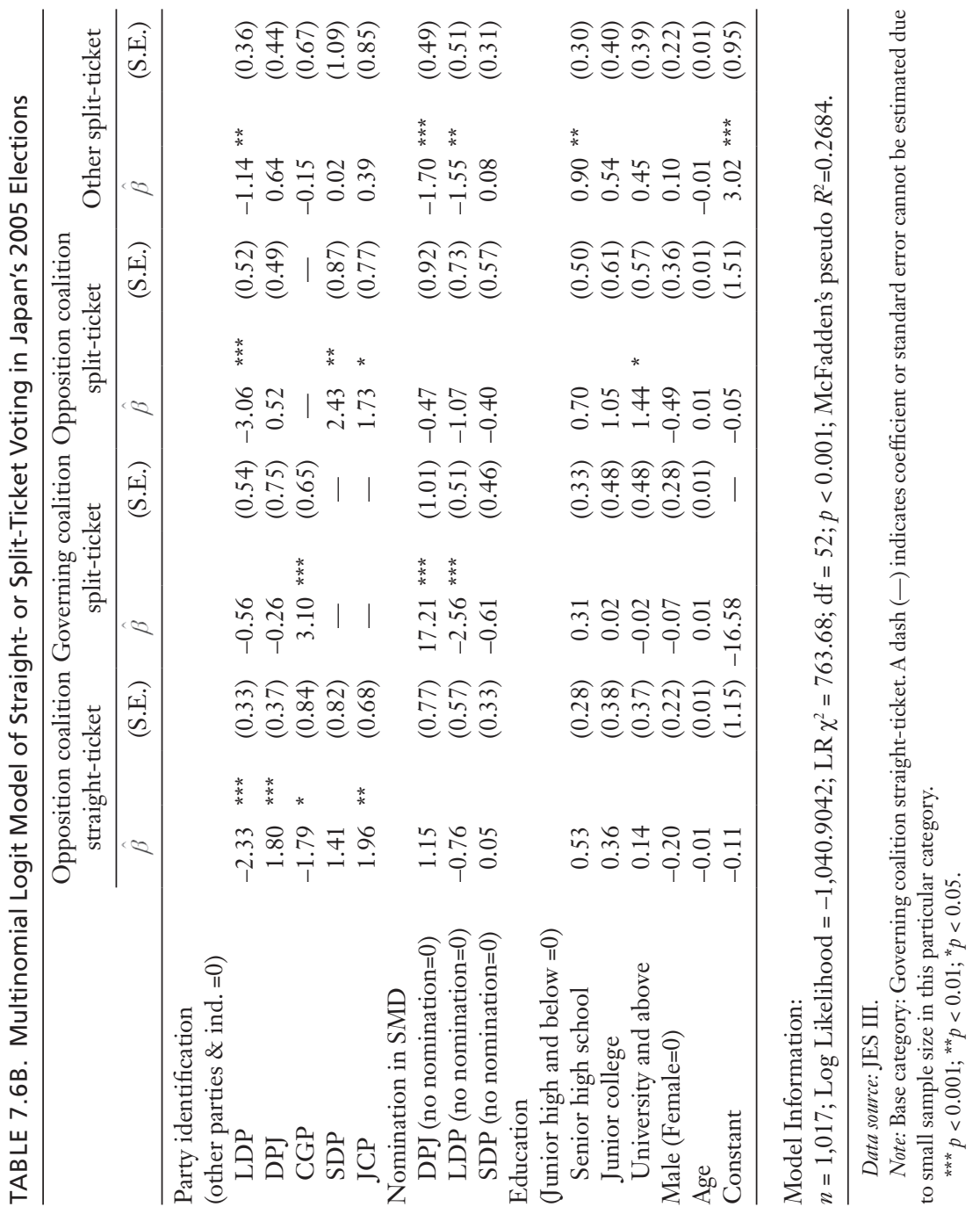




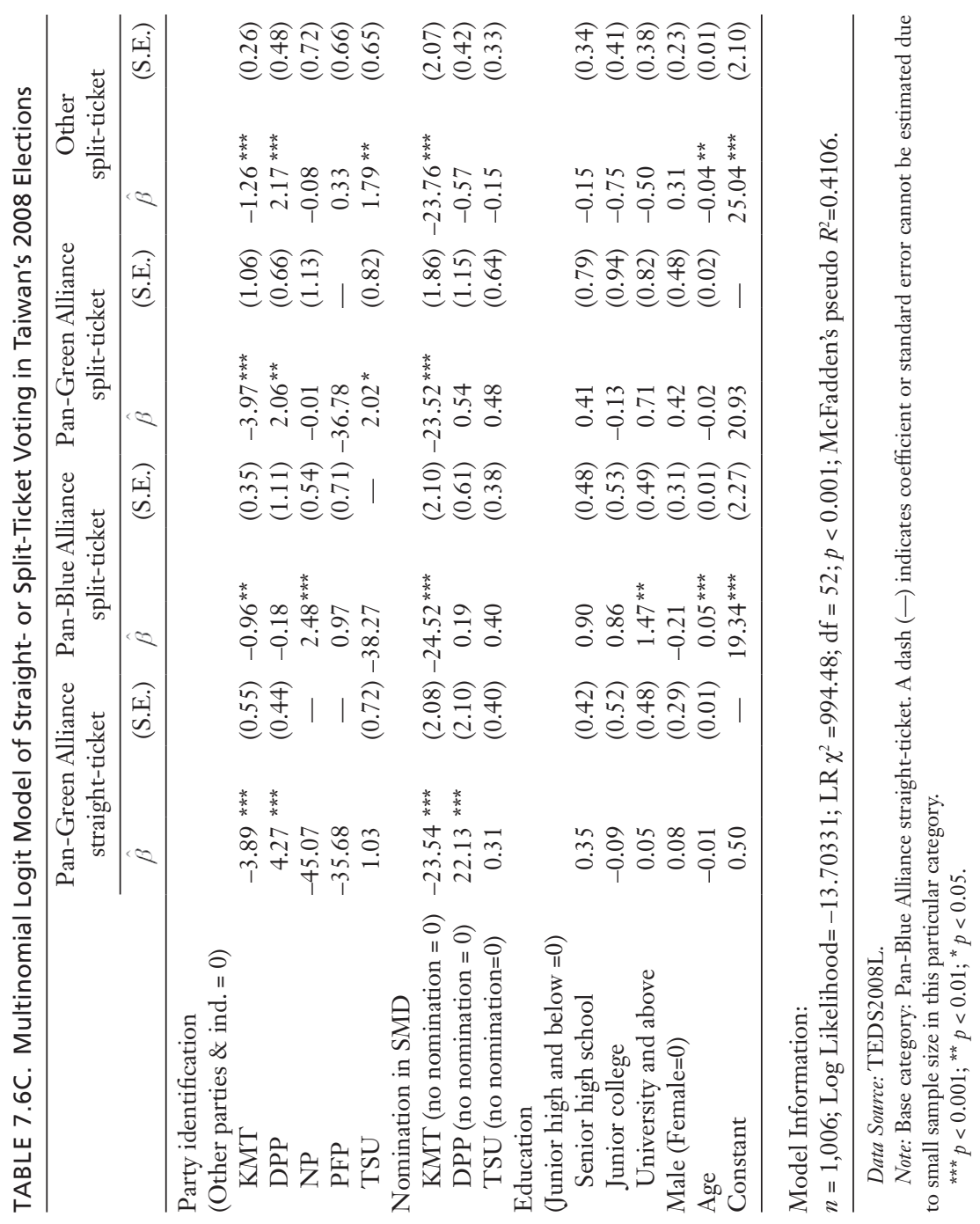




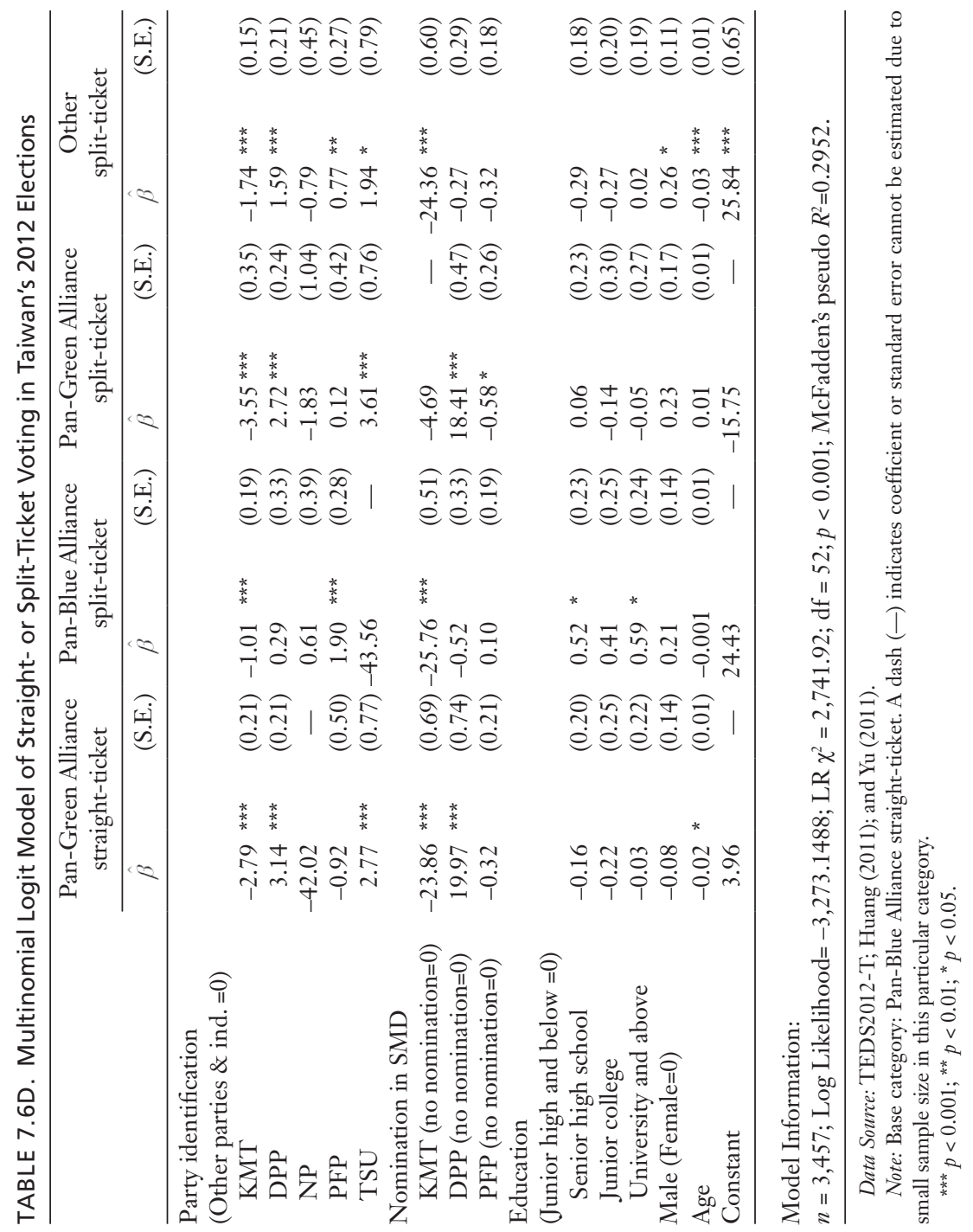




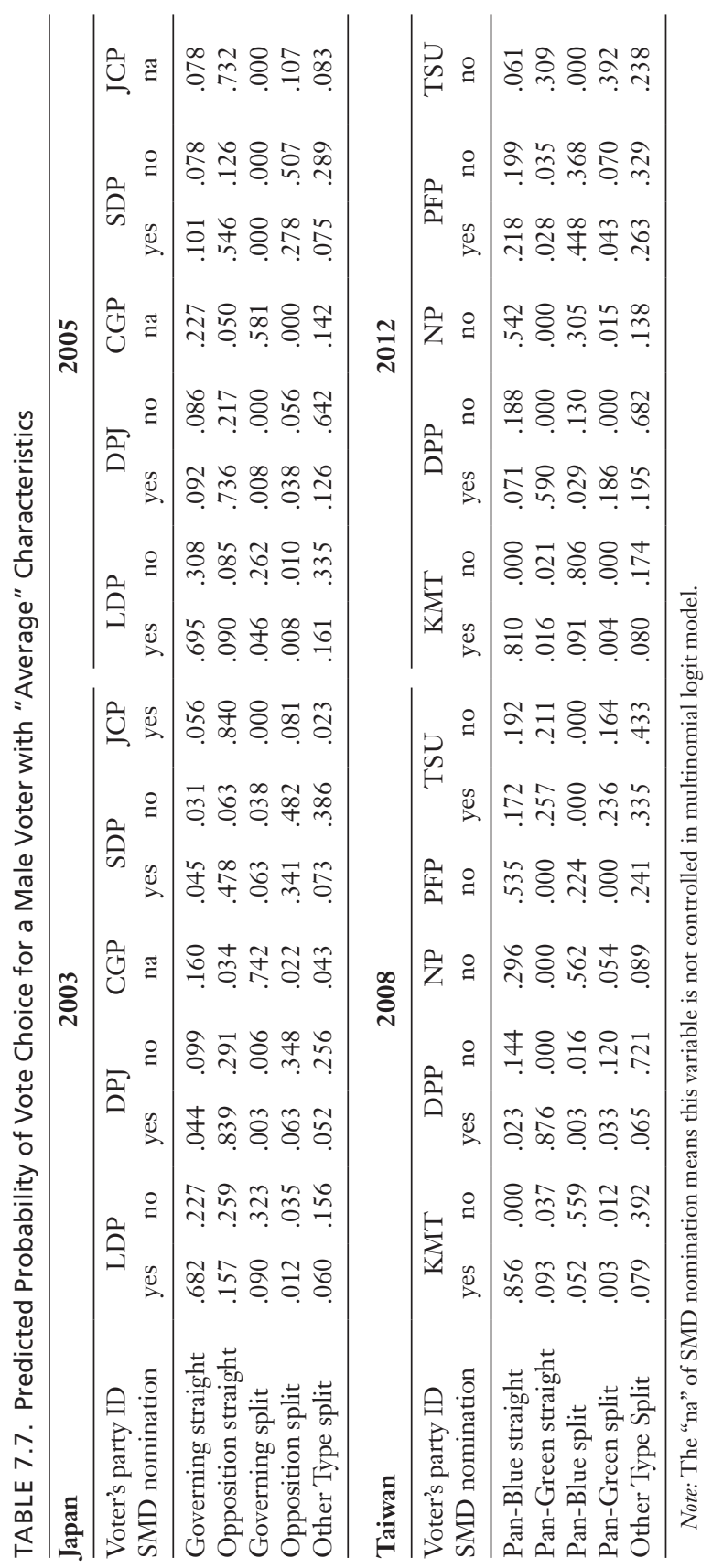


different political affiliations, there is considerable scholarly interest in the degree and nature of ticket-splitting in such systems. The electoral reforms adopted in recent years by Japan and Taiwan provide an opportunity to examine electoral behavior in mixed-member systems.

This study hypothesizes that partisan identification remains the primary determinant of citizens' voting behavior in both countries but the effect of partisan loyalty is mitigated by the institutional design of the new electoral rules. The empirical evidence of this study supports this hypothesis. The mechanical and psychological effects characterized by Duverger have important effects on citizens' electoral behavior in both Japan and Taiwan. While supporters of major political parties tend to cast sincere straight-tickets, identifiers of minor political parties have a higher likelihood of becoming ticket-splitters with the worry that their votes for trailing candidates may be wasted. To be consistent with partisan loyalty, identifiers of minor parties tend to be sincere in their PR votes but back viable district candidates of major parties. Their defections in the SMD tier are generally limited to candidates of the same coalitions/alliances. Thus, partisan loyalty continues to exert an important impact on electoral choice in mixed-member systems, but the institutional design of the electoral systems still matters. The fact that consistent findings are identified across four legislative elections in two different countries suggests the robustness of these conclusions.

Moreover, the above findings show that the rules applying to the PR or the SMD tier do indeed shape the results in that tier. The effects of each set of rules, however, can be manipulated through the party elites' campaign strategies in one or both tiers. Through coordinated nominations and campaigns, parties of similar political positions can provide a clear voting cue to their supporters lest they compete with each other and divide the pool of support. The net effects are that political coalitions/alliances may maximize their collective seat shares and provide minor parties with a chance of survival in an otherwise rather competitive environment. Coordinated campaigns by party elites thus may generate another form of "contamination or "interaction" effect. Though mixed-members systems are hybrids of two sets of rules, they are more than the sum of their two parts. As a result, MMM systems are internally distinct in that they are characterized by sets of incentives different from the pure forms of PR and SMD.

\section{NOTES}

1. For a detailed discussion of mixed-member systems and the new electoral systems in Japan and in Taiwan, see chapter 1 by Huang, Kuo, and Stockton. 
2. The survey data of the 2008 Legislative Yuan elections in this paper are from "Taiwan's Election and Democratization Study, 2008: Legislative Election (TEDS2008L) (NSC 96-2420-H004-002-025). The coordinator of the multiyear project TEDS is Professor Chi Huang of National Chengchi University in Taipei. The TEDS2008L project focuses specifically on the 2008 legislative elections in Taiwan, and its principal investigator is Professor Yun-han Chu of Academia Sinica. More information on TEDS projects can be accessed at http://www.tedsnet.org.

3. The three datasets, which are composed of pre-2012 election rolling surveys, include (1) "Taiwan Election and Democratization Study: Telephone Interview of the Presidential and Legislative Elections, 2012" (TEDS2012-T) (NSC100-2420H-002-030). The principal investigator of TEDS2012-T is Professor Chi Huang; (2) "Causal Inference: Methodology and Application to the Study of Contamination Effect in Mixed-Member Electoral Systems (2/3)" (NSC99-2410-H-004036-MY3). The principal investigator is Professor Chi Huang (hereafter Huang 2011); (3) "Citizen's Knowledge of New Legislative Electoral System in Taiwan" (NSC100-2410-H-004-090-MY2). The principal investigator is Professor Chinghsin Yu (hereafter Yu 2011).

4. The Japan Election Studies III Research Project (Participants: Ken'ichi Ikeda, University of Tokyo; Yoshiaki Kobayashi, Keio University; and Hiroshi Hirano, Gakushuin University) is a part of "The Nationwide Chronological Studies on Voting Behaviors in the Early 21st Century" supported by Grants-in-Aid for Scientific Research 2002-2006 from the Ministry of Education, Culture, Sports, Science, and Technology of Japan. More information on JES projects can be accessed at http:// www.coe-ccc.keio.ac.jp/data_archive_en/data_archive_jesIII.html. The authors thank the aforementioned institutions and individuals for making the data available, but the authors alone are responsible for the views expressed herein.

5. It is important to note that ticket-splitting voting and strategic voting are two different concepts. Strategic voting arises when voters adjust their vote choices based on the considerations that their most preferred candidate is not viable and their votes are likely to be wasted. Thus, strategic voting can occur in the pure SMD system in which voters are offered only one ballot. In mixed electoral systems, the psychological effect of the "wasted vote" may also lead to such strategic considerations leading to ticket-splitting.

6. Other studies have disputed the findings on the "contamination effect." It is argued that parties tend to nominate candidates in districts where they have strong support. For instance, Maeda (2008) employs a treatment-effects model and finds that fielding SMD candidates does not help a party to receive additional PR votes. We have no intention to settle the dispute since there are no available data to test the relevant hypothesis but instead to examine the effects of electoral coordination on voters' electoral choice.

7. As it will be explained below, Taiwan's KMT entered an electoral pact with the People First Party (PFP) and the New Party (NP) in 2008. However, the PFP dropped out of the pact ahead of the 2012 elections. See also Nemoto and Tsai, chapter 6 , this volume.

8. The Japanese political landscape has undergone further changes since the 2005 elections as the ruling LDP coalition has started losing hold. The then opposition DPJ won a smashing victory in the 2009 election and organized a coalition 
government with the SDP and the People's New Party (Nihon Shinto). Hampered by the issue of Futenma U.S. Marine Base in Okinawa, a sluggish economy, a series of scandals, and perceived incompetence in dealing with the Fukushima nuclear disaster, the approval rating of the DPJ ruling coalition has slid since 2009. In the 2012 elections, Japanese voters returned governing power to the LDP, which won 294 of the 480 seats-arguably the biggest electoral victory ever for the party. The LDP soon formed a coalition government with its long-time political partner-the CGP - that has yielded a 320-seat veto-proof "supermajority" in Japan's House of Representatives (Pekkanen 2012; Rosenbluth 2012).

9. "Nonopportunity voters" are also characterized as "frustrated voters" because they are forced to split their ticket due to the failure of their most preferred party to offer a choice on both PR as well as SMD ballots (Benoit, Giannetti, and Laver 2006).

10. In Japan, since each regional PR bloc has a different number of seats and thus a different implied threshold (see chapter 1), voters have a much more difficult task in trying to figure out which parties are at the point of winning.

11. The JCP is categorized as a member of the opposition coalition in this study because it has never been in any ruling coalition and its political position is closer to that of the DPJ and the SDP. Thus, when both SMD and PR ballots were cast for the JCP, the coding is "opposition coalition straight-ticket." An "opposition coalition split-ticket" is registered if a voter cast one ballot for the JCP and the other ballot for the DPJ or the SDP, while an "other forms of split-ticket voting" is coded if one ballot was for the JCP and the other ballot for parties other than the DPJ and the SDP.

12. Note that there is no dummy variable for CGP nomination because the CGP and the LDP coordinated their nominations in both elections. In no district did the LDP and the CGP both nominate candidates in SMD races in 2003 and 2005. Adding a dummy variable for CGP nomination will thus cause multicollinearity. The lack of a dummy variable to register the PFP nomination in Taiwan's 2008 elections is due to the fact that the PFP only made one SMD nomination in Lienchiang, a district that the TEDS did not cover.

\section{REFERENCES}

Akuto, Hiroshi. 1971. "Political Process and Public Opinion: Voting Behavior and Mass Communication.” In International Studies of Broadcasting, ed. Hirosuki Eguchi and H. Ichinohe. Tokyo: NHK Radio and Television Culture Research Institute.

Alesina, Alberto, and Howard Rosenthal. 1995. Partisan Politics, Divided Government, and the Economy. San Francisco: W. H. Freeman.

Barker, Fiona, Jonathan Boston, Stephen Levine, Elizabeth McLeay, and Nigel S. Roberts. 2001. "An Initial Assessment of the Consequences of MMP in New Zealand." In Mixed-Member Electoral Systems: The Best of Both Worlds?, ed. Matthew Søberg Shugart and Martin P. Wattenberg, 297-322. New York: Oxford University Press.

Bartels, Larry M. 2000. "Partisanship and Voting Behavior, 1952-1996." American Journal of Political Science 44 (1): 35-50. 
Bawn, Kathleen. 1993. "The Logic of Institutional Preferences: German Electoral Law as a Social Choice Outcome." American fournal of Political Science 37 (4): 965-89.

Bawn, Kathleen. 1999. "Voter Responses to Electoral Complexity: Ticket Splitting, Rational Voters and Representation in the Federal Republic of Germany." British Fournal of Political Science 29 (3): 487-505.

Beck, Paul Allen, Lawrence Baum, Aage R. Clausen, and Charles E. Smith. 1992. "Patterns and Sources of Ticket Splitting in Subpresidential Voting." American Political Science Review 86 (4): 916-28.

Benoit, Kenneth, Daniela Giannetti, and Michael Laver. 2006. "Voter Strategies with Restricted Choice Menus." British Fournal of Political Science 36:459-85.

Born, Richard. 1994. "Split-Ticket Voters, Divided Government, and Fiorina's Policy-Balancing Model.” Legislative Studies Quarterly 19 (1): 95-115.

Brandy, David W. 1993. "The Causes and Consequences of Divided Government: Toward a New Theory of American Politics?" American Political Science Review 87 (1): 189-94.

Burnham, W. D. 1970. Critical Elections and the Mainsprings of American Politics. New York: W. W. Norton.

Campbell, Angus, Philip Converse, Warren Miller, and Donald Stokes. 1964. The American Voter: An Abridgment. New York: John Wiley and Sons.

Campbell, David, John C. Green, and Geoffrey C. Layman. 2011. "The Party Faithful: Partisan Images, Candidate Religion, and the Electoral Impact of Party Identification." American Fournal of Political Science 55 (1): 42-58.

Choi, Jungug. 2006. "Institutional Interaction and Strategic Voting in Korea's New Mixed Electoral System.” Fournal of International and Area Studies 13 (2): 111-22.

Chu, Yun-han. 1996. "The Partisan Factor in Electoral Choice: A Case Analysis of the 1991 National Assembly Elections" [in Chinese]. Xuanju yanjiu [Journal of Electoral Studies] 3 (1): 17-48.

Cox, Gary W. 1990. "Centripetal and Centrifugal Incentives in Electoral Systems.” American Fournal of Political Science 34 (4): 903-35.

Cox, Gary W. 1996. "Is the Single Nontransferable Vote Superproportional? Evidence from Japan and Taiwan." American fournal of Political Science 40 (3): 74055.

Cox, Gary W. 1997. Making Votes Count: Strategic Coordination in the World's Electoral Systems. Cambridge: Cambridge University Press.

Cox, Gary W., and Emerson Niou. 1994. "Seat Bonuses under the Single Nontransferable Vote System: Evidence from Japan and Taiwan." Comparative Politics 26 (2): 221-36.

Cox, Karen E., and Leonard J. Schoppa. 2002. "Interaction Effects in MixedMember Electoral Systems: Theory and Evidence from Germany, Japan, and Italy." Comparative Political Studies 35 (9): 1027-53.

Downs, Anthony. 1957. An Economic Theory of Democracy. New York: Harper and Row.

Duverger, Maurice. 1959. Political Parties: Their Organization and Activity in the Modern State. 2nd English ed. New York: John Wiley and Sons.

Feigert, Frank B. 1979. "Illusions of Ticket-Splitting." American Politics Quarterly 7 (4): 470-88. 
Ferrara, Federico, and Erik S. Herron. 2005. "Going It Alone? Strategic Entry under Mixed Electoral Rules." American Fournal of Political Science 49 (1): 16-31.

Ferrara, Federico, Erik S. Herron, and Misa Nishikawa. 2005. Mixed Electoral Systems: Contamination and Its Consequences. New York: Palgrave Macmillan.

Fiorina, Morris P. 1996. Divided Government. 2nd ed. New York: Macmillan.

Fisher, S. L. 1973. “The Wasted Vote Thesis.” Comparative Politics 5 (2): 293-99.

Fu, Hung-der. 1996. "The Determinants of Voting Choice: Structural, Psychological, and Rational Factors" [in Chinese]. Xuanju yanjiu [Journal of Electoral Studies] 3 (2): 157-85.

Gallagher, Michael. 1998. "The Political Impact of Electoral System Change in Japan and New Zealand, 1996." Party Politics 4 (2): 203-28.

Garand, James C., and Marci Glascock Lichtl. 2000. "Explaining Divided Government in the United States: Testing an Intentional Model of Split-Ticket Voting." British fournal of Political Science 30 (1): 173-91.

Glasgow, Garrett, and R. Michael Alvarez. 2008. "Discrete Choice Methods." In The Oxford Handbook of Political Methodology, ed. Janet M. Box-Steffensmeier, Henry E. Brady, and David Collier, 513-29. Oxford: Oxford University Press.

Green, Donald, Bradley Palmquist, and Eric Schickler. 2002. Partisan Hearts and Minds: Political Parties and the Social Identities of Voters. New Haven: Yale University Press.

Gschwend, Thomas, Ron Johnston, and Charles Pattie. 2003. "Split-Ticket Patterns in Mixed-Member Proportional Election Systems: Estimates and Analyses of Their Spatial Variation at the German Federal Election, 1998.” British Fournal of Political Science 33 (1): 109-27.

Hall, Peter A., and Rosemary C. R. Taylor. 1996. "Political Science and the Three New Institutionalisms." Political Studies 44 (5): 936-57.

Herron, Erik S., and Misa Nishikawa. 2001. "Contamination Effects and the Number of Parties in Mixed-Superposition Electoral Systems." Electoral Studies 20 (1): 63-86.

Hetherington, Marc J. 2011. "Resurgent Mass Partisanship: The Role of Elite Polarization (Updated)." In Controversies in Voting Behavior, ed. Richard G. Niemi, Herbert F. Weisberg, and David C. Kimball. Washington, DC: CQ Press.

Hizen, Yoichi. 2007. “The Effect of Dual Candidacy on Voting Decisions.” Fapanese Journal of Political Science 7 (3): 289-366.

Ho, Szu-yin. 1994. “Taiwan Voter's Party Preference Change: 1989-1992” [in Chinese]. Xuanju yanjiu [Journal of Electoral Studies] 1 (1): 39-52.

Hsu, Yung-ming, and Chang-ping Lin. 2009. "Re-examining 'Southern Politics' in Taiwan" [in Chinese]. Xuanju yanjiu [Journal of Electoral Studies] 16 (1): 1-35.

Huang, Chi. 2001. "Straight- and Split-Ticket Voting: Methodological Reflections" [in Chinese]. Renwen yu Shebui Kexue Fikan [Journal of Social Sciences and Philosophy] 13 (5): 541-74.

Huang, Chi. 2007. "Assessing the Impact of Mixed Electoral System in Taiwan: Methodological Challenges of Testing Interaction Effects." Presented at the International Symposium on Mixed Electoral Systems in East Asia, National Chengchi University, Taipei, May 26.

Huang, Chi. 2008a. "Contexts and Consequences of Electoral Systems" [in Chi- 
nese]. In Rube Ping Gu Xuanzhi Bianqian: Fangfa Lun de Tantao [The consequences of electoral system change: Methodological perspectives], ed. Chi Huang and Chin-hsing Yu, 1-18. Taipei: Wunan Press.

Huang, Chi. 2008b. "How to Study Voter Choice under the Mixed-Member Majoritarian Systems: A Multilevel Mixed Logit Model [in Chinese]. In Rube Ping Gu Xuanzhi Bianqian: Fangfa Lun de Tantao [The consequences of electoral system change: Methodological perspectives], ed. Chi Huang and Chin-hsing Yu, 129-50. Taipei: Wunan Press.

Huang, Chi. 2011. "Causal Inference: Methodology and Application to the Study of Contamination Effect in Mixed-Member Electoral Systems (2/3)." National Science Council Project NSC99-2410-H-004-036-MY3. Taipei: National Science Council.

Huang, Chi, Lu-huei Chen, and Ying-lung Chou. 2008. "Taiwan's New Mixed Electoral System and Its Effects on the 2008 Legislative Election." Paper presented at the 2008 Annual Meeting of the Japanese Electoral Studies Association, Tokyo, May 17-18.

Huang, Chi, and Yi-ching Hsiao. 2009. "Vote Choices under the Mixed-Member Majoritarian System in Taiwan's 2008 Legislative Election.” Paper presented at the International Conference on Elections in Taiwan, Japan, and Korea under the Mixed-Member Majoritarian Systems, Election Study Center, National Chengchi University, Taipei, May 24.

Huang, Chi, Ding-ming Wang, and Ming-feng Kuo. 2008. "Straight- and SplitTicket Voting in a Mixed-Member Majoritarian System: An Analysis of the 1996 House Election in Japan" [in Chinese]. Xuanju yanjiu [Journal of Electoral Studies] 15 (2): 1-35.

Huang, Chi, Ching-hsin Yu, and Yi-ching Hsiao. 2011. "Citizens' Awareness of the New MMM Electoral System in Taiwan: A Cohort Analysis." Election Studies 1 (2): 7-43.

Jacobson, Gary C. 1991. "Explaining Divided Government: Why Can't Republicans Win the House?" PS: Political Science and Politics 24 (4): 640-43.

Jesse, Eckhard. 1988. "Split-Voting in the Federal Republic of Germany: An Analysis of the Federal Elections from 1953 to 1987." Electoral Studies 7 (2): 109-24.

Johnston, Ron, and Charles Pattie. 2002. "Campaigning and Split-Ticket Voting in New Electoral Systems: The First MMP Elections in New Zealand, Scotland and Wales." Electoral Studies 21 (4): 583-600.

Jou, Willy. 2009. "Electoral Reform and Party System Development in Japan and Taiwan: A Comparative Study." Asian Survey 49 (5): 759-85.

Karp, Jeffrey A., Jack Vowles, Susan A. Banducci, and Todd Donovan. 2002. "Strategic Voting, Party Activity, and Candidate Effects: Testing Explanations for Split Voting in New Zealand's New Mixed System." Electoral Studies 21 (1): 1-22.

Keith, Bruce E., D. B. Magleby, C. J. Nelson, E. Orr, M. C. Westlye, and R. E. Wolfinger. 1992. Myth of the Independent Voter. Berkeley: University of California Press.

Kingemann, Hans-Dieter, and Bernhard Wessels. 2001. "The Political Consequences of Germany's Mixed-Member System: Personalization at the Grass Roots?" In Mixed-Member Electoral Systems: The Best of Both Worlds?, ed. Mat- 
thew Søberg Shugart and Martin P. Wattenberg, 279-96. New York: Oxford University Press.

Kohei, Shinsaku. 1972. "Political Behavior of the Japanese People." Mimeo. Tokyo: NHK Public Opinion Research Institute.

Kohno, Masaru. 1997. "Voter Turnout and Strategic Ticket-Splitting under Japan's New Electoral Rules.” Asian Survey 37 (5): 429-40.

Kuo, Ming-feng. 2011. "The Contamination Effect in a Mixed-Member Majoritarian System: The Impact of Party's Dual Candidacy Strategies in Japanese House Elections" [Bingli Shi Hunhe Xuanzhi Xia LiangPiao Zhi Liandong Xiaoguo: Riben Zhong Yi Yuan Xuanju Zheng Dang Chongfu Ti Ming Celue yu ChengXiao] [in Chinese]. PhD diss. Taipei: National Taiwan University.

Lee, Xin-fang. 2012. "Defending Taiwan with the DPP. Tsai: Hope the TSU Passes 5\% Threshold" [Yu Minjindan Shoubu Taiwan. Xiaoying: Pan TSU Guo 5\%] [in Chinese]. Liberty Times, December 26, A2.

Lewis-Beck, Michael S., William G. Jacoby, Helmut Norpoth, and Herbert F. Weisberg. 2008. The American Voter Revisited. Ann Arbor: University of Michigan Press.

Lewis-Beck, Michael S., and Richard Nadeau. 2004. "Split-Ticket Voting: The Effects of Cognitive Madisonianism.” Fournal of Politics 66 (1): 97-112.

Lin, Jih-wen. 2006. "The Politics of Reform in Japan and Taiwan." Fournal of Democracy 17 (2): 118-31.

Liu, I-chou. 1994. "Generational Difference of Party Image among Taiwanese Voters” [in Chinese]. Xuanju yanjiu [Journal of Electoral Studies] 1 (1): 53-73.

Long, J. Scott. 1997. Regression Models for Categorical and Limited Dependent Variables. Thousand Oaks, CA: Sage.

Long, J. Scott, and Jeremy Freese. 2006. Regression Models for Categorical Dependent Variables Using Stata. 2nd ed. College Station, TX: Stata Press.

Maeda, Ko. 2008. "Re-Examining the Contamination Effect of Japan's Mixed Electoral System Using the Treatment-Effects Model." Electoral Studies 27 (4): 72331.

Miller, Warren E., and J. Merrill Shanks. 1996. The New American Voter. Cambridge: Harvard University Press.

Mizusaki, Tokifumi, and Hiroki Mori. 1998. "Tokubyou deeta kara mita heiritsusei no mekanizumu" [Mechanisms of the mixed-member system analyzed on the basis of vote shares] [in Japanese]. Senkyo Kenkyu [Electoral Studies] 13:50-59.

Moser, Robert G., and Ethan Scheiner. 2004. "Mixed Electoral Systems and Electoral System Effects: Controlled Comparison and Cross-National Analysis." Electoral Studies 23 (4): 575-99.

Moser, Robert G., and Ethan Scheiner. 2009. "Strategic Voting in Established and New Democracies: Ticket Splitting in Mixed-Member Electoral Systems.” Electoral Studies 28 (1): 51-61.

Nie, Norman H., Jane Junn, and Kenneth Stehlik-Barry. 1996. Education and Democratic Citizenship in America. Chicago: University of Chicago Press.

Niou, Emerson M. S. 2004. "Understanding Taiwan Independence and Its Policy Implications." Asian Survey 44 (4): 555-67.

Pekkanen, Robert. 2012. "The 2012 Japanese Election Paradox: How the LDP Lost Voters and Won the Election." National Bureau of Asian Research, Decem- 
ber 18, http://nbr.org/downloads/pdfs/PSA/Pekkanen_Commentary_121812. pdf.

Pekkanen, Robert, Benjamin Nyblade, and Ellis S. Krauss. 2006. "Electoral Incentives in Mixed Member Systems: Party, Posts, and Zombie Politicians in Japan.” American Political Science Review 100 (2): 183-93.

Pomper, G. M. 1967. "Classification of Presidential Elections." Fournal of Politics 29 (3): 535-66.

Reed, Steven R. 1999. "Strategic Voting in the 1996 Japanese General Election." Comparative Political Studies 32 (2): 257-70.

Reed, Steven R. 2003. "Heiritsusei ni okeru shousenkyoku koubosha no bireidaibyou tokubyouritsu eno eikyou" [The effect of the PR tier on SMD nomination strategies in mixed member systems: Some evidence from Japan] [in Japanese]. Senkyo Kenkyu [Electoral Studies] 18:5-11.

Reed, Steven R. 2005. "Japan: Haltingly Towards a Two-Party System.” In The Politics of Electoral Systems, ed. Michael Gallagher and Paul Mitchell, 277-93. Oxford: Oxford University Press.

Reed, Steven R., and Michael F. Thies. 2001. "The Causes of Electoral Reform in Japan." In Mixed-Member Electoral Systems: The Best of Both Worlds?, ed. Matthew Søberg Shugart and Martin P. Wattenberg, 152-72. Oxford: Oxford University Press.

Richardson, Bradley M. 1988. "Constituency Candidates versus Parties in Japanese Voting Behavior." American Political Science Review 82 (3): 695-718.

Roberts, Geoffrey K. 1988. "The 'Second-Vote' Campaign Strategy of the West German Free Democratic Party." European Fournal of Political Research 16:317-37.

Rochon, Thomas. 1981. "Electoral Systems and the Basis for the Vote: The Case of Japan." In Parties, Candidates, and Voters in Fapan: Six Quantitative Studies, ed. J. C. Campbell, 1-28. Michigan Papers in Japanese Studies, No. 2. Ann Arbor: University of Michigan Center for Japanese Studies.

Roscoe, Douglas D. 2003. "The Choosers or the Choices? Voter Characteristics and the Structure of Electoral Competition as Explanations for Ticket Splitting." Fournal of Politics 65 (4): 1147-64.

Rosenbluth, Frances McCall. 2012. "Japan in 2011: Cataclysmic Crisis and Chronic Deflation.” Asian Survey 52 (1): 15-27.

Schoen, H. 1999. "Split Voting in German Federal Elections 1953-90: An Example of Sophisticated Balloting." Electoral Studies 18:473-96.

Sheng, Shing-yuan. 2002. "The Issue of Taiwan Independence vs. Unification with the Mainland and Voting Behavior in Taiwan: An Analysis of the 1990s" [in Chinese]. Xuanju yanjiu [Journal of Electoral Studies] 9 (1): 41-80.

Sheng, Shing-yuan, and Yin-yan Chen. 2003. "Political Cleavage and Party Competition: An Analysis of the 2001 Legislative Yuan Election" [in Chinese]. Xuanju yanjiu [Journal of Electoral Studies] 10 (1): 7-40.

Shugart, Matthew Søberg, and Martin P. Wattenberg. 2001. Mixed-Member Electoral Systems: The Best of Both Worlds? Oxford: Oxford University Press.

Shyu, Huo-yan. 1991. "Party Identification and Vote Choice: An Analysis of the Electorate's Party Images, Partisan Preferences and Voting Behavior in Taiwan" [in Chinese]. Renwen yu Shebui Kexue Fikan [Journal of Social Science and Philosophy] 4 (1): 1-57. 
Shyu, Huo-yan. 1992. "Party Realignment in a Democratic Transition: A Study of Changes in Democratic Values, Party Preferences and Vote-Choices among Taiwanese Voters" [in Chinese]. Renwen yu Shehui Kexue Fikan [Journal of Social Science and Philosophy] 5 (1): 213-63.

Stanley, Harold W., and Richard G. Niemi. 2010. Vital Statistics on American Politics 2009-2010. Washington, DC: CQ Press.

Tsai, Chia-hung. 2008. "Making Sense of Issue Position, Party Image, Party Preference, and Voting Choice: A Case Study of Taiwan's 2004 Legislative Election” [in Chinese]. Renwen yu Shebui Kexue fikan [Journal of Social Science and Philosophy] 20 (1): 1-24.

Wang, T. Y., and I-chou Liu. 2004. "Contending Identities in Taiwan: Implications for Cross-Strait Relations.” Asian Survey 44 (4): 568-90.

Weaver, K., and B. Rockman. 1993. Do Institutions Matter? Government Capabilities in the United States and Abroad. Washington, DC: Brookings Institution.

Wolfinger, Raymond E., and Steven J. Rosenstone. 1980. Who Votes? New Haven: Yale University Press.

Wu, Nai-teh. 1999. "Family Socialization and Ideology: The Generational Difference of Party Identification among Taiwanese Voters" [in Chinese]. Taiwan Shebui Хue Yanjiu [Taiwanese Sociological Review] 3:53-85.

Wu, Yu-shan. 2004. "Taiwanese Nationalism and Its Implications: Testing the Worst-Case Scenario.” Asian Survey 44 (4): 614-25.

Yu, Ching-hsin. 2004. "Direction and Strength of Voter's Party Identification in Taiwan after 2000" [in Chinese]. DongWu ZhengZhi Xue Bao [Soochow Journal of Political Science] 19:39-70.

Yu, Ching-hsin. 2011. "Citizen's Knowledge of New Legislative Electoral System in Taiwan.” National Science Council Project NSC100-2410-H-004-090-MY2. Taipei: National Science Council. 
PART TWO

Coordination in Mixed-Member Systems in Comparative Perspective 


\title{
Thailand and the Philippines under MMM
}

\author{
Allen Hicken
}

This volume centers on the puzzle arising from the cases of Taiwan and Japan. The two have used very similar electoral systems that nonetheless produce very different outcomes-particularly in relation to the number of political parties. In their introduction Batto and Cox build on existing theory to argue that the reason the Taiwan and Japanese cases may seem puzzling is that, essentially, we have been looking in the wrong place. Scholars have focused overly much on the effects of electoral systems at the constituency level and the competition for legislative seats. While this type of competition is a crucial determinant of a country's party system, it is not the only determinant-nor is it necessarily the most important one. The electoral system gives us clues about the incentives of candidates, voters, and parties to coordinate within a given electoral system, but it tells us little about the incentives of these groups to coordinate across districts to form a modest number of large, national parties. These cross-district coordination incentives are shaped by assessments of the value of, and competition for, executive office (Cox 1997; Hicken 2009). The potential reward for forming a large national party to compete for the executive reflects the power the executive wields vis-à-vis subnational governments (Chhibber and Kollman 2004), the concentration of power within national level political institutions (e.g., the power of the president vis-à-vis the legislature) (Hicken 2009; Hicken and Stoll 2011, 2013), and the chance that the largest legislative party will be able to capture executive power (Hicken 2009). ${ }^{1}$ 
Drawing on these executive-centric theories Batto and Cox argue that the differences in the nature of competition for executive office in presidential Taiwan versus parliamentary Japan account for differences in the number of parties under similar electoral systems. Competition for the presidency in Taiwan travels down the ticket and drives party competition toward two large parties allied with the two presidential front-runners (see also Hicken and Stoll 2011). By contrast, the indirect selection of the prime minister and cabinet in Japan, combined with the specific norms about which legislative parties are able to form the government, undermine incentives for bipartism.

Given this argument the cases of Thailand and the Philippines appear to present us with an additional puzzle. Both countries have adopted mixed-member systems similar to those found in Japan and Taiwan. And yet it is parliamentary Thailand that has moved closest to a two-party system, while the party system in presidential Philippines remains highly fragmented. In remainder of this chapter I explain this variation using an executive-centric approach, but I draw on elements of this approach that focus as much on the differences within regime types as between them. In the next section I briefly review the legislative and executive institutions in Thailand and the Philippines, focusing on the adoption of mixed-member systems in 1997 and 1987, respectively. I then compare each case to its East Asian counterpart, focusing on why presidential institutions produce two parties in Taiwan but many in Philippines, and why the parliamentary systems of Thailand and Japan consolidated at different rates after reform.

\section{Legislative and Executive Systems}

Thailand is a parliamentary system. ${ }^{2}$ For most of its history the parliament has consisted of two chambers, the House of Representatives and the Senate. Prior to 1997 the Senate was a fully appointed body. Between 1997 and 2007 the Senate was directly elected, and since 2007 half of senators are elected and the other half appointed. ${ }^{3}$ Thailand has used two basic sets of electoral systems for electing the House of Representatives. Prior to 1997 the vast majority of Thailand's prereform elections for the House of Representatives used the block vote electoral system. This relatively uncommon electoral system combines multiseat constituencies with multiple votes and the plurality rule. In the Thai case the country's 76 provinces were divided into 142-156 electoral constituencies, almost all containing two or three seats. Voters in each constituency could cast as many separate votes as there were seats in that constituency (e.g., two votes in a two-seat constituency, 
three votes in a three-seat constituency). Voters cast their votes for individual candidates (not parties) and were allowed to split their votes between candidates from different parties and to partially abstain (i.e., not cast all of their votes). However, they were prohibited from cumulating multiple votes on a single candidate. Political parties wishing to contest a constituency were required to field a full team of candidates (e.g., three candidates in a three-seat constituency).

The 1997 constitution dramatically overhauled Thailand's electoral system for the House. The block vote system was replaced by a mixedmember majority system with 400 seats elected from single-seat constituencies via the plurality rule and 100 seats elected from a single nationwide constituency via proportional representation. Voters cast two separate votes-one for a candidate in their single-seat constituency, and one for a party for the national list tier. Neither the votes nor seat allocation between the tiers were linked in any way and, unlike in Japan, candidates had to choose between running in the constituency or running on the party listthey could not do both. Parties who received fewer than $5 \%$ of the party list votes received no list tier seats.

In 2006 the military launched a coup against the government of Thaksin Shinawatra and subsequently crafted a constitution (adopted in 2007) designed to undermine the capacity of future political parties and elected leaders to challenge Thailand's conservative forces (Hicken 2007, 2013). First, the single-seat electoral constituencies were replaced with the old multiseat, block vote system. Second, the single national party list election was scrapped and replaced with eight regional party lists, with parties allowed to run in just some of the lists. The consequence of this reform was that the party list campaign no longer served as a national referendum on each party's platform and prospective prime minister since each region voted on a separate slate of party list candidates, and potentially, a different set of parties. ${ }^{4}$

In 2011 the electoral system was once again amended back to a more standard mixed-member system, with 375 single-seat constituencies and 125 seats filled via PR party list elections in a single nationwide district.

The Philippines uses a presidential system with a directly elected president, and two legislative chambers: the House of Representatives and the Senate, both directly elected. ${ }^{5}$ During the premartial law period (1946-72) the House was elected from single-seat districts. After the fall of Marcos in 1986 a new constitution was passed that included provisions for an unusual mixed-member system. However, while the provision for a mixed-member majority system was included in the 1987 Constitution a law fully imple- 
menting the measure was not passed until 1995 and not used in an election until 1998. In the Philippines MM system the party list seats make up to $20 \%$ of the total House and are allocated using proportional representation. Both political parties and sectoral organizations can compete for the seats, save the five largest parties from the previous election, which are barred from competing. To obtain a seat parties (or sectoral organizations) must receive at least $2 \%$ of the PR votes. For every $2 \%$ of the vote a party is awarded a seat, with an upper limit of three seats in the list tier (Hicken and Kasuya 2003). The remainder of the House seats are filled from singleseat districts.

\section{Explaining Variation}

In both Thailand and the Philippines legislative-centric explanations fail to fully account for the size of the legislative party system and variation over time. That is not to say that legislative-centric explanations have no power. Quite the contrary. The average effective number of parties competing at the district level in both countries is about what we would expect given the electoral system (table 8.1). Changes in average district magnitude correspond to the expected changes in the average effective number of parties in each constituency, though the changes over time are rather modest. But this is only a small part of the story. The local-level party system in the Philippines, for example, increased by less than .2 parties between the preand post-martial law periods, from 2.0 to 2.2. At the same time the national party system nearly doubled in size, from 2.3 to 4.3 parties. In Thailand the party electoral reforms lowers the constituency-level party system from 3.2 to 2.3 , but we see an even greater decline in the number of parties nationally, from 7.2 to 3.2. In short, in both countries the number of parties nationally has often departed quite dramatically from the number of parties locally. Variation in the incentives over executive-focused competition explains this pattern.

\section{Thailand}

Pre-1997

Elsewhere I have argued that the dramatic decline in the number of parties nationally in Thailand primarily reflects stronger incentives for voters, parties, and candidates to coordinate across districts in a bid to capture executive power (Hicken 2009). (Cross-district coordination is also referred to as 
nationalization, linkage, and aggregation in the literature). Those nationalization incentives are a function of (a) the payoff to being the largest party at the national level (the size of the prize) and (b) the odds that the largest party will capture that payoff. In pre-1997 Thailand an appointed Senate, factionalized parties, and reserve domains combined to limit the size of the potential nationalization payoff. The practice of selecting someone other than the leader of the largest party as premier for much of the period also reduced the expected utility of nationalization.

Leaders of the largest party in pre-1997 Thailand faced significant checks on their power, which reduced the perceived payoff to coordination and nationalization. Specifically, the presence of bicameralism, reserve domains, and party factionalism all reduced the size of the nationalization payoff (Hicken 2009). First, Thailand's Senate reduced the potential payoff to large parties in the House. Strictly speaking the Senate was not a formal veto gate, possessing only delaying power. However, while the Senate did not have the formal power to block legislation, it was nonetheless difficult for elected governments to ignore the interests of the Senate. Until 1997 the Senate was an appointed body. During the 1980s these appointees were generally former military officials and bureaucrats. Representing as it did the interests of Thailand's conservative forces-who had a long history of intervening to shut down democratic institutions- the Senate's position on a matter carried a good deal of weight. This was especially true when the senators were relatively united on an issue. In effect the Senate functioned as a reserve domain. The existence of an unelected Senate stocked with representatives of the military and bureaucracy meant that the parties that controlled the House and cabinet still did not hold all the reins of power.

Throughout much of the 1980s another piece of executive power was off-limits to party leaders-macroeconomic and budgetary policy. This reserve domain emerged as the result of a compromise between elected politicians, Thailand's conservative forces, and Prime Minister (and former

TABLE 8.1. District Magnitude and Effective Number of Parties

\begin{tabular}{lccc}
\hline & $\begin{array}{c}\text { District magnitude } \\
\text { (for lower tier in } \\
\text { MMS) }\end{array}$ & $\begin{array}{c}\text { Average effective } \\
\text { number of parties / } \\
\text { constituency }\end{array}$ & $\begin{array}{c}\text { Effective number of } \\
\text { electoral parties }\end{array}$ \\
\hline Philippines (1946-69) & 1 & 2.0 & 2.3 \\
Philippines (1987-2010) & 1 & 2.2 & 4.3 \\
Thailand (1986-97) & $2-3$ & 3.2 & 7.2 \\
Thailand (1997-2006) & 1 & 2.3 & 3.2 \\
Thailand (2007) & $2-3$ & 2.9 & 4.1 \\
Thailand (2011) & 1 & 2.2 & 2.8 \\
\hline
\end{tabular}


general) Prem Tinsulanonda. ${ }^{6}$ As part of this "pork-policy compromise" macroeconomic and budgetary policy was shielded from elected politicians and run by Prem-backed technocrats. In exchange, the political parties were given control of the sectoral ministries (e.g., Commerce, Industry, Education, Agriculture) and were allowed to run them as they saw fit provided they avoided major scandal and respected the budgetary ceilings set by the technocrats (Hicken 2001).

By the early 1990s both of these reserve domains were withering away. In 1988 an elected politician became Thailand's prime minister for the first time since 1976 and immediately did away with the pork-policy compromise by seizing control of macroeconomic and budgetary policy (Hicken 2001). In addition, the composition of the Senate gradually changed so that over time business interests came to make up a larger and larger portion of Senate appointees. Yet, while these reserve domains were in place they represented a significant diffusion of political authority and a disincentive for coordination and nationalization.

Another factor contributing to weak nationalization incentives-one that did not change over the course of the 1980s and 1990s-was the factionalized nature of Thai parties. Similar to Japan, Thai political parties were extremely factionalized. Although, unlike Japan, Thai factions were relatively promiscuous-frequently changing parties from election to election. Because of the rampant party factionalism the leader of a political party was more like a first among equals than the head of a political hierarchy. The fact that the leader of the largest party might still find his power checked by rival factions within his own party discouraged greater attempts at building larger parties. Party factionalism was a major cause of the frequent cabinet reshuffles and short-lived governments that so characterized Thailand's prereform system as disgruntled faction leaders actively sought to bring down their rivals, including sometimes the nominal head of the party-the prime minister (see Chambers 2003). Factional conflict within the ruling party and/or within its coalition partners was a major cause of the collapse of nearly every democratic government prior to 1997 (Chambers 2003).

During this pre-1997 period Thai political parties were not large national organizations. Each governing party controlled only a relatively modest plurality of parliamentary seats and drew support from only one or two regions. Yet even these moderately sized, nonnational parties were unable to manage internal conflicts between factions. The lesson internalized by nearly all party leaders and politicians during the 1980s and 1990s was that attempts to better coordinate across districts in an effort to 
build a larger, national party would not be worth the cost to party cohesion (Chambers 2003).

Finally, in parliamentary systems like Thailand's the method of selecting the prime minister determines the probability that becoming the largest party will translate into control of government and access to cabinet positions. If the rules or norms of parliament are such that the leader of the largest party always has the first opportunity to form a government and usually succeeds, then nationalization may be worthwhile. If, on the other hand, actors other than the leader of the largest party often form or get a chance to form the government, then coordination incentives are weaker.

In Thailand the leader of the largest party did successfully head a new government after the September 1992, 1995, and 1996 elections, but this was not always the norm. After the 1979, 1983, 1986, 1988, and March 1992 elections, nonelected individuals (military figures) were invited to form a government either immediately after the election or after political party leaders failed in their attempts. In 1988 the man invited to be prime minister, General Prem Tinsulanonda, turned down the invitation, and the head of Chart Thai, the largest party, became prime minister. After a nonelected individual was again invited to form the government after the March 1992 elections (resulting in mass protests) a constitutional amendment was passed requiring that the prime minister be a member of the House of Representatives. Prior to the amendment, however, the high probability that the leader of the largest party would not get the opportunity to form a government undermined the incentives to try to create a large national party.

To summarize, the pre-1997 institutional environment generated weak coordination and nationalization incentives. The existence of party factionalism together with an appointed Senate and the presence of other reserve domains placed checks on the power of the largest party and kept the potential payoff to nationalization low throughout the period. In addition, for much of the pre-1997 period the selection procedure for the prime minister was uncertain. This uncertainty together with the small nationalization payoff undermined incentives to coordinate across districts to form large, national parties.

\section{7 and 2007 Constitutional Reforms}

By 1997 most of these structural barriers had been removed. Since 1992 the prime minister was required to be a member of the House of Representatives, and the norm was such that the leader of the largest party formed the government. Parts of the bureaucracy were also no longer shielded 
from partisan control. The final reserve domain - the unelected Senatewas removed in 1997 as the Senate became a fully elected body. However, the change in the 1997 constitution with the biggest bearing on nationalization incentives was increased powers for the prime minister relative to factions within his own party. ${ }^{7}$ This enhanced the power of the prime minister over intraparty factions and thereby increased the payoff to being the largest party in government.

The result was a sharp reduction in the number of parties. Some of this reduction was due to changes to the electoral system-specifically the reduction in district magnitude-and the accompanying decline in the effective number of parties at the local level. By only the second postreform election in 2005 competition at the constituency level was essentially a two-party affair (figure 8.1). However, more dramatic was the improved coordination across districts-consistent with the stronger nationalization incentives under the 1997 constitution. Figure 8.1 compares the effective number of parties at the constituency and national levels before and after constitutional reform. ${ }^{8}$ Note the narrowing of the gap between the effective number of parties nationally and the average effective number of parties locally in 2001 and 2005. This is evidence of improved cross-district coordination. Whereas before the reforms poor nationalization accounted for the majority of the size of the national party system (54\%), in 2005 only $16 \%$ of the effective number of parties nationally was attributable to poor cross-district coordination.

The result of fewer parties at the local level (lower $\mathrm{N}_{\text {local }}$ ) and improved nationalization is a sharp reduction in the effective number of parties nationally $\left(\mathrm{N}_{\mathrm{SMD}}\right)$. The number of parties nationally $\left(\mathrm{N}_{\mathrm{SMD}}\right)$ fell to 3.8 in 2001 and 2.4 in 2005 from an average of 7.2 prior to 1997 . Better nationalization was a bigger factor in reducing the effective number of parties nationally than the decline in the average effective number of parties at the district level. The effective number of parties contracted by $67 \%$ nationally compared to only $38 \%$ at the district level.

As discussed earlier, the 2006 coup leaders attempted to refragment the party system via the 2007 constitution. Specifically, they sharply reduced the power of the prime minister, including power over party factions; split the national party list tier into eight regional party list elections; and reintroduced the block vote at the constituency level. However, the nature of partisanship had fundamentally changed in Thailand in the wake of the 1997 reforms. $^{9}$ As a result, the potentially fragmentary effects of the 2007 reforms on the party system were muted. New party reputations and collective partisan identities largely overrode attempts to undercut the success 


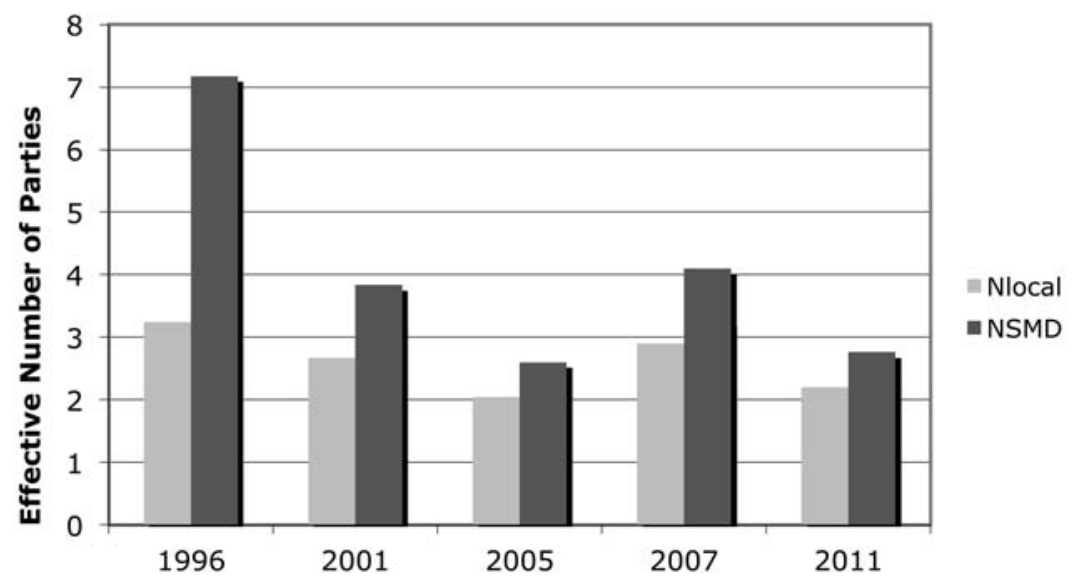

Fig. 8.1. Effective number of parties: District vs. National

of national parties. The result is that while we saw a modest increase in the number of parties in each constituency and nationally, as expected, the number of parties stayed well below the pre-1997 level. Finally, the 2011 election, held under modified 1997 rules, produced a return to the smaller party system characteristic of 2001 and 2005.

The comparison between Thailand and Japan is an interesting one. Both are parliamentary systems that, prior to the introduction of an MM system, employed highly candidate-centered electoral systems. The party system in each country was composed of multiple, highly factionalized political parties-though the Thai party system was more fragmented than the Japanese system. The MM systems adopted in the two countries were also very similar. And yet the effect of the reforms on the party systems was somewhat different. While both countries experienced greater consolidation of their party systems, the move toward two parties occurred much more rapidly in Thailand than it did in Japan. Despite starting at a much higher level of party system fragmentation, a two-party system had emerged in Thailand by the second postreform election, as measured by the effective number of parties in the legislature (table 8.2). (The military intervention and subsequent constitutional reforms led to an increase in fragmentation in the third election.) By contrast, after the second postreform election in Japan the effective number of legislative parties was still more than three. Only after the last election, the fifth since the reforms were introduced, did Japan approach bipartism (table 8.2). 
What accounts for the different rates of consolidation across the two countries? As Batto and Cox suggest in the introduction, the key lies in the different norms relating to competition for executive office. In Japan the 1993 election shattered the norm that the largest party in the Diet would form the government and capture the premiership. After the post of prime minister went to the leader of a party with less than $7 \%$ of the seats, party leaders rightly calculated that it was worth competing as a small or medium-sized party, given that there was still a chance that they could emerge as the head of government after postelectoral bargaining. This was not the case in Thailand, where the strong norm and practice was that the leader of the largest party formed the government and assumed the post of prime minister. There the removal of lingering structural barriers and the increase in the incentives to form large, national parties brought about by the 1997 reforms were enough to induce greater coordination across districts and a quick move toward bipartism. ${ }^{10}$

\section{Philippines}

The Philippines has one of the oldest democratic traditions in Asia. Under U.S. colonial auspices elections for both national and local offices were the norm from the early 1900s. After a brief interruption during the Japanese occupation, elections resumed in 1946 in a fully independent Philippines. Elections were a mainstay of Filipino life until 1972 when President Ferdinand Marcos declared martial law. After 14 years of dictatorship democratic government was restored in 1986. The post-Marcos constitutional drafters chose to reinstate the pre-Marcos American-style presidential system, with an elected president, a House of Representatives, and a Senate.

What has the Filipino party system looked like during the two democratic periods since independence? In many respects the parties and party system in the two eras look remarkably similar (Hicken 2009). Parties in both periods are characterized by factionalism, frequent party switching

TABLE 8.2. The Effective Number of Legislative Parties

\begin{tabular}{lcc}
\hline & Thailand & Japan \\
\hline Last 3 prereform elections & 5.6 & 3.1 \\
First postreform election & 3.0 & 2.9 \\
Second election & 1.7 & 3.2 \\
Third election & 2.8 & 2.6 \\
Fourth election & 2.6 & 2.3 \\
Fifth election & - & 2.1 \\
\hline
\end{tabular}


(called "turncoatism" in the Philippines), and party labels that generally mean little to voters or candidates. Philippine parties are generally organized around a powerful leader, or a temporary alliance of leaders, and tend to be primarily concerned with distributing the spoils of government to themselves and their local supporters. This continuity over time makes sense given (a) the sociohistorical roots of the Philippine party system (see Hutchcroft and Rocamora 2003; Landé 1965; Wurfel 1988), and (b) political institutions that have provided disincentives for forming strong, national parties (Hicken 2009). ${ }^{11}$

Prior to the imposition of martial law more than 20 years of elections in the Philippines had produced a relatively stable two party system-with the Nacionalista and Liberal parties vying for power in every election. By contrast, in the post-Marcos party period a multiparty system has been the rule.

So, compared to Thailand, Taiwan, and Japan, the Philippines is an exception. It is the only case where the move to a MM system has been accompanied by substantial fragmentation of the party system. From 1946 to 1969 the average effective number of national parties $\left(\mathrm{N}_{\mathrm{SMD}}\right)$ was 2.3 . Since $1987 \mathrm{~N}_{\mathrm{SMD}}$ has averaged 4.3 (see table 8.1), reaching a high of 5.3 in the 2007 election. ${ }^{12}$ This is puzzling given the executive-centric theories discussed in the introduction and in this chapter. Presidential institutions tend to have a deflationary effect on the legislative party system (Shugart 1995; Hicken and Stoll 2011; Golder 2006). Competition for the top prize of the presidency drives the number of presidential candidates to two, and the competition between these two frontrunners casts a shadow down into legislative contests. ${ }^{13}$ Both within and across districts candidates, parties, and voters have incentives to organize themselves behind one of the frontrunners, and thus bipartism in the presidential party system tends to have a deflationary effect on the number of parties in the legislative party system (Hicken and Stoll 2011).

It is this deflationary effect that Batto and Cox cite as the primary reason for why there are fewer parties under the Taiwanese MM system than we observe in Japan. Why, then, do we not see something similar in the Philippines? Why do presidential elections not produce the same deflationary effect we observe in Taiwan? Why do the Philippines have more parties than parliamentary Thailand?

One possibility could be the MM system itself. As discussed above, the Philippines uses an unusual MM system that (1) caps the number of seats any party can win in the list tier at three seats, and (2) prohibits mainstream political parties from competing for list tier seats. Thus, the system provides ample opportunity for fragmentation and the proliferation of 
small parties. Despite this, the MM system is clearly not the main driver of greater fragmentation. To begin with, while the MM provisions were part of the 1987 constitution the system was not implemented until 1998. In the three elections prior to 1998 the system operated as a simple single-seat district election, the same as had existed prior to martial law. And in those elections there was already clear evidence of fragmentation. The average effective number of parties before martial law was 2.1. In 1992 and 1995 the number was 4.6 and 3.0, respectively. To make comparison easier across time I have excluded the party list election results from the calculation of $\mathrm{N}_{\mathrm{V}}$ in this chapter, but even with the party list parties excluded the average effective number of electoral parties post-Marcos is 4.6.

To understand this increase we must understand its source. I will first demonstrate that the rise in the number of parties nationally is not being driven by more competitors winning votes at the district level. Rather, post-Marcos we have a deterioration in the extent to which candidates coordinate across districts under the banners of a few large parties. Finally, I will show how changes to the 1987 constitution, particularly the imposition of a single term limit for the president, undermined the incentives to coordinate across districts during elections.

Table 8.3 compares the mean effective number of parties nationally $\left(\mathrm{N}_{\mathrm{SMD}}\right)$ with the average number of parties in each district $\left(\mathrm{N}_{\text {local }}\right)$, before and after martial law. The table makes it clear that the growth in $\mathrm{N}_{\mathrm{SMD}}$ is not a result of many more parties winning seats at the district level after 1986. From 1946 to 1969 the average effective number of parties at the district level was 2.0. After $1986 \mathrm{~N}_{\text {local }}$ increased only slightly to 2.2, an increase of less than $10 \%$. Indeed, a large change in $\mathrm{N}_{\text {local }}$ would be surprising given that the electoral rules for the House remained virtually unchanged between the two periods. This small increase in the average size of the local party system cannot account for the $87 \%$ increase in the size of the national party system. In short, more competitors winning seats at the local level is not primarily to blame.

So what, then, is the cause of the post-Marcos fragmentation of the party system? Recall that the national party system is the product of two sets of interactions-within districts and across districts. It is in the area of cross-district coordination where we see the greatest change post-Marcos. This is where the party system, in short, has broken down. One way to measure the extent of cross-district coordination or nationalization is with a fragmentation score. This party system fragmentation score $(F)$ is computed by dividing the difference between the average number of parties per district $\left(\mathrm{N}_{\text {local }}\right)$ and the number of parties nationally $\left(\mathrm{N}_{\mathrm{SMD}}\right)$ by $\mathrm{N}_{\mathrm{SMD}}$ 
(Cox 1999, 17). ${ }^{14} F=\left(\mathrm{N}_{\mathrm{SMD}}-\mathrm{N}_{\text {local }}\right) / \mathrm{N}_{\mathrm{SMD}}$. The resulting fragmentation score tells us what portion of the size of the national party system is due to poor cross-district coordination/nationalization, and what percentage reflects what is happening within districts. If $F$ is .10 this suggests that $10 \%$ of the size of the national party system can be attributed to different parties garnering votes in different parts of the country (poor nationalization), with the other $90 \%$ ascribable to the average number of parties at the district level. The larger the fragmentation score, the lower the level of nationalization.

Prior to martial law coordination between districts was extremely good. The same two parties, the Nacionalista and Liberal parties, were the frontrunners in most districts nationwide. Thus, the average inflation score was .098 - in other words, less than $10 \%$ of the size of the national party system was due to nationalization failures. This stands in stark contrast to the post-Marcos inflation score of .48 (table 8.3). Nationalization has clearly declined in the recent democratic period and it is this failure to coordinate across districts that is primarily responsible for the larger effective number of parties nationally.

How, then, do we explain the deterioration of nationalization postMarcos? A variety of explanations have been offered in an attempt to explain the fragmentation of the national party system since $1986 .{ }^{15} \mathrm{I}$ argue that the key change was new limits to presidential reelection. When democratic government made its return to the Philippines the rules and institutions in place before martial law were largely readopted. Within the national government the distribution of power remained relatively concentrated in the hands of the president. ${ }^{16}$ But, while there was a high degree of institutional continuity before and after martial law, the 1987 Constitution did introduce one important change- $\mathrm{a}$ ban on reelection for the president. Before 1972 Philippine presidents were limited to two terms. In the wake of the Marcos dictatorship the constitution drafters opted to limit presidents to a single term. Elsewhere I have argued that the introduction of a reelection ban was a key factor in fragmenting the party system (Hicken 2009). I reexamine that claim here, using new data.

Prior to 1972 incumbent Filipino presidents regularly marshaled the

TABLE 8.3. Nationalization and the Number of Parties before and after Martial Law

\begin{tabular}{lccc}
\hline Country (election year) & Average $\mathrm{N}_{\text {local }}$ & Average $\mathrm{N}_{\mathrm{SMD}}$ & Average $\mathrm{F}$ \\
\hline Philippines I (1946-69) & 2.0 & 2.3 & .098 \\
Philippines II (1992-2010) & 2.2 & 4.3 & .48 \\
\hline
\end{tabular}


resources and influence of the presidency to back their reelection bids. All but Marcos were unsuccessful in their bid for a second term, but nonetheless the costs associated with challenging a sitting president weeded out all but the most serious of challengers and enabled voters to easily distinguish the frontrunners from the also-rans. This changed with the introduction of the reelection ban. The ban lowered the barriers to entry for presidential contenders and undermined the incentives for sitting presidents to invest in party-building. The result has been a large increase in the number of viable presidential candidates. ${ }^{17}$ This is clear from a comparison of the effective number of presidential candidates. During the 26 years before martial law the average effective number of presidential candidates $\left(\mathrm{N}_{\text {Pres }}\right)$ was 2.2. By contrast, the effective number of presidential candidates between 1992 and 2010 ranged between 3.2 and 5.8, for an average of 4.2 (see the $\mathrm{N}_{\text {Pres }}$ column in table 8.4). The end of incumbency does appear to have had the effect of fragmenting the presidential races.

To understand why more presidential candidates should affect the legislative party system, recall that the deflationary effect of presidential elections is a contingent one. Proximate presidential elections only have the theorized deflationary effect when there are a small number of presidential candidates (Cox 1997; Golder 2006). Hicken and Stoll (2011) find that beyond two candidates the deflationary effect of presidential elections disappears, and there is some evidence that where the effective number of presidential candidates is very large, presidential elections may actually have an inflationary effect on the legislative party system.

With this in mind we can see how the differences in the competition for the presidency in Taiwan and the Philippines enable us to explain the dif-

TABLE 8.4. Presidential Election Years

\begin{tabular}{lcc}
\hline Year & $\mathrm{N}_{\text {Pres }}$ & $\mathrm{N}_{\text {SMD }}$ \\
\hline 1946 & 2.0 & 3.3 \\
1949 & 2.4 & 2.4 \\
1953 & 1.7 & 2.6 \\
1957 & 3.4 & 2.1 \\
1961 & 2.0 & 2.0 \\
1965 & 2.2 & 2.3 \\
1969 & 1.9 & 2.1 \\
Average: 1946-1969 & $\mathbf{2 . 2}$ & $\mathbf{2 . 4}$ \\
1992 & 5.8 & 4.6 \\
1998 & 4.3 & 3.2 \\
2004 & 3.2 & 4.7 \\
2010 & 3.5 & 4.6 \\
Average: 1992-2010 & $\mathbf{4 . 2}$ & $\mathbf{4 . 3}$ \\
\hline
\end{tabular}


ferent level of consolidation in the two countries. In Taiwan "[c] ompetition for the presidency ... drove the system toward two main candidates who, in turn, had strong incentives to organize legislators behind their candidacies" (Batto and Cox, introduction). In the Philippines a ban on reelection led to a proliferation of presidential candidates, and this has corresponded with the fragmentation of the legislative party system (table 8.4). Before martial law the effective number of electoral parties is 2.4 , as opposed to 4.3 after martial law. ${ }^{18}$

\section{Conclusion}

The cases of Thailand and the Philippines underscore the argument of this volume-namely, that the appeal of, and competition for, executive office shapes the legislative party system as much as, and perhaps more than, competition in the legislative arena. In both cases changes to the legislative electoral systems had predictable effects, but it was other constitutional changes - a presidential reelection ban in the Philippines and greater incentives for cross-district coordination in Thailand-that had the most substantial impact on the party system.

Taken together the cases of the Philippines, Thailand, Japan and Taiwan suggest that while the differences between presidential and parliamentary systems have a powerful effect on the party system, variation within regime type can be just as powerful. In parliamentary Japan and Thailand differences in the norms about which party could form the government help explain why the Japanese party system was slower to consolidate compared to the Thai system, while the differences in the number of presidential candidates standing for office produced differently sized party systems in the Philippines and Taiwan.

\section{NOTES}

1. The scope and pattern of ethnic cleavages can modify these institutional effects (Cox and Knoll 2003; Hicken and Selway 2011).

2. This section draws on Hicken 2006, 2009, 2013.

3. Senators are elected from multiseat districts using SNTV.

4. In addition, the coup leaders outlawed the Thai Rak Thai party and banned its top leadership, including Thaksin, from office.

5. Senators are elected via the block vote within a single nationwide district.

6. For more on this compromise, see Christensen (1993), Doner and Ramsay (2004), and Hicken (2001).

7. Two changes are particularly worth noting. First, cabinet members were 
required to give up their seats in parliament if they choose to join the cabinet. Since parties or ministers that chose to leave the cabinet, or are expelled by the prime minister, could no longer return to parliament the stakes associated with breaking with the prime minister were much higher. Second, the constitution placed new restrictions on party switching. In order to compete in future elections candidates had to be members of a political party for at least 90 days. The rule was designed to curb the 11th hour party switching by individuals and factions that traditionally occurred in the run-up to Thai elections. Once the House was dissolved elections had to be held within 45 days (if the House's term has expired) or 60 days (if parliament is dissolved) - not enough time for would-be party switchers to meet the membership requirement. The prime minister, with the power to dissolve the House and call new elections, gained the most from this change. The prime minister could credibly threaten to call new elections if party factions tried to bolt, thus forcing the members of the faction to sit out one election.

8. Since the 1997 Thai system contains both constituency and party list votes one must decide whether to combine those votes to produce $\mathrm{N}_{\mathrm{SMD}}$ and the inflation scores or to use only the votes cast in the constituency elections. There are pros and cons to either approach. The numbers I report in the text, tables, and figures are calculated using total party vote shares - that is, I combine the party list and constituency votes for each party. Excluding party list votes produces slightly higher $\mathrm{N}_{\mathrm{SMD}}$ and inflation scores for 2001 and 2005 but these inferences remain the same.

9. See Hicken 2013 for more details.

10. An additional difference is the effect of upper house elections. In Japan strong performance in upper house elections could result in smaller parties receiving a more favorable portfolio allocation within the government (see Lin's chapter 2 in this volume). As a result, small parties who did poorly in lower house elections could still gain access to the cabinet if they did well in upper house elections. By contrast, Thai Senate elections were, by constitutional requirement, nonpartisan affairs - candidates for the Senate were forbidden from affiliating with a political party. Thus, unlike in Japan, election results for the Senate could not boost the fortunes of smaller parties.

11. These institutions include a powerful presidency (see Samuels and Shugart 2010), candidate-centered electoral arrangements for both the House and Senate, and, until 2010, ballot design that undermined the utility of party labels. See Hicken 2009 for more details.

12. The 1987 elections are excluded due to the lack of comprehensive data on candidate and party vote shares. This rise in the number of parties has been the subject of much scholarly attention in the Philippine literature (see, for example, Kimura 1992).

13. The shadow of presidentialism is strongest where presidential and legislative elections are concurrent (Shugart 1995; Cox 1997), where there are few presidential candidates (Golder 2006; Hicken and Stoll 2011), and where the president is very powerful vis-à-vis the legislature (Hicken and Stoll 2013).

14. Note, this is equivalent to Cox's Inflation score (I) (1997). Because the word inflation can be confusing due to its use as an economic term, I use the term "fragmentation."

15. These include a change in the structure of local politics in the Philippines, 
the decreased importance of the board of elections, and the advent of synchronized local and national elections. See Hicken 2009 for a critique of these explanations.

16. In a response to the excesses of the Marcos era a few of the president's powers were curtailed, including the ability to declare a state of emergency and the ability to transfer "saved funds" between governmental departments.

17. Choi (2001) also draws the connection between term limits and an increase in the effective number of presidential candidates post-Marcos, but does not discuss the implications for the legislative party system.

18. However, a closer look at the post-Marcos presidential elections presents us with a few puzzles. First, while there is clearly a correlation between the rise in the effective number of presidential candidates and the increased number of parties, the year-to-year correlation is imperfect. Second, it is puzzling that in 2004, post-Marcos lows in both the effective number of presidential candidates (3.2) and the effective number of parties in the district (1.9) correspond with a post-Marcos high in terms of the number of parties nationally (4.7). Something else other than presidential term limits is clearly at work in 2004 (see table 8.4). Finally, one wonders why nationalization has not improved over time. In fact, there is a noticeable increase in fragmentation starting in 2001 that continues through the most recent election. A ban on presidential term limits post-Marcos cannot account for this change over time. Hicken (2011) argues that the timing of decentralization reforms in the Philippines helps explain these puzzles.

\section{REFERENCES}

Chambers, Paul W. 2003. "Factions, Parties, Coalition Change, and Cabinet Durability in Thailand: 1979-2001." PhD diss., Northern Illinois University.

Chhibber, Pradeep, and Kenneth Kollman. 2004. The Formation of National Party Systems: Federalism and Party Competition in Canada, Great Britain, India, and the United States. Princeton: Princeton University Press.

Choi, Jungug. 2001. "Philippine Democracies Old and New: Elections, Term Limits, and Party Systems." Asian Survey 41 (3): 488-501.

Christensen, Scott. 1993. Thailand: The Institutional and Political Underpinnings of Growth. Washington, DC: The World Bank.

Christensen, Scott, David Dollar, Ammar Siamwalla, and Pakorn Vichyanond. 1993. Thailand: The Institutional and Political Underpinnings of Growth. Washington, DC: World Bank.

Cox, Gary. 1997. Making Votes Count: Strategic Coordination in the World's Electoral Systems. New York: Cambridge University Press.

Cox, Gary, and Jonathan Knoll. 2003. "Ethnes, Fiscs and Electoral Rules: The Determinants of Party System Inflation." Paper presented at the Annual Meeting of the American Political Science Association, Philadelphia, Aug. 27.

Doner, Richard, and Ansil Ramsay. 2004. "Growing into Trouble: Institutions and Politics in the Thai Sugar Industry." Fournal of East Asian Studies (4) 1: 97-138.

Golder, Matt. 2006. "Presidential Coattails and Legislative Fragmentation." American Fournal of Political Science 50 (1): 34-48.

Hicken, Allen. 2001. "Parties, Policy and Patronage: Governance and Growth in 
Thailand." In Corruption: The Boom and Bust of East Asia, ed. J. E. L. Campos. Quezon City: Ateneo de Manila Press.

Hicken, Allen. 2006. "Party Fabrication: Constitutional Reform and the Rise of Thai Rak Thai." Journal of East Asian Studies 6 (3): 381-8.

Hicken, Allen. 2007. "The 2007 Thai Constitution: A Return to Politics Past." Crossroads 19 (2): 128-60.

Hicken, Allen. 2009. Building Party Systems in Developing Democracies. New York: Cambridge University Press.

Hicken, Allen. 2011. "Decentralization and the Fragmentation of the Post-Marcos Party System." Presented at the Annual Meeting of the American Political Science Association, Seattle, Sept. 1-4.

Hicken, Allen. 2013. "Late to the Party: Institutional Reform and the Development of Partisanship in Thailand." Trans: National and Regional Studies of Southeast Asia 1 (2): 1-5.

Hicken, Allen, and Yuko Kasuya. 2003. "A Guide to the Constitutional Structures and Electoral Systems of Asia." Electoral Studies 22 (1): 121-51.

Hicken, Allen, and Joel Sawat Selway. 2011. "Social Structure and Party Nationalization." Presented at the Annual Meeting of the American Political Science Association, Seattle, Sept. 1-4.

Hicken, Allen, and Heather Stoll. 2011. "Presidents and Parties: How Presidential Elections Shape Coordination in Legislative Elections." Comparative Political Studies 44 (7): 854-83.

Hicken, Allen, and Heather Stoll. 2013. "Are All Presidents Created Equal? Presidential Powers and the Shadow of Presidential Elections." Comparative Political Studies 46 (3): 291-319.

Hutchcroft, Paul, and Joel Rocamora. 2003. "Strong Demands and Weak Institutions: The Origins and Evolution of the Democratic Deficit in the Philippines." Fournal of East Asian Studies 3 (2): 259-92.

Kimura, Masataka. 1992. "Philippine Political Parties and the Party System in Transition: Leaders, Factions and Blocs.” Pilipinas 18 (Spring): 43-65.

Landé, Carl H. 1965. Leaders, Factions, and Parties. New Haven: Southeast Asian Studies, Yale University.

Samuels, David J., and Matthew S. Shugart. 2010. Presidents, Parties, Prime Ministers: How the Separation of Powers Affects Party Organization and Behavior. New York: Cambridge University Press.

Shugart, Matthew Søberg. 1995. "The Electoral Cycle and Institutional Sources of Divided Presidential Government." American Political Science Review 89 (2): 327-43.

Wurfel, David. 1988. Filipino Politics: Development and Decay. Ithaca: Cornell University Press. 


\title{
Political Consequences of New Zealand's MMP System in Comparative Perspective
}

\author{
Matthew S. Shugart and Alexander C. Tan
}

The distinctions between single-member plurality systems and proportional representation systems are well known among students of electoral systems. The contrast between these two "ideal" types is such that most students can effortlessly list a litany of political consequences emanating from the choice of either of these systems, including the impact on the number of parties, coalition government, cabinet durability, and so forth. But beyond the ideal types, there continue to be interesting puzzles that capture scholarly attention. One of these puzzles, which this edited volume focuses on, is the question of why countries with seemingly similar electoral systems have different outcomes. In the introduction to this book, Batto and Cox observe that while Japan and Taiwan both have adopted mixed-member majoritarian (MMM) electoral systems, the countries have differed in the number of parties in their party systems. In this chapter, we extend the discussion of mixed-member systems to include the Asia-Pacific's one case of a mixedmember proportional (MMP) system, New Zealand.

A particular puzzle of the New Zealand experience with MMP is that, over the years the system has been in place, the effective number of electoral parties has generally declined. This trend is evident in spite of an electoral system design that is highly proportional, and stands in contrast to the mostly similar case of Germany, where recent elections have seen a rise in the effective number of parties. Moreover, in New Zealand, unlike 
both the East Asian and German cases, the number of very small parties is high. We argue that the persistence of these "microparties" in New Zealand can be understood only by taking into account both specific features of its MMP system and politicians' pursuit of ministerial posts. Thus, we agree with Batto and Cox, in this volume, that the electoral system and its effects on legislative competition provide only a partial explanation. We must also consider the contribution of executive-centric explanations.

In their comparison of Japan and Taiwan, Batto and Cox stress those two countries' different executive formats-semipresidential in Taiwan but parliamentary in Japan. They also stress another factor, intraparty factions competing for executive posts, including at the subnational level in the case of Taiwan. New Zealand, like Germany, is a parliamentary system, and neither of these MMP countries has anything like the entrenched factional competition of Japan and Taiwan. Rather, when there are internal party disagreements, they must either be worked out within the confines of the party or else the party splits. The establishment of new parties out of divisions in old ones has been a factor in both Germany and New Zealand. In the former case, a substantial upward push to the effective number of parties occurred when the leading party of the Center-Left, the Social Democrats, split and the defectors merged with the ex-Communists of the old East Germany to form the Left Party. The formation of the Left Party was thus the result of a policy-based split in a then-governing party. ${ }^{1}$ In New Zealand, however, most splinters have been ambitious seekers of ministerial posts who use their safe seats to launch new parties. The main exception is the Green Party of Aoteroa New Zealand, which emerged out of the turmoil of the left-wing Alliance ${ }^{2}$ in the early years of the new electoral system and subsequently established itself as an alternative policy-seeking party.

In this chapter, we examine the New Zealand experience of its mixedmember proportional system and suggest that to explain the political consequences witnessed in New Zealand requires us to examine both the mechanical effects of electoral rules, including features specific to New Zealand's variant of MMP, and the incentives of politicians to seek ministerial posts outside of the main parties. In the next section, we offer an overview of the system's performance over its first six elections, and then discuss issues relevant to the 2011 referendum on the electoral system. In the subsequent section, we restate the theoretical predictions of the effects of a shift from its former first past the post or also known as single-member plurality (SMP) 3 system to MMP on the party system and its competitiveness, on the impact on coalition formation, and the "contamination effects" (Herron and Nishikawa 2001) between the plurality and PR components 
of the system. We argue that the number of parties in New Zealand under MMP, averaged across six elections, is consistent with what electoral systems theory should lead us to expect. However, were it not for peculiar features of the New Zealand system, and the presence of what we term "legacy politicians" seeking to obtain ministerial positions, we would be unlikely to observe as many very small parties as we have in New Zealand. We also find that in recent elections, there is decreasing evidence of "contamination" as the two tiers have diverged in their effective number of parties (two-party dominance of plurality races, but higher fragmentation in the PR tier) - a pattern quite different from what has emerged in the German MMP system, especially recently. Finally, we explore the "intraparty dimension" (Shugart 2005), where we find evidence for a different kind of contamination, whereby dual candidacy appears to encourage even legislators elected via the party lists to behave almost as if they represented a local district.

\section{New Zealand under MMP}

Ten years after the Royal Commission published its report, Towards a Better Democracy, in 1996 New Zealand conducted its first parliamentary elections under MMP. In table 9.1, we see the results of the elections under MMP since 1996. It is immediately evident that many more parties have run for, and won, parliamentary seats under this proportional electoral system. Moreover, no party has won more than half the seats, in stark contrast to the SMP system prior to 1996. Table 9.1 further shows the breakdown for each party between seats won via the nominal tier, which is made up of 60-70 (depending on the year) single-seat districts (known as electorates in New Zealand), and the list tier.

Under New Zealand's MMP system, only parties that win at least $5 \%$ of the party vote, or at least one district, may participate in the distribution of list seats. The consequences of this provision can be seen also in the 2008 results, when New Zealand First won $4.1 \%$ of the party votes, but no seats, yet ACT won five seats on only $3.7 \%$ of the party vote. Both parties obviously failed to clear the $5 \%$ threshold, yet the reason ACT won seats is that one of its electorate candidates won his contest. Having thus qualified for representation (in effect, waiving the party-vote threshold), this party was eligible to win full compensation via the list, electing another four MPs.

We can quickly contrast MMP in New Zealand (and the broadly similar system in Germany) with the mixed-member majoritarian type otherwise more common in the Asia-Pacific region. ${ }^{4}$ Table 9.2 compares two MMM 
systems (Japan and Taiwan) and two MMP (New Zealand and Germany) on the widely accepted measure of disproportionality, Gallagher's Least Squares Index, in which the lower the number, the more proportional the result. Germany is shown separately for both the pre-1990 West Germany and the postunification period from 1990 on, when disproportionality has tended to be somewhat higher. The two MMM systems have sharply higher disproportionality; in fact, Japan's lowest value (8.52 in 2003) is substantially higher than the highest value observed under MMP in Germany or New Zealand. Thus table 9.2 shows very clearly the mechanical effect of MMP vs. MMM.

\section{The 2011 Referendum on Whether to Retain MMP}

Fifteen years after New Zealand adopted the mixed-member proportional representation system, on November 26, 2011, New Zealanders were asked in a referendum whether they would like to keep or replace the mixedmember proportional representation system. Though the referendum was largely overshadowed by the concurrent parliamentary election, the lead

TABLE 9.1. New Zealand Electoral Statistics, 1996-2011

\begin{tabular}{|c|c|c|c|c|c|c|c|}
\hline Party & & 1996 & 1999 & 2002 & 2005 & 2008 & 2011 \\
\hline \multirow[t]{2}{*}{ National } & Vote \% & 33.8 & 30.5 & 20.9 & 39.1 & 44.9 & 47.3 \\
\hline & Seats* & $44(30,14)$ & $39(22,17)$ & $27(21,6)$ & $48(31,17)$ & $58(41,17)$ & $59(42,17)$ \\
\hline \multirow[t]{2}{*}{ Labour } & Vote \% & 28.2 & 38.7 & 41.3 & 41.1 & 34.0 & 27.5 \\
\hline & Seats & $37(26,11)$ & $49(41,8)$ & $52(45,7)$ & $50(31,19)$ & $43(21,22)$ & $34(22,12)$ \\
\hline \multirow[t]{2}{*}{ NZ First } & Vote \% & 13.4 & 4.3 & 10.4 & 5.7 & 4.1 & 6.6 \\
\hline & Seats & $17(6,11)$ & $5(1,4)$ & $13(1,12)$ & $7(0,7)$ & 0 & $8(0,8)$ \\
\hline \multirow[t]{2}{*}{ ACT } & Vote $\%$ & 6.1 & 7.0 & 7.1 & 1.5 & 3.7 & 1.1 \\
\hline & Seats & $8(1,7)$ & $9(0,9)$ & $9(0,9)$ & $2(1,1)$ & $5(1,4)$ & $1(1,0)$ \\
\hline \multirow[t]{2}{*}{ Alliance } & Vote $\%$ & 10.1 & 7.7 & 1.3 & 0.1 & 0.1 & 0.1 \\
\hline & Seats & $13(1,12)$ & $10(1,9)$ & 0 & 0 & 0 & 0 \\
\hline \multirow[t]{2}{*}{ Green } & Vote \% & - & 5.2 & 7.0 & 5.3 & 6.7 & 11.1 \\
\hline & Seats & - & $7(1,6)$ & $9(0,9)$ & $6(0,6)$ & $9(0,9)$ & $14(0,14)$ \\
\hline \multirow[t]{2}{*}{ Progressive } & Vote $\%$ & - & - & 1.7 & 1.2 & 0.9 & - \\
\hline & Seats & - & - & $2(1,1)$ & $1(1,0)$ & $1(1,0)$ & - \\
\hline \multirow[t]{2}{*}{ United Future } & Vote \% & 0.9 & 0.5 & 6.7 & 2.7 & 0.9 & 0.6 \\
\hline & Seats & $1(1,0)$ & $1(1,0)$ & $8(1,7)$ & $3(1,2)$ & $1(1,0)$ & $1(1,0)$ \\
\hline \multirow[t]{2}{*}{ Maori } & Vote $\%$ & - & - & - & 2.1 & 2.4 & 1.4 \\
\hline & Seats & - & - & - & $4(4,0)$ & $5(5,0)$ & $3(3,0)$ \\
\hline \multirow[t]{2}{*}{ Mana } & Vote $\%$ & - & - & - & - & - & 1.1 \\
\hline & Seats & - & - & - & - & - & $1(1,0)$ \\
\hline Others & Vote $\%$ & 7.5 & 6.1 & 3.6 & 0.1 & 2.4 & 3.3 \\
\hline Total seats & & 120 & 120 & 120 & 121 & 122 & 121 \\
\hline
\end{tabular}

Note: Percentages are for party-list votes. For each party, seats are given as total (electorates, list seats). 
up to the referendum and the general election created the normal buzz of electioneering and campaigning among proponents and opponents of MMP. Despite some misgivings about MMP, $57.8 \%$ of the voters voted to keep it.

One of the provisions of the law mandating the referendum was that, were MMP to be retained, there would be a mandatory review of ways to "improve" it. The Electoral Commission carried out an independent review in 2012, which included opportunities for public submissions and hearings on several aspects of the system. The review addressed the level of the threshold for earning proportional seats, the question of dual candidacy (i.e., candidates running in both tiers), and several other matters (see New Zealand Electoral Commission 2012). It specifically was not permitted to consider the size of parliament or the provisions for representation of the country's indigenous Maori minority. The Electoral Commission, in its final report released in August 2012, recommended modest changes: reducing the threshold from $5 \%$ to $4 \%$, abolishing the alternative onedistrict threshold, and abolishing the provision of overhang seats for parties not reaching the threshold. ${ }^{5}$ Any changes would have to be approved by parliament. We will address several of the Commission's findings and recommendations in the course of this chapter.

The mean reason for holding a referendum on the electoral system is that the National Party had promised to review the system before coming back to power in 2008, and even accused Labour of having reneged on an earlier promise to undertake a review. That the National Party would have greater skepticism about the MMP system is comprehensible as MMP is more disadvantageous to a Center-Right party that draws its support mainly from conservative, rural, and upper middle class and wealthy New Zealanders in a country whose median voter is more left of center. Moreover, it has consolidated the Center-Right vote to the extent that it won $44.9 \%$ in 2008 and $47.3 \%$ in 2011 , in contrast to Labour's average of around $40 \%$ in the three straight MMP elections in which it was the largest party. Thus the National Party is in a strong position to win parlia-

TABLE 9.2. Least Squares Index Values of Disproportionality

\begin{tabular}{lcccc}
\hline Country (time period) & Electoral System & Mean & Min. & Max. \\
\hline Japan (1996-2012) & MMM & 14.53 & 8.52 & 25.73 \\
Taiwan (2008-2012) & MMM & 12.98 & 9.07 & 16.89 \\
New Zealand (1996-2011) & MMP & 2.69 & 1.13 & 3.84 \\
West Germany (1953-87) & MMP & 2.20 & 0.50 & 4.69 \\
Germany (1990-2009) & MMP & 3.36 & 2.16 & 4.63 \\
\hline
\end{tabular}


mentary majorities under a nonproportional system, whereas such a system could pose coordination challenges to the Center-Left, particularly given the rise in strength of the Green Party since 2002 (see table 9.1). ${ }^{6}$ The majority support in the referendum probably closes for some time any further consideration of replacing MMP.

\section{Effects on the Number of Parties}

New Zealand was a quintessential example of a Westminster majoritarian parliamentary democracy. With the SMP electoral system, pre-1996 governments were solidly single-party majority governments controlled by one of just two dominant parties.

It is, however, important not to overstate the "two-partyness" of New Zealand politics from the 1970s on. Several elections under SMP resulted in substantial vote shares for parties other than Labour and National. Nonetheless, the mechanical effect of plurality seat-allocation, and the lack of significant regional strongholds for any of the smaller parties, meant that parliament remained almost completely the preserve of the two big parties. In fact, in elections via SMP after 1945, the maximum number of parties with seats in any election was three until 1993, when four parties won seats in the final SMP election, which was concurrent with the referendum in which MMP was approved. Even more to the point, in none of these elections did the third party win more than two seats.

In New Zealand's elections under SMP, majority governments always resulted, although often based on only around $40 \%$ of the votes. Thus we can say that the mechanical effect was working as expected from Duverger's Law, forcing the real choice to be between just two parties. Nonetheless the "psychological effect" had less impact over time. In every election from 1960 on, the third party (usually Social Credit) won over 6\% of the vote, and from 1984 on, with the exception of the 1987 election, the third largest party always had anywhere from $12 \%$ to a high of more than $20 \%$. Thus voters showed some willingness to vote for third parties that had no realistic chance of winning significant numbers of seats, let alone any governing influence.

Of course, as expected, a move to a proportional system starting in 1996 has meant that many parties can earn representation, even with relatively small vote shares, as table 9.1 showed. New Zealand's sixth parliament of the MMP era, elected in 2011, has eight political parties represented. The National, Labour, and Green parties account for 107 of the 121 parliamentary seats, leaving 14 additional seats divided among five parties. The 2011 
election is not an outlier: as table 9.3 shows, the number of parliamentary parties has been between six and eight since 1996. This is a stark contrast to the two or three parties represented in elections under SMP.

The relatively high number of parliamentary parties under MMP, however, masks the imbalance in parliamentary representation among them. To take account of the relative sizes of parties, the most common index is the "effective" number of parliamentary parties $\left(\mathrm{N}_{\mathrm{S}}\right)$ index, presented in table 9.3 , which counts the parties by weighting them by their sizes. For New Zealand's six elections under MMP, $\mathrm{N}_{\mathrm{S}}$ was at its highest in the first MMP election of 1996 (3.76) and was as low as 2.78 in 2008. It has averaged 3.28. It is evident from these statistics that New Zealand, as predicted by theory, has moved away from two-party dominance to a multiparty parliamentary system. In comparison to the raw number of parliamentary parties, the lower effective number reflects the presence of two strong parties, plus various smaller parties. As a result, coalition negotiations have always revolved around one of the big parties, Labour or National, and various smaller partners, as we discuss in detail later.

How does the presence of 6-8 parties winning at least one seat, but an effective number of parliamentary parties averaging just over three compare to what might be expected from an electoral system like New Zealand's? We will address this question from two perspectives: first, comparing to the only long-established MMP system prior to New Zealand, that of Germany; second, by reference to theoretical work in comparative electoral systems.

Germany's postwar electoral system is similar to that adopted by New Zealand in 1996. In elections since 1953, the voter has been allowed two votes, one for a candidate in a single-member district and one for a party list; overall proportionality is calculated nationwide based on party-list

TABLE 9.3. Post-SMP Parliamentary Parties and Effective Number of Parties $\left(\mathrm{N}_{\mathrm{S}}\right)$

\begin{tabular}{lccc}
\hline & $\begin{array}{c}\text { \# of } \\
\text { parties }\end{array}$ & $\mathrm{N}_{\mathrm{S}}$ & $\begin{array}{c}\text { \% seats, third party } \\
\text { (and identity) }\end{array}$ \\
\hline 1996 & 6 & 3.76 & 14.2 (New Zealand First) \\
1999 & 7 & 3.45 & 8.3 (Alliance) \\
2002 & 7 & 3.76 & 10.8 (New Zealand First) \\
2005 & 8 & 2.95 & 5.8 (New Zealand First) \\
2008 & 7 & 2.78 & 7.4 (Green) \\
2011 & 8 & 2.98 & 11.6 (Green) \\
Mean (6 elections) & 7.2 & 3.28 & 9.7 \\
\hline
\end{tabular}

Source: New Zealand Electoral Commission and authors' own calculations. 
votes for those parties clearing a nationwide threshold of $5 \% .^{7}$ While the number of parties earning at least one seat was higher in the first elections, from 1961 on every election resulted in four parties in the Bundestag (Christian Democratic Union, Christian Social Union, ${ }^{8}$ Social Democratic Party, and Free Democratic Party) until 1983, when the Green Party surpassed the threshold for the first time. Since reunification in 1990, there have been six parties, with the former East German Communist Party, renamed the Party of Democratic Socialism, joining the mix. This latter party combined with a left-wing splinter from the Social Democrats before the 2002 election to form the Left Party, keeping the number of represented parties at six as of 2009.

Thus, even with the recent increase in the number of parties in the German parliament to six, that country continues to have fewer parties with parliamentary representation than New Zealand has had in any election since 1999. Nonetheless, in Germany since reunification the effective number of parties in parliament has been higher: taking the seven elections from 1990, $\mathrm{N}_{\mathrm{S}}$ values have been 3.17, 3.45, 3.31, 3.38, 4.05, 4.83, 2.80. ${ }^{9}$ The generally upward trend until the last election in that sequence $(2013)^{10}$ is notable, and contrasts with the more erratic but recently downward trend in New Zealand's MMP era (table 9.3). By contrast, in the last six elections in Germany before reunification, 1969-87, $\mathrm{N}_{\mathrm{S}}$ averaged only 2.99 and was over 3.00 only in 1980 and $1983 .{ }^{11}$ Thus, in terms of the effective number of parliamentary parties, New Zealand since 2005 looks more like Germany in the 1970s and 1980s than like the latter country's more recent elections. However, the more recent increase in Germany's effective number, particularly in the first decade of the 2000s, should serve as a reminder that an effective number near three, such as New Zealand has had recently, is not necessarily what we should expect as "typical" under MMP.

A further puzzle in comparing these two MMP systems lies in the fact that New Zealand's actual number of parties having at least one seat is somewhat higher, while its effective number is, especially recently, lower than in Germany. The main factor driving this difference is that most of the minor parties in New Zealand tend to be exceptionally small parties, sometimes earning only one or a few seats each. As we will discuss in more detail below, a key reason that New Zealand has some very small parties, but Germany does not, is that in New Zealand a party that falls below the $5 \%$ party-vote threshold nonetheless qualifies for proportional representation seats if it wins just one district. In Germany, a party below the threshold needs three district pluralities. ${ }^{12}$ Only once since the 1950s has 
a party in Germany entered parliament despite not clearing the party-vote threshold. ${ }^{13}$ In New Zealand, there have been four such parties in each of the three most recent elections $(2005,2008,2011)$. Except for the Maori Party (discussed below), each of these parties has entered parliament by winning just one district seat; some of these have then qualified for anywhere from one to four additional seats from the party list. ${ }^{14}$ Only once has the number of parties clearing the party-vote threshold exceeded five; starting in 2005, just three or four have done so. Thus, were it not for small parties winning districts in New Zealand, the number of parties would be substantially lower.

How about expectations based on the theory of electoral systems? We can draw on the work of Taagepera (2007), who has taken the institutional constraints of "simple" electoral systems as a starting point for estimating logically what the number of parties "should be" on average. Of course, a mixed-member proportional system is not simple, in that it has two tiers of allocation. However, ignoring the threshold for a moment, New Zealand's MMP does allocate seats as if it were one district of 120 seats. Given nationwide calculation of seat shares from party votes, and further given the possibility of a party winning a seat with a vote share much less than the $5 \%$ threshold (by winning just one district), treating the system as a national district without a threshold is not wildly off, even if it is an oversimplification. If we use these simple assumptions, Taagepera's Seat Product ${ }^{15}$ leads to a prediction of 11 parties winning at least one seat, and effective $\mathrm{N}_{\mathrm{S}}=4.90$. However, of course, there is a threshold. In a more recent work (Taagepera, n.d.), models are derived estimating the number of parties, both actual and effective, from a nationwide threshold. Applying these models ${ }^{16}$ to New Zealand's 5\% threshold, we get an estimate of 4.47 parties winning at least one seat and effective $\mathrm{N}_{\mathrm{S}}=2.71$.

Given that we don't know which threshold is more constraining, onedistrict or $5 \%$ party-vote, a logical extension of Taagepera's technique would be to take the geometric mean of the two predictions. That leads to:

Actual number of parties, $\operatorname{sqrt}\left(11^{*} 4.5\right)=7.0$

Effective number of parliamentary parties $\left(\mathrm{N}_{\mathrm{S}}\right), \operatorname{sqrt}\left(4.9^{*} 2.7\right)=3.6$

These derived estimates closely match the observed average values (table 9.3): 7.2 actual parties and an effective number of 3.28. We have too few elections to work with here to say for sure that it is not just by chance 
that the number of parties (effective or otherwise) comes close to predictions derived from our application of Taagepera's methods, but the conclusion we can draw is that the number of parties is not "too high" in New Zealand, given institutional constraints. ${ }^{17}$ Moreover, as table 9.3 showed, the effective number of parties has not been greater than 2.98 for the last three elections. This value is closer to what we expect from the $5 \%$ threshold itself. Such a value is also consistent with the idea of the two major parties reasserting themselves via the district-level Duvergerian effect. If such an effect is also carrying over to the party-list ballot, it would be an argument for a "contamination" effect, which is a theme we return to below.

\section{Effects on Government Formation}

As a result of the greater number of parties in New Zealand under MMP, all governments since 1996 have been multiparty coalition cabinets (and most have been minority governments). Indeed, New Zealand's experience is quite similar to Germany's: two large parties holding positions just to the right and left of center and a group of smaller parties. Like Germany as well, the two large parties have taken turns leading the government, although New Zealand has not had a "grand coalition" of the two big parties as Germany has experienced three times (following elections of 1966, 2005, and 2013). A substantial difference from the German experience is that every government in Germany has consisted of just three or four parties $^{18}$ while in New Zealand most governments have entailed formalized cooperation between one big party and an additional two or three smaller parties. Often each of the small parties has only one or a few seats in parliament.

In this section, we go beyond the analysis of the electoral system to consider how incentives for seeking executive posts have affected the number of parties. We draw on the insights of Batto and Cox (introduction, this volume), who aptly remind us that the pursuit of executive posts may have an independent effect. Batto and Cox note that in parliamentary systems competition for executive posts allows for a mixture of both electoral and postelectoral strategies. In New Zealand, postelectoral strategies have been common, ${ }^{19}$ as small parties, often founded from splinters off the main parties, have been influential in the government-formation process. We will first outline the main features of New Zealand's interparty bargaining, and then offer an explanation grounded in specific features of the country's MMP system and the pursuit of executive posts to explain these patterns. 


\section{Coalition and Minority Governments}

As can be observed from table 9.4, the number of political parties in coalition governments has increased after 1999. As we will discuss later in this section, New Zealand parties have come up with creative arrangements other than outright coalition cabinets, such as the confidence and supply agreement ${ }^{20}$ or ministers outside of cabinet. Despite the recent prevalence of such arrangements, we can still speak of coalitions, of varying degrees of formality, between one major party and multiple smaller ones that have received ministerial posts. In many of these cases, the parties in coalition agreements have only one to three MPs, and have depended not on clearing the $5 \%$ threshold, but rather winning at least one district seat, to be in parliament. Examples of parties with ministerial posts but less than $5 \%$ of the vote include Progressive in 2002 and 2005, United Future in 2005-11, and both ACT and the Maori Party in 2008 and 2011. In fact, of the parties cooperating in government with either National or Labour since MMP was enacted, only New Zealand First in 1996 and 2005, Alliance in 1999, and United Future in 2002 have had more than $5 \%$ of the party vote.

Notably New Zealand's Green Party has so far not obtained any ministerial portfolios, despite having cleared the $5 \%$ party-vote threshold in every election it has contested (since 1999). Only in the 1999-2002 parliament did the Greens have a confidence and supply agreement with the government. Thus we can divide the parties other than Labour and National

TABLE 9.4. Party Composition of MMP Governments in New Zealand

\begin{tabular}{lll}
\hline Year & Main party & Coalition partners with ministerial positions \\
\hline 1996 & National & New Zealand First \\
1999 & Labour & Alliance \\
2002 & Labour & Progressive, United Future $_{20}$ \\
2005 & Labour & Progressive, NZ First, United Future \\
2008 & National & ACT, Maori, United Future \\
2011 & National & ACT, Maori, United Future \\
\hline
\end{tabular}

Source: New Zealand Electoral Commission.

Notes: Italics indicate parties that entered parliament via winning at least one district, rather than obtaining over $5 \%$ of the party vote.

All coalition partners indicated had their ministerial positions "outside cabinet" with the exception of New Zealand First (1996) and Alliance (1999) and Progressive (2002 and 2005), which were full cabinet partners in those governments.

an addition, the Green Party was in a confidence and supply agreement with Labour during this government, but did not have any ministerial positions. 
into two categories: "microparties" that enter parliament with just a few MPs and despite missing the 5\% threshold, and "midsized parties" that clear the threshold. Some parties, such as ACT, New Zealand First, and United Future, have been in one category in one election and the other at other times. Only the Greens have consistently been a threshold-clearing midsized party.

\section{Microparties and Legacy Politicians}

As we saw above (see table 9.3), New Zealand under MMP has had a relatively high number of parties with at least one seat in parliament, but a relatively low effective number of parties. In fact, microparties have been a consistent feature of New Zealand's MMP-era parliaments. For instance, of the eight parties represented in the parliament elected in 2011, three (ACT, Mana, and United Future) have one seat each and one other party (Maori Party) has three seats. With the exception of Mana, each of these earned ministerial concessions from the National Party in the postelectoral bargaining (as indeed they had done in 2008).

Why, then, is there a large number of microparties in the New Zealand parliament? We argue that the answer lies partly in electoral-system provisions-not only the one-seat alternative threshold for proportional representation but also the retention of the special Maori districts even under MMP. ${ }^{21}$ However, these factors are insufficient to explain the microparties, the persistence of which also depends, we argue, on incentives to seek executive posts via anticipated concessions in postelectoral bargaining. There is also another (and probably relatively minor) factor, the issue of parliamentary compensation, subsidy, and support for parties.

As noted above, New Zealand electoral rules require political parties to win $5 \%$ of the party vote or at least one district seat to be eligible for proportional-representation seats. The low alternative threshold allows for microparties to survive with ease as long as these parties have at least one politician with a local support base. Interestingly, these microparties are actually splinter parties of a large party, Labour or National. United Future's party leader, Peter Dunne, was a longtime Labour politician with strong support in a wealthy suburb of Wellington. In 2005 the Foreshore and Seabed Act, directly affecting Maori customary rights, saw the creation of the Maori Party when some Maori politicians defected from the Labour Party. The National Party had politicians split from it in 1993 to create the New Zealand First Party led by Winston Peters and the ACT Party led at the 2011 election by John Banks. ${ }^{22}$ While the populist New Zealand First has sometimes been a microparty dependent on Peters winning 
his electorate (Tauranga, till he was defeated in 2005) and other times has cleared the threshold (as in 1996, 2005, and 2011), throughout it has been a party dependent primarily on the personal appeal of its leader, whose career spans back to the SMP era. ACT Party, on the other hand, managed to win $6-7 \%$ of the party vote in the first three MMP elections, but in the three subsequent elections it would not have been represented had it not won an electorate seat. In 2011, its electorate (Epsom, in Auckland) was the only seat it won. The importance of the one-seat threshold and legacy politicians is especially observable in the career of Jim Anderton. He was a longtime Labour MP in the Christchurch era, first elected in 1984, who split off to lead the Alliance. ${ }^{23}$ This party split during its coalition with Labour between the 1999 and 2002 elections, with Anderton leaving to form a vehicle officially registered as Jim Anderton's Progressive Coalition (rendering Alliance both without a prominent politician to win a district and too small to clear the threshold). Anderton's safe seat continued to allow his party to win one or two seats (table 9.1) as long as he remained an MP, but when he retired before the 2011 election, he shut down his Progressive party. The one-seat threshold, then, has been a major factor in why New Zealand has so many microparties. Needless to say, these have implications for the complexity of postelection coalition negotiations that were depicted in table 9.4.

A second reason for microparties and legacy politicians is the nature of the Maori special seats. In the New Zealand system, the Maori special seats, which already existed under the first-past-the-post system, are superimposed on the whole country; that is, every voter resides in both a general district and a Maori district, and if the voter is of Maori descent, he or she may choose which one to register to vote in. ${ }^{24}$ Currently, there are seven Maori district seats; the number is adjusted according to the size of the Maori electoral roll. A Maori enrolled voter receives the Maori district ballot as well as the party vote ballot (which, counting for nationwide representation, is the same for all voters). Maoris historically identified with the Labour Party; thus, prior to 2005, Maori MPs were mainly Labour. However, in 2005 the former Labour MPs who formed the Maori Party were able to tap into this constituency base and the new party won four of the seven Maori special seats. In 2008, the Maori Party kept its four seats but in April 2011 a split saw one of its MPs establish the rival Mana Party, which retained its one seat in 2011. Similar in effect to the low threshold levels for the parties competing in the general electorate, the Maori special seats have aided in the success of these microparties in the MMP era. Without MMP and its mechanical effects, there may never have been one separate 
party for Maori voters, let alone two of them. However, combined with the expectation that under MMP single-party majority governments are unlikely, having the separate Maori districts has created a further incentive to split off from a major party and possibly represent this constituency with a party that can engage in postelectoral bargaining for ministerial positions and policy concessions. We now turn to a discussion of how smaller parties have related to the major parties in government formation.

\section{Postelectoral Bargaining over Executive Posts and Policy}

The political consequences of a proportional electoral system point to the relative likelihood of coalition governments instead of single-party majority cabinets. As such, the occurrence of coalition governments in post-SMP New Zealand is to be expected. Yet the electoral system is insufficient for explaining the types of coalition that form, or accounting for the presence of the microparties in sometimes prominent roles in government. In the New Zealand case, coalition arrangements are quite varied and have had features that present challenges in classifying them. Of the six governments formed in the MMP era, most are technically minority governments, despite the confidence-and-supply agreements with supporting parties (table 9.4). Since 2005, New Zealand governments have been innovative in cabinet formation with several small and microparties supporting the large party in a coalition but absolving themselves of collective cabinet responsibility by remaining outside of cabinet. The Labour government of 2005 was a four-party coalition that included the Progressives, New Zealand First, and United Future. Each of the party leaders of these small parties (microparties in the case of United Future and Progressives) held ministerial posts. The United Future leader held the post of minister of revenue while the New Zealand First leader became foreign affairs minister, yet both of them were formally not considered cabinet members in order for their parties not to be bound by cabinet collective responsibility outside the areas of the portfolios. In 2008, the National government continued this practice, entering a partnership with ACT, United Future, and the Maori Party. This arrangement continued following the 2011 election.

These innovative arrangements of holding ministerial appointments and rank but staying outside of cabinets are unique but have not necessarily spared the microparties of incumbency responsibility and costs. At times the supporting parties have been able to vote against cabinet policy such as the case of the United Future voting against the emission trading scheme (ETS) in 2008. Miller and Curtin (2011), in their study of the costs of coalition, provided evidence that small parties in coalition governments 
have paid the price by losing parliamentary seats in subsequent elections. Using the 2011 general election as an example, the United Future lost one of its two MPs and the ACT Party lost three of its four, despite not being bound to cabinet responsibility outside their own ministerial positions.

Why, then, does this type of minority government exist in New Zealand? The impact of MMP on the New Zealand model is part of the story, but a critical factor is the nature of the executive. As mentioned in an earlier section, New Zealand's relatively low threshold for seat allocation, in particular the alternative to the party-vote threshold, has unwittingly stimulated the growth of microparties and thereby enhanced the leverage of legacy politicians. The proliferation of political parties led by ambitious seekers of executive portfolios has created complications for coalition formation. With limited options from the Left to Right spectrum and the requirements for coalitions of at least four parties, the innovation of creating governments that are technically minority governments, yet provide pivotal roles to microparties, has come to typify the New Zealand experience.

Furthermore, the consequence of New Zealand's Westminster parliamentary tradition cannot be ignored in explaining the prevalence of minority governments. As Boston $(2011,80)$ argues, “[g]iven the uncomplicated and predictable nature of government formation under the first-past-thepost electoral system, New Zealand had no need to develop the kind of formal and informal rules that characterize the process in most countries with proportional representation." As New Zealand shifted to MMP, many of the formal and informal rules were never revised. Boston (2011) notes that New Zealand coalition negotiations are unencumbered and tend to be "free-style bargaining environment" (82) as there are no constitutional provisions to the appointment of a formateur or informateur, nor are there explicit rules on how the interparty bargaining is to be conducted. In addition, there is no constitutional constraint on the duration of government formation or the need for an investiture vote (Boston 2011). We can infer from the absence of these formal constitutional constraints and informal rules increased incentives both to form minority governments and to seek innovative ways of establishing cooperation among multiple parties. The combination of an MMP rule allowing parties to gain proportional representation seats even if they fall below $5 \%$-provided they win one district - with an unusually informal parliamentary executive structure makes for significant incentives to splinter parties. All that is needed is an assurance of one safe seat for a microparty, and then even if its party vote is not sufficient for a second seat, that (one-MP) party may be in a pivotal bargaining position. In the government following the 2011 election, 
United Future (with one safe seat for its leader, Peter Dunne, who has held it since 1984), ACT (with what otherwise would be a safe National seat in Auckland), plus the Maori Party (which won only in Maori districts), all have been able to earn ministerial posts and policy influence.

The flexibility of interparty relationships in New Zealand under MMP is demonstrated even further by the case of a consistently midsized party, by our definition: the Green Party, which has cleared the threshold in every election since 1999, and in 2011 elected 14 MPs. Despite its consistent middle size, the Greens have never held ministerial positions. However, they have had various policy-based relationships with Labour-led governments and in specific policy areas even with National.

The Greens supported the Labour-Progressive minority coalition of 1999-2002 via a confidence-and-supply agreement, which entailed no executive posts for the Green Party, but offered them policy influence. The two parties diverged in a very public way over the government's intention to lift a moratorium on the importation of genetically modified crops. ${ }^{25}$ As a result of the disagreement, Labour PM Helen Clark called the 2002 election a few months early. In the campaign the Greens pledged that they would not support a government that would lift the moratorium. Following that election, Labour and Progressives were able to obtain support on confidence and supply from the United Future Party (which won eight seats, its strongest showing to date). The Greens, who also increased their support from seven to nine seats, went into opposition. By standing firm on an issue, the Greens cemented their reputation as a policy-seeking party.

In the run-up to the 2005 election, the Greens and Labour both campaigned on a series of proenvironment policies, including the possible introduction of a carbon tax. ${ }^{26}$ During the campaign, the Greens publicly indicated an intention to assume cabinet positions. ${ }^{27}$ However, the election did not give these two parties, plus Progressives, a majority in parliament. Labour instead signed confidence-and-supply agreements with United Future and New Zealand First, both of which vetoed a Green presence in the cabinet. During the life of that government, Greens had only a "cooperation agreement" and a role of "spokesperson" on energy efficiency and a "Buy Kiwi Made" campaign. ${ }^{28}$ Thus the 2002-5 term of parliament featured further examples of the sort of flexible interparty arrangements that we discussed above. In addition to this being the government that pioneered the concept of ministers outside cabinet, it also had the unusual situation of what was technically an opposition party (because the Greens were not committed to supporting the government on confidence and supply) ${ }^{29}$ serving as the government's official voice on some policy issues. 
In the final months of the government, prior to the 2008 election, the Green Party backed the Labour government's emissions trading scheme when the United Future party invoked the "agree to disagree" clause in its confidence-and-supply agreement and announced it would vote against the scheme. The Greens undertook a consultation process with their supporters over whether to accept the ETS, which was much weaker than the carbon tax they (and Labour) had promised in 2005. In the end, they supported the ETS in exchange for the inclusion of a provision offering credits to homeowners who installed insulation. ${ }^{30}$ Even under the National-led government of 2008-11, which significantly revised the ETS to be more favorable to business and farmers ${ }^{31}$ the Greens maintained a written agreement with the government to pursue some policies of mutual agreement, such as home insulation and regulation of natural health products. ${ }^{32}$ These various examples thus show a case of a midsized party that enjoys representation thanks to the MMP system-never being dependent on winning districts to enter parliament ${ }^{33}$-and employs a wide range of different tactics to enhance its policy influence despite so far never having one of its MPs appointed to a ministerial post.

What is distinctive about the Greens in the New Zealand party system is their being a policy-based midsized party. Other parties have tried to carve out a niche in the policy space, but have failed to remain consistently over the threshold (ACT, New Zealand First [NZF]). United Future once has surpassed the threshold, in 2002, with the aid of an alliance with a conservative Christian group, but its support subsequently declined. It even tried to reposition itself as an outdoorsman's party in 2011 by placing campaign signs on the South Island against a pesticide being used to combat invasive pests, but received little electoral payoff and retained only the seat of its leader (on the North Island).

Thus, so far only the Greens have enjoyed middle-party status. New Zealand's lack of midsized policy-based parties other than the Greens stands in marked contrast to Germany, where in most elections since 2005 there have been three such parties: the Free Democrats as a liberal probusiness party (which has been in many coalitions dating back to the early postwar years), the Greens (in coalition cabinets with the Social Democrats from 1998 to 2005), and the Left (which has not had federal ministerial posts).

As for New Zealand's microparties, their future is uncertain. First of all, those that are dependent on the legacy politician who founded the party may not outlast the eventual retirement or defeat of that leader. As noted, the Progressive Coalition has already shut down with the retirement of Jim Anderton. United Future has so far had only one election in which it 
could enter parliament without needing founder Peter Dunne's district. New Zealand First has sometimes needed leader Winston Peters's former Tauranga seat, and other times it has cleared the threshold, as it did in 2011. (It also has a more consistent voting bloc and a policy profile.) ACT is an intermediate case. It has staked out a position as a more liberal (in the sense of promarket) party than the National Party, and has won districts with different politicians in different elections. It also, as we noted, was large enough to qualify as a "midsized" party in the first three MMP elections (see tables 9.1 and 9.3). Nonetheless, it has not had more than $7 \%$ of the vote since 2002 .

The other reason why the microparties might be threatened is if one of the recommendations of the Electoral Commission during the MMP Review were to be implemented: the Commission recommended abolishing the one-district alternative threshold. The Commission's final report states that the existing arrangement is "arbitrary and inconsistent" because it "gives voters in some electorates [districts] significantly more influence over the make-up of parliament than voters in other electorates" (8). Under the proposal-which would have to be accepted by parliament to become law-a party could still enter parliament by winning one or more districts, but doing so would not qualify it for participation in proportional allocation. Without the possibility of winning additional seats, the attractiveness of voting for-or even forming - a microparty might diminish. As a partial counterweight to eliminating the one-seat alternative threshold, the Electoral Commission has recommended lowering the party-vote threshold from 5\% to $4 \%,{ }^{34}$ as in fact the Royal Commission initially had recommended in 1986.

\section{Party Financing}

Besides the institutional factors of MMP as adopted in New Zealand and the pursuit of executive posts, one other factor creates an interesting incentive as it changes the utility calculation of party politicians. In New Zealand, the state is the primary source of party funding for many parties. Based on the size of parliamentary representation, political parties are given a subsidy in order for them to perform their elected duties and manage their parliamentary and electorate offices. Salaries of members of parliament are also in accordance to seniority and position held as MPs. For example, cabinet members have ministerial salaries in addition to their MP salaries. A prime minister who is also a party leader receives a prime minister's salary, an MP salary, and a stipend as party leader.

For the large parties, National and Labour, the sources of party financ- 
ing are well established. For the smaller parties, on the other hand, party subvention by the Crown becomes their main source of income. For the microparties, the party leader who is also an MP receives the extra stipend of a party leader besides the usual financial support that MPs receive. For politicians with strong local support and in tandem with the low threshold for allocation of parliamentary seats, utility calculation of party politicians can favor defecting from a major party, forming a small party, increasing their chances of being a party leader (if elected) as well as their chances of being a player in future coalition government negotiations. Since 1996 New Zealand has seen many microparties with varied life spans but with a decidedly unequivocal impact on the party system and coalition formation. In fact, from 1999 onward each of the governments had at least one coalition partner with a ministerial appointment that can be considered a microparty.

In this section we have seen how various features of the MMP system, when combined with the country's flexible arrangements for interparty cooperation in government formation, policy making, and party-financing laws, have contributed to the persistence of several microparties as well as the growth of one consistently midsized party. We now turn our attention to the relationship between the two tiers of the electoral system-the issue of "contamination" between the SMP and list-PR systems that comprise MMP.

\section{Contamination and Dual Candidacies}

In recent years, a substantial literature has grown up around the issue of so-called contamination effects in mixed-member systems. ${ }^{35}$ The concept essentially means that the effects of one tier may affect how the other tier works. The main direction of contamination (or "spillover") discussed in the literature has been from the list tier to the nominal, resulting in more parties running and winning votes in the plurality races than would be expected if Duverger's Law of plurality elections were constraining. The argument is typically that parties might expect to receive fewer list votes if they abandoned the district race, but that voters are sufficiently reluctant to split tickets that this behavior by parties results in their candidates obtaining votes even where they are not competitive in the district (Cox and Schoppa 2002).

Another variant of the contamination thesis is that parties that have incumbent MPs in districts might benefit from a "personal vote" cultivated by their MP (Karp 2009). Again, this argument assumes many voters will not split a ticket, and will vote for the list of the MP's party. This form of 
contamination actually implies that the presence of a nominal tier with personal-vote-earning MPs will reduce the fragmentation of the PR tier, given that smaller parties rarely have the opportunity to benefit from a personal vote of a district MP.

\section{Contamination Effects and the Number of Parties}

How does contamination, if present, affect the number of parties? On the one hand, the number of parties entering and receiving some significant vote shares in the single-seat districts might tend to be inflated, relative to a pure SMP system, by the presence of a list tier using proportional representation. A "reverse" version of the argument is that, despite proportional representation, the presence of SMP competition depresses the overall number of parties, because voters may cue on the major parties and their popular incumbents and then be reluctant to split their tickets. Obviously these two potential directions of contamination work against each other, and if both are present, we should see moderate multiparty competition dominated by the top two, and little difference in the effective number of parties across the two tiers. Parties other than the top two would be present in the districts, and would earn seats based on their party votes, but there would not be a large difference between the vote shares of parties in each tier. The alternative to the contamination thesis is that the two tiers behave as though they were separate SMP and PR systems: a multiparty system in the PR tier, but competition in the districts centered around two dominant parties.

The New Zealand case is especially auspicious for testing this thesis, given the change from SMP to MMP. Here we will do so by comparing prereform and postreform elections in terms of the effective number of electoral parties. We will consider both the average of the various singlemember districts before and after reform, as well as the national aggregate vote-in the MMP era, meaning both candidate and party votes. We have already seen, in a previous section, that while the prereform party system was essentially a two-party system in parliament, there was considerable third-party voting especially from the mid-1970s on. Here we will look closer at the trends by bringing the district level in. It is, after all, at the district level where most of the posited effects on voter behavior take place (Moser and Scheiner 2012).

Figure 9.1 shows a graph with three trends in the effective number of vote-earning parties $\left(\mathrm{N}_{\mathrm{V}}\right)$ since 1963: the national aggregate of the candidate (district) votes (solid circles and connecting line); the mean of the individual districts (open circles and dashed line); party list votes under 


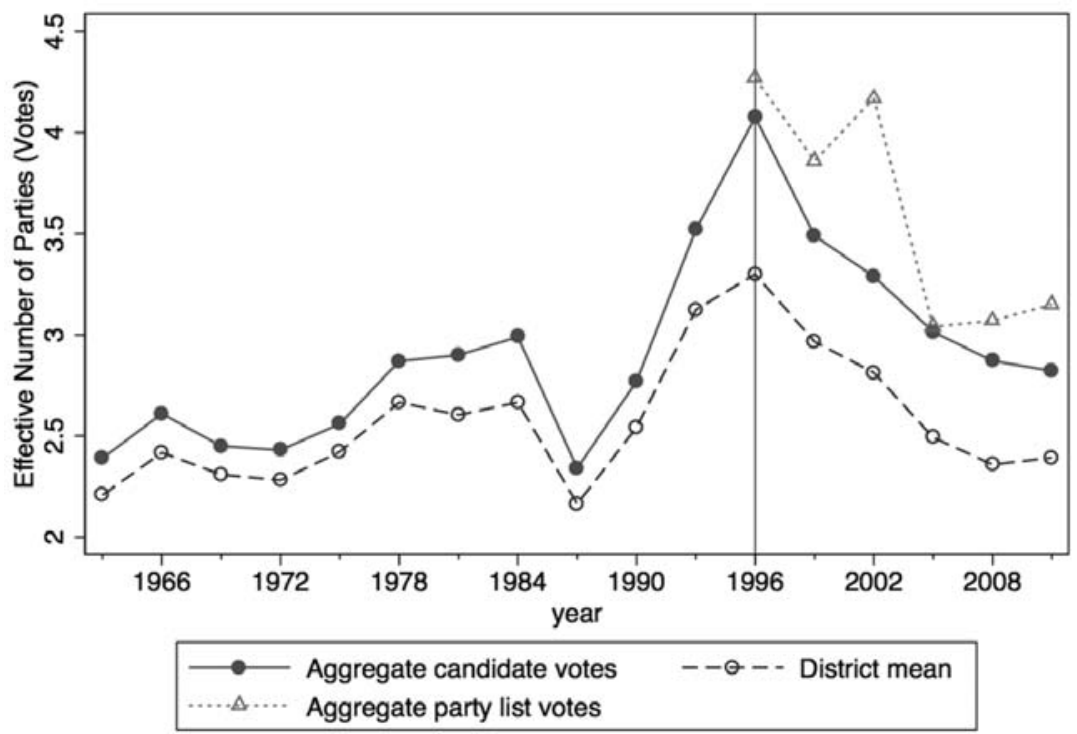

Fig. 9.1. Effective number of parties over time in New Zealand

MMP (triangles). Several noteworthy observations can be made. First of all, there was a mostly upward trend in the effective number of electoral parties $\left(\mathrm{N}_{\mathrm{v}}\right)$ from 1975 onward, with the notable exception of 1987. (Perhaps one might discount the 1993 rise, given that the referendum that was expected to approve MMP was concurrent with this election.) Moreover, the national aggregate and district means track each other quite closely, signaling that the rise was not principally a result of a deficiency in what Cox (1997) refers to as "linkage"; that is, it was not due to different patterns of district competition being inflated when we project the districts up to the national level. There is some greater uptick in the national aggregate than there is for the district mean in the 1978-84 period, but not much. The two lines increase at almost the same rate again in 1990-93. In other words, Duvergerian patterns of two-party competition were breaking down to some degree not only nationally but also in the average district during these times. Nonetheless, we should not exaggerate the trend, because in no election had $\mathrm{N}_{\mathrm{V}}>3.0$ until 1993.

As for the MMP period, there was a major spike in $\mathrm{N}_{\mathrm{V}}$ by all three measures in 1996, as we might expect. We might say there was substantial contamination from the party vote to the district vote, as the average district sees $\mathrm{N}_{\mathrm{V}}$ rise to 3.3. However, there is also an apparent reduction of linkage, 
suggesting district patterns became more distinct than they had been prereform. We see evidence for this in the fact that the national aggregate $\mathrm{N}_{\mathrm{V}}$ based on candidate votes was closer to that based on party-list votes than it was to the district mean.

Then, with each passing election under MMP, there has been a downward trend in $\mathrm{N}_{\mathrm{V}}$ based on candidate votes (both aggregate and district mean), even in years when $\mathrm{N}_{\mathrm{V}}$ based on party votes turned upward, as it did in 2002 and, more modestly, in the 2005-11 period. Strikingly, the district mean $\mathrm{N}_{\mathrm{V}}$ is lower in the most recent three elections under the MMP era than it was in any election in the later SMP period of 1978-93, except for 1987. This is, of course, evidence against one variant of the contamination thesis, because a case could be made that the average single-seat district is more "Duvergerian" under the proportional mixed-member system than it was during a time when such districts were the only game in town.

The overall decline in fragmentation from its high point with the first MMP election suggests that the dominant trend is not so much contamination as it is the emergence of separate vote patterns in the two tiers. ${ }^{36}$ This is suggested most especially by the three recent elections when $\mathrm{N}_{V}$ on party votes has trended modestly upward again, but that based on electorate votes has been lower than in most of the elections of the latter prereform period.

It is worth noting that the pattern we see in figure 1 in which the two tiers showing a distinct "psychological" effect (in Duverger's terms) need not be typical of MMP. Compare figure 9.2, which replicates what we saw in figure 9.1, only for the case of Germany since 1953. Before unification in 1990 , the mean district $\mathrm{N}_{\mathrm{V}}$ was generally below 2.5 , and hence quite "Duvergerian." Moreover, there is little difference between the aggregate $\mathrm{N}_{\mathrm{V}}$ for either nominal or list votes, suggesting little ticket-splitting — a finding consistent with literature that directly addressed the phenomenon (e.g., Fisher 1973). In the 1990s and especially in the 2005 and 2009 elections, on the other hand, the mean district has become notably more fragmented. All three indicators have turned sharply upward, and the somewhat larger gap between nominal and list votes implies more ticket-splitting as well (confirmed in a study of the 1998 election by Gschwend, Johnston, and Pattie 2003), but not—critically — to the extent of keeping anything like a Duvergerian equilibrium in the single-member districts. In fact, Germany's mean district $\mathrm{N}_{\mathrm{V}}$ has not been below 2.5 since 1983 , and rose to 2.9 in 2005 and 3.5 in 2009. Thus, at least over several recent elections, the two MMP systems seem to be diverging. Germany seems to be experiencing contamination from the PR tier to the nominal, whereas in New Zealand 


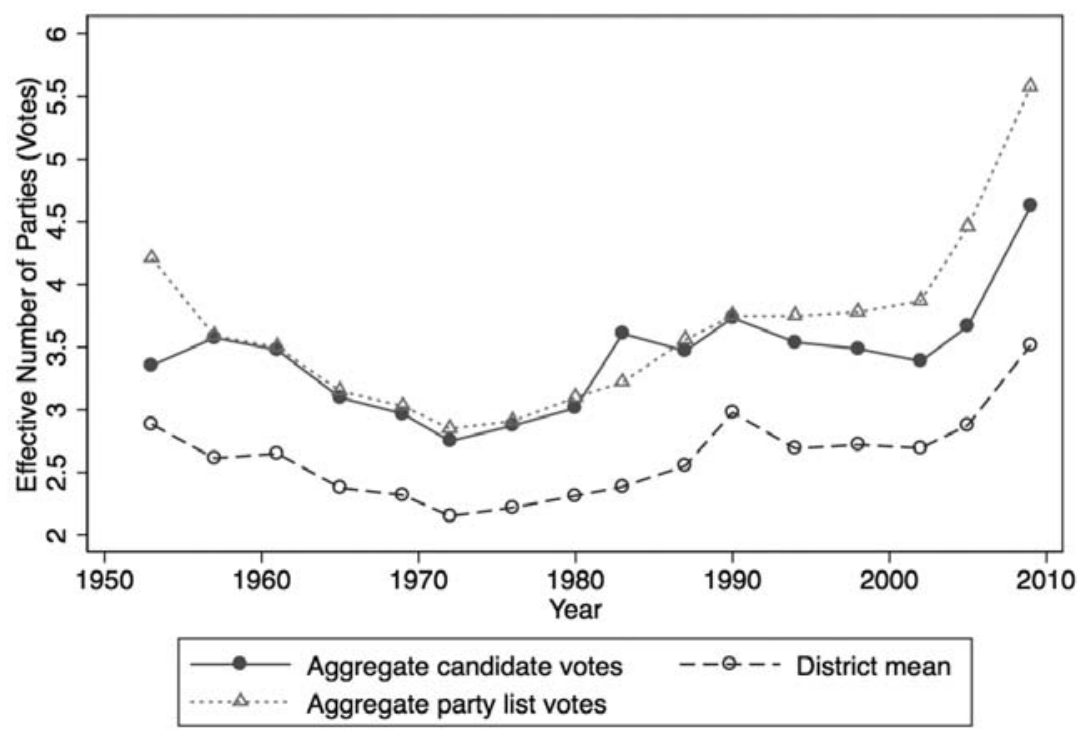

Fig. 9.2. Effective number of parties over time in Germany

the two tiers are showing distinct patterns-two-party dominance in the single-seat districts, but considerable third-party voting on the PR vote. ${ }^{37}$

\section{Dual Candidacy and Personal-Vote Contamination Effects}

As we noted previously, some variants of the contamination thesis imply that large parties benefit from the "personal vote" cultivated by their incumbent MPs, and that this results in those parties that win many plurality races also performing especially well on the party-list vote. We have already cast some doubt on this form of contamination, by observing a recent growth in the gap between $\mathrm{N}_{\mathrm{V}}$ based candidate and party votes. ${ }^{38}$ There are other possible forms of cross-tier contamination, however, which we take up in this section. In particular, the practice of dual candidacy may create important cross-tier contamination effects. We could observe contamination on the intraparty dimension, meaning how parties and candidates relate to one another and how much incentive legislators have to cultivate connections to a locality (Shugart 2005). Specifically, intraparty contamination could mean either district-level electoral competition affording less local representation and accountability than a pure SMP system, or the list tier becoming "personalized" and "localized" in a way that would be 
unusual if the system were entirely a list proportional system (assuming lists are closed, as they are in New Zealand). At least in the New Zealand context, the former direction of possible contamination-weakening of district-level incentives on politicians-is controversial and perceived as normatively "bad" due to the perceived illegitimacy of dual candidacy. The other direction of contamination likely would be considered "good" if it were perceived to be functioning. The consideration of how contamination works on the intraparty dimension in New Zealand is tied up in the issue of dual candidacy - the right of candidates to stand for office simultaneously in a district and on a party list.

In New Zealand, as in Germany and Japan but unlike in Taiwan, dual candidacies are allowed. In Germany, there seems little controversy over the practice, in contrast to the deep controversy found in Japan, where the "best loser" provision by which parties may choose to rank their lists may exacerbate the perceived illegitimacy of dual candidacy. In New Zealand, the major parties, Labour and National, have tended to have a majority of their candidates run in both tiers simultaneously; in recent elections, the percentage has been $70 \%$ or higher. The Green Party likewise has dually nominated most of its candidates, including $97 \%$ of them in 2011 . The microparties' behavior has been somewhat variable. (Data from Vowles 2012.)

Dual candidacy has increasingly come under scrutiny and criticism. In fact, it was explicitly one of the provisions subject to the review of MMP following the referendum of 2011, under the Electoral Referendum Act of 2010. A case can be made that dual candidacy can be an efficient and desirable feature of a mixed-member system- " good contamination," in a sense. Allowing dual candidacy means that parties have an incentive to nominate high-quality personnel in districts that they may have little chance of winning. If dual candidacy were banned, a party might be disinclined to risk wasting a good candidate in a likely losing district contest, and instead ensure the candidate a place in parliament via a good rank on the party list. This risk would be especially acute for parties that expect to win seats only, or primarily, via the list. For instance, a party like the Greens, were there no dual candidacy, would be unlikely to nominate its best candidates in districts, because it depends on the party vote to gain seats. As the New Zealand Electoral Commission put it in its final report from the MMP review: "Without dual candidacy, MMP elections would be poorer contests" (Electoral Commission 2012, 9).

A positive feature of dual candidacy is that it may encourage greater local representation than either a pure SMP or PR system would do. If MPs elected via the list set up local offices in the constituencies they con- 
tested but lost, then voters have representatives that they can contact for assistance from more than just the party that won the most votes in their area. Evidence from the parliament elected in 2011 appears to bear this out. Eleven dual-listed National Party MPs who won their seat via the party list maintain electorate offices and often identify themselves by titles such as "List MP based in [electorate name]." Labour has eight list MPs who follow a similar strategy of maintaining an electorate office..$^{39}$ Even the Greens, despite not coming close to winning an electorate, maintain several "Electorate Offices" although in fact the offices are shared between multiple MPs and the offices are located in just a few cities where the party has its greatest strength. This pattern fits a party that is less geographically focused in its platform, but that has mainly an urban constituency. As for the fourth largest party, New Zealand First, in 2011 all but the leader, Winston Peters, were dual nominees and all but two of their MPs maintain electorate offices. ${ }^{40}$

The biggest controversy over dual candidacy stems from incumbents losing their district race yet remaining in parliament via the party list. That these legislators are sometimes referred to by names like "zombies" or "back-door MPs" calls attention to their perceived illegitimacy. Despite the controversy, there is little objective evidence that it is a major phenomenon in the New Zealand experience with MMP. For example, Vowles (2012) shows that the overall turnover of MPs from one election to the next actually has been greater under MMP than it was under SMP. Moreover, from 1999 through 2011, only once has the percentage of incumbent MPs defeated in a district race but remaining in office due to the list been above $10 \%$ of all district MPs (in 2005); it was only $2.9 \%$ in 2011 . Moreover, most of the district losers who remain by winning a list seat retire after just one more parliamentary term (Vowles 2012).

The controversy over dual candidacy thus does not seem based in the actual results of elections in New Zealand. Moreover, if New Zealanders wanted to remove the possibility of district losers continuing, a simple "incumbent defeat assurance" provision could be inserted into the law as follows: a losing district incumbent whose own candidate vote trails his or her party's vote in the district is skipped on the list. In this way, if the MPs in question lost because their party became less popular (which will often be a nationwide swing, and not a specifically local effect) they can retain their seat if they are sufficiently valued by their party as to have a list rank that permits their election. However, if they lose because they are less popular than their party, they are done- the list can't "save" them from rejection by their electorate. Such a proposal is discussed in the Electoral Commission's 
online Proposals Paper during the MMP review, although not specifically recommended. ${ }^{41}$ In the end, the Commission recommended no change to the dual-candidacy provision.

\section{Conclusion}

Fifteen years after the switch from SMP to MMP, not all New Zealanders are totally convinced of the merits of MMP as evidenced by the modest majority obtained by the current system at the referendum of 2011. The Royal Commission of 1985-86, which originally proposed the MMP system, certainly anticipated many of the well-known mechanical effects of MMP - particularly the high degree of proportionality—as the German example was available as a reference.

Yet little did anybody anticipate that, beyond the mechanical effects, the switch to MMP would result in some features of New Zealand politics that are distinctive. For example, the effective number of parties in the country has actually turned out to be somewhat lower than in Germany, despite the broad similarity of the systems. In recent years, the two cases have diverged, with Germany becoming more fragmented in both the nominal and list tiers. By contrast, in New Zealand it seems that the tiers may be diverging from one another, as the two traditional parties, Labour and National, continue to dominate the district competition while various other parties combine for $20-25 \%$ of the party vote and a comparable share of the seats. New Zealand is characterized by many more very small parties than is Germany, which we attributed to the incentives of both the alternative threshold (one district victory being sufficient to win proportional representation) and the attractiveness of entering cabinets or becoming a support partner to either major party. This latter feature may be subject to change in the future, as the "legacy politicians" who founded several of the smaller parties eventually retire and especially if the Electoral Commission's recommendation to abolish the alternative threshold is followed.

In surveying the effects of several mixed-member systems, Shugart and Wattenberg (2001b) asked whether they could offer "the best of both worlds." While any such conclusions are necessarily normative, our overview of the consequences of MMP in New Zealand suggests that the answer may be yes. On the one hand, the system is overall proportional, as expected from its mechanical effect. On the other hand, voting in the single-seat districts has become relatively concentrated on the two main 
parties, and the presence of the nominal tier appears to allow for some degree of personal vote. In fact, legislators appear to maintain contact with local constituents (e.g., through electorate offices) even in districts where a different party has won the local contest. In these ways, we see the impact of both tiers shaping the political process in New Zealand.

\section{NOTES}

1. Thus far the Left has not been considered a party with coalition potential.

2. In fact, the Green Party's roots go back before the Alliance was formed, and may be found in the Values Party that contested several elections (but won no seats) in the 1970s and 1980s.

3. While the term first past the post electoral system is more commonly used in New Zealand to describe the single-member plurality (SMP) electoral system, in this chapter we use the term SMP as part of the standardized usage of acronyms and terminology in this volume.

4. For a detailed typology of MMP and MMM systems, see Shugart and Wattenberg (2001a).

5. An "overhang" results when a party with less than $5 \%$ of the party-list vote obtains at least one district seat. Under current practice, not only does such a party qualify for list seats, but if its number of districts won exceeds its proportional share (of 120), the size of parliament is expanded to account for the overhangs. The Electoral Commission proposed ending both practices. In addition, it recommended retaining the status quo for by-election candidacy, dual candidacy (which we discuss below), and the ordering of party lists.

6. Nonetheless, the National Party, as of 2011, has actually formed three of the six post-MMP governments, albeit with some bargaining challenges, as we discuss in the section below on government formation.

7. As in New Zealand, there is a provision for overhang seats (ïberbangmandate). A key difference in Germany is that even though overall proportional entitlements to parties are determined nationwide, the overhangs are determined within each state.

8. As is typical, we count the Christian Democratic Union and the Christian Social Union as separate parties. The latter competes only in Bavaria, whereas the former competes in the rest of the country. The two act as a single party in parliament.

9. If we were to count the CDU and CSU as one party, these figures would be about .84 as high, on average (3.97 in 2009). All but the 1990 figure (2.65) would remain higher than any value in New Zealand under MMP.

10. $\mathrm{N}_{\mathrm{S}}$ fell in 2013 in large part due to the Free Democratic Party failing to clear the threshold.

11. Counting CDU and CSU as one, the $1969-87$ average is 2.44 and it would not be over 3.00 until 2005.

12. It is worth noting that, due to the difference in parliament sizes, Germany's alternative threshold of three districts won is not clearly higher than New Zealand's one district. Germany's was equivalent to about $1.2 \%$ of total districts before 
reunification but is about $0.5 \%$ of districts in the larger postunification Bundestag. New Zealand's is around $1.4 \%$ of districts. Nonetheless, it is presumably more difficult for a very small party to find three candidates capable of winning districtsassuming it is not a party focused on a regional cleavage-than it is to have one such candidate. In the case of New Zealand, as we discuss later, that one candidate is often the party founder who already held the seat with one of the larger parties in the pre-MMP era.

13. In 1994, the Party of Democratic Socialism won three districts in the formerly Communist east, but only $4.4 \%$ of the nationwide party vote. In 1990, it won representation with only $2.4 \%$ of the nationwide party vote, but at that election there was a one-time variance in the threshold: a party had to win $5 \%$ in only one of the former separate countries of West Germany and East Germany, rather than nationwide.

14. In practice, a party that has one district win needs about $1.5 \%$ of the party vote to qualify for a second seat.

15. The Seat Product is the average district magnitude $(M)$ multiplied by the size of the assembly (S). Taagepera's models predict that the number of seat-winning parties (of any size) is the fourth root of the Seat Product, while the effective number is the sixth root: $\mathrm{N}_{\mathrm{S}}=(\mathrm{MS})^{1 / 6}$.

16. Actual parties are approximated by the inverse square root of the threshold (expressed in fractions rather than percent), and $\mathrm{N}_{\mathrm{S}}$ by the inverse cube root, according to the logical models.

17. In Germany, given the greater difficulty of a small party winning despite being below the threshold, one would want to use only the threshold-based models. An estimated 4.47 parties (of any size) in parliament is close to the recently observed 5 , but the observed effective number is now much higher than the estimated 2.71. Perhaps it is Germany, and not the newer MMP case of New Zealand, that is the hard case to explain!

18. The minimum in any one cabinet has been three if we count the two Christian Democratic parties (CDU and CSU) separately. While they always have entered government or gone into opposition as if they were one party, they maintain their separate party organizations and leadership.

19. This is in partial contrast to Japan and Taiwan, where preelectoral alliances have been more common.

20. Such agreements state that a minor party will not vote against the government in motions of confidence or supply, typically in exchange for some cooperation on policy areas of mutual interest.

21. As discussed in greater detail below, Maori voters under both the SMP and MMP systems have had the option of voting in separate single-member districts set aside to ensure representation of the Maori. The Royal Commission had recommended abolishing the Maori districts as unnecessary under a proportional system, but waiving the usual party-vote threshold for parties representing Maori.

22. A Labour defector, former finance minister Roger Douglas, was also a cofounder of ACT.

23. After a brief stint with a party called New Labour.

24. In the voter registration period, citizens are asked whether they claim Maori ethnicity and, if so, if they would like to be enrolled in the Maori roll.

25. See "Greens Given GM Warning," New Zealand Herald, March 6, 2002. The narrative here also draws heavily on Carroll (2005). 
26. "Labour Takes Green Road," New Zealand Herald, August 31, 2005; “Concessions Squeezed Out of Labour," New Zealand Herald, October 18, 2005.

27. "Greens Demand Two Posts in Cabinet," September 15, 2005.

28. "Labour-Led Government Co-operation Agreement with Greens," October 17, 2005 (accessed by authors from Green Party website on October 20, 2005).

29. In fact, the party went so far as to issue a press release on October 19, 2005 saying the presence of New Zealand First and United Future meant the government was "bad news for New Zealand workers."

30. "Labour Wins Crucial Votes on Emissions Trading Plan," New Zealand Herald, August 27, 2008.

31. The amendments to the ETS secured the support of the now Nationalaligned United Future. In addition, the Maori Party was pivotal, and for its support obtained a provision allowing carbon credits for the planting of trees on tribal land. See "Emissions Trading Money Scramble," The Press (Christchurch), November 23, 2009, and "'Sellout' Claim over ETS Deal," The Press (Christchurch), November 24, 2009. The staunchly promarket ACT, also a National partner, voted against the amended ETS (preferring no ETS at all).

32. "Memorandum of Understanding between the New Zealand National Party and the Green Party of Aotearoa New Zealand," dated April 8, 2009 (accessed from the Green Party website in November 2009).

33. The Greens won an electorate (Coromandel) once, in 1999, thanks to some informal cooperation with the Labour Party, which did not withdraw its candidate from the district, but did encourage supporters to vote for the Green candidate in the otherwise National-leaning district.

34. In fact, the Commission's Report says that $3 \%$ would be preferable and would not be so low as to threaten government stability. However, it concludes such a change would be too drastic and politically unpalatable, thereby settling on $4 \%$.

35. Apparently the first use of the term contamination to refer to concurrent majoritarian and proportional balloting not being identical to the respective systems when used separately is Shugart and Carey (1992, 239-42). They refer to cases of presidential elections using plurality and legislative elections using PR. In the literature on mixed-member systems, the concept of contamination appears to have been used first by Herron and Nishikawa (2001), who emphasized in a comparison of the Japanese and Russian MMM systems that the PR tier results in a lessened impact of the single-seat districts on the number of parties.

36. Even as early as the second MMP election, Karp et al. (2002) noted that splitvoting followed a predictable pattern, with "strategic defections" from parties that were not viable in the voter's electorate.

37. The Scottish and Welsh MMP systems appear to be in between the effects we show here for Germany and New Zealand: a significantly lower $\mathrm{N}_{\mathrm{V}}$ for the nominal tier compared to the list, but also average $\mathrm{N}_{\mathrm{V}}$ in the districts that is greater than 3.0 (Crisp et al. 2012).

38. Horiuchi, Shugart, and Vowles (2013), analyzing the effect of redistricting on the vote in New Zealand, find evidence for a personal vote for incumbents, who tend to obtain fewer candidate votes from voters who were not in their district prior to redistricting. However, they do not find evidence for contamination, as voters who are redistricted are not less likely than other voters to vote for the list of the incumbent's party. 
39. Labour and National each have a few MPs who ran only on a list. Some of these were recruited from the private sector for their policy expertise (e.g., trade or health), while others represent minority ethnic communities. Some of these listonly candidates set up offices upon being elected, while others did not.

40. The two are Peters and the MP elected in Peters's former electorate of Tauranga, Brendan Horan.

41. See http://www.mmpreview.org.nz/proposals/dual-candidacy (last accessed February 27, 2013). The Commission acknowledges a submission to the MMP Review by Shugart as the source of this suggestion.

\section{REFERENCES}

Bollard, Alan. 1994. "New Zealand.” In The Political Economy of Policy Reform, ed. John Williamson. Washington, DC: Institute for International Economics.

Boston, Jonathan. 2011. "Government Formation in New Zealand under MMP: Theory and Practice." Political Science 63 (1): 79-105.

Carroll, Royce. 2005. "Legislative and Electoral Coalition Politics in MMP New Zealand, 1993-2003." Case study prepared for the Graduate School of International Relations and Pacific Studies, University of California, San Diego.

Cox, Gary W. 1997. Making Votes Count: Strategic Coordination in the World's Electoral Systems. Cambridge: Cambridge University Press.

Cox, Karen E., and Leonard J. Schoppa. 2002. "Interaction Effects in MixedMember Electoral Systems: Theory and Evidence from Germany, Japan, and Italy." Comparative Political Studies 35 (9): 1027-53.

Crisp, Brian F., Joshua D. Potter, and John J. W. Lee. 2012. "Entry and Coordination in Mixed-Member Systems: A Controlled Comparison Testing the Contamination Hypothesis." Fournal of Politics 74 (2): 571-83.

Denemark, David. 2001. "Choosing MMP in New Zealand: Explaining the 1993 Electoral Reform.” In Mixed-Member Electoral Systems: The Best of Both Worlds?, ed. Matthew Søberg Shugart and Martin P. Wattenberg. Oxford: Oxford University Press.

Fisher, Steven L. 1973. "The Wasted Vote Thesis: West German Evidence.” Comparative Politics 5:293-99.

Gschwend, Thomas, Ron Johnston, and Charles Pattie. 2003. "Split-Ticket Patterns in Mixed-Member Proportional Systems: Estimates and Analyses of Their Spatial Variation at the German Federal Election, 1998." British Fournal of Political Science 33:109-27.

Herron, Erik S., and Misa Nishikawa. 2001. "Contamination Effects and the Number of Parties in Mixed-Superposition Electoral Systems.” Electoral Studies 20 (1): 63-86.

Horiuchi, Yusaku, Matthew S. Shugart, and Jack Vowles. 2013. "Electoral Redistricting and the Personal Vote under the Mixed-Member Electoral System: New Evidence from New Zealand." Paper presented at the 2013 Annual Meeting of the Midwest Political Science Association, Chicago, April 11-14.

Karp, Jeffrey A. 2009. "Candidate Effects and Spill-over in Mixed Systems: Evidence from New Zealand.” Electoral Studies 28:41-50.

Karp, Jeffrey A., Jack Vowles, Susan A. Banducci, and Todd Donovan. 2002. "Strate- 
gic Voting, Party Activity, and Candidate Effects: Testing Explanations for Split Voting in New Zealand's New Mixed System." Electoral Studies 21:1-22.

Lijphart, Arend. 1984. Democracies: Patterns of Majoritarian and Consensus Government in Twenty-One Countries. New Haven: Yale University Press.

Lijphart, Arend. 1999. Patterns of Democracy. New Haven: Yale University Press.

Miller, Raymond, and Jennifer Curtin. 2011. "Counting the Costs of Coalition: The Case of New Zealand's Small Parties." Political Science 63 (1): 106-25.

Moser, Robert G., and Ethan Scheiner. 2012. Electoral Systems and Political Context: How the Effects of Rules Vary across New and Established Democracies. Cambridge: Cambridge University Press.

Nagel, Jack H. 1998. "Social Choice in a Pluralitarian Democracy: The Politics of Market Liberalization in New Zealand.” British Fournal of Political Science 28 (2): 223-67.

New Zealand Electoral Commission. 2012. Report of the Electoral Commission on the Review of the MMP Electoral System. Report provided to the Minister of Justice for presentation to Parliament in accordance with section 78 of the Electoral Referendum Act 2010, Wellington, New Zealand, 29 October. http://www.elec tions.org.nz/sites/default/files/bulk-upload/documents/Final_Report_2012_ Review_of_MMP.pdf, (accessed 10 August 2015).

Nielson, Daniel L. N.d. "The Politics of Economic Reform in New Zealand." Case study prepared for the Graduate School of International Relations and Pacific Studies, University of California, San Diego.

O'Brien, Thomas. 2013. "Leaving the Minors: The Green Party of Aotearoa New Zealand and the 2011 General Election." Representation 49 (1): 69-81.

Shugart, Matthew S. 2005. "Comparative Electoral Systems Research: The Maturation of a Field and New Challenges Ahead." In The Politics of Electoral Systems, ed. Michael Gallagher and Paul Mitchell. Oxford: Oxford University Press.

Shugart, Matthew S., and John M. Carey. 1992. Presidents and Assemblies: Constitutional Design and Electoral Dynamics. Cambridge: Cambridge University Press.

Shugart, Matthew S., and Martin P. Wattenberg. 2001a. "Mixed-Member Electoral Systems: A Definition and Typology." In Mixed-Member Electoral Systems: The Best of Both Worlds?, ed. Matthew Søberg Shugart and Martin P. Wattenberg. Oxford: Oxford University Press

Shugart, Matthew S., and Martin P. Wattenberg. 2001b. "Are Mixed-Member Systems the Best of Both Worlds?" In Mixed-Member Electoral Systems: The Best of Both Worlds?, ed. Matthew Søberg Shugart and Martin P. Wattenberg. Oxford: Oxford University Press.

Taagepera, Rein. 2007. Predicting Party Sizes: The Logic of Simple Electoral Systems. Oxford: Oxford University Press.

Taagepera, Rein. N.d. "Predicting Party Sizes on the Basis of Legal Thresholds." Unpublished MS, Dept. of Political Science, University of California, Irvine.

Taagepera, Rein, and Matthew S. Shugart. 1991. Seats and Votes. New Haven: Yale University Press.

Vowles, Jack. 2012. "Legislative Accountability under New Zealand's MMP: Turnover, Dual Candidacy, and 'Party-Hopping'." http://www.jackvowlesdomain. co.uk/Accountability_MMP.pdf (last accessed April 23, 2013). 


\title{
Presidents and Blank Votes in the Bolivian and Russian Mixed-Member Systems
}

\author{
Nathan F. Batto, Henry A. Kim, and Natalia Matukbno
}

Mixed-member electoral systems confront voters with two choices: a list tier ballot to be cast on the basis of the party and a nominal tier ballot to be cast on the basis of the characteristics of the local candidates. Some voters do not make these two choices independently, but instead use information about the choices in one tier to help make the choice in the other tier. These sorts of "contamination" effects have been the subject of a great deal of research (Cox and Schoppa 2002; Herron and Nishikawa 2001; Nishikawa and Herron 2004; and Ferrara, Herron, and Nishikawa 2005).

In the introduction to this volume, Batto and Cox argue that directly elected executives shape the legislative party system differently than indirectly elected executives. We build on this idea and argue that in presidential systems, a third consideration-what the voters know of the presidential candidates-may also shape the vote choice on the list and nominal tier ballots. Presidential elections typically dominate public discourse during an election campaign, and voters often know much more about the presidential candidates than the party platforms or their local district candidates. Many voters might project what they know of a presidential candidate onto his party's list or district nominee. However, we argue that the presidential candidates do not affect list and district tier decisions equally. The connections between the presidential candidate and the party list are typically much closer and more apparent, and voters may consequently be 
less willing to assume that the district nominee is simply a local avatar for the presidential candidate.

This is especially apparent in new democracies with less institutionalized parties that do not penetrate deeply into society. When a party is simply a hastily constructed vehicle for a presidential candidate's national campaign, local organizations are often weak, underfunded, and impotent. Many district candidates for such parties are likely to be unknown political novices without a credible chance of winning. Even people who turn out to support the presidential candidate and are willing to back the national party list may balk at voting for a completely unknown quantity with little chance of winning on the district ballot.

Some countries allow voters to vote "blank" or "against all," and we examine patterns in these blank votes to infer how presidential candidates affect voting in the list and nominal tiers. An explicit blank vote can be interpreted as a sign that none of the candidates in that tier have inspired the voter to vote, so the impetus to vote must have come from elsewhere. ${ }^{1}$ We examine two elections that took place in very different political environments, Bolivia in 2002 and Russia in 2003, and find that blank votes were much more common in the nominal tier than in the list tier. More important, larger numbers of blank votes were correlated with better performance in the list tier by more loosely organized parties led by personally popular and charismatic presidential candidates. These results are consistent with the idea that presidential candidates had a larger contamination effect on the list vote than on the district vote, and the effect was particularly strong for presidential candidates of newer and less organized parties.

\section{Contamination Effects and Presidential Candidates}

The basis of the contamination effect is commonly thought to be psychological. Herron and Nishikawa suggest that voters value consistency in their vote choices. That is, if voters observe the same choices available on both ballots, they are inclined to make the same vote choices in both tiers (2001, 68-69). Cox and Schoppa also argue that the physical presence of the district candidate campaigning locally and furnishing a "human face" to a race has a positive impact for a party. Such a presence helps mobilize what they term "either way voters," those without a strong psychological or habitual commitment to that party. Moreover, the presence of a district candidate can increase the party's list tier totals, even if that district candidate stands no chance of capturing the nominal tier seat $(2002,1031)$. 
Ferrara, Herron, and Nishikawa $(2005,67)$ make the argument explicitly informational by explaining the effect as an informational shortcut: voters can judge the quality of all the candidates on the party list by simply looking at the quality of the particular candidate in their local district. In the presence of this contamination effect, even small parties without any prospect of winning the election in the nominal tier are encouraged to field candidates in as many districts as they can in order to improve their list tier performance, thus countering the Duvergerian incentive to abstain from participating in unwinnable races.

These arguments all look at how the district race contaminates the party list race. The most compelling evidence comes from parliamentary democracies, such as Italy, New Zealand, Germany, and Japan. This is no coincidence. Parliamentary systems often lack a single, nationalized party politician with a separate electoral mandate from his or her legislative counterparts, who can furnish a distinct "face" for the rest of the party (Samuels and Shugart 2010). By the nature of the institution, voters in a parliamentary system are not asked to vote explicitly for the party's national standard bearer in an election. While parties may conscientiously attempt to draw voter attention to their leaders, the linkage is at best indirect in the absence of an ability to vote directly for their standard bearers by name. Furthermore, party leaders in a parliamentary system often are not the most electorally profitable choices to act as their parties' "human faces." Party leaders in parliamentary democracies have often risen through the ranks on the basis of their skills as backroom operators in the legislative process, rather than on their ability to arouse the masses outside the chamber (Samuels and Shugart 2010). In other words, the voters in a parliamentary system can sometimes be confronted with a set of rather dry or uninspiring national party faces to base their party list decision on.

Presidential systems are qualitatively different, especially when the presidential and legislative elections are held concurrently. Presidential candidates provide a visible and recognizable face. Often, they are political outsiders who have built a strong, well-defined reputation of their own. Indeed, many successful presidential contenders, regardless of the country, are likely to have risen in politics through their ability to mobilize supporters through their own actions, rather than their roles in the inner workings of parties (Samuels and Shugart 2010). Media coverage is usually dominated by the presidential campaign, and the messages and reputations of local candidates are often drowned out amid the focus on the executive race. Such focus on the personal appeals of the presidential candidates is arguably justified. After all, the person elected president will be the head of 
government, and parties have no mechanism like a vote of no confidence to ensure that presidents from their party actually follow the party line. Quite the contrary, presidents almost always become the de facto party leaders and often decide to lead their parties in new directions chosen according to their personal priorities. Thus, not only is the information about the presidential candidate more easily accessible than corresponding information about a party leader in a parliamentary system, voters are fully justified in adjusting their attitudes about a particular party based on that information.

Particularly in U.S. politics, the electoral impact of the president on legislative elections has long been recognized in numerous studies of the so-called coattail effect and its impact on legislative elections (Burnham 1975; Calvert and Ferejohn 1983; Campbell 1997; Miller 1955). However, the importance of the president may be even greater in other presidential democracies, especially where presidents enjoy greater formal power relative to other political actors or where political parties have shorter histories and weaker reputations. Newer and less institutionalized parties are much more likely to field a reasonably charismatic presidential candidate than to be able to recruit a full slate of well-known candidates to run for the legislature. Modern media technology can help project the faces of presidential candidates to the homes of voters in every district, regardless of the efficacy of the local party organizations in promoting voters' familiarity with candidates for the legislature. In short, information from the national race, or more accurately, the presidential race, is likely to be much stronger, clearer, and more omnipresent than information garnered from the local races.

Presidential elections also affect turnout. More people turn out to vote in legislative elections when a presidential election is being held concurrently. Perhaps more significantly, voters in concurrent elections also turn out to vote for different reasons. ${ }^{2}$ Since they have been bombarded with information about the presidential race, they are often thinking primarily about the presidential race and supporting a particular presidential candidate. The legislative race is usually a secondary consideration. Indeed, many people may cast their legislative vote as an expression of support for the presidential candidate.

If the presidential candidate is the human face of the party, the extent to which this human face spills over to the list and district votes may differ. The presidential candidate is usually the leader of the party. Even when he stresses positions that are at odds with orthodox party doctrine, other party leaders tend to downplay these differences since highlighting intraparty divisions during a campaign is usually a losing strategy. Hence, equating a vote for the party list with support for the presidential candidate is 
relatively straightforward. Doing so for the district candidate, however, is more complicated. District races are run along different contours from the national campaign. Districts may diverge significantly from the national average on many dimensions, such as ethnic makeup, partisan balance, and economic vitality. Different issues may matter locally, and local preferences may be at odds with national preferences. Because of this, a local party nominee may not always follow the national party in lockstep. Voters in local districts must also consider the question of viability. Party list seats are distributed proportionally, and even parties with relatively low levels of support can win list seats. This is not the case in the nominal tier with single-seat districts. Disorganized, underfunded, and unknown candidates are usually sure losers. Strategic voters may be loath to waste their district vote on such a candidate, even if they support the party's presidential candidate. Alternatively, they may simply decide that voting for the party's district nominee is hopeless and choose not to vote at all in the nominal tier. ${ }^{3}$ In short, some voters will base their legislative votes on their opinions of the presidential candidate, and this is more likely to occur in the list tier than in the nominal tier.

\section{Blank Votes and Inchoate Parties}

In a number of countries, including Bolivia and Russia, voters have the option to vote "blank" or "against all" - to indicate that the voter does not want to support any of the candidates or parties. Blank votes are not the same as null votes, in which a voter votes for multiple candidates, does not mark any option, writes something inappropriate on the ballot, or otherwise spoils the ballot, and blank votes are counted separately from null votes. ${ }^{4}$

Why would a voter cast a blank vote? It is possible that the voter is highly informed about each candidate and simply dislikes all of them. However, most highly informed voters can eventually conclude that one candidate is a little better than the others, or at least that one is awful enough that it is worth it to vote for someone else in order to stop the worst candidate. Another possibility, which we suspect is more common, is that most blank votes reflect extremely low levels of information. That is, the typical blank vote occurs when the voter does not know enough about any of the options to decide that any of them are better (or worse) than the others.

This begs the question of why such a voter would turn out in the first place. Of course, it could just be that the voter has a strong sense that voting is a democratic duty (Achen and Hur 2011) and believes that the 
actual choice is less important than the mere act of participation. More significantly for our purposes, a voter may turn out to vote because she has a strong opinion in a different race taking place at the same time. For example, with concurrent party list and district elections, the voter may have a strong opinion in the former elections but not in the latter race. In this case, the voter might vote for a party in the list tier and vote blank in the district tier.

Since information about presidential candidates is so prevalent, and this information leaks primarily into the list tier and only secondarily into the district tier, most voters should be able to make a choice in the list tier. Information from the presidential race is less useful in local races, and more voters might be unable to differentiate among the various names on the ballot. Some of these voters will respond by explicitly not making any choice, by casting a "blank" ballot. Alternatively, voters who turn out expressly to support the presidential candidate may vote for the party list, which is closely associated with the president, but not the district candidate, who may not be viable or may take somewhat different positions. More of these voters should vote blank in the nominal tier than in the list tier. This implies:

H1: In countries with a presidential system and a mixed-member electoral system, blank votes should be more common in the district tier than in the list tier.

H1 is fairly crude; it makes only a single, national-level prediction. However, we can use the differences between more institutionalized and less institutionalized parties to draw a more finely tuned hypothesis. The relative degree to which the presidential candidate defines the "face of the party" varies from party to party. We are particularly interested in parties that revolve around a single leader. Where these types of parties are strong, blank votes should be more common.

These personal vehicle parties are often hastily organized for the upcoming presidential campaign, and the rest of the party is somewhat of an afterthought. Ironically, it may be precisely the presidential candidates who most thoroughly embody their party image who have the most trouble extending that image and influence voting down to the local level. It is often much harder for new and disorganized parties to assemble a roster of competent local candidates. Instead, these inchoate parties are often only able to cobble together a group of unknown, unimpressive, and underfunded local politicians. Such local politicians will have difficulty commu- 
nicating information about themselves to the voters, so they cannot compete with, modify, or reshape the image projected by the national party. However, they might also be so anonymous that there is effectively no local presence for the national party face to be projected onto. The more invisible the local candidate, the more likely voters are to decide that there is no viable foot soldier for their favored presidential candidate. Almost by definition, an anonymous candidate is an incompetent candidate. In such a district, voters might decide simply to vote for the presidential candidate's party in the list tier and to vote blank in the nominal tier.

Older, more established, or less personalized parties are likely to have a stable of fairly well-known local candidates supported by a substantial network of organizations at the grassroots level. The better the organization, the easier it is for politicians to familiarize and ingratiate themselves with their voters. Access to such organizational resources permits candidates of more established parties a greater opportunity than their counterparts in more inchoate parties to communicate to the voters and, in so doing, assert their viability. In such a party, the presidential candidate is not the sole face of the party, and local candidates may even try to present a slightly different platform or image. However, because of the national focus on the presidential race, the presidential candidate will still be the dominant face of the party. Even the strongest local candidates are generally happy to cloak themselves in the aura of their party's presidential candidate. Voters in these situations who want to support the presidential candidate have a viable candidate and a clear strategy. In essence, the difference between more and less organized parties is that the roster of viable candidates fielded by the former has the capacity to soak up all the votes from supporters of the presidential candidate while the roster of the latter may not.

Many parties in presidential systems are formed precisely as personal vehicles to promote the political fortunes of a politician with presidential ambitions. ${ }^{5}$ These parties are often hastily organized and lack any sort of organizational capacity to penetrate deeply into society. Indeed, the rest of the party is somewhat of an afterthought. For these parties, the projection from the presidential candidate to the party list should be quite strong. Since the presidential candidate dominates the party, the top spots on the party list usually go to his close allies or cronies, and, with a lower electoral threshold, viability is less of a problem. However, parties formed as personal vehicles are precisely the types of parties that find it difficult to cobble together a full roster of competent local candidates. ${ }^{6}$ They may have strong local candidates in some districts, but these newer parties typically round out the roster with unqualified, unknown, underfunded, or oth- 
erwise dismal candidates. At the extreme, they may not even be able to field a candidate at all. Such local politicians will have difficulty communicating information about themselves to the voters, so they cannot compete with, modify, or reshape the image projected by the national party. However, they might also be so anonymous that there is effectively no local presence for the national party face to be projected onto. The more invisible the local candidate, the more likely voters are to decide that there is no viable foot soldier for their favored presidential candidate. Ironically, it may be precisely the presidential candidates who most thoroughly embody their party image who have the most trouble extending that image and influence voting down to the local level.

In short, whereas the rosters of established parties tend to be filled with competent local candidates, inchoate parties have a higher percentage of incompetent local candidates. Since voters are more likely to vote blank in the nominal tier when the local candidate of their favored party is incompetent or missing altogether, parties that are newer, less organized, or personal vehicles should be more associated with blank votes in the nominal tier than older and more institutionalized parties. This leads to our second hypothesis:

H2: In countries with a presidential system and a mixed-member electoral system, blank votes in the nominal tier should be more common in areas in which less institutionalized parties win a higher vote share in the list tier.

\section{Methodology and Case Selection}

Methodologically, this paper employs a most different systems research design. In this research design, cases that are different on a set of control variables are compared. However, the independent variables of interest and the dependent variables of the cases should be the same. If the theorized process works the same way, with the same independent variables leading to identical outcomes, in very different contexts, this provides confidence that the outcome is not the result of some third variable (Przeworski and Teune 1970, chap. 2).

Given the preceding theoretical discussion and hypothesis, we need cases with directly elected presidents, mixed-member electoral systems for the legislature, the option to vote blank, and a party system in which parties' capacity to field a roster of credible local candidates varies. The cases 
should be different in as many other aspects as possible. The patterns of blank votes should then vary in predictable and similar ways.

We have chosen to examine Bolivia in 2002 and Russia in 2003. Both countries have a presidential system and elect their national legislature by a mixed-member system. In Bolivia, voters can vote "blank," while in Russia, voters can cast a vote "against all." The party systems are discussed below, and we argue that both cases featured some parties that could present credible candidates in most races and other parties that did not have such broad-based organizations.

In the remainder of this section, we note some of the more obvious differences between the two cases. Russia is much larger, ecologically diverse, and more populous. Bolivia was a Spanish colony, while Russia was the heart of an empire. In the Cold War, Russia was a central player while Bolivia was a peripheral pawn. Following the Russian Revolution of 1917 , most property was collectivized and controlled by the state. After the Bolivian Revolution of 1952, land was seized from landlords and given to local communities and syndicates who held it collectively on behalf of the local peasants (Klein 2003, 214-15). Bolivia remains a much more rural and agricultural society. Ethnically, both countries are diverse, but Russia is dominated by ethnic Russians, while Bolivia has historically been dominated by its white minority rather than by the indigenous peoples who collectively make up a majority. ${ }^{7}$ In recent years, indigenous peoples have transformed their numbers into political power through extensive grassroots organizing by social organizations. There has been no equivalent wave of grassroots social movements in Russia. In Bolivia, the mobilization of large numbers of previously inactive citizens led to an enormous increase in voting. ${ }^{8}$ By contrast, turnout has declined in Russia. ${ }^{9}$

There are a few notable differences in the two electoral systems. First, Russia had an MMM system, while Bolivia employs an MMP system. Second, Bolivia uses a fused vote. Voters cast two ballots, and the nominal tier ballot elects the local district seat for the lower house. The second ballot is more consequential. It not only decides the seat share for each party in each department, it is also used to elect the president and the Senate. In fact, what we are calling the list tier ballot is better understood as a presidential ballot that is also applied to legislative seats. In this chapter, we assume that presidential candidates effectively become the face of their party. The Bolivian fused vote almost necessarily assures that this is the case, since a vote for the presidential candidate is indistinguishable from one for the party list. However, Russia does not use a fused vote. In 2003, voters cast three separate ballots for the district, party list, and president. A 
third difference is that parties in Bolivia run full slates of candidates. One possible reason for a blank vote is that the voter's favorite party may not run a candidate in the local district race. Rather than vote for another, less favored party, the voter might simply vote blank. This was certainly a possibility in Russia, but it probably does not drive the overall results because Bolivian parties present full slates of candidates. That is, every party that runs one candidate for president or the legislature runs a candidate for every seat available. In 2002, 11 parties presented presidential candidates, each of the 68 legislative districts had 11 candidates, and each of the e11 parties listed 62 candidates for the 62 party list seats. Unaffiliated candidates were not allowed, so the partisan choice set was exactly the same for every voter. If a Bolivian voter had a favorite party, she could vote for that party on both ballots.

\section{The Bolivian Party System in 2002}

In the later part of the 2000s, the Bolivian party system underwent a dramatic change, evolving into a dominant party system. However, in 2002 the Movimiento al Socialismo (MAS) was just beginning its rise to power, and it was just one of several contenders for power. The party system was a rather fragmented multiparty system, and no party had won an absolute majority in votes or seats since the restoration of democracy in the early 1980s.

Three parties, the Movimiento Nacionalista Revolucionario (MNR), the Acción Democratica y Nacionalista (ADN), and the Movimiento de Izquierda Revolucionaria (MIR), dominated politics throughout the 1980s and 1990s. All the presidents in that era came from one of these three parties, and they collectively won over half the vote in every election. The MNR and MIR can both trace their roots to the 1940s, while the ADN was formed in the 1970s by the former military dictator Hugo Banzer (Klein 2003). Ideologically, the MIR presents itself as a leftist party, the MNR as a centrist party, and the ADN as a rightist party. However, all three signed on to the neoliberal economic reforms of the 1980s and 1990s, and by 2002 there was not a great difference among the three traditional parties' stances on economic issues (Singer and Morrison 2004, 174). Instead, the three parties' primary focus was on distributing patronage to their followers (Gamarra and Malloy 1995; Domingo 2005, 1731).

Prior to the electoral reform of 1994, seats in the lower house of the legislature were elected by closed list PR. As might be expected, power within the traditional parties was characterized as centralized and hierar- 
chical. In particular, nominations were tightly controlled by the top leaders (Gamarra and Malloy 1995, 419). Indeed, one of the main reasons for the electoral reform was to encourage closer ties between politicians and their voters (Mayorga 2001a, 201), and stronger pressures for district candidates to develop local reputations began to emerge after reform (Mayorga 2001b, 438-42). At the same time, the Law of Popular Participation passed in 1994 marked a significant devolution in political power from the central government to localities, making it much easier for local politicians to establish local power bases (Van Cott 2008). By 2002, the three traditional parties had been concentrating on distributing patronage for over a decade. Much of this patronage went through local politicians who used it to build personal reputations. ${ }^{10}$ As such, by 2002 the three traditional parties could field rosters of candidates who would have been quite well known in their local districts.

A second group of parties was quite different. In 2002, two new parties emerged as contenders for power, finishing second and third in the presidential election. The Nueva Fuerza Republicana (NFR) was led by Manfred Reyes Villa, a former prefect of Cochabamba. The NFR was a vehicle for Reyes Villas's presidential candidacy, and it declined quickly after his defeat in the 2002 election.

The Movimiento al Socialismo won second place over the NFR by fewer than a thousand votes. The MAS was dominated by a campesino movement headed by Evo Morales. Morales had been elected to the legislature in 1997 under the banner of the Izquierda Unida, but had split off to form his own organization in 1998. Because the costs of establishing a formal political party are high, MAS agreed to let Morales and his organization run under their banner in 2002 (Van Cott 2008, 53). While Morales has now been the dominant force within MAS for a decade, the party in 2002 was less a coalition of politicians than an umbrella group of heterogeneous social movements supporting a charismatic leader (Mayorga 2008). While MAS had candidates with local organizations and popularity in some areas, this network was patchy. Moreover, the leaders of these movements were primarily social activists and only secondarily candidates for political office. These two very different challenges require very different types of organizations, tactics, and appeals.

A third party, the Movimiento Indígena Pachakuti (MIP) vied with the MAS for leadership of the movement for indigenous people's rights, taking a more aggressively proindigenous stance (Domingo 2005, 1737-38; Madrid 2005, 165). Like the NFR and MAS, it was dominated by a char- 
ismatic leader, Felipe Quispe. Van Cott suggests that "the MIP is more a personalist vehicle for Quispe than the electoral expression of a socialmovement organization. It is a classic charismatic party in that the leader determines party goals, chooses all militants and candidates, mediates all disputes, oversees all communications, distributes all incentives, and prevents the institutionalization of structures or leadership beyond his personal control" $(2008,55)$.

The NFR, MAS, and MIP looked very different from the three traditional parties in 2002. Whereas the latter had networks of established local politicians, the former were dominated by charismatic leaders. Their rosters of district candidates were almost certainly characterized by candidates who had not been funneling patronage resources into building personal followings for several years.

In the 2002 election, the three traditional parties won $42 \%$ of the list vote, while the three new parties won $48 \%$. Five small parties combined to win the remaining $10 \%$. In this paper, we will not consider the five small parties.

\section{The Russian Party System in 2003}

Not unlike the Bolivian elections in 2002, the Russian elections in 2003 featured a fragmented mixture of parties, none of which enjoyed anything approaching dominant electoral support. Most of the parties were relatively new, having been born in the chaotic 1990s following the collapse of the Soviet Union. Indeed, only one, the Communist Party of the Russian Federation (KPRF), the successor to the Communist Party of Soviet Union, could be considered an "old" established party among the contenders in 2003. The newer parties differed among themselves in terms of the paths to party organization they adopted. Some were built around centralized leadership of charismatic leaders without much organization at the local level while others established close connections with the central government in Moscow and leveraged their access to power to build organizational networks that could support local candidates.

The KPRF inherited substantial organizational assets from the old Communist Party of the Soviet Union. In addition, many of its members retained control over administrative resources in much of the country throughout 1990s, especially in the southern regions of Russia, which became known as the "red belt" on the account of continued strong sup- 
port that the party retained (Hadenius 2002). Its leader, Gennady Zuganov, was a former bureaucrat famously lacking in charisma and with little personal following (White 2005).

United Russia, the party associated with Vladimir Putin, would soon become the dominant party, but in 2003 it was still merely a plurality party. United Russia had been constructed on the foundation of earlier attempts to build a party of power (Gel'man 2008). In the mid-1990s, Yeltsin supporters had formed Our Home Russia as a party of power to support the Kremlin in the Duma. In 1999, these Kremlin insiders were challenged by a coalition of local governors operating under the label of Fatherland, and Fatherland almost won a majority in the Duma. In an effort to consolidate power and tie the powerful local governors to the Kremlin, Our Home Russia merged with Fatherland to create a new party, called Unity. This new party, which was later renamed United Russia, was meant to promote penetration into Russian society and prevent future strong challengers from emerging (Hale 2006). United Russia relied heavily on local governors, other officials supportive of the Putin administration, and on the country's largest companies (White 2005). Each brought their respective constituencies into the coalition as well as impressive abilities to mobilize the electorate.

The Union of Right Forces (URF) was founded by high-level officials in the Yeltsin government who had been associated with attempts to implement liberal economic reforms and continued to push for a deepening of market liberalization and democratization (Kara-Murza 2001). The URF envisioned itself as a party that would work within the power structure whenever possible, cooperating with the authorities to implement their preferred policies (Klyamkin 2004), and it continued to enjoy some support from and access to the Kremlin during the early 2000s (Sakwa 2005; Gel'man 2008).

United Russia and the URF thus constituted the de facto legislative coalition supporting the Kremlin and its program in the early years of Putin's administration (Rose, Munro, and White 2001; Sakwa 2005). This connection to the regime likely yielded them the resources necessary to build organization at the local level, to recruit a superior slate of local candidates, and certainly to better familiarize voters with their candidates.

Three other parties, the Liberal Democratic Party of Russia (LDPR), Yabloko, and Motherland, had far less organizational strength or local reach. The LDPR serves as a personal vehicle for its charismatic leader, Vladimir Zhirinovsky. Zhirinovsky's appeal centers on economic issues and nationalism. LDPR attempted to create strong grassroots organiza- 
tions during the 1990s, but these efforts have largely failed. While it still maintains regional branches, caucuses, and committees, its regional leaders remain mostly unknown (Hadenius 2002).

Similarly, Yabloko was dominated by a charismatic leader, Grigory Yavlinsky. Yabloko tried to model itself along the lines of European social democratic parties (White 2005), but its electoral and organizational bases remained confined to Moscow and St. Petersburg (Hadenius 2002). Unlike the other major liberal force, the URF, Yabloko operated as a pure opposition party, systematically opposing government proposals, and it did not enjoy access to a stream of resources from the Kremlin (Gel'man 2008).

The third party of this group, Motherland, was only created a few months before the 2003 elections and had very little time to develop an organization or establish a reputation. It was founded by federal and local elites who were opposed to Putin and United Russia. Motherland hoped to siphon away supporters from the KPRF and LDPR, and the party appealed to nationalist voters who supported some socialist ideals but were dissatisfied with the Communists (White 2005).

In sum, we identify the KPRF, United Russia, and the URF as more institutionalized parties at the time of 2003 election, and the LDPR, Yabloko, and Motherland are classified as less institutionalized.

\section{Data and Results}

H1 makes a simple national-level prediction, that there should be more blank votes in the nominal tier than in the list tier. This expectation is clearly realized. Table 10.1 summarizes the results of the two elections. In Bolivia in 2002, $12.0 \%$ of the votes in the district tier were blank, nearly three times the $4.4 \%$ blank votes in the list tier. In Russia in 2003, the disparity was similar. Only $4.7 \%$ of the votes in the list tier were blank, but $13.3 \%$ of voters cast blank votes in the district tier. Note that this pattern is not confined to the two elections we are studying. Table 10.2 shows that there have been far more blank votes in the district tier than in the list tier in all eight elections held under mixed-member rules. In fact, the trend was particularly dramatic in Bolivia in 2005 and 2009. In 2005, a whopping $25.2 \%$ of district votes were blank, while only $4.0 \%$ of list votes were. In 2009 , there was again an enormous disparity, with $21.4 \%$ blank in the district tier and $3.3 \%$ blank in the list tier. The consistently high numbers of blank votes in the districts tier is a stunning finding, especially from the perspective of mobilization. One of the old tropes of political campaigns 
TABLE 10.1. Summary of 2002 Bolivian and 2003 Russian Elections

\begin{tabular}{lrrrrr}
\hline & \multicolumn{2}{c}{ List tier } & & \multicolumn{2}{c}{ District tier } \\
\cline { 2 - 3 } \cline { 5 - 6 } & \multicolumn{1}{c}{ votes } & $\%$ & & votes & $\%$ \\
\hline Bolivia 2002 & & & & \\
MNR (M) & 624,126 & 22.5 & & 611,027 & 23.9 \\
MAS (L) & 581,884 & 20.9 & & 373,454 & 14.6 \\
NFR (L) & 581,163 & 20.9 & & 395,559 & 15.5 \\
MIR (M) & 453,375 & 16.3 & & 478,614 & 18.7 \\
MIP (L) & 169,239 & 6.1 & & 134,177 & 5.3 \\
ADN (M) & 94,386 & 3.4 & & 190,618 & 7.5 \\
Other parties & 274,635 & 9.9 & & 371,670 & 14.5 \\
Valid votes & $2,778,808$ & 100.0 & & $2,555,020$ & 100.0 \\
Null & 84,572 & 2.8 & & 73,417 & 2.5 \\
Blank & 130,685 & 4.4 & & 359,380 & 12.0 \\
Total votes & $2,994,065$ & 100.0 & & $2,987,817$ & 100.0 \\
Russia 2003 & & & & \\
United Russia (M) & $22,776,294$ & 40.1 & & $14,124,122$ & 28.6 \\
KPRF (M) & $7,647,820$ & 13.5 & & $6,119,161$ & 12.4 \\
LDPR (L) & $6,944,322$ & 12.2 & & $1,827,716$ & 3.7 \\
Motherland (L) & $5,470,429$ & 9.6 & & $1,719,147$ & 3.5 \\
Yabloko (L) & $2,610,087$ & 4.6 & & $1,54,1463$ & 3.1 \\
Union of Right & $2,408,535$ & 4.2 & & $1,757,146$ & 3.6 \\
$\quad$ Forces (M) & & & & \\
Other Parties & $8,975,297$ & 15.8 & & $7,173,919$ & 14.5 \\
Independents & & & $15,127,780$ & 30.6 \\
Valid votes & $56,832,784$ & 100.0 & & $49,390,454$ & 100.0 \\
Null & 948,435 & 1.6 & & $1,247,512$ & 2.1 \\
Blank & $2,851,958$ & 4.7 & & $7,745,248$ & 13.3 \\
Total votes & $60,633,177$ & 100.0 & & $58,383,214$ & 100.0 \\
\hline
\end{tabular}

Notes: $(\mathrm{M})$ indicates party is classified as more institutionalized; $(\mathrm{L})$ indicates party is classified as less institutionalized. Vote shares for parties and candidates are calculated using valid votes; shares of null and blank votes are calculated using total votes.

TABLE 10.2. Blank Votes in Mixed-Member Elections in Bolivia and Russia

\begin{tabular}{cccc}
\hline & & List tier & District tier \\
\hline Bolivia & 1997 & $3.3 \%$ & $8.7 \%$ \\
& 2002 & $4.4 \%$ & $12.0 \%$ \\
& 2005 & $4.0 \%$ & $25.2 \%$ \\
& 2009 & $3.3 \%$ & $21.4 \%$ \\
Russia & 1993 & $4.2 \%$ & $15.4 \%$ \\
& 1995 & $2.8 \%$ & $9.9 \%$ \\
& 1999 & $3.3 \%$ & $11.9 \%$ \\
& 2003 & $4.7 \%$ & $13.3 \%$ \\
\hline
\end{tabular}

Source: All Bolivian data and the Russian data for 2003 are from the official election commissions. Russian data for 199399 come from the Project for Political Transformation and the Electoral Process in Post-Communist Europe dataset (http:// www.essex.ac.uk/elections/). 
is that you just have to get your voters to the polls. However, in most of these elections, one-tenth of the voters who were at the polls chose not to vote for any district candidates. One imagines throngs of voters coming in to the polls, voting for the president, then turning to a district ballot full of bewilderingly anonymous names, and either voting for the candidate with the same party label as their preferred presidential candidate or simply voting blank to fulfill their obligations as citizens to participate.

$\mathrm{H} 2$ states that there should be more blank votes in the district tier when a new and less organized party does better in the list tier. Based on the discussion in the previous two sections, we can crudely classify the various parties as more or less institutionalized.

For each country we ran two simple OLS regressions. We analyzed the 2002 Bolivian and 2003 Russian elections using sub-district-level election returns. In Bolivia, we examined the 19,876 precincts, while in Russia we looked at the 2,756 towns. The dependent variable is the excess of blank votes in the district tier. This is calculated as the percentage of blank votes in the district tier minus the percentage of blank votes in the list tier. ${ }^{11}$ The independent variables are the party list vote shares of the more institutionalized and less institutionalized parties. We expect the coefficient for the less institutionalized parties to be larger than that for more institutionalized parties, reflecting a greater number of blank votes where less institutionalized parties are more popular. We operationalize the independent variables in two different ways. The simpler method is to add all the less (more) organized parties together to see the overall pattern. We also examine the individual parties to make sure that the pattern applies to each party within the group.

The results are in table 10.3. Models 1 and 3 compare the two groups of parties. The coefficients for the more organized parties should be smaller than those for the less organized parties. ${ }^{12}$ In both models, this is, in fact, the case. That is, higher numbers of blank votes in the district tier (controlling for blank votes in the list tier) are associated with better performances by less organized parties in the list tier. To illustrate the magnitude of this effect, we might consider some hypothetical cases. In Bolivia, consider a precinct with $45 \%$ for the more organized parties in the list tier, $45 \%$ for the less organized parties, and 10\% for all other parties. In Russia, consider a town with $60 \%$ for the more organized parties, $25 \%$ for the less organized parties, and $15 \%$ for all others. These cases, which are fairly close to the national averages, should yield $7.2 \%$ and $8.1 \%$ more blank votes in the district tier than in the list tier, respectively. If we make a modest change by giving the organized parties $10 \%$ more and the less organized parties $10 \%$ 
less, the excess blank votes decline to $6.1 \%$ and $4.9 \%$ in the Bolivian and Russian examples, respectively. Even relatively small changes are sufficient to produce notable differences in the percentages of blank votes.

In Models 2 and 4, we disaggregate the groups into individual parties in order to ensure that these results apply to each individual party. In fact, we find exactly the patterns we expect. In both countries, all three of the less organized parties have larger coefficients than any of the more organized parties. Moreover, the differences between these coefficients are statistically significant. Table 10.4 looks at post-hoc pairwise comparisons of the coefficients. In Bolivia, the coefficients for all parties are significantly different at the $p<.001$ level. In Russia, there are pairs within each group that are not significantly different, but all pairs between groups are significant.

Overall, we find clear support for our hypotheses. There are far more blank votes in the district tiers than in the list tiers. Moreover, higher percentages of district blank votes are associated with better list tier performance by relatively inchoate parties.

TABLE 10.3. OLS Regression of Blank Votes and Party List Vote Shares

\begin{tabular}{llrrr}
\hline & & b & s.e. & \multicolumn{1}{c}{$t$} \\
\hline Bolivia 2002 & & & & \\
Model 1 & Constant & .120 & .006 & 19.84 \\
Adj $R^{2}=.156$ & Less organized & .002 & .007 & .31 \\
$N=19,876$ & More organized & -.109 & .007 & -16.00 \\
& & & & \\
Model 2 & Constant & .127 & .006 & 21.06 \\
Adj $R^{2}=.184$ & MIP & .052 & .007 & 7.36 \\
$N=19,876$ & MAS & -.028 & .007 & -4.17 \\
& NFR & -.009 & .007 & -1.20 \\
& MIR & -.084 & .007 & -11.36 \\
& MNR & -.121 & .007 & -16.77 \\
Russia 2003 & ADN & -.182 & .009 & -19.43 \\
\cline { 2 - 3 } & Constant & -.053 & .012 & -4.46 \\
Adj $R^{2}=.254$ & Less organized & .381 & .017 & 22.27 \\
$N=2,757$ & More organized & .064 & .014 & 4.52 \\
& & & & \\
Model 4 & Constant & -.014 & .013 & -1.10 \\
Adj $R^{2}=.277$ & Yabloko & .599 & .049 & 12.22 \\
$N=2,757$ & LDPR & .326 & .027 & 11.92 \\
& Motherland & .278 & .027 & 10.37 \\
& United Russia & .038 & .015 & 2.63 \\
& URF & -.006 & .042 & -0.06 \\
& KPRF & -.065 & .024 & -2.74 \\
\hline
\end{tabular}




\section{Conclusion}

This volume examines many ways in which the constitutional system affects other elements of the political system. Various chapters examine the effects of the constitutional system on the party system, the faction system, the way candidates are nominated, the ways in which candidates campaign, and so on. This chapter examines another facet of this theme: how the electoral system, in conjunction with the presidential system, shapes the linkage between elections for different offices. In particular, presidential candidates shape the legislative elections by acting as the public faces of the parties that color voters' evaluations of legislative parties and candidates.

Our perspective departs from the previous studies of contamination effects that have generally focused on parliamentary systems and have emphasized how local district candidates influence national party list choices. In contrast, this chapter argues that the presidential system provides a basis for a potentially powerful contamination effect in the opposite direction. Voters project what they know of the presidential candidate onto the party list and, to a lesser extent, local district candidates. This complements, rather than repudiates, the existing research by elucidating a broader institutional context in which such intertier electoral interactions take place. By virtue of having the chief executive subject to a direct election, presidential systems encourage recruitment and development of charismatic party leaders who can successfully appeal directly to the broad electorate, with an independent political base of their own. The institutional

TABLE 10.4. Pairwise Comparison of Regression Coefficients from Table 10.3

\begin{tabular}{lccccc}
\hline Bolivia & MAS & NFR & MIR & MNR & ADN \\
MIP & $*$ & $*$ & $*$ & $*$ & $*$ \\
MAS & & $*$ & $*$ & $*$ & $*$ \\
NFR & & & $*$ & $*$ & $*$ \\
MIR & & & & $*$ & $*$ \\
MNR & & & & & $*$ \\
\hline Russia & LDPR & Motherland & UR & URF & KPRF \\
Yabloko & $*$ & $*$ & $*$ & $*$ & $*$ \\
LDPR & & & $*$ & $*$ & $*$ \\
Motherland & & & $*$ & $*$ & $*$ \\
United Russia & & & & & $*$ \\
URF & & & & & \\
\hline
\end{tabular}

Note: An asterisk $\left(^{*}\right)$ indicates the difference between the two coefficients is statistically significant; the probability that they are equal is $p<.0001$. 
role normally required of parliamentary systems, of appealing largely to a relatively limited group of party elites applies comparatively less to those in a presidential system. Leaders in a presidential system, thus, tend to be better equipped to exert an influence on the vote choices in legislative elections, even if the formal institutional linkages may be potentially more tenuous.

This chapter, however, also observes that the extent to which the presidential election can contaminate the legislative election is constrained by the nature of the parties. Counterintuitively, the more a presidential candidate monopolizes the party image, the less he may be able to project the party face onto local candidates. We have shown that the district candidates representing less institutionalized parties do not appear to be as able to capitalize on the popularity of their own presidential candidates as their better institutionalized counterparts. In parties organized around a single presidential candidate and with anonymous local candidates, voters may not see the local nominee as an avatar for the presidential candidate. Rather, they might simply conclude that there is no viable local foot soldier for their favored presidential candidate. To successfully project the party face, the local candidate must meet a certain standard of competence. That is, presidents most successfully act as the face of their parties when the party can field a full roster of candidates who each have their own local identities, resources, and networks in society. Shared party label alone, then, is not a sufficient condition for the separation of mandates inherent in a presidential system to be overcome in the electoral arena. The institutional separation between elections to different offices remains significant: successfully bridging this gap requires a superior party organization at the local level.

\section{NOTES}

1. We draw distinction between an explicit blank vote, where the voter deliberately chose no particular candidate, from an invalid vote, where the nonchoice of the voter may be due to technical reasons other than actual voter choice.

2. This linkage is important in the pattern of "Surge and Decline" well known from studies of U.S. presidential and off-year elections (see Jacobson 2009 for an overview).

3. The incentives to vote strategically differ in MMM and MMP. In MMM, standard Duvergerian logic applies. Voters have an incentive to avoid wasting their votes on lower ranking candidates. In MMP, the seat shares of each party are determined by the list tier vote, so incentives to vote strategically are much weaker. After all, if a party loses a particular nominal seat, it will be compensated with one additional list seat. On the one hand, this frees voters to vote sincerely for their 
favorite party. On the other hand, if they do not have strong feelings about the local race, voters are also free to abstain or vote blank. While the logic differs, the critical point for this paper is that in both MMM and MMP there are reasons for voters who support a national party with an uncompetitive local candidate to eschew voting for that local candidate.

4. In this paper, we consider both blank and null votes to be invalid votes. That is, they are included in calculating turnout, but they are not included when calculating the vote share of candidates or parties. This is consistent with the practice in Bolivia, but not in Russia. In Russia, both blank and null votes are counted in the divisor for the purposes of determining whether a party has passed the $5 \%$ threshold to receive list tier seats.

5. For example, Hicken notes that in the Philippines the number of legislative parties is inflated by the number of presidential candidates. Many of the parties are newly formed personal vehicles of a particular presidential candidate and are typically not highly institutionalized (Hicken, chapter 8 , this volume).

6. It is not always the case that hastily organized parties cannot recruit a large number of competent local figures. For example, in Taiwan James Soong's People First Party was hastily organized before the 2001 legislative election and attracted many established politicians. We do not consider this sort of party as an inchoate party. The key question is not whether the party has a charismatic leader, but whether the leader stands alone as nearly the only politician with a popular following in the party.

7. In the 2006 LAPOP survey, Bolivians self-identified as $64.8 \%$ mestizo, $19.3 \%$ indigenous, and $11.0 \%$ white. On a separate question asking which, if any, indigenous group they belonged to, 36.4\% said they were Quechua, 24.2\% were Aymara, $10.9 \%$ mentioned another indigenous group, and $28.5 \%$ belonged to no indigenous group (Seligson et al. 2006). In general, self-identification as indigenous has increased markedly since 1998 .

8. In 1989, 1.57 million votes were cast in the presidential election; in 2002, the number of votes nearly doubled to 2.99 million.

9. Turnout in Russia was $54.2 \%$ in $1993,64.3 \%$ in $1995,61.3 \%$ in 1999 , and $55.3 \%$ in 2003 (Nohlen and Stover 2010).

10. See Lazar 2004 for a case study of one such politician.

11. These percentages are calculated using total votes. Party list vote shares are calculated using valid votes only.

12. The constant is determined by the minor parties. These parties are outside the scope of this paper, so the fact that the constant is positive in Model 1 and negative in Model 3 is unimportant.

\section{REFERENCES}

Achen, Christopher H., and Aram Hur. 2011. "Civic Duty and Voter Turnout in Japan and South Korea." Election Studies 1 (2): 45-69.

Burnham, Walter Dean. 1975. "Insulation and Responsiveness in Congressional Elections." Political Science Quarterly 90:411-35.

Calvert, Randall, and John Ferejohn. 1983. "Coattail Voting in Recent Presidential

Elections." American Political Science Review 77 (2): 407-19. 
Campbell, James E. 1997. The Presidential Pulse of Congressional Elections. Lexington: University of Kentucky Press.

Cox, Karen, and Leonard Schoppa. 2002. "Interaction Effects in Mixed-Member Electoral Systems: Theory and Evidence from Germany, Japan, and Italy.” Comparative Political Studies 35 (9): 1027-53.

Domingo, Pilar. 2005. "Democracy and New Social Forces in Bolivia." Social Forces 83 (4): 1727-44.

Ferrara, Federico, Erik Herron, and Misa Nishikawa. 2005. Mixed Electoral Systems: Contamination and Its Consequences. New York: Palgrave Macmillan.

Gamarra, Eduardo A., and James M. Malloy. 1995. "The Patrimonial Dynamics of Party Politics in Bolivia." In Building Democratic Institutions: Party Systems in Latin America, ed. Scott Mainwaring and Timothy R. Scully. Stanford, CA: Stanford University Press.

Gel'man, V. 2008. "Party Politics in Russia: From Competition to Hierarchy." Europe-Asia Studies 60 (6): 913-30.

Hadenius, A. 2002. The Development of Political Parties: Russia in Perspective. Glasgow: Centre for the Study of Public Policy, University of Strathclyde.

Hale, Henry E. 2006. Why Not Parties in Russia? Democracy, Federalism, and the State. Cambridge: Cambridge University Press.

Herron, Erik, and Misa Nishikawa. 2001. "Contamination Effects and the Number of Parties in Mixed-Superposition Electoral Systems.” Electoral Studies 20 (1): 63-86.

Jacobson, Gary C. 2009. Politics of Congressional Elections. 7th ed. New York: PearsonLongman.

Kara-Murza, Alexey. 2001. "At the Intersection of Politics and Science" [in Russian]. Virtual Esse-Polis-Political Studies (December). http://www.politstudies.ru/ universum/esse/index.htm\#02_04. Accessed June 6, 2012.

Klein, Herbert S. 2003. A Concise History of Bolivia. New York: Cambridge University Press.

Klyamkin, Igor. 2004. "Postmodernity within Traditionalist Dimensions" [in Russian]. Polis-Political Studies (January).

Lazar, Sian. 2004. "Personalist Politics, Clientalism, and Citizenship: Local Elections in El Alto, Bolivia." Bulletin of Latin American Research 23 (3): 228-43.

Madrid, Raul L. 2005. "Indigenous Parties and Democracy in Latin America." Latin American Politics and Society 47 (4): 161-79.

Mayorga, Rene Antonio. 2001a. "Electoral Reform in Bolivia: Origins of the Mixed-Member Proportional System." In Mixed-Member Electoral Systems: The Best of Both Worlds?, ed. Matthew Søberg Shugart and Martin P. Wattenberg. New York: Oxford University Press.

Mayorga, Rene Antonio. 2001b. "The Mixed-Member Proportional System and Its Consequences in Bolivia." In Mixed-Member Electoral Systems: The Best of Both Worlds?, ed. Matthew Søberg Shugart and Martin P. Wattenberg. New York: Oxford.

Mayorga, Rene Antonio. 2008. "Populism in Bolivia: Can a Social Movement Govern without a Party?" In Woodrow Wilson Center Update on the Americas, No. 2 Democratic Governance and the "New Left": Bolivia: Social Movements, Populism, 
and Democracy, ed. Brooke Larson, Raul Madrid, Rene Antonio Mayorga, and Jessica Varat.

Miller, Warren. 1955. "Presidential Coattails.” Public Opinion Quarterly 19 (4): 35368.

Nishikawa, Misa, and Erik Herron. 2004. "Mixed Electoral Rules' Impact on Party Systems." Electoral Studies 23 (4): 753-68.

Nohlen, Dieter, and Philip Stover, eds. 2010. Elections in Europe: A Data Handbook. Baden-Baden: Nomos.

Przeworski, Adam, and Henry Teune. 1970. The Logic of Comparative Social Inquiry. New York: Wiley.

Rose, Richard, Neil Munro, and Stephen White. 2001. "Voting in a Floating Party System: The 1999 Duma Election.” Europe-Asia Studies 53 (3): 419-43.

Sakwa, Richard. 2005. "The 2003-2004 Russian Elections and Prospects for Democracy." Europe-Asia Studies 57 (3): 369-98.

Samuels, David J., and Matthew S. Shugart. 2010. Presidents, Parties, and Prime Ministers: How the Separation of Powers Affects Party Organization and Behavior. New York: Cambridge University Press.

Seligson, Mitchell A., et al. 2006. "Democracy Audit: Bolivia 2006 Report." http:// www.vanderbilt.edu/lapop/bolivia/2006-audit.pdf. Accessed March 23, 2013.

Singer, Matthew M., and Kevin M. Morrison. 2004. "The 2002 Presidential and Parliamentary Elections in Bolivia." Electoral Studies 23 (1): 172-82.

Van Cott, Donna Lee. 2008. Radical Democracy in the Andes. New York: Cambridge University Press.

White, Stephen. 2005. "The Political Parties." In Developments in Russian Politics 6, ed. Stephen White, Zvi Gitelman, and Richard Sakwa. Durham: Duke University Press. 


\title{
Mixed-Member Systems Embedded within Constitutional Systems
}

\author{
Chi Huang
}

A concluding chapter may be expected to pull all the previous chapters together. Although inferring from individual chapters generally applicable statements about the consequences of mixed-member electoral systems is not easy, we can still expound upon the common threads running through the entire volume and briefly summarize the major findings of our puzzlesolving efforts.

Theoretically, the most important theme that has emerged from this volume is that the effects of electoral systems must be considered within a specific context. Whereas the conventional approach is to consider the effects of legislative electoral systems in isolation, hence called legislaturecentric, this volume has repeatedly demonstrated that similar electoral systems embedded within different constitutional arrangements can produce very different sets of incentives. Specifically, researchers should keep both legislative seats and executive offices in view while analyzing the effects of legislative electoral systems. Institutions matter, but the institutional context within which those institutions are embedded also matters.

\section{Starting Point: A Puzzle}

Grofman (2001) suggests that political science in general and comparative politics in particular can advance by solving real-world puzzles. This book 
starts with a puzzle for researchers of electoral systems: Why is it that two similar East Asian democracies, Taiwan and Japan, both switched from similar SNTV to similar new MMM systems, yet displayed divergent speeds and degrees of approaching theoretically expected political consequences (see Huang 2011)? As Huang, Kuo, and Stockton point out in chapter 1, after the electoral reform in 1994, Japan saw a gradual evolution from a multiparty system toward a two-party system over five House of Representatives election cycles. In contrast, after Taiwan's constitutional amendment in 2005 , the party system changed almost immediately to a two-party mold in the first postreform legislative election in 2008 and remained so in the second election in 2012.

\section{Comparative Methodology}

The approach we have adopted in this book to solve the puzzle is to look beyond legislative electoral systems per se. Besides examining the similarities and differences between each country's electoral rules, we further embed each legislative electoral system within its broad political contexts, especially its constitutional framework of executive power (see also Grofman 1999).

At first glance, this approach seems to complicate our task since each country tends to have a unique combination of electoral arrangements, constitutional set-ups, and party systems. Yet this broader perspective forces us to conduct comparative studies both within and between countries. By tracing the same country over time before and after the electoral reform, we can focus more on the pure effects of electoral system change under the identical constitutional framework, although within-case design also tends to lose sight of the inherent interaction between electoral systems and constitutional arrangements. This shortcoming is overcome by drawing comparisons between systems so as to isolate and verify the best candidate, that is, the coordination for pursuing executive offices, to explain their differences in outcomes. The 10 chapters in this volume adopt, explicitly or implicitly, this joint within-system and between-system comparisons approach.

\section{Solution to the Puzzle: Executive-Centric Theory}

Through elaborate country comparisons, all the contributors reach the same conclusion. That is, the electoral system is no doubt important since 
it determines how votes cast in an election are translated into seats in the legislature. Yet it does not operate in vacuum. Since parties and elites aim at winning both executive offices and legislative seats, whether the head of government is directly elected and how cabinet posts are allotted also affect how the legislative electoral system shapes politicians' incentives. Therefore, the competition for executive power shapes the party system as much as it does the legislative arena. To fully understand the effects of an electoral system, we must imbed it within the broader political contexts, especially the constitutional framework, of the country in question. The reason for this is because the appeal of and the competition for the executive offices often occupy a higher priority for political parties and elites, and it is the combination of the legislative electoral system and the constitutional setup that defines the payoffs of capturing executive offices and the degree of cross-district coordination required to capture the executive office.

To evaluate the impacts of the mixed-member electoral systems, several factors should be taken into account. Legislature-centric theory indeed spells out clearly the impact of district magnitude, the effective threshold for the party list tier, the ballot structure, assembly size, and dual candidacy, among other factors. Executive-centric theory, on the other hand, further broadens our theoretical landscape by examining "embedded effects" of electoral systems, including the payoffs of the executive offices, the degree of coordination required to capture the executive offices, and the sustainability of the executive offices (e.g., term limits). Other things being equal, the higher the payoffs and the greater degree of cross-district coordination required to win the executive offices, the stronger the incentives for elites to form and stay in the major parties, and therefore the faster the country will move toward a two-party system. As Lin argues in chapter 2, this explains why Japan under the parliamentary system, which allows for some leeway in postelection bargaining, took a much longer time to evolve into a two-party system, while Taiwan under the semipresidential system, in which the winner of the presidential race takes all the cabinet posts and leaves no room for postelection bargaining, moved almost immediately to a two-party system after shifting from SNTV to MMM.

However, the comparative studies looking beyond Japan and Taiwan in part II caution us not to jump to a conclusion that the presidential/ semipresidential system under MMM hastens a two-party system while the parliamentary system does otherwise. As Hicken points out in chapter 8, parliamentary Thailand moved from a multiparty system to a two-party system after adopting an MMM system in 1997 while the presidential 
Philippines changed in the opposite direction in the post-Marcos era even before implementing an MMM system. This seemingly contradictory pair serves as a warning against treating the institutional rules mechanically and directs our attention to the underlying factor: the nature of the executive office, including the appeal of capturing the office and the sustainability of the office. Instead of generating a new puzzle, the cases of Thailand and the Philippines actually reinforce the executive-centric theory.

The same argument extends to a different type of mixed-member system-mixed-member proportional (MMP). As Tan and Shugart argue in their chapter 9 on parliamentary New Zealand, since MMP was adopted in 1993 the effective number of electoral parties rose between 1993 and 1996 and then has generally declined since the first MMP election in 1996 but a high number of very small "microparties" remains. This stands out in contrast to the mostly similar case of Germany. Taking into account not only the features of the MMP system but also politicians' pursuit of ministerial posts in the cabinet can help illuminate this idea. Batto, Kim, and Matukhno's chapter 10 on Bolivia and Russia further indicates that the so-called contamination effect in the literature of MMM systems is not limited to the two ballots for legislators but may well also exist between executive and legislative ballots. In other words, what the voters know of the presidential candidate may also shape their vote choices on the SMD and PR ballots. They find that while voters may vote for the PR list to support the presidential candidate, whether or not these contamination effects extend to the nominal tier depends on the level of institutionalization of the party. This implies that the coattail effects often considered unique to presidential systems combined with single-member congressional districts may also apply in mixed-member systems due to the visibility of the presidential candidates, another example of executive-centric theory.

\section{Extensions to Other Parts of the Political Systems}

The number of parties is one of the most heavily researched variables in comparative politics, but other facets of the political system are also crucial in determining the ways in which politics operate in any country. In this volume, contributors have examined faction systems, nominations, post allocation, preelectoral coalitions, and ticketsplitting and found that the embedded institutional context produces interesting variations in each of these areas. 


\section{Faction Systems}

In parliamentary Japan, the change from SNTV to MMM shifted the focus of competition away from intraparty competition and toward interparty competition. As many expected, this did somewhat weaken the LDP's internal factions and strengthen the party leadership. However, Kobayashi and Tsukiyama argue in chapter 3 that the prime minister's need to maintain parliamentary confidence gives the factions leverage and ensures that they will continue to exercise considerable influence. In contrast, Batto and Huang find in chapter 4 that electoral reform has had a much more modest influence on Taiwanese factions. KMT local factions are constructed to win control of local governments, especially city mayors and county magistrates, so the change in the national legislative electoral system has not affected them much. DPP factions are more focused on national politics, but the evolution of those factions from legislative-centered to presidential contender-centered is primarily a result of the presidency becoming an achievable goal rather than because of electoral reform. The experience of the KMT and DPP factions also points to the limits of focusing solely on the electoral system in the national legislature, as both have been shaped by a variety of electoral rules, including those for local executives, local assemblies, and party offices.

\section{Candidate Selection, Post Allocation, and Preelectoral Coalitions}

The centrality of executive offices also explains some differences in intraparty competition, nominations, and preelectoral coalitions. Yu, Shoji, and Batto suggest in chapter 5 that because legislators are commonly appointed to executive positions in Japan but not in Taiwan, the incentives to remain in the parliament are much stronger in Japan. The resulting different emphasis on incumbency implies different sets of problems that parties need to resolve in the nomination stage. In Japan, where the best districts are usually occupied by entrenched incumbents, parties developed the innovative kobo system to allocate nominations for less desirable districts. In Taiwan, incumbents are not protected, and the parties developed a system of polling primaries to determine hotly contested nominations in very desirable districts. Nemoto and Tsai point out in chapter 6 that, in both Taiwan and Japan, parties used cabinet positions to reward party politicians for going out and winning votes in elections. However, while the use of cabinet posi- 
tions as carrots was widespread in Japan, it was much more limited in Taiwan due to the fact that legislators could not concurrently serve as ministers. Likewise, they argue that the presence of institutional features such as the confidence vote and bicameralism made alliances between large and small parties more tenable in Japan.

\section{Voters' Behavior}

The differences in the feasibility of small parties, nomination strategies, and preelectoral coalition that result from differences in the constitutional structures in turn define the choice set available to voters and thus shape their patterns of straight- and split-ticket voting. As Wang, Lin, and Hsiao find in chapter 7, in both Taiwan and Japan ticket-splitting takes place mainly within the two major coalition camps rather than across camps. Identifiers with small parties are more likely to be ticketsplitters when they vote sincerely in their PR ballot but support viable district candidates of major parties of the same alliances. This result of voter-level analysis meets the expectation of the conventional legislaturecentric theory well. However, it does not mean that the legislature-centric perspective is sufficient to explain ticket-splitting patterns. Quite the contrary, it further confirms the importance of understanding how preelectoral coalitions are shaped to begin with by both executive posts and legislative seats, a point our executive-centric perspective emphasizes. In essence, political elites structure the alternatives based on institutional incentives-executive as well as legislative-and then voters respond to the available choice set on ballots based the electoral rules. In this respect, executive-centric theory reminds researchers to pay close attention to how both constitutional and electoral systems impose restraints on the way voters can vote.

Although this volume focuses on the effects of mixed-member electoral systems, especially MMM systems, we believe that our findings and conclusions have profound implications for the study of electoral systems in general. Electoral systems, important as they are, do not operate in a vacuum. Their origins, evolution, and impacts can be fully understood only when they are embedded within their constitutional frameworks.

The literature on electoral rules is indeed impressive and often considered as one of the most advanced areas in political science. Explicitly incorporating executive-centric theory into electoral systems research may be the critical next step leading to future scientific breakthroughs. 


\section{Implications for the Quality of Democracy}

This book mainly focuses on describing and explaining why similar mixedmember electoral systems embedded within different constitutional systems can produce quite different impacts on the party systems and faction systems. Yet the executive-centric theory and the empirical evidence of this volume also have important implications for concern about the quality of democracy, both inside and outside academia.

There have been ongoing debates on the trade-off between democratic accountability and representation. There are also advocates of political reforms through electoral engineering. Yet most of the discussions and debates are either on the relative merits of different democratic regimes or on the advantage and disadvantages of various legislative electoral systems. For example, Lijphart (1999) argues that the parliamentary system is superior in terms of the quality of democracy and democratic representation, while Persson, Roland, and Tabellini (1997) find that presidential system is superior in term of fostering accountability. Meanwhile, it is well known that the more "permissive" an electoral system is (such as the PR system), the easier it is for preexisting social cleavages to manifest as political parties and thus promote representation. The more "restrictive" electoral systems (such as the SMD system), on the other hand, tend to constrain the number of parties and thus clarify political responsibility (Taagepera and Shugart 1989). Mixed-member systems, despite its hope for getting the "best of both worlds," unavoidably also inherit the advantage and disadvantages of either according to the way SMD and PR tiers are combined. MMM, which weighs heavily in favor of the SMD tier and against the PR list, tends to strengthen accountability at the cost of representation, while MMP, which allocated seats by the PR ballot, is relatively balanced between the two criteria of the quality of democracy.

Although these arguments are enlightening, they tend to miss the key link between the constitutional arrangements and electoral systems. This book bridges the gap by embedding electoral systems within their constitutional systems. The executive-centric theory argues that political parties and elites seek not only to maximize seats in the parliament but also to seize executive offices. It is the combination of the legislative electoral system and the constitutional set-up that defines the payoffs of capturing executive offices and the degree of cross-district coordination required to win the executive offices. Hence to fully understand the effects of an electoral system, we must imbed it within the broader 
political context, especially the constitutional framework, of the country in question.

For example, in presidential and semipresidential systems the president exercises the executive authority. The ultimate goal of most political parties and their leaders is undoubtedly to control both executive and legislative branches, although the appeal of and the competition for the presidency often occupies a higher priority (Curini and Hino 2012). This implies that presidential contests often spill over to legislative elections (Huang and Wang 2014). Thus the conventional wisdom that the separation of power offers voters a better opportunity to hold politicians in different branches accountable for different things deserves further close scrutiny under the executive-centric perspective.

\section{Implications for Electoral Reform}

Electoral systems do not change often, but when they do they are often motivated by high hopes of solving some political problems and enhancing the quality of democracy. But the executive-centric theory of this book implies that electoral reform alone is not a panacea. Whether and to what extent electoral reform achieves the advocated goals depends not only on the specification of new electoral rules per se but also on the context within which such rules are embedded (see also Bowler and Donovan 2013). If a real-world electoral reformer/engineer wants to assess whether their goals are realistically attainable or not, be they reducing money politics, downsizing factions, or enhancing electoral accountability, she needs a more comprehensive theory to predict how politicians and voters would actually react to such reform. This book brings in a large part of the political payoff, that is, executive offices, that reformers, just like academics, have not always kept clearly in mind.

For example, one of the goals of electoral reform in Japan is to break the importance of factions in order to shift the focus toward interparty competition in policy issues. As Kobayashi and Tsukiyama point out in chapter 3, changing from SNTV to MMM did somewhat weaken the internal factions of the LDP, but this trend has been slower and far less intense than initially expected. If reformers had taken into account the parliamentary system and the importance of cabinet posts, they would have been less surprised by this result. In fact, the strengthened prime minster even has found room to maneuver within the faction system, preserving the overall 
system while enhancing his own power by favoring his own faction and giving posts to smaller rival factions. In New Zealand, on the other hand, the primary aim of the shift from pure SMD to MMP was to increase the quality of representation by encouraging stronger ties between representatives and voters. Shugart and Tan find in chapter 9 that the results are indeed more reflective of the voters' preferences. Yet as mentioned earlier, the effective number of electoral parties has generally declined but a high number of very small "microparties" remain. This has contributed to one of the more unpopular facets of the new system, that smaller parties are often the kingmakers in coalition politics. This fragmentation of the party system can be understood only by taking account of politicians' pursuit of ministerial posts in the cabinet under New Zealand's parliamentary system.

Thailand and the Philippines constitute another pair of examples. Electoral reformers in both countries desire a stronger nationalized party system. Yet as Hicken points out in chapter 8 , Thailand was successful in moving toward a nationalized politics and a two-party system after adopting the MMM system while the Philippines failed. Limiting the president to one term in the Philippines provides a disincentive for presidential candidates to build strong nationalized parties. Again, the competition for executive offices is important and mediates the effects of electoral systems.

In short, the executive-centric perspective advanced in this book matters in the world beyond academia. Political pundits, politicians, reformers, and the general public alike can gain greater insight by keeping both legislative and executive payoffs in mind while deliberating the relative merits of different democratic institutions.

\section{REFERENCES}

Bowler, Shaun, and Todd Donovan. 2013. The Limits of Electoral Reform. Oxford: Oxford University Press.

Curini, Luigi, and Airo Hino. 2012. "Missing Links in Party-System Polarization: How Institutions and Voters Matter.” Fournal of Politics 74 (2): 460-73.

Grofman, Bernard. 1999. "Preface: Methodological Steps toward the Study of Embedded Institutions." In Elections in Fapan, Korea, and Taiwan under the Single Non-Transferable Vote: The Comparative Study of an Embedded Institution, ed. Bernard Grofman, Sung-Chull Lee, Edwin A. Winckler, and Brian Woodall. Ann Arbor: University of Michigan Press.

Grofman, Bernard, ed. 2001. Political Science as Puzzle Solving. Ann Arbor: University of Michigan Press.

Huang, Chi. 2011. "Political Consequences of the MMM Electoral Systems in Taiwan and Japan." Paper presented at the 2011 Annual Meeting of the American Political Science Association, Seattle, September 1-4. 
Huang, Chi, and T. Y. Wang. 2014. "Presidential Coattails in Taiwan: An Analysis of Voter- and Candidate-Specific Data." Electoral Studies 33 (March): 175-85.

Lijphart, Arend. 1999. Patterns of Democracy: Government Forms and Performance in Thirty-Six Countries. New Haven: Yale University Press.

Persson, Torsten, Gerard Roland, and Guido Tabellini. 1997. "Separation of Powers and Political Accountability." Quarterly fournal of Economics 112 (4): 11631203.

Taagepera, Rein, and Matthew Søberg Shugart. 1989. Seats and Votes: The Effects and Determinants of Electoral Systems. New Haven: Yale University Press. 


\section{Contributors}

Nathan F. Batto is an Assistant Research Fellow at the Institute of Political Science, Academia Sinica and a jointly appointed Assistant Research Fellow at the Election Study Center, National Chengchi University. His research focuses on electoral systems, legislative politics, and Taiwanese politics. His research has appeared in journals such as Electoral Studies, Fapanese Fournal of Political Science, and Legislative Studies Quarterly.

Gary W. Cox is William Bennett Munro Professor of Political Science at Stanford University. In addition to numerous articles in the areas of legislative and electoral politics, Cox is author of The Efficient Secret (winner of the 1983 Samuel H. Beer dissertation prize and the 2003 George H. Hallett Award), coauthor of Legislative Leviathan (winner of the 1993 Richard F. Fenno Prize), author of Making Votes Count (winner of the 1998 Woodrow Wilson Foundation Award, the 1998 Luebbert Prize, and the 2007 George H. Hallett Award), and coauthor of Setting the Agenda (winner of the 2006 Leon D. Epstein Book Award). A former Guggenheim Fellow, Cox was elected to the American Academy of Arts and Sciences in 1996 and the National Academy of Sciences in 2005.

Allen Hicken is Associate Professor of Political Science, a Research Associate Professor at the Center for Political Studies, and Director of the Center for Southeast Asian Studies at the University of Michigan. He is the author of Building Party Systems in Developing Democracies (Cambridge University Press) and the editor of two volumes: Party and Party System 
Institutionalization in Asia (Cambridge University Press, coedited with Erik Kuhonta), and Politics of Modern Southeast Asia: Critical Issues in Modern Politics (Routledge). His articles have appeared in the American fournal of Political Science, Fournal of Politics, Comparative Political Studies, Fournal of East Asian Studies, Asian Survey, and Electoral Studies.

Yi-ching Hsiao is an Associate Professor in the Department of Public Administration, Tamkang University. His research focuses on voting behavior, congressional politics, and public opinion survey research. His research has appeared in Taiwanese journals such as the Fournal of Electoral Studies, Taiwanese Political Science Review, Taiwan Democracy Quarterly, Political Science Review, Chinese Political Science Review, and Soochow fournal of Political Science.

Chi Huang is a University Chair Professor of Political Science and Research Fellow of the Election Study Center at National Chengchi University. His research interests focus on survey research, quantitative methodology, electoral systems, and voting behavior. He has coauthored or coedited six books and published many articles in leading international and Taiwanese journals, including American Political Science Review, American Fournal of Political Science, Fournal of Politics, Comparative Political Studies, Electoral Studies, Party Politics, Political Research Quarterly, Fapanese fournal of Electoral Studies, Issues \& Studies, and Taiwanese Political Science Review. He served as President of the Taiwanese Political Science Association (2003-5) and has been the Coordinator of the Taiwan's Election and Democratization Study (TEDS) interuniversity survey project since its inception in 2000.

Hsin-ta Huang is an Assistant Professor in the Department of Political Science at Tunghai University. He received his $\mathrm{PhD}$ from National Chengchi University. His research interests include political methodology, quantitative analysis, local factions, party systems, electoral systems, and voting behavior.

Henry A. Kim is an unaffiliated researcher with a $\mathrm{PhD}$ in political science from the University of California, San Diego. His research includes elections, parties, legislative politics, and the cognitive psychology of decisions under uncertainty. His publications have appeared in State Politics and Policy Quarterly, Fapanese fournal of Political Science, and American fournal of Political Science.

Yoshiaki Kobayashi is a Professor of Political Science at Keio University and a Vice President of Science Council of Japan, Prime Minister's Office of the 
Japanese Government. He serves on the editorial board of several international journals including International Political Science Review, Pacific Focus, and 7PSS. His research interests focuses on democracy in civil society, particularly political attitudes, electoral behavior, and electoral systems. He has authored 12 books in English, Japanese, Korean, and Chinese, and coauthored or coedited 51 books and 300 articles in leading International and Japanese journals. He has served as President of the Japanese Political Science Association, the Japanese Association of Electoral Studies, and the Japan Public Choice Society.

Ming-Feng Kuo is a Research Fellow at the School of Public Administration, Sichuan University, China. His research interests include Japanese politics, comparative politics, public management, policy analysis, and quantitative methodology. His research has appeared in journals such as Administration \& Society, Taiwanese Fournal of Political Science, Fournal of Social Sciences and Philosophy, Fournal of Electoral Studies, Chinese Political Science Review, Fournal of Civil Service, and Wenti Yu Yanjiu.

Chang-chih Lin is an Adjunct Assistant Professor of Political Science at National Chengchi University. His research interests focus on comparative politics, electoral systems and party politics, voting behavior, and survey research. His research has appeared in journals such as the fournal of Electoral Studies, Taiwanese Political Science Review, Issues \& Studies, Wenti Yu Yanjiu, and Chinese Political Science Review.

Jih-wen Lin is Research Fellow in the Institute of Political Science at Academia Sinica and Professor of Political Science at National Chengchi University. He received his $\mathrm{PhD}$ in political science from the University of California at Los Angeles (1996). His research interests cover game theory and comparative institutional design, and he has had articles published in Party Politics, Fournal of Democracy, Electoral Studies, China Quarterly, fournal of East Asian Studies, and Issues \& Studies, among others.

Natalia Matukhno is Research Fellow at the Centre for the Study of Public Policy at the University of Strathclyde. She received her PhD in political science from the University of Arizona in 2013. Her research interests include comparative political institutions and comparative political behavior, particularly for democratizing countries. Her dissertation focuses on the varieties of corruption.

Kuniaki Nemoto is Assistant Professor at Waseda University, Japan. He previously taught at the Department of Political Science, University of 
British Columbia, Canada, and was Korea Foundation Postdoctoral Fellow at the Korea Institute, Harvard University. He earned his $\mathrm{PhD}$ in political science and international affairs from the University of California, San Diego. He is interested in elections, party politics, and legislatures, with a regional focus on the Asia-Pacific. His articles have appeared in the British Fournal of Political Science, Comparative Political Studies, Party Politics, and Electoral Studies.

Hans Stockton is Director of the Center for International Studies at the University of St. Thomas in Houston, Texas, Chair of the Department of International Studies, and holder of the Sarofim-Cullen Trust Endowed Chair in International Studies. His areas of academic specialization are democratization, elections, and security in contemporary Asia Pacific. He has published in journals of political science, economics, public administration, and Asian Studies; authored multiple chapters in edited volumes on military affairs in the Asia Pacific and Taiwan's political development; and authored two books. He currently serves as President of the Southwest Conference on Asia Studies, Vice President of the American Association of Chinese Studies, and Coordinator of the Conference Group on Taiwan Studies.

Kaori Shoji is a Professor in the Department of Political Studies at Gakushuin University in Japan. Her research focuses on party organizations, electoral systems, policy innovation, and American politics.

Matthew S. Shugart is Professor of Political Science at the University of California, Davis. He is the coeditor of Mixed Member Electoral Systems: The Best of Both Worlds? (Oxford, 2001) and coauthor of Presidents, Parties, and Prime Ministers: How Separation of Powers Affects Party Organization and Behavior (Cambridge, 2010). His articles on electoral systems have appeared in the American Fournal of Political Science, Electoral Stud$i e s$, and other journals. He acknowledges the Research School of Asia and the Pacific, Australian National University, and the U.S. National Science Foundation (grant SES-0751662) for supporting field research in New Zealand in November 2011.

Alexander C. Tan is Professor of Political Science at the University of Canterbury in Christchurch, New Zealand. He has published works in the areas of East Asian politics, comparative political economy, and political parties, and his articles have appeared in journals such as fournal of Politics, 
Political Research Quarterly, Comparative Political Studies, Comparative Politics, European Fournal of Political Research, Electoral Studies, and Party Politics.

Chia-hung Tsai is Director and Research Fellow at the Election Study Center, National Chengchi University. He served as a visiting faculty member in the Department of Political Science, Massachusetts Institute of Technology, in 2012-13. His research focuses on public opinion, voting behavior, and methodology. He has published research in journals such as Party Politics, International Political Science Review, and Issues \& Studies.

Hiroki Tsukiyama is a research associate at Keio University. His research interests include Japanese politics and legislative politics. He received his $\mathrm{PhD}$ in Political Science from Keio University. His dissertation explores the legislative process of Japanese local legislatures.

T. Y. Wang is Professor of Political Science at Illinois State University. He currently serves as the coeditor of the Fournal of Asian and African Studies and was the Coordinator of the Conference Group of Taiwan Studies (CGOTS) of the American Political Science Association. Professor Wang's current research focuses on Taiwanese national identity, cross-Strait relations, Chinese politics, electoral studies, U.S. policy toward China and Taiwan, and research methodology. He has authored, coauthored, or edited 6 books/special issues and published more than 30 articles/book chapters in such scholarly journals as the American Political Science Review, Asian Survey, International Studies Quarterly, Issues \& Studies, Fournal of Peace Research, Political Research Quarterly, and Social Science Quarterly.

Eric Chen-hua Yu is an Associate Research Fellow of the Election Study Center and jointly appointed as an Associate Professor of Political Science at National Chengchi University in Taiwan. His research interests include public opinion, electoral politics, quantitative methods, and American politics. Yu recently published academic articles on Taiwan's and U.S. domestic politics in Taiwan Political Science Review, Fournal of Electoral Studies, Review of Social Sciences, Fapanese Fournal of Electoral Studies, and Fapanese Fournal of Political Science. Yu received a MS (2000) in Public Policy Analysis from the University of Rochester, and a PhD in political science (2006) from Columbia University. 


\section{Index}

Acción Democratica y Nacionalista

(Bolivia), 287, 292, 294-95

ACT (New Zealand), 249, 250, 257-64, 274-75

Alliance (New Zealand), 248, 250, 253, $257,259,273$

average effective number of electoral parties in each district $\left(\mathrm{N}_{\text {local }}\right), 236,240-41$

best loser provision, 27, 33, 42-44, 167, $177,182,189,270$

bicameralism, 54-55, 57, 62, 66-67, 183$84,233,305$

bifactionalism, 14, 103-9, 113, 116, 120, 122,128

bipolar competition (bipartisan, bifactional), 5,12

blank votes (against all votes), 278-80, 282-87, 289, 291-97

block vote, 69, 230-31, 236, 243

Bundestag, 254, 274

cabinet appointment, 172-75, 189 cabinet portfolios (ministerial posts, executive positions), 2, 12, 16, 20, 53-56, 58-59, 61-63, 66-69, 99, 244, 257, 260-61

campaigning, 61, 97, 155, 172, 251, 279 candidate coordination, $55,166-67,182$, 188-90

candidate selection method (nominations), 2, 7-8, 14-15, 17, 30, 46, 73, $75-76,81-82,84,95,97,109,117-18$, $120,124-26,132,135-46,148-56$, 158-62, 166, 175, 177, 181-82, 18889, 191, 196-98, 201-2, 207-8, 210, $212,218,220,288,303-4$

Chen Shui-bian, 7, 9, 14, 31, 59, 60, 119-20, 173, 187

Christian Democratic Union (Germany), 254, 273

Christian Social Union (Germany), 254, 273

Clean Government Party (Komeito) (Japan), 33, 45, 46, 183-86, 188, 190, 199-200, 202-5, 207-10, 212-14, 217, 220

closed list PR, 29, 33, 69, 74, 287

closed primaries, 149, 157, 159-60

Communist Party of the Russian Federation, 289, 291-92, 294-95

constitutional reform, 191, 236

contamination effects, $42-43,67,188$, 248, 265-66, 269, 278-79, 295, 303 coordination (role of political parties), 2-3, 10-11, 19, 27, 29, 46, 54-55, 61, $76,127,151,162,166-67,172,182-$ 83, 188-90, 196, 201, 219, 229, 
coordination (continued)

232-36, 238, 240-41, 243, 252, 3012, 306

county assembly, 9, 13, 103, 109-12, 131

county magistrate (city mayor, local executive), 103, 107-9, 112-13, 129

cross-district coordination, 229, 232, 236, 240-41, 243, 302, 306

democratic accountability, 306

Democratic Party of Japan, 33, 37, 65, $66,80,135,138-39,152-63,165,168$, 176-92, 199-220

Democratic Progressive Party (Taiwan), $7-8,11-15,17,20,28,31,38,60,102-$ $31,135-50,161-62,171-73,178-82$, 186-91, 199-217, 304

Diet, 12, 28, 30-31, 33, 36, 40, 45, 5355, 57, 62-63, 74-80, 89, 91, 94-95, 97-98, 151, 153, 168-70, 176, 199200, 238

Diet committees, 77, 168, 170

district magnitude, 7, 9, 28, 32, 34, 136, $177,190,232-33,236,274,302$

dual candidacy, 15, 27, 33, 42-44, 161, 167-68, 176-77, 189, 249, 251, 26973, 302

Duvergers Law / Duvergerian incentives, 36, 38, 182, 186, 197, 205-7, 218-19, 248, 252, 265, 268

effective number of electoral parties $\left(\mathrm{N}_{\mathrm{V}}\right), 36-37,43,182-83,233,240$, 243, 247, 266-69, 275, 303, 308

effective number of electoral parties in $\mathrm{PR}$ tier $\left(\mathrm{N}_{\mathrm{PR}}\right), 36-38$

effective number of electoral parties in SMD tier $\left(\mathrm{N}_{\mathrm{SMD}}\right), 36-38,45,236$, 239-41, 244

effective number of electoral parties in SNTV tier $\left(\mathrm{N}_{\mathrm{SNTV}}\right), 36-37$

effective number of parliamentary parties $\left(\mathrm{N}_{\mathrm{S}}\right), 6,36-39,41-43,253-55$, 273-74

effective number of parties, 3, 6, 32, 36$37,53,58,67,199,232-33,236-37$, 240-41, 245, 247-49, 253-54, 256, $258,266,272$ effective number of presidential candidates $\left(\mathrm{N}_{\text {pres }}\right), 242,245$

Electoral Referendum Act, 270, 306 electoral reform, 1, 3-10, 12, 15-17, 26-28, 30-31, 35-36, 38, 41, 44, 52$53,57-58,62,66,68-69,74,76-81$, 83-85, 89-91, 93-95, 97-100, 102-3, $118,123,127,135-36,138,143$, 151-52, 156, 160-61, 166, 169, 179, 198, 218, 232, 287-88, 298, 301, 304, $307-8$

endorsement. See candidate selection methods

executive-centric theory, 2, 27, 52, 301$3,305-7$

executive-legislative relations, 2, 27, 52, 301-3, 305-7

faction proportionality system, 85,89 , 91, 93-95

faction systems, 1, 3, 5, 12, 16-17, 103, $107,128,303-4,306$

factionalism, 6, 9, 13, 20, 30-31, 68, $73-75,78,103,106,113,116,127-28$, $166,173,182,233-35,238$

female candidates, 160, 176, 181

Foreshore and Seabed Act (New Zealand), 258

Formosa faction (Taiwan), 13-14, 118$21,125-28$

fragmentation, 18, 52, 166-67, 185, 237, 239-41, 243-45, 249, 266, 268, 308

Free Democratic Party (Germany), 254, 273

fused vote, 286

Gallaghers Least Squares Index, $250-51$

governing coalition, 199-200, 209, 211, 213-14

Green Party (Germany), 254

Green Party (New Zealand), 248, 250, 252-54, 257-58, 262-63, 270-71, 273, 275

guanxi, 20, 105-6

Hatoyama, Yukio, 64-66

head voters (rentou dangyuan), 140-41, 149 
Hosakawa, Morihiro, 31

House of Councillors, 31, 53-57, 62-68, 156,185

House of Representatives, 31, 34-38, 53-55, 62-63, 66-69, 137, 152-60, 163, 194, 220, 230-31, 235, 238, 301

inchoate parties, 19, 282-85, 294 information (for voters), 37, 61, 82, 87, 91, 97-98, 155, 213, 214-16, 219, 278, 280-85

institutionalized parties, 279, 281, 283, 285, 291, 293, 296

interparty coalitions, $7,9,14-15,17,20$, $116,118,166-67,182,184,186,188$ 91, 196, 198, 204, 208, 211, 218, 257, $261,263,303-5$

intraparty competition, 30-31, 76, 95, $135-36,143-44,153,304$

Japan Restoration Party, 33, 64, 152, 159, 186, 191-92

Japan Socialist Party, 10-11, 19, 28, 64, $138,152-53$

Japanese Communist Party, 33, 200, 202-3, 205, 207-10, 214, 217, 220

joint PR list, 183, 187

Justice Alliance (Taiwan), 14, 119-22, $124-27,131$

kenren (prefecture party branch), 153-57, 159,163

kobo system (public recruitment), 17, 135-36, 138-39, 150, 152-63, 175, 304

Koizumi, Junichiro, 64, 77-79, 83, 85, 87, 90-92, 94-95, 98-99. 176, 190

Komeito. See Clean Government Party

Kuomintang. See Nationalist Party

Labour Party (New Zealand), 257-59, 262, 275

Left Party (Germany), 248, 254

legacy politicians, 249, 258-59, 261, 272

Legislative Yuan, 10, 31-32, 40-41, 54, $58-60,68,70,109,112,121,135,141-$ $43,145,161,172-73,179,219$ legislative-centric theory, 52, 232, 302, 305

Liberal Democratic Party (Japan), 6-8, 13-15, 17, 27-46, 64-65, 73-100, 102, $116,125-39,151-61,165-70,176-91$, 199-220, 290, 307

Liberal Democratic Party of Russia, 290-92, 294-95

Liberal Party (Philippines), 239, 241

list ranking, 176-77, 189

list tier, 4-5, 18-19, 27, 32-35, 42-45, $118,161,167,173,175-77,179$, 182-83, 185-86, 189, 231-32, 236, 239, 249, 265-66, 269, 272, 278-80, 282-86, 291-94, 296-97, 302

list tier threshold, 27, 34-35, 43, 46, 207, 302

Ma Ying-jeou, 9, 59-60, 70, 124, 172-74, 187,201

majoritarian-leaning electoral system, $52-53,63,67$

Mana Party (New Zealand), 250, 258-59

Maori Party (New Zealand), 250, 255, 257-60, 262, 275

Maori special seats, 258-59, 274

Marcos, Ferdinand, 231, 238, 241-42, 245

mechanical effect. See Duvergers Law microparties, 248, 258-61, 263-65, 270, 303,308

minimum winning coalition, 91

ministers / vice ministers, 97, 168, 184

MMM characteristics, Japan and Taiwan compared, 6, 27, 30-35, 52

most similar systems design, 16, 38, 53, 301

Motherland (Russia), 290-92, 294-95

Movimiento al Socialismo (Bolivia), 287-89, 292, 294-95

Movimiento de Izquierda Revolucionaria (Bolivia), 287, 289, 292, 294

Movimiento Indígena Pachakuti (Bolivia), 288-89, 292, 294-95

Movimiento Nacionalista Revolucionario (Bolivia), 287, 292, 294-95

multinomial logit model, 211, 213-17 
Nacionalista Party (Philippines), 239, 241

National Assembly (Taiwan), 32, 109, 161

National Party (New Zealand), 251, 258, 264, 271, 273, 275

Nationalist Party (Kuomintang) (Taiwan), 8-11, 13-14, 17, 19-20, 27-28, 31-32, 59-61, 70, 102-17, 128-30, $135,139-50,161-62,171-91,199$ 219, 304

New Party (Taiwan), 20, 31, 34, 200201, 203, 205-8, 210, 212, 215-17, 219

New Tide faction (Taiwan), 13-14, 108, 114, 118-27, 131-32, 190

New Zealand First Party, 249, 253, 25758, 260, 262-64, 271, 275

1955 system (Japan), 27-28, 45, 75 nominal tier, 5-6, 14, 18-19, 32-33, 35, $38,45,161,169-70,175-76,181-82$, 187-89, 249, 266, 273, 275, 278-80, 282-86, 291, 303

nominations. See candidate selection methods

nonopportunity voters, 202, 205, 207-8, 210-11, 220

nonpartisan ministers, 57, 59-60, 63, 68-70

Non-Partisan Solidarity Union (Taiwan), 200-203, 207-8

Nueva Fuerza Republicana (Bolivia), 288-89, 292, 294-95

one-way ANOVA, 59-61, 63, 65, 68 opposition coalition, 185, 199, 209, 21314,220

overhang, 251, 273

Pan-Blue alliance, 31, 38, 110, 186, 188, 201, 205, 209, 211-12, 215-17

Pan-Green alliance, 172, 187-88, 201, 206-7, 209, 212, 215-17

parliamentary system, $13,16,38,53,62$, 67-69, 74, 95, 137, 160, 167, 230, 235, $237,243,248,253,256,280-81,295-$ 96, 302, 306-8

party factions, 7, 140, 166, 236, 244, 248 party headquarters, 74-78, 81-83, 86-87,
$95,98,139,141-42,144-47,152-56$, $158,163,171$

party identification, 196-97, 199, 204-9, 211,218

party leadership, 75, 128, 130, 166, 173, 304

Party of Democratic Socialism (Germany), 254, 274

party posts, 15, 17, 73, 75-77, 97, 168

party reputation (party image), 165-66, 169, 236, 283, 285, 296

party system, 5-6, 12, 18, 26-29, 35, 37-38, 41-44, 52-53, 58, 63, 66, 69, 198-99, 229-30, 232, 236-43, 245, 248, 263, 265-66, 278, 285, 287, 289, 295, 301-2, 308

patronage, 73, 104-6, 116-17, 120, 129, 287-89

patron-client relationships. See patronage

People First Party (Taiwan), 11, 20, 34, $38,61,110,112-14,187-88,190$, 200-3, 205-8, 210, 212, 215-17, 21920, 297

Peoples New Party (Japan), 66, 152, 184-85, 188, 190, 200, 220

personnel management, $75,78-79,90$, 95

pivot, 54-55, 63, 261, 275

plurality rule, 1, 7-8, 25, 32, 116, 130, 197, 230-31

Political Funds Control Act reform, 76

polling primary, 17, 135-36, 138-50, $160,162,304$

portfolio allocation. See cabinet portfolios

PR constituency, 31, 33-34, 43-44

preelectoral coalition, 17, 116, 165-91, 303-5

presidential coattails, 167, 186-87, 281, 303

presidential system, 16, 38, 58, 67-68, $137,160,231,238,278,280,283-86$, 295-96, 302-3, 306-7

proportional representation (PR), 1-2, $5,26,29,31,33-36,42-44,46,55,61$, $69,74,76,97,156,161-62,168,175-$ 77, 183, 185, 187, 191, 195, 197-208, 
210, 212, 218-20, 231-32, 248-49,

265-66, 268-70, 275, 287, 303, 305

psychological effect. See Duvergers Law

quality of democracy, 306-7

quasi-experimental design, 26, 35, 38

recruitment, 17, 74, 78-84, 88, 97-98, $135,151-52,158,175,181,295$

representation, 1, 25, 34-35, 69, 74, 97,

195, 198, 231-32, 247, 249-54, 258-

59, 261, 263-64, 266, 269-70, 272,

274, 306, 308

research design, 35, 285

semipresidential system, 16, 38, 58, 67$69,137,160,167,171,189,302,307$

Senate, 230-38, 244, 286

seniority, 13, 77, 137-38, 160, 168-69, 264

$\operatorname{sesh} u$ (hereditary succession), 151, 15658,160

Shinawatra,Thaksin, 231, 243

single-member district (SMD), 1-2, 4, 27, 32-33, 35-38, 42, 44-46, 56, 67, $74,79,123,136,156,159,161,166-$ 70, 177-78, 181-83, 185-89, 191-92, 195, 197-208, 210-20, 253, 266, 268, 274, 303, 306, 308

single-member plurality (SMP), 5, 43, 66-67, 183, 200, 209, 248-49, 252-54, 259-60, 265-73

single nontransferable vote (SNTV), 3-9, 12-15, 17, 19, 26-32, 36-41, 44-46, 55-57, 59-61, 63, 65-67, 69, 73-85, 89-95, 97, 99, 102-3, 109-10, $112,114,116-18,125-29,136-37$, $143,151,160,165-66,173-75,182$, 189, 191, 243, 301-2, 304, 307

Social Democratic Party (Germany), 248,254 split-ticket voting, 17-18, 194, 196, 198, 203, 208-9, 211-16, 220, 305

straight-ticket voting, 197, 202, 205, 208-9, 211-12, 213-16, 218, 220, 305 strategic voting, 36, 42, 138, 207, 219, 282

Taagepera's Seat Product, 255-56, 274

Taichung County Black faction (Taiwan), 103, 107-8, 110-15, 130

Taichung County Red faction (Taiwan), $103,107-8,110-15,128,130-32$

Taiwan Solidarity Union, 12, 20, 34, 44, 61, 110, 112-14, 174, 186-88, 190, 200-3, 206-10, 212, 215-17

term limits, 240, 245, 302

Tomorrow Party of Japan, 33, 186, 192

two-party system, 5-6, 18, 26-27, 29-30, $35,37-38,42,44,52,198-99,202$, 230, 237, 266, 301-2, 308

unified and divided governments, 57, 59-60, 219-22

Union of Right Forces (Russia), 290-91, 294-95

United Future (New Zealand), 250, 257$58,260-63,275$

United Russia, 290-92, 294, 295

vote of no confidence, 54, 58-59, 94-95, 281

Welfare State Alliance (Taiwan), 14, 114, 119-22, 124, 126, 127

Yabloko (Russia), 290-92, 294-95

Your Party (Japan), 152, 186

zombie, 15, 20, 33, 43, 168, 170, 177, 189,271 
